\title{
III. Kaiser und Stadt: Konstantins Rom
}

Für die Entwicklung der stadtrömischen Heiligenverehrung bedeutete die konstantinische Zeit einen deutlichen Einschnitt. Diese lakonische Feststellung ist ebenso evident wie problematisch, teilt sie doch ein Grundproblem, der sich jede Bewertung der konstantinischen Zeit ausgesetzt sieht: die beiden eng miteinander verbundenen Fragen, wie sehr die Annäherung Konstantins an das Christentum als religiöse Neuerung zu bewerten ist und welche Auswirkungen diese Christianisierung für das römische Reich und die Kirche hatte. Diese Problematik, die im deutschen Sprachraum häufig unter dem Stichwort der ,konstantinischen Wende“ - einem Ausdruck, der auf unterschwellige Weise eine Verbindung von persönlicher Bekehrung des Kaisers und welthistorischer Wende zum Ausdruck bringt - verhandelt wird, ist in der althistorischen Forschung der jüngeren Zeit weitgehend übereinstimmend dahingehend beantwortet worden, dass sich die Hinwendung Konstantins zum Christentum nicht als conversio im Sinne einer plötzlichen Bekehrung vollzog, sondern aus ihren religionsgeschichtlichen Voraussetzungen zu verstehen ist, und dass sie erst auf mittel- und langfristige Sicht zu Strukturveränderungen innerhalb der römischen Gesellschaft und im Verhältnis von Staat und Kirche führte. ${ }^{1}$ Ohne der konstantinischen Zeit ihren Zäsurcharakter $\mathrm{zu}$ nehmen, herrscht damit insgesamt die Tendenz vor, die individuelle

1 Dass Konstantin - entgegen der christlichen wie der paganen historiographischen Konstruktionen, die schon zu seinen Lebzeiten einsetzten - keine im Begriff der „Wende“ implizierte „Bekehrung“ zum Christentum vollzog, darf als wahrscheinlich gelten: Der Begriff der Bekehrung, der ein Konversionserlebnis und eine umfassende, den ganzen Menschen erfassende Neudefinition von Identität voraussetzt, ist für das frühe 4. Jh. insgesamt - nicht nur für Konstantin problematisch, da zahlreiche Lebensbereiche nicht durch spezifisch christliche Handlungs- und Verhaltensweisen geregelt waren (vgl. dazu Martin 31995, 13, 153-156); die Rede von einer Hinoder Zuwendung Konstantins zum Christentum erscheint dementsprechend angemessener. Die Diskussion um eine „konstantinische Wende“ ist in den letzten Jahren erneut belebt worden; dabei stehen Fragen, in welchem Maße die Hinwendung Konstantins zum Christentum strukturell vorbereitet war, welche Konsequenzen sein Handeln hatte und welche strategischen Spielräume dem Kaiser dadurch eröffnet wurden (s. dazu die kontroversen Einschätzungen von Bleicken 1992 und Bringmann 1995), im Vordergrund; für eine ausführliche und fundierte Diskussion der Forschungspositionen und -probleme vgl. Girardet 1998. Man wird mit Girardet daran festhalten müssen, dass die konstantinische Wende zu tiefgreifenden Veränderungen führte, auch wenn die Hinwendung eines spätantiken Kaisers zum Christentum, die Konstantin vollzog, möglicherweise nur eine Frage der Zeit war und die Folgen dieser „Wende“ für das Verhältnis von Staat und Kirche und für die kulturelle Entwicklung erst auf lange Sicht spürbar wurden. 
Bedeutung der Persönlichkeit Konstantins zu relativieren und stärker die Kontinuität der strukturellen Voraussetzungen zu betonen, in denen er sich bewegte und Wirkung entfaltete.

Mit Blick auf die Stadt Rom fällt diese Bewertung traditionell etwas anders aus. Für das einstige politische Zentrum des römischen Reichs erwies sich die Regierung Konstantins vor allem unter zwei Aspekten als ein bedeutsamer Eingriff. Zum einen verlieh die nachhaltige Förderung der christlichen Kulttopographie Roms der christlichen Gemeinde erstmals eine monumentale Präsenz im Stadtbild Roms und seines Suburbiums, zum anderen führte die Gründung der Konstantinsstadt am Bosporus, die sich in der Folge zu einer neuen Hauptstadt des Reichs entwickeln sollte, dazu, dass Rom seinen Rang als politisches Zentrum einbüßte. Während in letzterer Hinsicht, ähnlich wie in der Gesamtbewertung der konstantinischen Herrschaft, die Meinung vorherrscht, die konstantinische Zeit als Etappe eines langsamen Strukturwandels städtischer Identität zu deuten, dessen Konsequenzen sich erst aus mittel- und längerfristiger Perspektive bemerkbar machten, ${ }^{2}$ ist für die Bewertung der konstantinischen Baupolitik in Rom eine andere Sicht der Dinge charakteristisch, die strukturelle Vermittlungsprobleme und Entwicklungsbrüche betont und die konstantinische Bautätigkeit als Ausdruck eines scharfen Einschnitts in der städtischen Entwicklung und im Verhältnis des Kaisers zum alten caput imperii begreift. Grundlegend für diese Deutung ist die Auffassung, dass sich Konstantin im städtischen Zentrum Roms im wesentlichen darauf beschränkt habe, die von seinem Vorgänger Maxentius begonnenen Bauprojekte, die dieser zur Legitimierung seiner Herrschaft und als Ausweis der besonderen Bindung des Herrschers an Rom errichtet hatte, zuende zu führen und ihnen das Siegel seines Namen aufzudrücken, während er eigene Initiativen auf einem anderen Gebiet und in einem anderen räumlichen Kontext entfaltete: den christlichen Basiliken, die Konstantin am Rande der Stadt und im Suburbium Roms errichten ließ.

Diesem Befund, dass Konstantin sich bei der Errichtung der christlichen Basilikalbauten auf die Peripherie Roms beschränkte und im Zentrum Roms keine größere Bautätigkeit entfaltete, entspricht eine relativ einhellige Inter-

2 Die Verbindungen des alten caput imperii zu den Kaisern hatten sich schon während der Zeit der Soldatenkaiser im 3. Jh. stark gelockert: unter Diocletian erhielt diese Entwicklung dadurch weiteren Auftrieb, dass Städte wie Nikomedien, Mailand und Trier mit kaiserlichen Palästen ausgestattet und zu festen sedes imperii ausgestaltet wurden, die zu Rom in Konkurrenz traten. Die Frage, ob Konstantin mit Konstantinopel ein „neues Rom“ errichten wollte (so Calderone 1993) oder aber eine dynastische, auf ihn und seine Familie bezogene Gründung in der Tradition der tetrarchischen Residenzstädte, wird kontrovers beurteilt. Überzeugender sind jedoch die Argumente dafür, dass Konstantinopel erst unter der theodosianischen Dynastie den Rang einer neuen Hauptstadt erhielt - zur selben Zeit, als sich „,neues“ oder „zweites Rom“ als offizielle und offiziöse Bezeichnung einbürgerte und Konstantinopel zu einer ständigen Kaiserresidenz wurde (grundlegend Dagron 1974; vgl. zuletzt Mayer 2002, 91-93). 
pretation der Voraussetzungen und Konsequenzen der konstantinischen Baupolitik: ${ }^{3}$ Die Aussparung des monumentalen Zentrums der Stadt wird als ein bewusster Verzicht des Kaisers darauf gewertet, den christlichen Kult in die Stadt zu integrieren - mit der Konsequenz, dass sich die identitätsstiftenden Zentren der christlichen Gemeinde außerhalb der Stadt Rom formierten. Die Motive, die von der Forschung für Konstantins Handeln veranschlagt werden, sind vielfältig - sie reichen von religiösen Vorbehalten gegenüber einer paganen Senatsaristokratie über Respekt vor dem Traditionalismus der städtischen Eliten bis hin zu einem religiösen Pragmatismus des Kaisers und dem fehlenden Bedarf danach, die Zugehörigkeit zu einer noch bis in die Anfangsjahre seiner eigenen Herrschaft hinein verfolgten Religion in der Öffentlichkeit zu signalisieren. Was jedoch alle Ansätze miteinander verbindet, ist der Umstand, dass sie Dichotomien zum Ausgangspunkt der Interpretation machen: Konstantins Handeln habe sich danach zwischen ,Stadt' und ,Suburbium‘, zwischen ,Zentrum‘ und ,Peripherie‘, zwischen ,öffentlichen` und ,privaten' Räumen, zwischen ,profanen' und ,christlichen` Monumenten bewegt. Grundlegend für diese Interpretationsrichtung ist die Auffassung von einer weitgehend unabhängig vom kaiserlichen Handeln existierenden, fest lokalisierbaren und räumlich klar umrissenen Identitätskonstruktion der Stadt Rom. In Umkehrung eines berühmten Diktums, das der Historiker Herodian Pompeianus, einem Schwager des Commodus, in den Mund legte - „Rom ist dort, wo der Kaiser ist" ${ }^{\text {" }}$ - könnte man sagen, dass die städtische Identität Roms unberührt vom kaiserlichen Handeln und den Räumen, in denen er bauliche Akzente setzte, blieb. Die „Stadt“ entwickelte nach dieser Interpretation in ihren Monumenten und Räumen ein Eigenleben, das durch das kaiserliche Handeln nur in begrenztem Maße beeinflusst oder modifiziert werden konnte: Seine Lokalisierung im städtischen Raum entschied darüber, ob ein kaiserliches Bauwerk zur Stadt Rom gehörte, nicht umgekehrt.

Diese Lesart der konstantinischen Bautätigkeit in Rom entspricht literarischen Zeugnissen christlicher Schriftsteller, die im ausgehenden 4. Jh. über eine räumliche Gegenüberstellung von Zentrum und Peripherie klare Abgrenzungen zwischen christlicher und paganer Identität zu etablieren suchten und das römische Suburbium mit seiner Heiligentopographie zum räumlichen Bezugspunkt einer neuen städtischen Identität machten. So formulierte Hieronymus in einem häufig zitierten Passus: „Das goldene Kapitol starrt vor Schmutz; Ruß und Spinnweben bedecken alle Tempel Roms. Die Stadt hebt sich hinweg von ihren Sitzen und das vor den halbzerfallenen Heiligtümern

\footnotetext{
$3 \mathrm{Zu}$ dieser Interpretationsrichtung und den Forschungspositionen, die sich mit ihr verbinden, s. u., S. 112-114.

4 Herodian. 1, 6, 5. Vgl. auch den Auftritt Gordians I. in Karthago im Jahr 238 (ebd. 7, 6, 1f.).
} 
dahinströmende Volk eilt zu den Gräbern der Märtyrer““.5 Etwa zur selben Zeit verkündete Prudentius, die „Kurie des Euander“ habe nur noch wenige ihrer Mitglieder auf dem tarpeischen Felsen zurückgelassen und sich stattdessen zu den fontes apostolici - gemeint ist das Baptisterium der Petrusbasilika auf dem Vatikan - begeben, um dort ihre Taufe zu empfangen. ${ }^{6}$ Die in diesen und ähnlichen Zeugnissen zutage tretende räumliche Relation von Peripherie und Zentrum und die damit verbundenen Identitätsdiskurse lassen sich freilich nicht bedenkenlos in die konstantinische Zeit zurückprojizieren: Die diskursive Gegenüberstellung von Stadt und Suburbium und die jeweiligen religiösen Kennzeichnungen als ,paganes Zentrum‘ versus ,christliche Peripherie stehen im weiteren Kontext einer um die Wende vom 4. zum 5. Jh. verbreiteten Tendenz, Lebensbereiche der antiken Kultur - darunter auch die Stadt und weite Teile des städtischen Lebens - religiösen Qualifizierungen zu unterwerfen und sie christlich zu transformieren. ${ }^{7}$

Eine Abgrenzung von paganem und christlichem Rom, die entlang einer klar ausgeprägten Grenze zwischen Zentrum und Peripherie verlief, ist somit das Ergebnis spezifischer historischer Voraussetzungen. Als Konstantin nur wenige Jahre nach seinem triumphalen Einzug in Rom sein Bauprogramm in die Tat umzusetzen begann, war eine derartige Dichotomisierung und die damit verbundene semantische Aufladung von Räumen, wie sie einige Jahrzehnte später fassbar wird, noch nicht absehbar. Sowohl die Motive des kaiserlichen Handelns als auch die Erwartungen und Wahrnehmungen, mit denen ihm seine Zeitgenossen begegneten, dürfen daher nicht im Lichte späterer Entwicklungen interpretiert, sondern müssen konsequent aus ihren eigenen Voraussetzungen heraus in den Blick genommen werden, um die Bedeutung der konstantinischen Bauten für die städtische Identität Roms angemessen zu bewerten. Damit soll keineswegs bestritten werden, dass das Denken in Kategorien von „Zentrum“ und „Peripherie“ für die römische Perspektive und Wahrnehmung von prägender Bedeutung war. ${ }^{8}$ Auch wird man fragen müssen, warum Konstantin nach seinem Sieg über Maxentius die

5 Hier., epist. 107, 1 (geschrieben 400): auratum squalet Capitolium, fuligine et aranearum telis omnia Romae templa cooperta sunt; movetur urbs sedibus suis et inundans populus ante delubra semiruta currit ad martyrum tumulos.

6 Prud., c. Symm. 1, 548-551 (verfasst 402/403): iamque ruit, paucis Tarpeia in rupe relictis, ad sincera virum penetralia Nazareorum atque ad apostolicos Evandria curia fontes, Amniadum suboles et pignera clara Proborum. Dass mit den fontes apostolici die vatikanische Petrusbasilika gemeint ist, steht außer Zweifel; spätestens seit Bischof Damasus (366-384) ist dort ein Baptisterium bezeugt (vgl. Damas., epigr. 3, 4, $4^{1}$ und u., S. 477, Anm. 264).

Vgl. dazu u., S. 311-315.

8 Vgl. dazu allgemein Hales 2003, 5. Eine andere Frage ist, woran sich diese Wahrnehmung mit Blick auf das Stadtbild Roms festmachte. Dass die aurelianische Mauer die Vorstellung von einer solchen Grenze beförderte und damit eine scharfe Abgrenzung des städtischen Raums vom Suburbium artikulierte, ist für die konstantinische Zeit noch nicht anzunehmen; diese Wahrnehmung dürfte sich erst im Laufe des 4. Jh. entwickelt haben (vgl. dazu u., S. 405, Anm. 6). 
erste Bischofskirche Roms auf dem aufgelassenen Kasernengelände der 312 aufgelösten equites singulares in der Nähe des kaiserlichen Sessoriumpalastes am südöstlichen Ende der Stadt errichtete und nicht etwa auf die im städtischen Zentrum gelegene Maxentiusbasilika an der via sacra zurückgriff. Doch erscheint eine Präjudizierung in dem Sinne, dass städtische Randlage und Peripherie eine Ausgrenzung aus der Stadt signalisiert hätten, nicht sinnvoll. So gibt insbesondere der Umstand, dass sich bereits vor Konstantin eine deutliche Verlagerung der kaiserlichen Bautätigkeit in die städtischen Randbezirke und das Suburbium Roms bemerkbar machte, ${ }^{9}$ Anlass dazu, nicht von einer vorschnellen Dichotomisierung von städtischem Zentrum und suburbaner Peripherie auszugehen, sondern von verschiedenen, einander jedoch nicht ausschließenden Kommunikationsfeldern und -räumen des Kaisers mit der städtischen Bevölkerung, die zwar unterschiedliche Aspekte der kaiserlichen Herrschaft akzentuierten, jedoch unter dem übergreifenden Dach einer verbindenden städtischen Identität angesiedelt waren.

Im folgenden soll daher die Frage verfolgt werden, welche Aspekte der Kaiserherrschaft und der Beziehung des Kaisers zur Stadt Rom Konstantin in den unterschiedlichen Räumen der Stadt kommunizierte, welche Gruppen für diese Kommunikation relevant waren und ob sie als getrennte Identitäten oder nicht vielmehr als unterschiedliche und komplementäre Sektoren einer übergreifenden Identitätskonstruktion der urbs Roma aufzufassen sind. Das folgende Kapitel gliedert sich dementsprechend in zwei größere Abschnitte, die die Kommunikation des Kaisers im Zentrum Roms und in den Coemeterien außerhalb der Stadt in den Blick nehmen. Der erste Abschnitt beginnt mit einer kurzen Skizze der Umgestaltungen des Forum Romanum in tetrarchischer Zeit und den baulichen Akzenten, die Konstantins Vorgänger Maxentius im Forumsbereich gesetzt hatte. Dabei wird deutlich, dass das Forum als ein besonderer Kommunikationsraum fungierte, in dem die magistratischen Züge des spätantiken Kaisertums betont und eine Interaktion des Kaisers mit dem senatus populusque Romanus inszeniert wurde, die an die Prinzipatsideologie des princeps civilis erinnerte und in dieser Eigenschaft auch für Konstantin von wesentlicher Bedeutung war. In einer umfassenden und kritischen Auseinandersetzung mit den traditionellen Forschungsansätzen, das kaiserliche Handeln in Rom entlang dichotomischer Linien zu interpretieren, wird Konstantins Herrschaftsinszenierung im Zentrum der Stadt nicht als Reflex einer Ausgrenzung der christlichen Gemeinde aus der Stadt, sondern vielmehr als eine bestimmte Option herrscherlicher Repräsentation und Selbstdarstellung interpretiert: Der Kaiser nutzte die maxentische Prägung des Forumsbereichs, um sich dort als Befreier Roms zu stilisieren und damit ein

9 Vgl. Coarelli 1986, 58, der u. a. auf Maxentius verweist, der an der via Appia eine monumentale Villa mit Mausoleum und Circus errichtet hatte. 
zentrales Element der römischen Prinzipatsideologie zu artikulieren. Dass dies Konstantin jedoch nicht daran hinderte, auch im Zentrum der Stadt seine Sympathien für die christliche Religion offen zu zeigen, ohne deswegen unter den Römern eine Identitätskrise auszulösen, wird exemplarisch in der Episode vom unterbliebenen kapitolinischen Opfer deutlich, die erst nachträglich zu einem Bruch des Kaisers mit der Stadt Rom umgedeutet wurde.

Im zweiten Abschnitt wird - komplementär zu Konstantins Inszenierung im Zentrum Roms - seine Baupolitik in den Coemeterien der Stadt als eine weitere Option stadtbezogener Kommunikation aufgefasst, bei der Konstantin sich diesmal auf die christliche Gemeinde als Adressaten stützte. Ausgehend von einer Interpretation der Coemeterialbasiliken als monumentale Totenkultanlagen, die in besonderer Weise auf den toten Kaiser ausgerichtet waren, wird der christliche Toten- und Heiligenkult als ein neuartiges kulturelles Modell interpretiert, das dem Kaiser eine Verbindung von divus- und Totenkult ermöglichte. Die für den römischen Kaiserkult ursprünglich konstitutive Trennung zwischen dem vergöttlichten und dem toten Kaiser war unter den gewandelten politischen Verhältnissen des 3. Jh. bereits in vorkonstantinischer Zeit brüchig geworden. Konstantin fand im Modell des Heiligen nicht nur eine Möglichkeit, den Kaiserkult unter christlichen Vorzeichen weiterzuführen, sondern zugleich eine überzeugende Lösung, um das Spannungsverhältnis zwischen Toten- und divus-Kult aufzulösen. Er kommunizierte damit im Suburbium ebenso wie in der Stadt Themen, die für die Identität Roms traditionell von zentraler Bedeutung waren: Die verschiedenen Räume und die Gruppen, zu denen der Kaiser in Beziehung trat, waren Sektoren einer umfassenden und einheitlichen Identitätskonstruktion - der Stadt Rom.

\section{1. Res publica Romanorum oder Kaiserstadt? Semantische Dimensionen eines ,städtischen Raums“}

Auch ohne eine detaillierte Diskussion der von Konstantin in der Stadt Rom ins Leben gerufenen Bauprojekte springt ein Umstand bereits bei einer summarischen Betrachtung ins Auge: Keiner der von Konstantin initiierten christlichen Kultbauten wurde im monumentalen Zentrum Roms ${ }^{10}$ errichtet,

10 Eine weite Definition des Begriffs „Zentrum“ umfasst sämtliche Regionen Roms, die eine besonders hohe Konzentration nicht-privater Bauten aufwiesen. An erster Stelle ist die regio VIII zu nennen, die das Forum Romanum, die Kaiserforen und das Kapitol umfasste. Es folgen daran südlich anschließend der Palatin mit dem Circus maximus, südöstlich das Colosseum mit den benachbarten Trajansthermen und dem templum Claudii, westlich vom Forumsbereich das forum Holitorium, nördlich davon der ausgedehnte Bezirk des Marsfeldes im Tiberknie, der sich in nördlicher Richtung bis zum Augustusmausoleum, in östlicher Richtung bis zur via Lata erstreckte. Dieses monumentale Zentrum war zwar zum Teil mit privaten Bauten durchsetzt, doch 
das seit der Metamorphose der urbs zur Marmorstadt unter Augustus über Jahrhunderte hinweg eine Fülle kaiserlicher Bauten und Anlagen in sich aufgenommen hatte. Um die Bedeutung dieses Umstands angemessen zu beurteilen, ist es erforderlich, sich zunächst zu vergegenwärtigen, welche Rolle das monumentale Zentrum für die kaiserliche Repräsentation und Kommunikation mit dem senatus populusque Romanus unter Konstantins Vorgängern gespielt hatte, um daraufhin die Frage zu klären, ob und in welcher Weise Konstantin an diese Tradition anknüpfte.

III. 1. 1. Kaiserliche Repräsentation und Kommunikation im Zentrum Roms vor Konstantin

In der Zeit vor Konstantin hatten zuletzt Diocletian (284-305) und Maximian (286-305) sowie Maxentius (306-312) im Bereich des Forum Romanum klare bauliche Akzente gesetzt. Nach dem Brand von 283, der das Forum und seine angrenzenden Bereiche verwüstet hatte, war das Forum Romanum grundlegend umgestaltet worden. ${ }^{11}$ Auf den augusteischen Rostra wurde anlässlich der Vicennalien der Augusti und der Decennalien ihrer Caesares im Jahr 303 das sogenannte „Fünfsäulendenkmal“ aufgestellt - eine etwa 20 Meter hohe Juppitersäule flankiert von vier 15 Meter hohen Säulen, die Statuen der Genien der vier Tetrarchen trugen. ${ }^{12}$ Dem Forum Romanum wurde dadurch ein dezidiert tetrarchischer Anstrich verliehen, der sich auch in der Gesamtgestaltung des Platzes und seiner Einbindung in den weiteren architektonischen Kontext widerspiegelte. Als Gegenstück zu den augusteischen Rostren am westlichen Ende des Forums wurden auf der östlichen Seite neue Rostren angelegt, auf denen sich ebenso wie auf den augusteischen Rostren fünf Säulen erhoben. Die beiden Rostren wurden ferner auf der südlichen Seite durch

dehnten sich die eigentlichen Wohnbereiche um das monumentale Zentrum herum aus. Vor allem die Subura, die Täler zwischen den hügelartigen Erhöhungen, das Tiberufer und Trastevere waren sehr dicht besiedelt. Auf den Hügeln erstreckten sich in einem Halbkreis von Norden nach Süden beiderseits der aurelianischen Mauer ausgedehnte Grünflächen (horti) mit großzügigeren domus. Im Bereich dieser Wohngebiete befanden sich mehrere große Thermenanlagen (thermae Diocletianae, Antonianae, Decianae). $\mathrm{Zu}$ dieser urbanistischen Bestandsaufnahme vgl. Krautheimer 1987 (1980), 20-28; als Zentrum im engeren Sinne kann die regio VIII, der Bereich der fora und des Kapitols, gelten, in dem sich nach Ausweis der spätantiken Regionarien praktisch keine Privathäuser, ob domus oder insulae, befanden.

11 Der Chronograph von 354 nennt die Senatskurie, das Caesarforum und die basilica Iulia; außerdem die scaena des Pompeiustheaters, zwei Portiken, drei Nymphäen, einen Isis- und einen Serapistempel, den arcus novus und die Diocletiansthermen (MGH AA IX, 148). Eine kurze Übersicht über die tetrarchischen Bautätigkeit in Rom bietet Curran 2000, 43-46.

12 Grundlegend für die Rekonstruktion des tetrarchischen Fünfsäulendenkmals sind L'Orange 1938; Kähler 1964, 7-28. Vgl. ferner Wrede 1981 (a), 121-142; Kolb 1987, 123-126; Mayer 2002, 176-180. 
eine Reihe von sieben monumentalen Säulen miteinander verbunden, ${ }^{13}$ so dass ein auf drei Seiten von Säulenmonumenten umschlossenes Karree entstand, das innerhalb des Forum Romanum eine eigenständige monumentale Platzanlage bildete. Die Tetrarchen schufen damit gleichsam ein eigenes tetrarchisches Forum, das sich durch seine geschlossene Form den kaiserlichen Fora annäherte, mit denen es über das Argiletum und das Nervaforum zu einem großen Komplex verbunden war. ${ }^{14}$

Dass diese tiefgreifende Umgestaltung des Forum Romanum in Verbindung mit einem Regierungsjubiläum, den Vicennalien der Augusti und den Decennalien ihrer Caesares, stand, verdient besondere Beachtung, da mit der Feier dieser Jubiläen zugleich ein spezifischer Kommunikationszusammenhang verbunden war. Der senatus populusque Romanus erfüllte anlässlich besonderer Jahrestage des kaiserlichen dies imperii (wie den Quinquennalia, Decennalia, Vicennalia oder Tricennalia) Gelübde, die er zugunsten der Kaiser und ihrer Caesaren geleistet hatte (vota soluta) und sprach gleichzeitig für die kommenden Jahre bis zum nächsten Jubiläum neue vota (decennalia o. ä.) in der Form von vota suscepta aus. ${ }^{15}$ Dies hatte auch Konsequenzen für die in Verbindung mit diesen vota errichteten Monumente. ${ }^{16}$ Anders als etwa die monumentalen Diocletiansthermen, die sich offen als eine Stiftung der Kaiser Diocletian und Maximian für ,ihren“ populus Romanus zu erkennen gaben, ${ }^{17}$ insinuierten die Decennalien- und Vicennalieninschriften auf dem tetrarchischen Säulenmonument eine umgekehrte Handlungsrichtung, die das Monu-

13 Steinby 1986, 141f. vermutet auf der Grundlage der verwendeten Ziegelstempel für die sieben Säulenmonumente an der Südseite des Forumsplatzes eine Entstehung in der Übergangszeit zwischen der Tetrarchie und der Herrschaft des Maxentius (306-312), also erst einige Jahre nach den tetrarchischen Vicennalien von 303. Grundlage für diese Annahme ist ein Ziegelstempel mit der Aufschrift Off(ficina) F(--) s(ummae) r(ei) d(omus) p(rivatae) $M(--)$ (CIL XV, 1590, 1), der beim östlichsten der sieben Säulenmonumente gefunden wurde und dessen Produktion in die maxentische Zeit fällt (Steinby 1986, 123f.). Allerdings wurde der Ziegel 1872 nicht in die Basis selbst verbaut, sondern nur in deren Nähe gefunden (s. den Kommentar zu CIL XV, 1590, 1: repertum ad basim latericiam primam); der Hinweis darauf, dass die Säulenmonumente erst unter Maxentius hinzugefügt wurden, ist also nicht sonderlich tragfähig. Die Anlage der östlichen Rostra ist wegen der Symmetrie mit dem Fünfsäulenmonument mit hoher Wahrscheinlichkeit tetrarchisch. Eine Zusammenfassung der Diskussion bei Bauer 1996, 31f. (östliche Rostra) und 42f. (sieben Säulenmonumente).

14 Zu dieser Interpretation der Umgestaltung des Forumsbereichs vgl. Giuliani/Verduchi 1987, bes. 185-187; Bauer 1996, 102.

15 Vota decennalia sind erstmals seit der hohen Kaiserzeit, in Münzprägungen für Antoninus Pius 148 n. Chr., belegt (vgl. Chastagnol 1988, 13). Zwar sind auf dem Fünfsäulendenkmal die Kaiser und Caesaren als diejenigen dargestellt, die das Opfer vornehmen (Chastagnol 1987, 493-497), doch agieren sie damit - ebenso wie die Magistrate, die vota darbrachten - als Handlungsträger des römischen Volks. Zu den unterschiedlichen Anlässen und Daten der vota pro salute principis in der frühen und hohen Kaiserzeit vgl. anhand der Arvalbrüderakten Scheid 1990, 289-363.

16 Eine Übersicht über die im Zusammenhang mit den Kaiserjubiläen überlieferten Votivstiftungen und -inschriften hat Chastagnol 1988, 19-24 zusammengestellt.

17 CIL VI, 1130: Romanis suis dedicaverunt. 
ment zu einer Votivgabe der Römer an den Kaiser machte. ${ }^{18}$ Der senatus populusque Romanus erschien damit nicht nur als reiner Empfänger und Adressat eines kaiserlichen Repräsentationswillens, sondern als Akteur, der am Zustandekommen herrscherlicher Repräsentation einen konstitutiven Anteil hatte.

Auch das Bildprogramm des Fünfsäulendenkmals unterstrich diesen Aspekt: Die einzige erhaltene Säulenbasis des Monuments zeigt einen der Caesaren, wie er beim Opfer von dem hinter ihm stehenden Genius des Senats bekränzt wird, während eine mit Attributen der aeternitas versehene Roma vom Bildrand aus auf die Szene blickt. ${ }^{19}$ Die Kaiser erscheinen auf diese Weise gleichzeitig als Garanten des ewigen Bestehens Roms ${ }^{20}$ und als Agenten der res publica, die in ihrem Auftrag das Opfer vollzogen und die vota leisteten. Das Fünfsäulendenkmal stellt damit eine eigentümliche Verbindung unterschiedlicher Elemente dar: Die Tetrarchen nutzten die politische Bühne des Forum Romanum keineswegs nur, um ihre auf göttlicher Erwählung beruhende und menschlicher Zuschreibung enthobene Herrschaftskonzeption zu visualisieren. ${ }^{21}$ Vielmehr brachten sie daneben auch geradezu magistratische Züge in der Person des Kaisers zu Darstellung, die sich in vergleichbaren bildlichen Darstellungen der Tetrarchen außerhalb Roms nicht finden und nur mit einer für Rom eigentümlichen Kommunikationssituation zu erklären sind. ${ }^{22}$ Die politischen Traditionen der urbs gaben einen Kommunikationsrahmen vor, in dem Elemente der Prinzipatsideologie auch unter den veränderten Bedingungen des spätantiken Kaisertums konserviert wurden. Wie weiter unten noch zu zeigen sein wird, hat auch Konstantin die Bühne des städtischen Zentrums genutzt, um sich dieses Kommunikationsmodus' zu bedienen, wenn auch unter veränderten Voraussetzungen und mit einer anderen Zielsetzung als die Tetrarchen bei ihrem Regierungsjubiläum im Jahr 303. ${ }^{23}$

18 Erhalten ist eine Reliefbasis mit der Inschrift Caesarum decennalia feliciter (CIL VI, 1203); zwei weitere Basen mit der Aufschrift Augustorum vicennalia feliciter (CIL VI, 1204) und Imperatorum vicennalia feliciter (CIL VI, 1205) sind verloren. Für die Lokalisierung der Inschriften im tetrarchischen Fünfsäulenmonument - an den Außenseiten die Basen mit den Inschriften für die Caesaren, zur Mitte hin die der beiden Augusti und zentral die auf alle vier Herrscher bezogen Basis mit der Vicennalieninschrift für die imperatores - vgl. L'Orange 1938. Die auf die vota bezogenen Inschriften nennen keinen Dedikanten; es muss jedoch - ähnlich wie beim Konstantinsbogen eine weitere Inschrift existiert haben, die das Monument als eine Weihung des senatus populusque Romanus auswies (vgl. Chastagnol 1988, 16f.).

$19 \quad$ Wrede 1981 (a), $122 \mathrm{f}$.

20 Zu diesem Aspekt der politischen Programmatik des Fünfsäulendenkmals vgl. Kolb 1987, $123 f$.

21 So - mit Verweis darauf, dass die Genien der Kaiser, nicht die Kaiser selbst, dargestellt waren Wrede 1981 (a), 137f.; Kolb 1987, 123-126 betont die im Fünfsäulendenkmal vollzogene Angleichung und Systematisierung der kaiserlichen Regierungsjubiläen und hebt die visuelle Umsetzung des von Diocletian inaugurierten Systems planmäßiger Herrscherwechsel hervor.

22 Dieser Aspekt wird auch von Mayer 2002, 180 zurecht herausgestellt.

23 Vgl. u., S. 130-133. 
Kaiser Maxentius hat, was die Anzahl und Dimension der von ihm ins Leben gerufenen Bauprojekte betrifft, noch ausgeprägter als seine tetrarchischen Vorgänger im Bereich des Forum Romanum seine Bindung an Rom und damit die besondere Verpflichtung denjenigen gegenüber inszeniert, denen er seine Herrschaft verdankte: Der in der tetrarchischen Nachfolgeregelung übergangene Sohn Maximians hatte die allgemeine Unzufriedenheit mit der Italienpolitik der Tetrarchen, die geplante Auflösung der Prätorianergarde und die Durchbrechung des tetrarchischen Nachfolgesystems durch die dynastische Proklamation des Sohnes von Constantius Chlorus, Konstantin, zum Augustus dazu genutzt, sich von den Prätorianern und der zivilen Bevölkerung Roms am 28. Oktober 306 zum Augustus ausrufen zu lassen. ${ }^{24}$ Die daraus erwachsene enge Beziehung zum caput imperii stellte Maxentius nicht nur auf seinen Münzemissionen, in denen er sich als conservator urbis suae feiern ließ, heraus, sondern auch durch eine umfangreiche Bautätigkeit. ${ }^{25}$ Ähnlich wie die Tetrarchen konzentrierte auch Maxentius einen wesentlichen Teil seiner Aktivitäten auf den erweiterten Forumsbereich, doch wählte er den Abschnitt östlich des unter Maximian und Diocletian umgestalteten Forums, wo er eine Reihe von neuen Bauwerken und Restaurationsmaßnahmen in Angriff nahm.

Ebenso wie bei der tetrarchischen Umgestaltung des Forum Romanum dürfte ein Brand, der im Jahr 307 den Venus und Roma-Tempel in Mitleidenschaft zog und vermutlich auch die an ihn angrenzenden Teile zerstört hat, den Raum und Anlass für eine größere Umgestaltung durch Maxentius gegeben haben. ${ }^{26}$ Maxentius schuf dort, wo die Senke zwischen Palatin und Colosseum auf den Venus und Roma-Tempel stieß, und entlang des nördlichen Saums der via sacra, die, vom Roma-Tempel ausgehend, in westlicher Richtung zum Forum Romanum verlief, einen Komplex von drei aufeinander folgenden Bauten (den Venus und Roma-Tempel, die Maxentiusbasilika und den sogenannte „Tempel des Romulus“ ${ }^{6},{ }^{27}$ der diesem

24 Aur. Vict., Caes. 40, 5: interim Romae vulgus turmaeque praetoriae Maxentium retractante diu patre Herculio imperatorem confirmant; vgl. außerdem Zos. 2, 9; Lact., mort. pers. 26, 1-3; Origo Const. 3, 6. Zu den politischen Hintergründen der Ausrufung des Maxentius zum Augustus vgl. Curran 2000, 50-53.

25 Übersichten über die von Maxentius in Rom lancierten Bauprojekte bieten Cullhed 1994, 49-61; Bauer 1996, 50-61, 103-105; Curran 2000, 56-63. Zu den Münzemissionen des Maxentius vgl. Cullhed 1994, 46-49; Curran 2000, 54 f.

26 Vgl. den Chronographen von 354 (MGH AA IX, 148): hoc (scil. Maxentius) imp(erante) templum Romae arsit et fabricatum est. Zos. 2, 13 berichtet von einem Brand, der offensichtlich so schwer war, dass er auch einen nicht näher bezeichneten Fortunatempel zerstörte.

27 Die Restaurationsarbeiten im Venus und Roma-Tempel und der Bau der Maxentiusbasilika sind durch Aurelius Victor belegt (s. u., Anm. 160). Dafür, dass auch der „Romulustempel“ unter Maxentius errichtet wurde, spricht vor allem, dass die Fassade des Gebäudes durch eine zweite, konkave Fassade ersetzt wurde, die aufgrund ihres Mauerwerks kurz danach errichtet worden sein muss, und auf der eine auf Konstantin bezogene Weihung angebracht war (vgl. u., S. 123f.). Es liegt nahe, dies mit einer Umweihung des maxentischen „Romulustempels“ an Konstantin zu 


\section{Abschnitt in der Forschung die Bezeichnung eines „Maxentiusforums“ eingetragen hat. ${ }^{28}$}

Die Deutung dieses maxentischen Komplexes wird außerordentlich dadurch erschwert, dass Dedikationsinschriften aufgrund der damnatio, der Maxentius nach seinem Sturz verfiel, nahezu vollständig aus der Überlieferung getilgt wurden und Konstantin sämtlichen Baumaßnahmen seines unterlegenen Gegners seinen eigenen Stempel aufdrückte. Dementsprechend besteht hinsichtlich der Funktion und symbolischen Programmatik der einzelnen Bauten große Unklarheit. ${ }^{29}$ Am wenigsten interpretationsbedürftig erscheint die Restauration des Venus und Roma-Tempels, die sich auf das Innere des Baus beschränkte und die hadrianische Fassade unangetastet ließ. ${ }^{30}$ Schon bald nach seiner Errichtung durch Hadrian war das Gebäude zum Sinnbild der Roma aeterna geworden. ${ }^{31}$ Es ist naheliegend, dass Maxentius diesen Bau zur Darstellung seiner romanitas nutzte, die er auch sonst im monumentalen

verbinden, ähnlich wie sie beim Venus und Roma-Tempel und bei der Maxentiusbasilika erfolgte (zu den Fassaden vgl. Frazer 1964, 97f., 110-113, der allerdings selbst von einer ursprünglichen Errichtung der Rotunde erst unter Konstantin ausgeht). Zu der von einigen Forschern vertretenen Annahme, dass die Rotunde an der via sacra auf mehreren Konsekrationsprägungen des Maxentius erscheint, vgl. u., S. $93 \mathrm{f}$.

28 Fiore 1981, 64, übernommen von Bauer 1996, 103f. Kritisch zuletzt Mayer 2002, 184f., der eine Bezeichnung als Forum aufgrund des fehlenden Platzcharakters ablehnt.

29 Dasselbe gilt auch für die Dimensionen des maxentischen Bauprogramms. Sehr weitreichende Vermutungen hat unlängst Ensoli 2000, 86-90 aufgestellt: Danach soll Maxentius neben den Bauten des „Maxentiusforums“ auch einen Vorläufer des Konstantinsbogens errichtet und die monumentale Solstatue vor dem Colosseum zu einer Statue seines divinisierten Sohnes Romulus umgearbeitet haben. Diese stark spekulativen Annahmen sind allerdings eher skeptisch zu bewerten. Beim Konstantinsbogen wird zwar diskutiert, ob er die Umarbeitung eines Vorgängerbogens aus hadrianischer Zeit darstellt, doch eine Bearbeitungsphase durch Maxentius lässt sich nicht nachweisen (s. u., Anm., 165). Bezüglich der Umwandlung des Sol in eine Romulusstatue stützt sich Ensoli auf eine bei Restaurationsarbeiten am Konstantinsbogen entdeckte monumentale Inschrift, aus der eine Dedikation eines colossus an den divus Romulus hervorgehe, und verweist auf einen traditionell mit Konstantin oder Constantius II. identifizierten kolossalen Bronzekopf, der seinerseits eine Umarbeitung der Romulusstatue darstelle. Letzteres ist u. a. mit Blick auf die Dimensionen des Bronzekopfes, der die überlieferten Maße des Solkolosses deutlich unterschreitet, zurecht zurückgewiesen worden (Parisi Presicce 2005, 152f.). Was die Dedikationsinschrift betrifft, ist sie nicht notwendig auf die kolossale Solstatue vor dem Colosseum zu beziehen; eine Bewertung des epigraphischen Zeugnisses wird zudem dadurch erschwert, dass es zwar seit mehreren Jahren in der Forschung als Beleg für eine Dedikation des Solkolosses an Romulus herangezogen wird (vgl. neben Ensoli auch Brandenburg 1992, 31; Currran 2000, 62), eine Edition jedoch nach wie vor aussteht.

30 Die Rückwände der beiden Tempelcellae wurden durch Apsiden ersetzt, die mit ihrem Scheitel aneinander stießen. Auch die Wände (Porphyrsäulen) und möglicherweise der Boden der Cellae (polychromer Marmorbelag) wurden umgestaltet (vgl. A. Cassatella, s. v. „Venus et Roma, aedes, templum“, in LTUR IV, 121-123). Für eine weitreichende Umgestaltung auch des Peripteros, von der Curran 2000, 57 spricht, finden sich hingegen keine Anhaltspunkte.

31 Vgl. dazu Gagé 1936; zur Verbindung des Venus und Roma-Tempels mit der Legende der Roma aeterna auf Münzen seit dem ausgehenden 2. Jh. s. ebd., 160; vgl. ferner D. Brown 1940, 8f. und 44-49. 
Zentrum Roms propagierte: So ließ er eine Statuengruppe, bestehend aus Mars und den Zwillingen Romulus und Remus sowie einer Statue seiner eigenen Person, unmittelbar neben dem Fünfsäulendenkmal auf dem Forum Romanum errichten und setzte dem tetrarchischen Monument mit seiner ubiquitären, von der konkreten Stadt Rom gelösten aeternitas-Symbolik eine stärker lokal geprägte Auffassung eines (stadt)römischen Kaisertums entgegen, indem er auf die Gründungslegende der Stadt am Tiber Bezug nahm. ${ }^{32}$

Inwieweit sich auch die übrigen Bauten an der Velia - die Basilika und die Rotunde - einem derartigen „nationalrömischen“ Konzept einfügten, lässt sich nicht beurteilen. Die Maxentiusbasilika - möglicherweise als Gerichtsbasilika für den Stadtpräfekten errichtet ${ }^{33}$ - fungierte fraglos als monumentaler Repräsentationsraum. Darauf weist auch die statuarische Ausstattung hin. Spätestens unter Konstantin stand hier in der Westapsis eine kolossale Sitzstatue des Kaisers, die ihn mit einem stabartigen Gegenstand (einem Langzepter oder einer Standarte) darstellte, der von Eusebius von Caesarea als ein Kreuz gedeutet wurde. ${ }^{34}$ Vermutlich modifizierte Konstantin hier einen maxentischen Aufstellungskontext: Die Statue weist Umarbeitungsspuren auf und scheint in ihren Dimensionen von vornherein für das Gebäude konzipiert gewesen zu sein. ${ }^{35} \mathrm{Ob}$ sie allerdings ursprünglich Maxentius selbst darstellte $^{36}$ und möglicherweise Teil eines statuarischen Programms war, das sich auf Maxentius und seine Familie bezog, muss vorerst eine offene Frage bleiben. ${ }^{37}$

32 Vgl. zu dieser Interpretation Wrede 1981 (a), 140-142; zustimmend Bauer 1996, 104.

33 So die Vermutung von Coarelli 1986, 22-31.

34 Eus., b. e. 9, 9, 10f., ähnlich ders., v. C. 1, 40, 2. Zur Diskussion darüber, was es mit dem


gehalten haben soll, vgl. zuletzt die ausführliche Aufarbeitung durch Thümmel 1998, 158-165; 171-179. Dass unter der Ortsangabe des Euseb, die Statue sei „am belebtesten Ort Roms“ aufgestellt gewesen, die Maxentiusbasilika zu verstehen sei, gilt gemeinhin als ebenso anerkannt wie die Faktizität des eusebischen Berichts selbst, obwohl die Inschrift, die Euseb im Zusammenhang mit der Statue überliefert, in dieser Form nicht authentisch sein kann (so auch Kuhoff 1991, 171; anderer Ansicht sind Kähler 1952, 27-30, Curran 2000, 77-79).

35 So Thümmel 1998, 173, gegen Kähler 1952, 6f., der auf die Unterkellerung der Apsis verweist und daher bezweifelt, dass dort bereits unter Maxentius die Errichtung einer Kolossalstatue geplant gewesen sei.

36 Für eine Bilanz der unterschiedlichen Meinungen (Maxentius, Kopf eines anderen Kaisers) vgl. Thümmel 1998, 172-174. Gesichert ist einzig, dass eine Umarbeitung stattgefunden hat (gegen Curran 2000, 82).

37 Zu einer auf die Dedikation einer kolossalen Statue für Maxentius' Sohn, Romulus, bezogenen Inschrift, die vor einigen Jahren entdeckt wurde, vgl. o., Anm. 29. Während es schwer fällt, diese Weihung auf die Solstatue vor dem Colosseum zu beziehen, scheint die genannte Inschrift in jedem Fall zu bestätigen, dass Maxentius im Bereich der Velia nicht nur durch normale Statuen (dazu Bauer 1996, 104f.), sondern auch durch überlebensgroße Statuen von Mitgliedern seiner Familie eine repräsentative Wirkung zu erzielen suchte. 
Keine geringeren Probleme wirft die Rotunde neben der Maxentiusbasilika auf. Die vor allem von Filippo Coarelli vorangetrieben Bemühungen, in ihr und den übrigen Bauten der Velia Bezüge auf die frührömische Geschichte und Architektur zu erkennen, beruhen auf ingeniösen Konstruktionen, die jedoch in hohem Maße spekulativ sind. Coarelli meint, dass Maxentius' Wahl für seine Bauprojekte auf die Velia gefallen sei, weil hier eine Reihe von Monumenten die Erinnerung an die Frühzeit Roms und an einen berühmten Vorfahren des Maxentius aus republikanischer Zeit, P. Valerius Poplicola, wachgehalten habe. Nach dieser Deutung soll die Maxentiusbasilika an der Stelle des Wohnhauses von Poplicola, das republikanische Quellen auf der Velia lokalisieren, 38 errichtet worden sein. Die Penaten des bei dieser Gelegenheit ebenfalls überbauten Penatentempels habe Maxentius im sogenannten Romulustempel wieder errichtet, um seine Verbundenheit mit dem Romgründer Aeneas zu signalisieren. ${ }^{39}$ Coarelli stützt sich dabei auf ein Architekturmotiv, das auf einer Reihe von maxentischen Kommemorationsprägungen für Maxentius' Sohn Romulus, für Maximian und Constantius Chlorus erscheint (ein kuppelüberwölbter Rundbau mit zwei flankierenden Statuen in Nischen), ${ }^{40}$ und das Coarelli auf den sogenannten Romulustempel an der via sacra bezieht, in dessen nischenartigen Seitenräumen neben dem Eingang die beiden Statuen aufgestellt gewesen sein sollen. Demgegenüber hat Lizia Luschi jedoch überzeugend zeigen können, dass es sich bei den auf den Münzen dargestellten Figuren nicht um Penaten, sondern um Graberoten handeln muss. ${ }^{41}$ Luschi nimmt dies allerdings ebenfalls zum Anlass, von einer Bezugnahme des Maxentius auf die mit der Velia verbundene monumentale Erinnerung an Valerius Poplicola auszugehen: Sie identi-

38 Vgl. das Dossier der einschlägigen Quellen - darunter auch eine Notiz bei Ammianus Marcellinus - bei Frischer 1982-1983, 58, 65. Angesichts der zum Teil tiefgreifenden Umgestaltungen, die die Velia in den Jahrhunderten vor Maxentius erfahren haben muss - man denke z. B. an den neronischen Brand, der auch im Bereich der Velia zu erheblichen Zerstörungen führte - kann man nicht voraussetzen, dass Maxentius zu Beginn des 4. Jh. an der via sacra monumentale Erinnerungszeichen, die auf die Valerier verwiesen, vorfand; zwei Inschriften von Valeriern, die im Bereich der domus des Poplicola gefunden wurden (CIL VI, 31; 618), datieren aus der späten Republik.

39 Coarelli 1986, 3-8 und 16-20; zustimmend Cullhed 1994, 55; Curran 2000, 60.

40 Zusammenstellung und Diskussion der Prägungen bei Talamo 1981, Rasch 1984, 76-78. Die Darstellungen umfassen vier unterschiedliche Typen, die im Erscheinungsbild des Gebäudes stark voneinander abweichen.

41 Luschi 1984, 43-50. Überkreuzte Beine finden sich nicht nur in Verbindung mit Graberoten, sondern waren als Trauergestus allgemein geläufig; vgl. als Beispiel einen Grabstein, auf dem zwei Soldaten mit phrygischen Mützen in dieser Haltung dargestellt werden (s. Keppie 2003, 42f. mit Abb. 8, der die beiden Figuren wegen ihrer Kopfbedeckung als Darstellungen des Attis deutet). Für die Ikonographie der Penaten im Tempel auf der Velia gibt es hingegen faktisch keine Anhaltspunkte; vgl. die Zusammenstellung der Zeugnisse bei Dubourdieu 1989, 419-430, die allerdings von Coarellis Identifizierung der beiden Statuen auf den maxentischen Kommemorationsprägungen mit den Penaten des Tempels auf der Velia ausgeht. 
fiziert - ebenso wie Coarelli - den Kuppelbau auf den Kommemorationsprägungen des Maxentius mit der Rotunde an der via sacra und interpretiert die funerale Assoziation der Graberoten als Hinweis darauf, dass Maxentius die domus, in der sich auch die Grablege des Poplicola befand, in einen Tempel für die divi der valerischen Gens umgewandelt habe. ${ }^{42}$

Auch dieser Ansatz kann jedoch nicht überzeugen. Zum einen weichen die einzelnen Typen der maxentischen Kommemorationsprägungen - selbst wenn man eine für spätantike Architekturdarstellungen auf Münzen charakteristische Tendenz zur Abstraktion in Rechnung stellt ${ }^{43}-$ zu stark voneinander ab, um auf ein konkretes Gebäude bezogen werden zu können. ${ }^{44}$ Zum anderen sind die in den Münzprägungen auftauchenden Graberoten ebenso wie andere ikonographische Elemente mit eindeutig sepulkraler Symbolik kaum an einem Gebäude vorstellbar, das sich mitten in der Stadt und in der unmittelbaren Nähe von Tempeln für die di superi erhob, sondern allenfalls an einem Mausoleum außerhalb der Stadt. Man hat aus diesem Grund das Gebäude auf den Münzen mit dem Maxentiusmausoleum an der via Appia in Verbindung gebracht, doch scheitert auch diese Interpretation an der Uneinheitlichkeit der Prägungen sowie daran, dass charakteristische Details dieses Baus sich nicht auf den Münzdarstellungen wiederfinden. Wie an späterer Stelle noch eingehender auszuführen ist, erscheint daher die Annahme am plausibelsten, dass das in den divus-Prägungen auftauchende Motiv eines Grabbaus ein gewandeltes Verhältnis zur Konsekration wiedergibt, das sich zwar durchaus auch im Grabtempel an der via Appia widerspiegelt, aber nicht auf ein konkretes Gebäude zu beziehen ist. ${ }^{45}$

Für die Rotunde an der via sacra bleibt nach all dem einzig festzuhalten, dass sie keinerlei äußere Hinweise auf eine kultische Funktion im Rahmen des Kaiserkults enthält ${ }^{46}$ und ein vestibülartiges Verbindungsglied zwischen der via sacra und dem hinter der Rotunde liegenden forum pacis darstellt. ${ }^{47}$ Zur Funktion des Baus lässt sich daher nach dem gegenwärtigen Stand der Kenntnisse nicht mehr sagen, als dass sie im Zusammenhang mit dem Teil des forum pacis gesucht werden muss, zu dem die Rotunde einen Zugang bildete. Möglicherweise war sie das Amtslokal eines ranghohen Beamten, ${ }^{48}$ doch muss auch dies Spekulation bleiben.

\footnotetext{
$42 \quad$ Luschi 1984, 51f.

43 Vgl. z. B. den Venus und Roma-Tempel, der in den maxentischen Prägungen teils als tetrastyler, teil als hexastyler Tempel erscheint (vgl. RIC VI, 325, nr. 113-118)

44 So auch Frazer 1964, 52f., ders., 1966, 389f.; Rasch 1984, 77; Dubourdieu 1989, 416f. Talamo 1981, 23f. meint, dass ein Teil der Prägungen sich auf die Rotunde an der via sacra, ein anderer Teil auf den Grabtempel der Maxentiusvilla an der via Appia beziehe.

45 Vgl. dazu u., S. 195 f.

46 Z. B. fehlen Nischen für Statuen (vgl. Frazer 1966, 77).

47 Frazer 1964, 114f., bestätigt durch jüngere Untersuchungen (vgl. Bauer 1996, 54-57).

48 So - in Anlehnung an Frazer - Mayer 2002, 185.
} 
Der Umstand, dass weder die Funktion der maxentischen Bauten entlang der via sacra sicher bestimmt werden kann noch Inschriften oder Reliefs erhalten geblieben sind, die Aufschluss über die mit ihnen verbundenen Aspekte kaiserlicher Repräsentation geben könnten, stellt einer Interpretation unüberwindliche Schwierigkeiten entgegen. Dass Maxentius bestrebt war, durch seine Bautätigkeit und Monumente seine enge Bindung an die Stadt Rom hervorzuheben, erscheint insbesondere mit Blick auf die Restauration des Venus und Roma-Tempels unbestreitbar. Ob er jedoch jenseits einer Demonstration von romanitas, wie sie auch in der als Pendant zum tetrarchischen Fünfsäulendenkmal auf dem Forum Romanum errichteten Statuengruppe mit den mythischen Stadtgründern und Mars zum Ausdruck kam, auf Bauten und Erinnerungsorte Bezug nahm, die bis in die Zeit der Republik zurückverwiesen, um sich dadurch als einen tief in den Wurzeln senatorischer Tradition verhafteten Römer darzustellen, ist eher zweifelhaft. Offen ist auch, inwieweit er im Rahmen seiner monumentalen Inszenierung im Zentrum der Stadt ${ }^{49}$ - ähnlich wie die Tetrarchen - die Vorstellung von einem magistratischen Herrscherbild vermittelte. Sicher ist einzig, dass er durch die Monumentalität der Basilika und der Statuenausstattung im Bereich der Velia starke bauliche Akzente setzte - Akzente, die auch sein Nachfolger nicht unbeachtet lassen konnte und zum Anlass nahm, seine Rolle als princeps civilis gegenüber der römischen Bevölkerung zu kommunizieren.

\section{1. 2. Zentrum und Peripherie: zu einem Deutungsmuster der konstantinischen Baupolitik}

Im Unterschied zu den Tetrarchen und zu Maxentius nahm Konstantin keine grundlegenden Umgestaltungen im Forumsbereich vor, sondern beschränkte sich im wesentlichen darauf, die Arbeiten seines verdrängten Rivalen Maxentius zu vollenden und den Monumenten seinen Namen aufzudrücken. ${ }^{50}$ Man hat diese Tatsache dahingehend interpretiert, dass Konstantin an einer Nutzung des Forumsbereichs als Ort kaiserlicher Repräsentation, auf die seine Vorgänger so großen Wert gelegt hatten, nicht gelegen gewesen wäre. ${ }^{51}$ Dass Konstantins Initiativen im Bereich des monumentalen Zentrums sich scheinbar in einer Umwandlung des maxentischen Bauprogramms erschöpften, darf

49 Der im Suburbium gelegene Baukomplex der Maxentiusvilla an der via Appia wird an anderer Stelle diskutiert, vgl. u., S. 190-195.

50 Vgl. dazu allgemein Krautheimer 1980 (1987), 39; Coarelli 1986, 1-35; Curran 2000, 76-90.

51 Dieser Auffassung neigt u. a. Bauer 1996, $107 \mathrm{zu}$ (,eigenartigerweise sind kaum Eingriffe Konstantins in den Bestand des Forums und der Kaiserfora überliefert"); ähnlich Brandt 2006, 86. Nach LaBranche 1968, 121 hätten die Kaiser der konstantinischen Dynastie das Forum als Ort der Legitimation geradezu ignoriert. 
jedoch nicht darüber hinwegsehen lassen, dass es dem Kaiser dabei um mehr ging als nur um eine reine Verdrängung der maxentischen Memoria. Obwohl dieser Aspekt selbstverständlich eine zentrale Rolle spielte, ${ }^{52}$ verdienen vor allem die nur wenig beachteten Modalitäten dieser monumentalen damnatio der Memoria des Maxentius besondere Aufmerksamkeit. Die Art und Weise, in der Konstantin diese Bauten umwidmete, zeigt, dass auch unter ihm das monumentale Zentrum der Stadt eine wesentliche Rolle in der politischen Kommunikation des Kaisers mit der städtischen Elite und den Römern spielte: Auch Konstantin nutzte das städtische Zentrum, um herrschaftsrelevante Botschaften gegenüber dem senatus populusque Romanus zu kommunizieren.

Die Ausführung dieses Punktes soll jedoch noch für einen Moment zurückgestellt werden, ${ }^{53}$ da die Forschungslage zur konstantinischen Baupolitik eine andere Vorgehensweise nahelegt. Im folgenden werden zunächst die christlichen Bauprojekte, die Konstantin in Rom initiierte, vorgestellt, ${ }^{54} \mathrm{da}$ ihre periphere Lage am Rande der Stadt und im Suburbium von weiten Teilen der Forschung als Schlüssel für die Interpretation der konstantinischen Baupolitik insgesamt angesehen wird. Im Anschluss daran erfolgt eine kritische Auseinandersetzung mit dieser Deutungsrichtung, die die Lokalisierung der auf Konstantins Initiative hin errichteten Sakralbauten mit Integrationsproblemen christlicher Kultstätten in den städtischen Kontext erklärt und die Errichtung der christlichen Basiliken als eine Privatangelegenheit des Kaisers ohne Einfluss auf die städtische Identität auffasst. Auf der Grundlage dieser Kritik soll ein alternativer Vorschlag präsentiert werden, der anstelle eines dichotomischen Modells von räumlich getrennten „öffentlichen“ und „privaten“ kaiserlichen Handlungsbereichen von komplementären, einander nicht ausschließenden Kommunikationsfeldern und -räumen des Kaisers mit der städtischen Bevölkerung Roms ausgeht.

Die in konstantinischer Zeit errichteten christlichen Basilikalbauten sind einzig aus der archäologischen und epigraphischen Überlieferung und aus mehreren Listen von Gütern bekannt, mit denen die Basiliken anlässlich ihrer Erbauung dotiert wurden und die in der Silvestervita des Liber Pontificalis überliefert sind. ${ }^{55}$ Dementsprechend problematisch und umstritten sind die

52 Auch die Konstantinsthermen gehen möglicherweise auf maxentische Vorgängerbauten zurück (so Steinby 1986, 142; anders Curran 2000, 85).

53 Vgl. weiteres u., S. 122-133.

54 Das nachfolgende Dossier beschränkt sich darauf, eine systematische Übersicht über die christlichen Bauten Konstantins, ihre Lokalisierung und die mit ihnen verbundenen Datierungsprobleme zu liefern. Eine ausführliche Auseinandersetzung mit der Funktion der Bauten erfolgt u., S. 153-171.

55 Zum historischen Quellenwert dieser Listen s. u., Anm. 333. 
Datierungs- und Zuordnungsfragen in den einzelnen Fällen. Nicht nur in bautypologischer Hinsicht, sondern auch in ihren Funktionen lassen sich vier Arten von Kultgebäuden unterscheiden: 1. Die Bischofskirche am Lateran 2. Die innerhalb des Lateranpalastes errichtete Kirche S. Croce. 3. Mehrere Coemeterial- oder Umgangsbasiliken, deren charakeristische Form in einem dreischiffigen Bau besteht, bei dem die Seitenschiffe einen Umgang um die Apsis des Mittelschiffs bilden. Diese Coemeterialbasiliken erhoben sich über Nekropolen und unterirdischen Grabanlagen im römischen Suburbium und dienten als monumentale Grablegen (basilica apostolorum/S. Sebastiano; SS. Pietro e Marcellino; basilica maior von S. Lorenzo f.l.m.; S. Agnese; Basilika an der via Praenestina [konstantinisch ?]). 4. Die Basiliken über den Gräbern von Petrus und Paulus, die sich ebenso wie die Coemeterialbasiliken in den Nekropolen außerhalb der Stadt erhoben und als Grablegen dienten, jedoch eine klare räumliche Ausrichtung auf den Kult eines Heiligen erkennen lassen. Was die Relation dieser christlichen Sakralbauten zu den übrigen Bauten des Kaisers in Rom betrifft, lassen sich dem nachfolgenden, chronologisch geordneten Dossier ${ }^{56}$ drei zusammenfassende Feststellungen vorausschicken: 1. Die christlichen Sakralbauten entstanden sämtlich am Rande der Stadt (Lateranbasilika, S. Croce) oder außerhalb der Stadtmauern (Coemeterialbasiliken, Basiliken für Petrus und Paulus) 2. Die ältesten dieser christlichen Sakralbauten wurden unmittelbar nach der Einnahme Roms von 312 in Angriff genommen. Es gibt keinen Grund zu der Annahme, dass Konstantin sich erst sekundär seinen kirchlichen Bauprojekten zuwandte. 3. Basilkale Bauten für die christliche Gemeinde Roms sind vor Konstantin nicht nachweisbar; die Einführung dieses monumentalen Bautyps in seinen unterschiedlichen Formen geht auf ihn zurück.

Der zuletzt genannte Punkt ist insbesondere mit Blick auf die basilica apostolorum an der via Appia - eine Coemeterialbasilika, die über der Kultstätte für die Apostel Petrus und Paulus ad catacumbas errichtet wurde - in Frage gestellt worden. Man hat daraus, dass der Liber Pontificalis keine konstantinische Stiftung der basilica apostolorum überliefert, und dass sich unter den Graffiti der durch die Basilika überbauten und dadurch unzugänglich gewordenen Triklia kein konstantinisches Christusmonogramm befindet, geschlossen, dass dieser Bau bereits vor Konstantin bestanden habe und auf Initiative des Maxentius errichtet worden sei. Richard Krautheimer hat diese Hypothese weiter untermauert, indem er auf Parallelen in der Architektur und im Mauerwerk der zum Maxentiuspalast gehörenden Bauten verwies, die sich nur wenige Meter entfernt auf der anderen Seite der via Appia erhoben, und daraus die Schlussfolgerung gezogen, dass die Basilika bereits nach 310 unter Maxentius errich-

\footnotetext{
56 Für weitere Bemerkungen zur relativen Chronologie der Coemeterialbasiliken s. u., S. 177f.
} 
tet worden sein könnte. ${ }^{57}$ Diese Auffassung ist allerdings zurecht auf Vorbehalte gestoßen. ${ }^{58}$ Dass die Silvestervita des Liber Pontificalis keine Nachricht über den Bau überliefert hat, lässt sich schwerlich als Argument dafür anführen, dass nicht Konstantin, sondern Maxentius der Erbauer der basilica apostolorum war. Denn Konstantin hätte die Memoria seines ausgeschalteten Rivalen bei einem so wichtigen Bauwerk mit Sicherheit nicht unbeeinflusst gelassen: Ähnlich wie bei anderen Bauprojekten des Maxentius, die Konstantin vollendete und mit Erfolg als konstantinische Bauten im Gedächtnis der Nachwelt verewigte, ${ }^{59}$ wäre auch in diesem Fall das aktive Bestreben Konstantins zu erwarten gewesen, als Gründer der basilica apostolorum zu erscheinen. Das Schweigen des Liber Pontificalis hat demnach keinen positiven realhistorischen Zeugniswert in dem Sinne, dass Konstantin nicht der Erbauer dieser Basilika war. Was auch immer der Grund dafür ist, dass der Verfasser des Liber Pontificalis die basilica apostolorum und ihren Erbauer nicht erwähnt, diese Überlieferungslücke taugt nicht als ein Hinweis darauf, dass das Gebäude schon vor Konstantin existierte und dieser daher keinen Anspruch auf den Bau der Basilika erheben konnte. ${ }^{60}$ Bei den bautypologischen Argumenten muss man zwischen den Architekturformen und dem Mauerwerk differenzieren. Die architektonischen Parallelen zwischen der Bogenform der Fenster und des Deambulatoriums der basilica apostolorum und den Nischen im Untergeschoss des Maxentiusmausoleums lassen sich nach jüngeren Untersuchungen des Mausoleums wohl nicht mehr aufrechterhalten. ${ }^{61}$ Was das Mauerwerk betrifft, so

57 Krautheimer, in: Corpus IV, 140, der damit eine ältere Vermutung von Enrico Josi aufgreift. Seine Argumente sind: 1. Die elliptische Form der Fenster und des Deambulatoriums der Basilika, die ein Pendant in den Wandnischen des Untergeschosses des Maxentiusmausoleums haben. 2. Das opus vittatum, das große Ähnlichkeit mit dem Mauerwerk der Quadriportikus aufweist, die das Maxentiusmausoleum umgibt. Für eine Datierung in maxentische Zeit entscheiden sich Jastrzebowska 1981, 99-101, dies. 2002; Heres 1982, 106. Auch Curran 2000, 99 neigt diesem Datierungsvorschlag zu.

58 Pietri 1976, Bd. 1, 46; Brandenburg 1979, 79-81, ders., 1992, 43; Tolotti 1982, 170f.; Schumacher 1987, 175.

59 Exemplarisch ist die Maxentiusbasilika: Ohne eine Notiz bei Aurelius Victor wäre die Erinnerung daran, dass Maxentius der Gründer der Basilika war, vollständig untergegangen (vgl. Coarelli 1986, 3).

60 Dasselbe gilt übrigens auch für den Versuch, die fehlende Zuschreibung im Liber Pontificalis damit zu erklären, dass die 326 hingerichtete Kaiserin Fausta die Stifterin des Bauwerks gewesen und das Andenken an die Stiftung nach ihrem Tod unterdrückt worden sei (so Schumacher 1987, 149f. mit Anm. 117).

61 Laut Rasch 1984, 35 und 48 mit Anm. 425 waren die Nischen der Ringmauer des Mausoleums als Rundbogen konzipiert, doch musste wegen der Breite der Nischen deren Bogenansatz höher angesetzt werden, um Disproportionen zu vermeiden - nach dieser Interpretation war die elliptische Form eines steilen Segmentbogens nur eine „Notlösung“, die durch die zu geringe Wandhöhe des Untergeschosses bedingt war. Auch die Fenster und das Deambulatorium der basilica apostolorum fasst Rasch nicht als elliptische Formen, sondern als marginale Abweichungen von der Grundform des Rundbogens auf. 
kann man dies - in gleicher Weise wie die räumliche Nähe der basilica apostolorum zu Maxentius' Residenz an der via Appia - ebenso zwanglos als ein Argument nicht für, sondern gegen eine Zuweisung an Maxentius interpretieren. Vermutlich griff Konstantin bei der Errichtung der Basilika auf eine Werkstatt an der via Appia zurück, die auch schon am Bau der Maxentiusvilla beteiligt gewesen war, und deren Eigenarten sich daher auch in der Apostelbasilika wiederfinden. ${ }^{62}$

Die wenigen Indizien ${ }^{63}$ reichen also zusammengenommen nicht aus, um die in ihren Ausmaßen stattliche und mit hohem statischem Aufwand errichtete $^{64}$ Basilika an der via Appia einem Kaiser zuzuweisen, der zwar ein Toleranzedikt erließ, darin jedoch vermutlich nicht weit über das hinausging, was bereits Gallienus gegen Ende der valerianischen Verfolgung verfügt hatte und was die übrigen Augusti nur wenige Jahre nach Maxentius auch beschlossen: eine Aufhebung der Verfolgungsmaßnahmen und die Restitution der konfiszierten Güter. ${ }^{65}$ Die Basilika an der via Appia verlangte jedoch eine deutlich darüber hinausgehende finanzielle Unterstützung für die christliche Gemeinde Roms, deren vom Bischof verwaltete Mittel nicht ausreichten, um ein darartiges Bauprojekt zu finanzieren. ${ }^{66} \mathrm{Da}$ wir keinerlei Hinweise darauf

62 So auch Brandenburg 1979, 80.

63 Das fehlende Christusmonogramm kann als ein reines argumentum e silentio keine Grundlage für weiterreichende Hypothesen bilden. Aufgrund der nur wenigen datierten Inschriften mit Christusmonogrammen lassen sich zur Entwicklung und Ausbreitung der unterschiedlichen Monogrammtypen insgesamt keine sicheren Aussagen machen (vgl. Mazzoleni 1997, 166); auch von daher sollte man das Nichtvorhandensein von Monogrammen unter S. Sebastiano nicht zu stark gewichten.

64 Die Substruktionen mussten einen Höhenunterschied von ca. $8 \mathrm{~m}$ zwischen den beiden Enden der Basilika ausgleichen, vgl. Spera 1999, 229.

65 Maxentius erließ vermutlich im Jahr 308 ein Toleranzedikt, das auch die Restitution von konfiziertem Kirchengut einschloss, deren Umsetzung in Rom allerdings erst im Jahr 311 unter Bischof Miltiades erfolgte (s. Aug., coll. c. Don. 3, 18, 34. 36; adv. Don. 13, 17). Vgl. Kriegbaum 1992, bes. 48-54, der Maxentius' Politik zurecht als Fortsetzung der gallienischen Toleranzpolitik begreift und die Distanz, die Maxentius im Unterschied zu Konstantin gegenüber dem christlichen Kult einnahm, herausstellt. Eine ähnliche Wendung vollzogen auch die übrigen Tetrarchen: Galerius ließ am 30. April 311 in Nikomedia ein Toleranzedikt veröffentlichen, in dem die Christen zur erneuten Abhaltung ihres Kultes aufgefordert wurden; da das Edikt im Namen von Galerius, Konstantin und Licinius erlassen war (Eus., h. e. 8, 17, 3-6), sind entsprechende Verfügungen auch in den übrigen Gebieten des Reichs vorauszusetzen. Von einer Restitution konfiszierter Güter ist darin zwar nicht ausdrücklich die Rede, nur davon, dass die Christen erneut das nomen christianorum führen und conventicula bilden sollten (Lact., mort. pers. 34, 4: ut denuo sint Christiani et conventicula sua componant); allerdings wird im Anschluss an diesen Satz auf Ausführungsbestimmungen verwiesen, die nicht erhalten sind (Lact., mort. pers. 34, 5). Entsprechend den Edikten des Gallienus (Eus., b. e. 7, 13) dürfte die Erlaubnis zur Abhaltung von Versammlungen zugleich mit einer Restitution von Kirchengut verbunden worden sein; vermutlich sollte sie in den Bestimmungen, auf die das Edikt von 311 anspielt, geregelt werden (vgl. Millar 21992, 578f.).

66 Dass der römische Bischof bis in die erste Hälfte des 5. Jh. für Bauprojekte auf die Unterstützung durch die Kaiserfamilie und durch reiche Familien angewiesen war, betont Pietri 1976, Bd. 1, 77-96. Aus diesem Grunde erscheint auch eine von Maxentius nur tolerierte, auf die eigene 
haben, dass Maxentius derartige Schritte unternommen hat, muss man - zumindest nach dem gegenwärtigen Stand der Untersuchungen - davon Abstand nehmen, im Vorgänger Konstantins den Patron eines Baus zu suchen, der sich im übrigen so problemlos in das konstantinische Bauprogramm der übrigen christlichen Basiliken einfügt.

Genauere Anhaltspunkte für eine Datierung der basilica apostolorum sind nicht vorhanden. Mehrere Inschriften aus Gräbern, die in den Boden der Basilika eingelassen wurden, datieren aus den Jahren zwischen 340 und 350, ${ }^{67}$ was jedoch nicht ausschließt, dass die Basilika bereits einige Jahrzehnte früher errichtet worden war. ${ }^{68} \mathrm{Da}$ die Abmessungen der basilica apostolorum $(73,40 \mathrm{x}$ $27,50 \mathrm{~m})$ denen von SS. Pietro e Marcellino (65,29 x 29,30m) vergleichbar sind, während die erst um die Mitte des 4. Jh. errichtete Basilika S. Agnese und die basilica maior von S. Lorenzo f.l.m. wesentlich größere Dimensionen erreichen, ${ }^{69}$ liegt es nahe, die Entstehungszeit der Basilika an der via Appia in die Nähe der Basilika von SS. Pietro e Marcellino zu setzen, mit deren Bau noch im 2. Jahrzehnt des 4 . Jh. begonnen wurde. ${ }^{70}$ Diese Frühdatierung ist al-

Initiative der römischen Gemeinde zurückgehende Errichtung der Basilika (so Krautheimer 1987 [1980], 35f.) unwahrscheinlich.

67 Ferrua 1961, 211-213. In einem der südlich von der Basilika gelegenen Mausoleen, dem Uraniermausoleum (nr. 41 auf dem Plan von Tolotti 1953), wurde eine Inschrift aus dem Jahr 349 gefunden (Ferrua 1961, 216). Vermutlich wurde das Mausoleum 41 erst nach den Mausoleen 43 und 42 errichtet, an die es sich anschließt; die Errichtung der Basilika muss demnach einige Zeit vor dem Mausoleum 41 erfolgt sein (vgl. zum ganzen Tolotti 1953, 232f.). Ein Monogramm auf der Schwelle einer Tür, die von der via Appia in ein der Basilika vorgelagertes Atrium führte, lässt sich zu Constantinus (I. oder II.), Constans oder Constantius auflösen, erlaubt also keine eindeutige Zuweisung innerhalb des Zeitraums von 312 bis 361 (vgl. zu den unterschiedlichen Auflösungen des Monogramms Spera 1999, 230).

68 Pietri 1976, Bd. 1, 46, geht von einer vergleichsweise späten Errichtung nach 325 aus; er stützt sich unter anderem auf die ungewöhnliche Stärke der moduli als Anhaltspunkt für diese späte Datierung. Die Stärke der moduli ist bei der basilica apostolorum jedoch nicht auf eine Erhöhung der Tuffstärken, sondern allein auf die relativ hohen Mörtelschichten zurückzuführen (vgl. Heres 1982, 106 und 343). Da sich die Erhöhung nicht in gleicher Weise auf die Tuff- wie auf die Mörtellagen bezieht, ist eine Vergleichbarkeit mit anderen stadtrömischen Bauwerken, die vor allem aufgrund der erhöhten Tuffsteinstärke ähnlich starke moduli aufweisen wie die basilica apostolorum, nicht gegeben. Zu den - insgesamt nur begrenzten - Möglichkeiten, aufgrund der Höhe der moduli Datierungen vorzunehmen, vgl. u., Anm. 75.

69 S. Agnese 98,30 × 40,30m und S. Lorenzo f.l.m. (basilica maior) 98,60 × 35,50m (alle Angaben nach La Rocca 2000, 204-207). Auch in der Gestaltung der Apsis lassen S. Agnese und S. Lorenzo gemeinsame Eigentümlichkeiten erkennen: Bei beiden Bauten schließt die Apsis nicht an die Mittelschiffarkaden an, sondern ist im Verhältnis zu den Seitenschiffmauern leicht nach innen versetzt (zu diesen eingezogenen Apsiden vgl. Tolotti 1982, 178-182).

70 Vgl. Brandenburg 1979, 78; ders., 1992, 43-45 vermutet den Tod der Fausta 325/326 als möglichen terminus ante quem; Tolotti 1982, 154-157; 160-163; 170f.; 201 setzt die basilica apostolorum in die Zeit zwischen 313 und 330 und sieht in ihr die früheste der römischen Umgangsbasiliken; LaRocca 2000, 204f. datiert den Bau auf etwa 317-320 (dort auch Verweise auf weitere Literatur). Anders Torelli 1992, 205, der eine Entstehung nach 330 oder sogar erst nach dem Tod Konstantins erwägt. 
lerdings durch die erst vor wenigen Jahren entdeckte Umgangsbasilika an der via Ardeatina relativiert worden, die ähnliche Dimensionen wie SS. Pietro e Marcellino aufweist, jedoch erst im Jahr 336 vollendet wurde. ${ }^{71}$ Man wird sich daher mit einer Datierung der basilica apostolorum in die konstantinische Zeit begnügen müssen, ohne aufgrund äußerer Kriterien eine genauere zeitliche Eingrenzung vornehmen zu können.

Neben der basilica apostolorum ist noch für eine zweite Umgangsbasilika die Vermutung geäußert worden, sie könne in vorkonstantinischer Zeit entstanden sein. ${ }^{72}$ Es handelt sich um die anonyme Basilika an der via Praenestina bei Tor de' Schiavi, die unmittelbar neben einem monumentalen Mausoleum errichtet wurde. Bautypologisch und funktional entspricht die Basilika an der via Praenestina den übrigen Coemeterialbasiliken in der Umgebung Roms: Die Basilika war ebenso wie die übrigen römischen Coemeterialbasiliken mit Gräbern belegt und weist denselben architektonischen Aufbau einer „Umgangsbasilika" mit einem durch eine Apsis abgeschlossenen Mittelschiff, einem um die Apsis herumlaufenden Seitenschiff und einer Abtrennung der Apsis vom Rest des Mittelschiffs auf. ${ }^{73} \mathrm{Da}$ in der Basilika keine Inschriften gefunden wurden, die eine nähere Datierung ermöglichen würden, beruht die Datierung allein auf dem Mauerwerk - ein unsicheres Kriterium, das zu sehr unterschiedlichen Einschätzungen geführt hat. Sicher scheint einzig, dass der Bau nicht vor Maxentius errichtet wurde, da das opus vittatum, aus dem das Mauerwerk besteht, erst zu dieser Zeit wegen der allgemeinen Ziegelknappheit verstärkt verwendet wurde. ${ }^{74}$ Ein Teil der Forschung neigt einer Spätdatierung zu und setzt die Basilika erst in die Zeit des römischen Bischofs Damasus (366-384). ${ }^{75}$ Eine Zuschreibung an Damasus erscheint jedoch aus allgemeinen historischen Erwägungen heraus nicht haltbar. Damasus’ Bautätigkeit kon-

$71 \quad$ Vgl. u., S. 106.

72 So v. Hesberg 1992, 53, der den Bau für ein nichtchristliches Bauwerk hält, das später von den konstantinischen Coemeterialbasiliken nachgeahmt worden sei. Ähnlicher Ansicht scheint Volpe 2000, 164 zu sein.

73 Vgl. Luschi/Ceccherelli 1987-1988; zur Abtrennung der Apsis vom Mittelschiff, die sich auch in der basilica apostolorum und in der kürzlich entdeckten Basilika an der via Ardeatina findet, vgl. Fiocchi Nicolai 1995-1996, 76).

74 Rasch 1984, 40f. Ein terminus post quem ist auch durch das Mausoleum gegeben, neben dem sich die Basilika erhob (vgl. u., Anm. 81).

75 Schumacher 1987, 152; Rasch 1993, 79f. datieren die Basilika in das dritte Viertel des 4. Jh., ohne dafür jedoch überzeugende Argumente liefern zu können. Rasch stützt seine Annahme auf die Höhe der Tuffstein- und Mörtellagen der Basilika. Aus seiner chronologisch angeordneten Zusammenstellung der Fugen- und Tufelli-Höhen von römischen Bauwerken des 4. und 5. Jh. lässt sich jedoch allenfalls die Vermutung ableiten, dass die Basilika noch vor dem ausgehenden 4. Jh. errichtet wurde, da ab dieser Zeit die Tuffstein- und Mörtellagen allgemein deutlich an Höhe zunehmen. Für eine genauere Datierung der Basilika innerhalb des 4. Jh. scheinen die Vergleichswerte jedoch nicht aussagekräftig genug. Dass im übrigen allein die Höhe des modulus für die Datierung von Mauerwerk nur unzureichende Informationen bietet, betont Heres 1982, $175 \mathrm{f}$. 
zentrierte sich auf die Märtyrergräber, die er durch altarartige Aufbauten, durch die Anlage von Zugängen und durch den Ausbau und die Erweiterung der unterirdischen Bereiche im Umfeld der Gräber monumentalisierte und für den Besuch größerer Gruppen zugänglich machte. ${ }^{76}$ Ein Märtyrerkult an der via Praenestina lässt sich jedoch weder für das 4. Jh. (vgl. die depositio martyrum im Chronographen von 354) noch in der späteren liturgischen und hagiographischen Tradition nachweisen. ${ }^{77}$ Auch eine Verbindung zwischen der Basilika und einem in der Nähe gelegenen Hypogäum ist durch nichts zu belegen, noch viel weniger, dass dieses Hypogäum mit der Verehrung irgendeines unbekannten Märtyrers in Verbindung stand. ${ }^{78}$ Ferner sind auch dort, wo die Anlagen des Damasus die Größe veritabler Basiliken erreichten, diese Basilikalbauten keine Umgangsbasiliken, sondern dreischiffige Anlagen, wie bei der Basilika in der Generosacoemeteriums an der via Portuensis und der halbunterirdischen Basilika für Nereus und Achilleus in der Domitillakatakombe an der via Ardeatina. ${ }^{79}$ Auch aus bautypologischen Erwägungen besteht demnach kein Anlass zu der Vermutung, Damasus habe die Umgangsbasilika bei Tor de' Schiavi errichtet.

Unmittelbar einsichtig erscheint hingegen eine Verbindung zwischen der Basilika bei Tor de' Schiavi und einem in Form eines Grabtempels errichteten Mausoleum, das sich direkt neben der Apsis der Basilika erhebt, und dessen Eigentümer zweifellos mit dem der luxuriösen Villa gleichzusetzen ist, die etwa 80 Meter von dem Komplex aus Mausoleum und Basilika entfernt

$76 \quad$ Einen zusammenfassenden Überblick über Damasus' Bautätigkeit bietet Nestori 1986. Zu den Monumentalisierungen der Gräber durch altarartige Aufbauten vgl. Weiland 1994; Guyon 1995. Zur Anlage von Pilgerwegen s. Fiocchi Nicolai 1995. Um die Märtyrergräber herum wurden große unterirdische Versammlungsräume angelegt, wie z. B. im Bassillacoemeterium an der via Salaria vetus die Basilika von S. Ermete, die unter Damasus oder seinem Nachfolger Siricius (384399) angelegt wurde (Krautheimer, in: Corpus I, 195-208; Pietri 1976, Bd. 1, 539f.). Nestori 1986, 169-171 u. 1990, 119-124 weist auch eine weitere - in ihrer Form und Größe der Hermesbasilika vergleichbare - unterirdische Basilika in einem anonymen Hypogäum an der via Ardeatina, nördlich des Coemeteriums von Marcus und Marcellianus gelegen, Damasus zu und identifiziert sie als seine Grablege; diese Zuweisung ist jedoch unsicher (vgl. die Einwände von Fiocchi Nicolai 1995-1996, 134f.; Spera 1999, 85-87; Saint-Roch 1999, 35-37). Zu den Basiliken der Generosa- und der Domitillakatakombe vgl. u., Anm. 79.

77 Vgl. Amore 1975, 107.

78 Vgl. Ferrua 1953-55, der keinerlei Hinweise auf eine christliche Belegung des Hypogäums ausmachen konnte.

79 Zur Generosabasilika vgl. Pergola 1986, 218-224. Auch die Nereus und Achilleus-Basilika weist Pergola ebd., 205-218 mit überzeugenden Gründen Damasus zu, während andere Forscher die Tätigkeit des Bischofs auf die Anlage eines größeren Raums von ca. 6 x 6 Metern beschränken und den Bau der Basilika erst in das 6. Jh. setzen, in eine Zeit, in der auch in anderen römischen Coemeterien ad corpus-Basiliken errichtet wurden (vgl. Krautheimer, in: Corpus III, 129-135; Fiocchi Nicolai 1997, 132). 
liegt. ${ }^{80}$ Das Mausoleum lässt sich aufgrund seines Mauerwerks in spättetrarchische oder frühmaxentische Zeit datieren, ${ }^{81}$ doch ist dadurch für die Basilika, die deutlich erkennbar auf den Grabtempel bezogen und daher später errichtet worden ist, nur ein terminus post quem gegeben. Auch über den Besitzer der Villa ist nichts bekannt und daher daraus kein Anhaltspunkt für eine Datierung zu gewinnen. ${ }^{82}$ Damit gilt - unter ähnlichen Voraussetzungen wie bei der basilica apostolorum - dasselbe methodische Prinzip der Datierung. Solange keine konkreteren Anhaltspunkte gefunden werden, besteht kein Grund, die Basilika von Tor de' Schiavi, die mit den konstantinischen Coemeterialbasiliken enge architektonische und funktionale Berührungspunkte aufweist, ${ }^{83}$ der vorkonstantinischen Zeit zuzuweisen. Auch diejenigen Forscher, die sich aus typologischen Gründen für eine frühe Datierung der Basilika aussprechen, gehen daher meist von einer Datierung in frühkonstantinische Zeit aus. ${ }^{84}$

Weniger umstritten als bei der basilica apostolorum und der anonymen Basilika bei Tor de' Schiavi sind die Auftraggeberschaft und die Entstehungszeit bei mehreren anderen christlichen Sakralbauten, die sich sicher Konstantin und Mitgliedern seiner Familie zuweisen lassen. Die Lateranbasilika und das danebenliegende Baptisterium wurden wohl noch vor 324 als Gemeindekirche des römischen Bischofs auf dem Caelius errichtet, wobei Konstantin auf das Gelände einer aufgelassenen Kaserne der 312 aufgelösten equites singulares zurückgriff. Diese zeitliche Eingrenzung (312/324) wird durch die in der Silvestervita des Liber Pontificalis überlieferte Liste von Liegenschaften nahegelegt, die der Kaiser für den Unterhalt der Kirche und des Baptisteriums

80 Die Skepsis von Rasch 1993, 1-3 bezüglich eines Zusammenhangs der Basilika mit der Villa erscheint übertrieben. Die Entfernung von 80 Metern zwischen der Villa und dem Grabtempel mit der danebenliegenden Basilika ist wohl kaum zu groß, um eine Verbindung zwischen den beiden Komplexen auszuschließen. Die im Suburbium Roms gelegenen Villen konnten in der Kaiserzeit z. T. erhebliche Ausdehnung erreichen (vgl. Coarelli 1986, 46f., der den durchschnittlichen Abstand zwischen den einzelnen, innerhalb größerer praedia gelegenen Villen mit einem bis zwei Kilometern beziffert und daraus eine Größe der Landgüter von 100 bis 400 Hektar ableitet).

81 Rasch 1993, 77-79 unterscheidet zwei Bauphasen (ca. 305/306 und zwischen 307 und 309).

82 Trotz ihrer gängigen Bezeichnung als villa Gordianorum, lässt sich nicht sicher erhärten, dass dieser Bau mit der berühmten Kaiservilla der Gordiane, die in der Hist. Aug., Gord. 32, 2f. beschrieben wird, identisch ist (vgl. Volpe 2000, 164, La Rocca 2000, 207). Von einer Identifizierung mit der villa Gordianorum und damit von einer Errichtung des Mausoleums und der Basilika auf kaiserlichem Besitz gehen aus Jastrzebowska 1981, 153; Brandenburg 1992, 45 (vgl. auch dens. 1979, 75, wonach die Villa an der via Praenestina zu einem ausgedehnten kaiserlichen Landgut „Subaugusta“ zwischen der via Latina und der via Praenestina gehört haben soll). Unabhängig von der Frage, ob es sich um die Villa der Gordiane handelt scheint es jedoch in jedem Fall plausibel, dass die Villa und das Mausoleum einem Mitglied der kaiserlichen Familie gehörten (so Tolotti 1982, 168f. mit Anm. 34; Coarelli 1986, 56 mit Anm. 294).

83 Neben der Belegung mit Gräbern vor allem die Verbindung mit dem Mausoleum einer hochrangigen Persönlichkeit, vgl. dazu u., S. 158f.

84 So zuletzt Brandenburg 1992, 45f., der damit eine ältere Vermutung korrigiert (vgl. dens. 1979, 72-76). 
stiftete, ${ }^{85}$ und in der keine Güter aus dem Osten des römischen Reichs verzeichnet sind, den Konstantin erst nach der Ausschaltung des Licinius kontrollierte. ${ }^{86}$ In Ermangelung weiterer Anhaltspunkte für eine genauere Datierung des Gebäudes, ${ }^{87}$ ist man auf allgemeine Erwägungen angewiesen. So scheint es naheliegend, dass Konstantin den Bischof von Rom, dem er bereits 313 wichtige Kompetenzen im Donatistenstreit übertrug, schon sehr früh mit einem entsprechenden Kirchengebäude ausstattete. Dass Konstantins Blick dabei auch schon bald auf den Caelius im Südosten der Stadt fiel, zeigt sich darin, dass die auf Konstantins Befehl zusammengekommene Bischofssynode, die im Jahr 313 unter dem Vorsitz von Bischof Miltiades in der Donatistenfrage ein Urteil fällen sollte, in einer domus Faustae in Laterano zusammenkam, die sich in der Nähe der späteren Lateranbasilika befunden haben muss. ${ }^{88}$ Zwar lässt sich nicht zeigen, dass Konstantin diese domus dem römischen Bischof als eine bischöfliche Residenz übertragen hat, aber es ist auffällig, dass die Synode, an deren Zustandekommen der Kaiser so großes Interesse gezeigt hatte, ${ }^{89}$ ausgerechnet dort stattfand, wo sich dann auch die Bischofskirche erhob: Dem Lateran war offensichtlich bereits früh die Rolle zugewiesen worden, ein Zentrum der bischöflichen Autorität in Rom zu bilden.

Komplementär dazu schuf Konstantin nur wenige hundert Meter von der Lateranbasilika entfernt ein kaiserliches Machtzentrum, indem er dort mehrere kaiserliche Besitztümer zu einer neuen Residenz, dem palatium Sessorianum, vereinigte..$^{90}$ Eine Halle dieses Palastes wandelte der Kaiser in eine Basilika um, in die dann später eine Kreuzesreliquie aus dem Heiligen Land überführt wurde. Für die Basilika S. Croce gilt dasselbe wie für die Lateranba-

$85 \quad$ LP I, 173-175.

86 Auf diesen Umstand hat erstmals Piganiol 1932, 113 aufmerksam gemacht; er wird seitdem allgemein als terminus ante quem in der Forschung akzeptiert. Möglicherweise fielen die Stiftungen sogar noch in die Jahre 313/314 (so Pietri 1976, Bd. 1, 8).

87 Für die in der Literatur häufig vertretene Auffassung (Krautheimer, in: Corpus V, 93f.; Brandenburg 1992, 33; Leeb 1992, 78), Konstantin habe die Lateranbasilika unmittelbar nach dem 28. Oktober 312 aus Dank für seinen Sieg über Maxentius als eine Votivstiftung für den christlichen Gott errichten lassen, finden sich allerdings keine expliziten Hinweise. Diese Annahme beruht im wesentlichen auf dem mittelalterlich überlieferten Weihedatum der Basilika, das den 9. November als den Tag der Weihe angibt. Krautheimer schließt daraus, das Gebäude sei im Jahr 312 dediziert oder im Jahr 318 konsekriert worden, da in beiden Jahren der 9. November auf einen Sonntag fiel. Wie Krautheimer jedoch in einem anderen Zusammenhang selbst einräumt, lässt sich für das 4. Jh. keine Regel aufstellen, dass Kirchengebäude an Sonntagen geweiht wurden (vgl. Krautheimer 1989, 22, Anm. 134).

88 Optat. 1, 23: convenerunt in domum Faustae in Laterano. Es gab vermutlich zwei domus, die nach Laterani benannt waren, beide befanden sich jedoch im Bereich der Lateranbasilika (vgl. Liverani 1988, 899-914).

89 Zur aktiven Rolle des Kaisers, der mit der Einberufung der Synode nach Rom bestehende synodale Regeln außer Kraft setzte, vgl. Girardet 1975, 28f.

$90 \quad$ Vgl. dazu u., S. 175-177. 
silika: Auch hier ist die im Liber Pontificalis überlieferte Stiftungsliste der einzige konkrete Hinweis auf einen Bau der Kirche noch vor 324. ${ }^{91}$ Und auch hier wird man, ähnlich wie der Lateranbasilika, aufgrund der äußeren Umstände davon ausgehen müssen, dass die Basilika bereits früh errichtet wurde, nämlich zu der Zeit, als Konstantin nach seiner Einnahme der Stadt den Südosten Roms zu seiner neuen Residenz ausbauen ließ. ${ }^{92}$

Neben diesen beiden Kirchen, die in unmittelbarem Zusammenhang mit dem Aufbau einer kaiserlichen Topographie der Macht im Südosten der Stadt entstanden, wurden außerhalb der Stadt neben der basilica apostolorum und dem anonymen Bau bei Tor de' Schiavi eine Reihe weiterer Umgangsbasiliken errichtet. Die vermutlich älteste unter ihnen, die auch für die basilica apostolorum und die Basilika an der via Praenestina das Vorbild abgegeben haben dürfte, ${ }^{93}$ ist die Basilika SS. Pietro e Marcellino an der via Labicana. Das an diese Basilika angeschlossene kaiserliche Mausoleum, das erst nach der Fertigstellung der Basilika an diese angebaut wurde, ${ }^{94}$ war bereits im Jahr 328/329 vollendet, da zu dieser Zeit Konstantins Mutter Helena dort beigesetzt wurde. ${ }^{95}$ Die Basilika selbst muss schon einige Zeit davor vollendet gewesen sein, was auch die Güter der Stiftungsliste im Liber Pontificalis bestätigen, die ebenso wie bei der Lateranbasilika und bei S. Croce - auf eine Dotierung der Basilika vor 324 verweisen. ${ }^{96}$ Legt man für die Bauzeit der Basilika mehrere

$91 \quad$ LP I, 180. Das Mauerwerk der Apsis, die in die bestehende Halle eingebaut wurde, wird in der Forschung unterschiedlich beurteilt (Pietri 1976, Bd. 1, 15, Anm. 3 vergleicht es mit dem Mauerwerk der Lateranbasilika; anders Colli 1996, 779, für den die Mauern der Apsis von S. Croce auf eine spätere Bauphase hindeuten). Holloway 2004, 67 möchte den Bau erst in die Zeit der Konstantinsöhne setzen, da die Kreuzeslegende erst nach dem Tod Konstantins aufgekommen sei.

92 Ob Konstantin die Basilika zu einer regelrechten „Palastkirche“ machte, und welcher Grad an Öffentlichkeit sich damit verband, ist in der Forschung umstritten. Gegen eine Deutung als „Palastkirche“ (so u. a. Pietri 1976, Bd. 1, 14-17) mit nur eingeschränkter Verfügungsgewalt des römischen Bischofs argumentiert mit guten Gründen Brandenburg 1979, 165; auch Colli 1996, 813f. meint, dass die Basilika in einem allgemein zugänglichen Teil des kaiserlichen Palastes lag, in dem sich auch der Audienzbereich des Kaisers befand. Die volle Übertragung der für die Basilika gestifteten Güter an die christliche Gemeinde hebt Marazzi 1998, 49 hervor.

93 Zur Begründung für diese Abfolge vgl. u., S. $177 f$.

94 S. u., S. 155 f.

95 Eus., v. C. 3, 47, 1; nach der Plazierung dieser Nachricht im Gesamtzusammenhang der eusebischen Konstantinsvita zu urteilen, fiel Helenas Tod in die Zeit zwischen Herbst 327 und Frühjahr 328; nach Ausweis der numismatischen Quellen möglicherweise erst in das ausgehende Jahr 329; vgl. Krautheimer 1989, 5f. Eine Münze von 324/326 im Mörtel zeigt, dass die Ausstattungsarbeiten erst kurz zuvor abgeschlossen worden waren (Deichmann/Tschira 1957, 64). Die Ziegelstempel sind wenig aussagekräftig, da viel Material wiederverwendet wurde (vgl. Steinby 1986, 143). Rasch 1998, 44f. datiert den Bau zwischen 320 und 324/325.

96 LP I, 183. Zur Bewertung vgl. Deichmann/Tschira 1957, 75; Brandenburg 1979, 69; Guyon 1987, 243. 
Jahre zugrunde, gelangt man für den Beginn der Basilika in das zweite Jahrzehnt des 4. Jh. ${ }^{97}$

Erst vor wenigen Jahren wurde eine Umgangsbasilika an der via Ardeatina entdeckt, die von den Ausgräbern überzeugend mit derjenigen Basilika identifiziert wird, die nach Ausweis des Liber Pontificalis der römische Bischof Marcus errichtete und in der er sich später bestatten ließ. ${ }^{98}$ Die Datierung des Baus ist damit klar umrissen: Vermutlich war er im Todesjahr des Bischof Marcus (336) bereits fertiggestellt. Obwohl der Bau nicht im engeren Sinne konstantinisch ist, sondern auf die Initiative des römischen Bischofs zurückgeht und Konstantin nur für seine Dotierung mit einer Landstiftung sorgte, wirft er ein wichtiges Licht auf die Funktion der konstantinischen Basiliken ${ }^{99}$ und liefert Erkenntnisse für die Datierung der übrigen Basilikalbauten. So entsprechen die Abmessungen der Basilika an der via Ardeatina (66 x 28 m) denen von SS. Pietro e Marcellino und der basilica apostolorum, was diese drei Basiliken formal zu einer einheitlichen Gruppe zusammenschließt und ein weiteres Argument dafür liefert, die Entstehung der basilica apostolorum in die konstantinische Zeit zu setzen.

Von der Gruppe dieser drei Umgangsbasiliken heben sich hinsichtlich ihrer Größe und ihrer Bautypologie ${ }^{100}$ zwei weitere Vertreter desselben Basilikaltyps ab: die Basilika von S. Agnese an der via Nomentana und die basilica maior von S. Lorenzo f.l.m. an der via Tiburtina, die bei Grabungen in den 40er und 50er Jahren des 20. Jh. entdeckt wurden. ${ }^{101}$ Nach Ausweis der Stiftungslisten der Silvestervita des Liber Pontificalis handelt es sich zwar auch bei diesen beiden Bauten um konstantinische Gründungen, ${ }^{102}$ doch sind diese Angaben skeptisch zu beurteilen. Aus S. Agnese ist eine Stiftungsinschrift durch die Tochter Konstantins, Constantina, überliefert, die es als unwahr-

$97 \quad$ Guyon 1987, 239 rechnet mit einem Baubeginn bereits kurz nach 312. Angesichts der raschen Bauzeit römischer Monumentalbauten im beginnenden 4. Jh. - die Maxentiusbasilika wurde zwischen 306 und 312 errichtet - ist es allerdings nicht zwingend, den Beginn so weit heraufzusetzen. Brandenburg 1992, 40 vermutet eine Zeit um 320.

98 LP I, 202: hic (scil. Bf. Marcus) fecit duas basilicas, unam via Ardeatina, ubi requiescit, et alium in urbe Roma iuxta Pallacinis. ex buius suggestione obtulit Constantinus Augustus basilicae quem cymiterium constituit via Ardeatina fundum Rosarium cum omnem agrum campestrorum, praest. sol. XL... qui etiam sepultus est in cymiterio Balbinae, via Ardeatina, quem ipse insistens fecit, pridie non. octob. Zur Beziehung dieser Nachricht auf die neuentdeckte Basilika vgl. Fiocchi Nicolai u. a. 1995-1996, bes. 126-132.

$99 \quad$ Vgl. u., S. 153-165.

100 Vgl. o., Anm. 69. Außerdem verwendete die basilica maior von S. Lorenzo f.l.m. als einzige Umgangsbasilika nicht Pfeiler, sondern Säulen - möglicherweise ein Hinweis darauf, dass die basilica maior die jüngste der römischen Coemeterialbasiliken ist (vgl. Brandenburg 1992, 47f.).

101 Zum archäologischen Befund in S. Agnese vgl. Deichmann 1946; zuletzt Barbini/Severini 2002, Pavolini 2002. Die Grabungsergebnisse zur basilica maior von S. Lorenzo sind dokumentiert von Krautheimer, in: Corpus II, 94-114.

102 Vgl. LP I, 182: eodem tempore fecit basilicam beato Laurentio martyri via Tiburtina in agrum Veranum...Zu S. Agnese vgl. die folgende Anm. 
scheinlich erscheinen lässt, dass die Gründung der Basilika nur ex rogatu filiae, wie es im Liber Pontificalis heißt, erfolgte: Constantina deum venerans Christoq(ue) dicata / omnibus impensis devota mente paratis / numine divino multum Christoq(ue) iuvante / sacravit templum victricis virginis Agnes. ${ }^{103}$ Constantina, nicht ihr Vater, wird hier explizit als Dedikantin des Gebäudes genannt; und nichts steht der Annahme im Wege, dass der Bau erst nach dem Tod Konstantins begonnen wurde. ${ }^{104}$ Zwar erweckt die Stiftungsnotiz des Liber Pontificalis, wonach Konstanin die Basilika auf Bitten seiner Tochter hin errichtet habe, den Eindruck, dass der Bau zumindest noch unter Konstantin in Angriff genommen worden worden sei, doch diese Nachricht des Liber Pontificalis beruht auf einer späten legendarischen Tradition und kann daher nicht als historisch zuverlässig betrachtet werden. ${ }^{105}$ Genauer lässt sich die Datierung nicht eingrenzen; in jedem Fall muss S. Agnese jedoch vor der Mitte des 4. Jh. vollendet worden sein, denn die Stifterin wurde dort 354 bestattet, vermutlich in dem Mausoleum (S. Costanza), das an die Südseite der Basilika angebaut war. ${ }^{106}$

103 Damas., epigr. 71.

104 So auch die communis opinio der Forschung, vgl. zuletzt Tolotti 1982, 157; Schumacher 1987, 138; Brandenburg 1992, 48; La Rocca 2000, 206.

105 Vgl. dazu LP I, 180 (Silvestervita): eodem tempore fecit (scil. Konstantin) basilicam sanctae martyris Agnae ex rogatu filiae suae et baptisterium in eodem loco ubi et baptizata est soror eius Constantia cum filia Augusti a Silvestro episcopo... Mackie 1997, 390f. möchte aus dieser Nachricht, in der von der Taufe der Tochter und der Schwester Konstantins die Rede ist, auf eine Errichtung der Basilika noch vor dem Tod der Konstantinsschwester Constantia (c. 330) schließen. Die Nachricht des Liber Pontificalis beruht jedoch auf einem Missverständnis der passio Gallicani, die der Verfasser der Silvestervita des Liber Pontificalis benutzte: In der passio Gallicani ist davon die Rede, dass die Tochter Konstantins - in den meisten Hss. der Passio nicht Constantina, sondern Constantia genannt - zwei Töchter des dux Gallicanus zum Christentum bekehrt, indem sie auf ihre Heilung von der Lepra durch die Fürbitte der Heiligen Agnes verweist. Kurz darauf kommt es zu folgender Begegnung zwischen Konstantin, Gallicanus und ihren Töchtern: tunc cum Augusto intrante pallatium Gallicano occurit Helena cum filia sua Constantia et filiabus ipsius Gallicani (Mombritius I, 571, 7f.). Dem schlechten Latein des Verfassers der passio ist es zu verdanken, dass er hier das reflexive sua (anstelle des sprachlich korrekten eius) verwendete, um den Bezug auf Konstantin zum Ausdruck zu bringen, damit jedoch den Eindruck erweckte, Constantia sei eine Tochter Helenas und nicht Konstantins (alternative Lesarten der passio haben diesen Fehler später zu korrigieren versucht, vgl. passio Gallicani 6 [AASS Iun. V, 38 D]: cum filia filii sui; Ado v. Vienne lässt in seinem Martyrologium [PL 123, 291] das sua ganz weg). Der Redaktor der Silvestervita - oder die hagiographische Tradition, auf der die Notiz beruhte - hat jedoch den Fehler nicht bemerkt, bezog das sua irrtümlich nicht auf Konstantin, sondern auf die Konstantinsmutter Helena und kam dadurch zu einer Schwester Konstantins namens Constantia, die er mit den Legenden um die Heilige Agnes in Verbindung brachte. Verkompliziert wird das Verständnis dadurch, dass 1. sich für den Namen der Konstantinstochter Constantina sehr bald die Variante Constantia verbreitete (zu den Namensvarianten vgl. PLRE I, 222, Constantina 2; wenig überzeugend Chausson 2002, 155) und 2. Konstantin in der Tat eine Schwester namens Constantia hatte (PLRE I, 221, Constantia 1). Nach dem vorigen ist jedoch klar, dass die Nachricht des Liber Pontificalis nicht historisch, sondern aus einem späteren Missverständnis der hagiographischen Texttradition erwachsen ist.

106 Julian ließ dort nur kurze Zeit später (360) auch seine Gattin Helena, die Schwester Constantinas, bestatten, vgl. Amm. 21, 1, 5: Helenae coniugis defunctae suprema miserat Romam in suburbano viae 
Die basilica maior bei S. Lorenzo f.l.m. erhob sich südlich von der Grabstätte des Heiligen Laurentius, die unter Pelagius II. (579-590) mit der heute noch sichtbaren ad corpus-Basilika überbaut wurde. Aufgrund der bereits erwähnten Notiz der Silvestervita des Liber Pontificalis wird auch diese Umgangsbasilika traditionell als eine konstantinische Gründung angesehen. Dagegen ist jedoch von Herman Geertman geltend gemacht worden, dass die im Liber Pontificalis überlieferte Ausstattung des Baus mit Lichtern und liturgischem Gerät für eine Umgangsbasilika von der Größe der basilica maior nicht ausgereicht hätte. ${ }^{107}$ Man müsse daher davon ausgehen, dass bereits Konstantin eine Basilika von nur etwa $600 \mathrm{~m}^{2}$ Grundfläche über dem Grab des Laurentius errichtet habe, die dann später durch den Bau von Pelagius II. ersetzt worden sei. Die basilica maior $\left(3250 \mathrm{~m}^{2}\right)$ sei erst unter Bischof Sixtus III. (432440) errichtet worden, dem der Liber Pontificalis den Bau einer Laurentiusbasilika zuweist, die mit kaiserlicher Zustimmung Valentinians III. - also entweder auf kaiserlichem Besitz oder auf staatlichem Grund und Boden - erbaut worden sei, eine Angabe, die Geertman auf das coemeterium des ager Veranus bezieht. ${ }^{108}$

Gegen diese Deutung sprechen zwar eine Reihe von Bedenken. Besonders schwer wiegt der Einwand, dass der Architekturtyp der Umgangsbasilika in Rom bisher nur in der ersten Hälfte des 4. Jh. nachgewiesen werden konnte und für Parallelen aus späterer Zeit sichere Hinweise fehlen. ${ }^{109}$ Auch erwähnt Prudentius um 400, am Festtag des Heiligen Hippolytus seien große Pilgermengen in der Nähe des Grabes in einer dreischiffigen Basilika zusammengeströmt, um dort einen Gottesdienst zu feiern. ${ }^{110}$ Dass mit diesem Bau die Laurentiusbasilika auf dem ager Veranus gemeint war, die sich unweit des Hip-

Nomentanae condenda, ubi uxor quoque Galli quondam, soror eius sepulta est Constantina. Zum Vorgängerbau von S. Costanza s. u., S. 156f.

107 Vgl. Geertman 1995, 130f., dens. 2002.

108 LP I, 234: fecit (scil. Sixtus III.) autem basilicam sancto Laurentio, quod Valentinianus Augustus concessit, ubi et optulit... Diese Notiz wird in der Forschung üblicherweise auf die Errichtung der Kirche S. Lorenzo in Lucina bezogen, da sie auf öffentlichem Grund und Boden erbaut worden sei (vgl. Krautheimer, in: Corpus II, 163; zuletzt Hillner 2002, 328f.). Dafür gibt es jedoch keine überzeugenden Anhaltspunkte (vgl. den Diskussionsbeitrag von Guidobaldi, in: Ecclesiae urbis. Atti del Congresso internazionale di studi sulle chiese di Roma (IV-X secolo), hrsg. von F. Guidobaldi/A. Guiglia Guidobaldi, Vatikanstadt 2002, Bd. 1, 441); auch wurde im Jahr 366 Damasus in Lucinis zum Bischof gewählt (vgl. Coll. Avell., epist. 1, 5), was ein Bestehen der Titelkirche bereits im 4. Jh. dokumentiert. Andere Forscher haben angenommen, dass sich die Notiz des Liber Pontificalis zwar auf den ager Veranus bezieht, Sixtus III. dort jedoch nicht, wie Geertman meint, die basilica maior, sondern einen Vorgängerbau der pelagianischen ad corpus-Basilika errichtet habe (so Deichmann/Tschira 1957, 95; Tolotti 1982, 198-200).

109 Dass auch die Basilika Santa Maria Maggiore, ebenfalls von Sixtus III. errichtet, eine Umgangsbasilika gewesen sei (de Blaauw 1994, Bd. 1, 350-355; Geertman 2002, 1231-1235), ist von Brandenburg 1995 (a), 49-51 als unbegründet zurückgewiesen worden.

110 Prud., perist. 11, 215-230. 
polytusgrabes erhob, ist sehr wahrscheinlich. ${ }^{111}$ Trotz dieser Argumente, die für eine Errichtung der basilica maior in konstantinischer Zeit sprechen, stellen die Überlegungen Geertmans durchaus ernstzunehmende Einwände dar. Am plausibelsten erscheint daher die Annahme, dass in konstantinischer Zeit eine bescheidener dimensionierte Umangsbasilika errichtet wurde, die durch Sixtus III., der die archäologische Disposition des Vorgängerbaus übernahm, erweitert wurde. ${ }^{112}$ In Ermangelung aussagekräftiger archäologischer Befunde der bisher nur in Ansätzen ergrabenen basilica maior ${ }^{113}$ erscheint dies als die überzeugendste Lösung, die unterschiedlichen Angaben miteinander zu verbinden. Festzuhalten bleibt, dass auch der konstantinische Bau bei Prudentius eine durchaus enthusiastische Beurteilung erfuhr: Auch wenn die basilica maior nicht seine Ausmaße wiedergeben mag, muss man daher auch am ager Veranus mit einer bedeutenden Baustiftung des Kaisers Konstantin rechnen. ${ }^{114}$

Einem anderen architektonischen Prinzip als die im vorigen vorgestellten Umgangsbasiliken folgte die Basilika, die über dem Petrusgrab am Vatikan errichtet wurde. Der monumentale Bau, der selbst die Lateranbasilika an Größe übertraf, ${ }^{115}$ setzte sich aus zwei eigenständigen Baukörpern zusammen, einem mit einer Apsis versehenen Memorialbereich um das Petrusgrab, der im Bau-

111 Vgl. Schumacher 1987, 161f. Es ist naheliegend, dass die basilica maior neben Laurentius auch der Kommemoration der übrigen römischen Kleriker und Märtyrer diente, die während der valerianischen Verfolgung im August 258 ums Leben kamen. So enthält das Martyrologium Hieronymianum zum 2. 11. die Weihenotiz einer Basilika für Sixtus II., Hippolytus und Laurentius, die zwar nicht auf die basilica maior zu beziehen ist (eine diesbezügliche Vermutung von Duchesne [1886], in: LP I, 236, Anm. 12, hat Delehaye, in: MH, Comm. [1931], 584 überzeugend widerlegt), doch kann auch für die römische Laurentiusbasilika vorausgesetzt werden, dass sie in ähnlicher Weise den übrigen, in der legendarischen Überlieferung mit Laurentius verbundenen Heiligen als Kommemorationsstätte diente.

112 Eine ähnliche Überlegung zuletzt bei Brandenburg 2004, 88, der eine Restauration der basilica maior durch Sixtus III. in Erwägung zieht. Das fecit der Stiftungsnotiz verweist jedoch eindeutig nicht auf Wiederherstellungsarbeiten, sondern auf einen Neubau, der den kleiner dimensionierten Vorgängerbau Konstantins ersetzt haben dürfte.

113 Das Mauerwerk der unter dem Camposanto des 19. Jh. liegenden Basilika konnte in den 1950er Jahren nur durch Stichgrabungen freigelegt werden; das geringe Material erlaubt keine Datierung (so Heres 1982, 110; optimistischer äußert sich Krautheimer, in: Corpus II, 135, der die Mauern „zweifelsfrei“" in das 4. Jh. setzt). Der von Brandenburg 1992, 48, Anm. 58 gegebene Hinweis, man habe beim Bau der basilica maior konstantinische Ziegelstempel verwendet, trifft nicht zu: Die wenigen bei S. Lorenzo und S. Agnese gefundenen Ziegelstempel können keiner Werkstatt aus konstantinischer Zeit zugewiesen werden (vgl. Steinby 1986, 144 u. 162f.).

114 Konstantin soll neben der Errichtung der Basilika auch größere Umbauarbeiten im Bereich des Laurentiusgrabes selbst vorgenommen haben (LP I, 181: usque ad corpus sancti Laurenti martyris fecit grados ascensionis et descensionis. in quo loco construxit absidam et exornavit marmoribus purphyreticis et desuper loci conclusit de argento et cancellos de argento purissimo ornavit, qui pens. lib M; et ante ipsum locum in crypta posuit... [es folgt eine Auflistung weiterer Gegenstände]). Auf zwei unterschiedliche Bauten auf dem ager Veranus könnten sich auch die Stiftungen des Hilarus (461-468) beziehen (LP I, 244 unterscheidet zwischen der Stiftung liturgischer Gerätschaften ad beatum Laurentium und in basilica beati Laurenti martyris).

115 S. Pietro: 122 x 66m; Lateranbasilika: 100 x 55m. 
ganzen das Querschiff der Basilika bildete, und dem daran angesetzten Längsschiffbereich, der in fünf Schiffe untergliedert war. ${ }^{116}$ Da die konstantinische Stiftungsliste im Liber Ponticalis für S. Pietro auch Güter aus dem Osten des Reichs aufweist, ${ }^{117}$ wurde der Bau sicher erst nach 324 in Angriff genommen. Der Zeitpunkt seiner Vollendung ist umstritten: Die Forschung schwankt zwischen einer Frühdatierung (Errichtung zwischen 324 und 333) und einer Spätdatierung (Fertigstellung des Baus erst nach 354). Insgesamt erscheinen die Argumente überzeugender, die von einer Dedikation des Baus noch unter Konstantin ausgehen; 118 in jedem Fall geht der Baubeginn jedoch noch auf seine Initiative zurück.

Im Unterschied zur gewaltigen Basilika am Vatikan wurde dem Paulusgrab an der via Ostiensis eine deutlich geringere Aufmerksamkeit zuteil. Auch für S. Paolo f.l.m. überliefert der Liber Ponticalis eine konstantinische Stiftungsliste, die jedoch in der vorliegenden Form spätere Erweiterungen enthält und sich ursprünglich nur auf ein kleines Stiftungsgut beim kilikischen Tarsos beschränkte - auch hier also, wie bei S. Pietro, ein Gebiet im Osten des Reichs, über das Konstantin frühestens seit 324 verfügen konnte ${ }^{119}$. Diesem geringen Vermögen entspricht auch die vergleichsweise kleine Dimension des Baus, von dem nur archäologische Überreste der Apsis erhalten blieben. Deren Durchmesser liegt mit 9,15m weit unter dem der Petrusbasilika, ${ }^{120}$ und obwohl die weitere Erstreckung der Basilika nach Osten nicht bekannt ist, kann sie kaum länger als $20 \mathrm{~m}$ gewesen sein.

Diese Übersicht verdeutlicht nicht nur die hohe Bedeutung, die die christlichen Bauten im Rahmen von Konstantins Bautätigkeit einnahmen, sondern auch, dass der Kaiser diesen Stellenwert schon bald, nachdem er sich des caput

116 Brandenburg 1979, 134-138; ders. 1995 (a), 44f. Diese ungewöhnliche Form des Memorialbereichs als ein in die Breite gezogenes Rechteck ist nicht aus spezifischen Traditionen christlicher Märtyrergrablegen ableitbar (vgl. Ward-Perkins 1969, 12).

117 LP I, 177.

118 Vgl. die Zusammenfassung der Forschungsdiskussion bei Krautheimer 1989, der sich mit plausiblen Gründen für eine Frühdatierung entscheidet. Die wesentlichen Argumente gegen eine Frühdatierung sind 1. die Inschrift der Apsis (ICUR II, 4094), die ,ihren Urheber dem Lob seines Erzeugers gleichstellt" und die man auf einen der Konstantinssöhne, vorzugsweise Constantius II., bezogen hat 2. Die Feier des 29. Juni, die nach Ausweis der depositio martyrum im Chronographen von 354 für Paulus an der via Ostiensis, für Petrus hingegen ad catacumbas und nicht in der (noch nicht fertiggestellten?) Basilika am Vatikan stattfand. Dagegen spricht jedoch 1. dass die Inschrift des Constantius sich nur auf eine neues Apsismosaik, nicht auf die gesamte Basilika bezieht (vgl. Krautheimer 1987); 2. dass das in der depositio martyrum unter dem 22. Februar verzeichnete Fest natale Petri de cathedra, das keine genauere Ortsangabe trägt, vermutlich in der vatikanischen Petrusbasilika begangen wurde (vgl. Ruysschaert 1969, 18-22). Für eine Spätdatierung der Vatikanbasilika sind zuletzt Curran 2000, 111f.; Bowersock 2002 eingetreten.

119 LP I, 178; vgl. dazu Krautheimer 1980-1982, 210.

120 Kirschbaum 21974, 185; leicht abweichend Krautheimer 1980-1982, 210 (9,10m). 
imperii im Oktober 312 bemächtigt hatte, zu signalisieren begann. Dies gilt insbesondere für die bischöfliche Basilika am Lateran und die innerhalb des Sessoriumpalastes gelegene Basilika, aber auch die Coemeterialbasilika von SS. Pietro e Marcellino, dessen Baubeginn wohl noch vor 320 angesetzt werden muss. Die beiden Monumente für Petrus und Paulus fallen hingegen erst in die Zeit nach 324; für die übrigen Umgangsbasiliken bleibt man, von der neuentdeckten Basilika an der via Ardeatina (336) abgesehen, in Ermangelung aussagekräftigerer Hinweise vor allem auf Vermutungen angewiesen. Wenn ein Gesetz von Constantius II., das alle Baumaßnahmen im Bereich von Nekropolen, die vor 333 erfolgten, vor einer actio wegen violatio sepulcri schützte, auf die römischen Coemeterialbasiliken zu beziehen ist, ${ }^{121}$ dann könnten alle konstantinischen Gründungen zumindest in ihren Vorarbeiten, bei denen regelmäßig in den Bestand bestehender Nekropolen eingegriffen wurde, bis 333 abgeschlossen gewesen sein.

Hinsichtlich der topographischen Verteilung der Bauten fällt das starke Gewicht des römischen Suburbiums ins Auge: Mindestens fünf große Umgangsbasiliken entstanden im Umkreis weniger Meilen außerhalb der Stadtmauern; hinzu kommen die beiden Monumente für Petrus und Paulus. Was sich hier und bei den Umgangsbasiliken als eine notwendige Konsequenz aus der Tatsache zu ergeben scheint, dass Konstantin die Märtyrer- und Totenerinnerung der christlichen Gemeinde monumentalisierte, die ihren traditionellen Ort außerhalb der städtischen Mauern hatte, setzte sich innerhalb der Stadt fort: Konstantin inszenierte auch hier, ebenso wie im Suburbium der Stadt, seine Unterstützung für den christlichen Kult mit einer basilikalen Repräsentationsarchitektur, deren Monumentalität um so sichtbarer ins Auge stechen musste, als Konstantin damit aus dem Nichts etwas absolut Neues schuf. ${ }^{122}$ Doch obwohl der Kaiser den christlichen Kult so sichtbar aufwertete und obwohl er sich dazu bereits bald nach 312 entschloss, scheint die Ortswahl für die Lateranbasilika diese öffentliche Signalwirkung nicht zum Ausdruck zu bringen: Nicht dort, wo Generationen von Kaisern vor Konstantin und zuletzt auch Maxentius Bauten von einer ähnlichen Öffentlichkeitswirkung errichtet hatten, nicht im Zentrum der Stadt, sondern in einer Randlage, nahe der Aurelianischen Mauer, gab Konstantin der römische Bischofskirche ihren Platz.

Diese konsequente „Auslagerung“ der christlichen Sakraltopographie hat in der Forschung wiederholt Anlass zu Erklärungsversuchen gegeben. Unter den Aspekten und Argumenten, die in die Diskussion eingebracht wurden, können manche von vornherein als wenig plausibel verworfen werden.

121 CTh 9, 17, 2 (vgl. dazu u., Anm. 152).

122 Wie oben ausgeführt, gibt es keinen überzeugenden Hinweis darauf, dass die christliche Gemeinde Roms schon vor Konstantin über Monumente mit einer vergleichbaren Öffentlichkeitsund Repräsentationswirkung verfügte. 
Darunter fällt etwa die Annahme, Konstantin habe aus rein pragmatischen Gründen, aus „Platzmangel“ im dicht bebauten Zentrum der Stadt, auf die Errichtung von christlichen Kultbauten verzichten müssen. ${ }^{123}$ Nur wenige Jahre zuvor waren beim Bau der Diocletiansthermen zahlreiche Privathäuser dem riesigen Bauprojekt zum Opfer gefallen, ohne dass dies unlösbare Schwierigkeiten bedeutet hätte. In jedem Fall aber hätte Konstantin mit der Maxentiusbasilika an der via sacra ein geeigneter Raum ${ }^{124}$ zur Verfügung gestanden, um seine ambitionierten Pläne für die römische Bischofskirche, wie sie dann kurze Zeit darauf in der fünfschiffigen Basilika am Lateran realisiert wurden, in die Tat umzusetzen. Warum kam es nicht dazu, warum wählte Konstantin stattdessen die periphere Lage für die von ihm ins Leben gerufene Sakralarchitektur?

Den prominentesten (und bis in die Gegenwart einflussreichsten) Erklärungsversuch hat Richard Krautheimer unternommen, der dabei ältere Ansätze von Andreas Alföldi, René Vielliard und André Chastagnol aufgriff. Krautheimer erklärte die christlichen Sakralbauten zu einer „Privatangelegenheit" des Kaisers, im Unterschied zu den konstantinischen Bauten im Zentrum der Stadt, denen Krautheimer einen „öffentlichen“ Status zuerkennt. Festgemacht wird diese Trennung zwischen „privat“ und „öffentlich“ weniger an der topographischen Randlage als vielmehr an dem juristischen Kriterium, dass die kaiserlichen Basilikalbauten sich sämtlich auf dem Privatbesitz des Kaisers befunden hätten. Im Unterschied zu den Bauten im Zentrum der Stadt, das locus publicus, öffentlicher Grund und Boden, gewesen sei, habe der Kaiser mit dem Bau der christlichen Sakralarchitektur auf kaiserlichem Privateigentum bewusst auf deren Integration in die städtische Öffentlichkeit verzichtet. Als Motiv für diese Vorgehensweise nennt Krautheimer religiöse Differenzen zwischen dem Kaiser und der paganen senatorischen Oberschicht Roms: Konstantin habe gegenüber einem überwiegend paganen Senat die Förderung einer Kultgemeinschaft, die bis vor kurzem noch verfolgt worden war, nicht demonstrativ herausstellen wollen. ${ }^{125}$

123 Reekmans 1989, 873.

124 Von liturgischer Seite hätten gegen eine derartige Lösung keine prinzipiellen Vorbehalte bestanden. Dass die kaiserlichen Bauten sich nicht an liturgischen Gegebenheiten orientierten, sondern umgekehrt die Liturgie eine Vielzahl unterschiedlicher Gebäudetypen zu funktionsfähigen liturgischen Räumen umgestaltete, hat Brandenburg 1995 (a) deutlich gemacht. Auch die Lateranbasilika, die sich am Typ der antiken Marktbasilika orientierte (vgl. Brandenburg 1992, 35-38), musste erst in ein ,liturgiefähiges“ Gebäude umgewandelt werden.

125 Krautheimer 1987 (1980), 34f., 39-42; ähnlich 54; vgl. dens. 1983, 26-31; 1993, 545f. Schon zuvor geäußert von v. Schoenebeck 1939, 87f.; Vielliard 21959, 62 u. 64; Alföldi 1948, 50-52; Chastagnol 1960, 140; LaBranche 1968, 121. An Krautheimer schließen sich u. a. an Reekmans 1989, 866; Guyon 1993, 57f.; Fraschetti 1993, 685; Colli 1996, 808; Mackie 1997, 390; Salzman 1999, 127; Odahl 2004, 147; in modifizierter Form Mayer 2002, 186. Eine andere Position bezieht hingegen Brandenburg 1992, bes. 33-35, der völlig zurecht hervorhebt, dass die Randlage 
In leicht abgewandelter Form begegnet dieser Erklärungsversuch bei Forschern, die weniger religiöse als vielmehr politische Gründe für Konstantins Verzicht auf eine Errichtung christlicher Basilikalbauten im Zentrum der Stadt verantwortlich machen. Ähnlich wie die pagane Religion mit ihren Priesterämtern der römischen Oberschicht einen vom Kaiser unabhängigen Status vermittelte, der auf einem nichtkaiserlichen, römischen Traditionalismus dieser Ämter beruhte, ${ }^{126}$ erscheint auch das städtische Zentrum Roms als eine symbolische Ressource römischer Identität, die von der Senatsaristokratie unabhängig vom oder sogar gegen den Kaiser reklamiert werden konnte. Besonders deutlich tritt dieses Konzept einer jenseits der kaiserlichen Person existierenden städtischen und staatlichen Öffentlichkeit dort hervor, wo es sich mit der Ebene von Traditionalismus und Vergangenheitsbezügen verbindet. ${ }^{127}$ So ist insbesondere in der älteren Forschung häufig von einem ideellen Rückbezug der römischen Senatsaristokratie auf die republikanische Vergangenheit Roms die Rede: Dieser Traditionsbezug habe der Senatsaristokratie der konstantinischen Zeit und besonders des ausgehenden 4. Jh., als Rom seine Stellung als Kaiserstadt eingebüßt hatte, einen politischen Status verliehen, der die Unabhängigkeit des Standes vom Kaiser zu Bewusstsein gebracht habe. ${ }^{128}$ Auch die städtischen Monumente werden in jüngerer Zeit zunehmend im Lichte dieser Auffassung interpretiert: Sie sollen einen öffentlichen, die Tradition Roms versinnbildlichenden Erinnerungsraum gebildet haben, ${ }^{129}$ der zunehmend symbolisch verfestigt und durch konservierende Baumaßnahmen ,musealisiert“" worden sei. ${ }^{130}$

der konstantinischen Kultbauten für die Integration in den städtischen Kontext nicht entscheidend gewesen sei. Kritisch auch Hunt 2003, bes. 115-118.

126 Vgl. zuletzt Salzman 2002, 74-77.

127 Bauer 1996, 108 konstatiert, dass Konstantin sich nicht mehr dem „traditionsreichen“ Stadtzentrum zugewandt, sondern stattdessen in der Peripherie Roms Kirchenbauten errichtet habe, für die ,auf dem Forumsplatz... weder architektonisch noch ideell Platz“ gewesen sei. Was „ideell“ hier genau bedeuten soll (Traditionsbezug, religiöse Fragen), bleibt offen. Zur identitätsrelevanten Bedeutung von monumental vermittelter ,alter Tradition“ für die städtischen Eliten seit der Mitte des 4. Jh. vgl. ebd., 137-141.

128 Vgl. Alföldi 1948, 122 (Rom als ,old Republican ,ruling city“); ähnlich ders. 1952, 93 und $96 f$. über den Konflikt des Senats mit Valentinian I.; Klein 1971, 23 („,republikanische Freiheitsidee“), 28f. (,alte Ordnung und Staatsidee“; ,altes Staatsdenken“; ,altes res publica-Denken“); Krautheimer 1987, 15f. (der Senat „repräsentierte Roms Geschichte“ und „machte die Stadt zum einzigen rechtmäßigen Regierungssitz, ungeachtet des jeweiligen Aufenthaltsorts des kaiserlichen Hofes“). Vgl. LaBranche 1968, 119-121 hebt die Relevanz republikanischer Bauformen und Räume wie des Forum Romanum hervor, das mit den „Quellen der römischen Macht“ verbunden gewesen und durch die späteren Kaiserforen nur zeitweise überschattet worden sei. Bauer 1996, 139 verknüpft mit der Restauration der Senatskurie im 5. Jh. eine Anspielung auf die „einstige Größe“ des Senats.

130 Für das Konzept einer Musealisierung im spätantiken Rom vgl. Bauer 1996, 110, 141; in gleicher Weise spricht auch Février 1993, 51 von einem „città-museo“, Witschel 2001, 122. Für einen 
Den referierten Erklärungsansätzen liegt in ihren unterschiedlichen Varianten eine - mehr oder weniger offen benannte - Konzeption römischer Staatlichkeit zugrunde, die eine identitätsstiftende Wirkung unabhängig vom Kaiser entfaltete und die ihre symbolische Verortung im Zentrum der Stadt erfuhr. Hier habe sich die durch die senatorische Oberschicht verkörperte res publica in einem öffentlichen Raum verdichtet, der einem rein privaten Handeln des Kaisers deutliche Grenzen gesetzt habe. Der Kaiser respektierte nach dieser Deutung die in der res publica gegebene „Öffentlichkeit“, aus der er seine persönliche, „private“ Religiosität ausgliederte. Konsequenterweise liegen den Deutungen von Konstantins Baupolitik in Rom dichotomische Identitätskonstruktionen zugrunde, zwischen denen sich das kaiserliche Handeln bewegte und deren räumliche Pole mit den Begriffen „städtisches Zentrum/öffentlicher Raum/profane Bauten“ auf der einen und „suburbane Peripherie/privater Handlungsbereich/christliche Bauten“ auf der anderen Seite benannt werden. Selbst diejenigen Forscher, die nicht von einer kaiserlichen Handlungs,,beschränkung“ ausgehen, sondern die - prinzipiell berechtigte Frage stellen, warum Konstantin im monumentalen Zentrum Roms überhaupt christliche Kultbauten hätte errichten und damit ein Signal für eine Christianisierung der Stadt setzen sollen, ${ }^{131}$ zeigen sich dieser Interpretationslinie verpflichtet. In Verbindung mit dem Umstand, dass Konstantin - im Unterschied zu seinen Vorgängern - scheinbar ${ }^{132}$ keine Initiativen zur baulichen Umgestaltung des städtischen Zentrums ergriff, läuft dieser Ansatz auf die Bewertung hinaus, dass die kaiserliche Bautätigkeit in Rom keine Auswirkungen auf die städtische Identität hatte, da Zentrum und Peripherie, profane und christliche Bauten nicht zueinander in Beziehung gesetzt wurden. Auch Hugo Brandenburg, der als einer der wenigen Forscher gegen diese Sichtweise Position bezogen und die allgemein vorherrschende Charakterisierung der konstantinischen Sakralbauten im südöstlichen Randbezirk und im Suburbium der Stadt als „peripher“ bezweifelt hat, konstatiert eine grundlegende Dichotomie im Bereich der konstantinischen Baupolitik: Der Kaiser habe profane Repräsentativbauten, die Rom als traditioneller Hauptstadt „gemäß“ gewesen seien, vernachlässigt und sich stattdessen auf christliche Kultbauten konzentriert. ${ }^{133}$

Bestimmte Voraussetzungen dieses Bildes sind (nicht erst in den letzten Jahren) kritisch hinterfragt worden. So ist insbesondere bezüglich der religiösen Orientierungen innerhalb der römischen Senatsaristokratie und der damit verbundenen identitätsstiftenden Relevanz mit einem differenzierteren Bild

Niederschlag dieser Vorstellung in den Inschriften vgl. die Bemerkungen von Smith 2003, 153155 .

131 So z. B. Curran 2000, 71.

132 S. aber u., S. 122-133.

133 Brandenburg 1992, 33. 
zu rechnen, als es die schematische Gegenüberstellung von paganer Senatsaristokratie und christlichem Kaiser zum Ausdruck bringt. ${ }^{134}$ Dennoch erweist sich das unter dem maßgeblichen Einfluss von Krautheimers Autorität begründete Bild einer räumlichen Gegenüberstellung von einer städtischer Öffentlichkeit und einem aus ihr ausgegliederten privaten Handlungsbereich des Kaisers als äußerst langlebig. Im folgenden sollen daher die Voraussetzungen dieses Erklärungsmodells kritisch überprüft werden. $\mathrm{Zu}$ diesem Zweck erscheint es sinnvoll, zunächst Krautheimers Argumentation einer eingehenden Revision zu unterziehen, bevor eine Auseinandersetzung mit den methodischen Grundlagen für die von ihm zugrundegelegte dichotomische Trennung zwischen „Öffentlichkeit“ und „Privatheit“ in der politischen Kultur des spätantiken Rom erfolgt.

Die kategoriale Trennung eines innerhalb der Stadt gelegenen öffentlichen Raums und der privaten kaiserlichen Landgüter außerhalb der Stadt, auf denen die christlichen Sakralbauten errichtet wurden, beruht für Krautheimer auf einer besitzrechtlichen Unterscheidung zwischen opera bzw. loca publica auf der einen und dem als privatum bezeichneten Bereich der domus auf der anderen Seite. ${ }^{135}$ Dies wirft zwangsläufig die Frage auf, wie es um die Möglichkeit bestellt ist, einen juristisch definierten kaiserlichen Privatbesitz im beginnenden 4. Jh. kategorisch zu erfassen. Krautheimer weiß zwar um die während des 3. Jh. erfolgten Umorganisationen der kaiserlichen Finanzverwaltung und um die damit verbundenen Schwierigkeiten, unterschiedliche kaiserliche Eigentumsformen voneinander abzugrenzen, ${ }^{136}$ hält aber dennoch daran fest, zu Beginn des 4. Jh. eine Unterscheidung zwischen einem privaten Vermögen (res privata) des Kaisers und einem öffentlich-staatlichen Besitz (fiscus) vor-

134 Bereits vor gut 40 Jahren hat Peter Brown die religiösen Konflikte der beiden letzten Jahrzehnte des 4. Jh. durch den Hinweis darauf relativiert, dass die schrittweise Christianisierung aristokratischer Familien und die Entstehung einer ,respectable christianity“ bereits seit der Mitte des 4. Jh. auf breiterer Ebene eingesetzt hatte und dass sich die spektakulären Auseinandersetzungen um den Victoriaaltar, die Niederlegung der pontifex maximus-Würde durch Gratian und die ,heidnische Usurpation“ des Eugenius nicht einfach auf eine Konfliktlinie zwischen Kaiser und senatorischer Oberschicht reduzieren lassen (Brown 1961 [1972]). Die Vorstellung einer schematischen Gegenüberstellung von einem christlichen Kaiser und einem pagan-konservativen römischen Senat ist aber nicht erst für die Mitte des 4. Jh., sondern auch schon mit Blick auf die konstantinische Zeit brüchig geworden: Timothy Barnes hat unlängst die überwiegend pagane Zusammensetzung der senatorischen Oberschicht unter Konstantin und Constantius II. mit ernstzunehmenden Fragezeichen versehen und damit ein etabliertes Deutungsmuster auf den Prüfstand gestellt (Barnes 1995, 142f.).

135 Zu den opera und loca publica vgl. Daguet-Gagey 1997, 21-23.

136 Die stadtrömische Ziegelstempelproduktion deutet darauf hin, dass eine in tetrarchischer Zeit noch fassbare terminologische Trennung zwischen fiscus und res privata unter Diocletian und Konstantin zu verschwinden begann (vgl. Steinby 1978, 1528; dies. 2001, 136). Die res privata hatte im Laufe des 3. Jh. vermutlich alle kaiserlichen Vermögen und auch die noch bestehenden Reste von Eigentum des populus Romanus in sich aufgenommen, vgl. Jones 1964, 411f.; für eine ähnliche Bestandsaufnahme zu Beginn des 4. Jh. vgl. Delmaire 1989, IX. 
nehmen zu können. Konstantin soll nicht nur für seine römischen, sondern für alle vor 324 errichteten Kirchenbauten auf die res privata zurückgegriffen und erst danach Mittel des fiscus für christliche Bauprojekte eingesetzt haben. ${ }^{137}$ Wie jüngere Untersuchungen jedoch bestätigt haben, ist jeder Versuch, „privates“ und „staatliches“ Handeln des Kaisers entlang einer solchen begrifflichen Differenzierung zwischen res privata und fiscus zu unterscheiden, zum Scheitern verurteilt: Obwohl die spätantiken Kaiser über Teile des Besitzes als Privatperson verfügten, umfasste der Begriff fiscus sämtliche dem Kaiser unterstellte Vermögensbereiche; er lässt sich daher nicht als klar umrissener Teilbereich des kaiserlichen Vermögens gegen eine res privata abgrenzen, sondern schloss diese mit ein. ${ }^{138}$ Auch in den von Krautheimer angeführten Beispielen für konstantinische Kirchengründungen bezeichnen res privata und fiscus keine unterschiedlichen, sondern identische Sachverhalte. ${ }^{139}$

Bei den römischen Basilikalbauten Konstantins beschränken sich die Anhaltspunkte für vermögensrechtliche Fragen in Ermangelung literarischer Quellen auf die im Liber Pontificalis überlieferten Stiftungslisten mit den für den Unterhalt der Bauten bereitgestellten Liegenschaften sowie auf die Lokalisierung der Kultbauten im Gefüge der Stadt und des Suburbiums. Beides führt in der Frage einer vermögensrechtlichen Zuordnung der Bauten nicht weiter. Die Liegenschaften der Stiftungslisten werden zwar mitunter als „private" Schenkungen des Kaisers eingestuft, doch erlauben weder die Provenienz der Güter ${ }^{140}$ noch die Modalitäten ihrer Übertragung ${ }^{141}$ hinreichenden

137 Krautheimer 1993; vgl. auch dens. 1983, 29f. Zustimmend Pensabene/Panella 1993-1994, 135.

$138 \mathrm{Zu}$ den unterschiedlichen Verwendungsweisen von fiscus im 4. bis 6. Jh. vgl. Delmaire 1989, 11 13; 675-678. Neben der allgemeinen Bedeutung als Gesamtheit der kaiserlichen Finanzen konnten auch in einem spezielleren Sinne die beiden dem Kaiser direkt unterstellten und zu seinem Hof gehörigen Finanzverwaltungen (sacrae largitiones/aerarium sacrum und res privata/ aerarium privatum) jeweils für sich oder zusammengenommen (aerarium) mit der Bezeichnung fiscus belegt werden. Umgekehrt umfasste die res privata auch Einkünfte, die nicht zum Privateigentum des Kaisers gehörten, wie z. B. die Güter von Tempeln und von städtischen Gemeinden, die zwar der Verwaltung der res privata angegliedert wurden, jedoch eigenständige Rechtstitel (de iure templorum; de iure reipublicae) behielten, was verdeutlicht, dass sie nicht in den Privatbesitz des Kaisers übergingen (vgl. Demaire 1989, 641-657; vgl. auch ebd. 597).

139 Vgl. die Gründung der Kirche von Cirta (330), bei der Krautheimer 1993, 516f. ein Zusammenspiel von privater und öffentlicher Finanzierung als gegeben sieht; in Wahrheit bezeichnen domus bonorum nostrorum (= res privata) und locus fiscalis hier jedoch ein und dasselbe (vgl. Delmaire 1989, 12 mit Anm. 17).

140 Krautheimer 1993, 534 leitet daraus, dass sich von Christen konfiszierte Landgüter unter diesen gestifteten Ländereien befinden, den privaten Charakter der Stiftungen ab, da konfisziertes Eigentum in die res privata des Kaisers gewandert sei. Dass dies jedoch kein Indiz für ein kaiserliches Privateigentum im engeren Sinne ist, wurde bereits festgehalten. Auch Marazzi 1998, 27-29 plädiert dafür, die Liegenschaften als private Schenkungen des Kaisers zu verstehen und stützt sich dabei auf eine von Guglielmo Nocera vorgeschlagene Unterteilung zwischen staatlichem Besitz (aerarium, sacrae largitiones) und kaiserlichem Krongut (fiscus, res privata). Eine derartige Unterscheidung führt jedoch mit Blick auf die konstantinischen Kirchenstiftungen in eine Sackgasse, da die für die römischen Basiliken gestifteten liturgischen Gerätschaften von den die 
Aufschluss auf einen „privaten“ oder „öffentlich-staatlichen“ Status der von Konstantin errichteten und dotierten Basiliken. Ähnliches gilt für den Grund und Boden, auf dem die Basiliken errichtet wurden. Nach Krautheimer erhoben sich sämtliche Basilikalbauten, die Konstantin in Rom und seinem Suburbium erbauen ließ, auf kaiserlichem Privatbesitz. ${ }^{142}$ Eine nähere Prüfung zeigt jedoch, dass sich die Annahme in dieser Form nicht aufrecht erhalten lässt. Dass die Basiliken im Suburbium Roms auf den Liegenschaften kaiserlicher Villen errichtet wurden, kann zwar zum Teil begründet vermutet werden. ${ }^{143}$ Bei der Basilika von S. Lorenzo f.l.m. ist dies jedoch nicht sicher nachweisbar, ${ }^{144}$ ebensowenig bei der basilica apostolorum und bei S. Pietro am Vatikan, wo eindeutige Zuordnungen zu kaiserlichen Villen fehlen, die mit der jeweiligen Basilika in Verbindung gebracht werden können, ${ }^{145}$ und wo im übrigen sicher die mit diesen Orten verbundene Erinnerung an die Apostel und nicht ein kaiserliches Eigentumsrecht am Grund und Boden den Ausschlag für die Errichtung der Basiliken gab. Was jedoch auf nahezu alle der römischen Coemeterialbasiliken zutrifft, ist die Tatsache, dass sie sich über

Edelmetallverarbeitung kontrollierenden sacrae largitiones finanziert wurden (vgl. Delmaire 1989, 590-593). Auf der Grundlage der von Marazzi favorisierten Trennung zwischen („privater") res privata und („öffentlich-staatlichen“) sacrae largitiones lässt sich also keine eindeutige Zuordnung der konstantinischen Basilikalbauten vornehmen.

141 Voelkl 1964, bes. 21-36, fasst die konstantinischen Stiftungslisten als leges templorum als eine Fortsetzung antiker Tempelstiftungen auf und leitet daraus einen „öffentlichen“ Charakter der konstantinischen Kirchenbauten in Rom ab: Der Kaiser habe in der Tradition des römischen Sakralrechts als Magistrat agiert, der im Auftrag des populus Romanus einen Ort dem christlichen Gott übergeben und damit zu einem locus sacer gemacht habe. Eine lex templorum muss jedoch nicht mit einer magistratischen Weihung zusammenhängen; auch von privaten Personen errichtete Tempel erhalten entsprechende leges (vgl. Wissowa 21912, 477). Die im Begriff der lex templi angesprochene Übergabe an eine Gottheit liefert allein keinen Aufschluss darauf, ob es sich um eine privat oder öffentlich vorgenommene Handlung handelt.

142 Krautheimer 1993, 530f.; vgl. auch Guyon 1993, 57-59, der diese Beobachtung mit ähnlichen Schlussfolgerungen wie Krautheimer bezüglich einer „qualità privati“ dieser kaiserlichen Ländereien verbindet. Keine Charakterisierung als ,privat", wohl aber die Betonung, dass die Kultbauten auf „kaiserlichem Besitz“ angelegt wurden, findet sich bei Brandenburg 1992, 33 u. 49 (alle konstantinischen Kultbauten in Rom); Jastrzebowska 1981, 160; Tolotti 1982, 164f.; Fiocchi Nicolai u. a. 1995-1996, 130 (Coemeterialbasiliken).

143 Dies gilt vor allem für die Basilika SS. Pietro e Marcellino, s. dazu u., S. 175-177.

144 Die Identifizierung als kaiserliches Landgut stützt sich auf den ager/fundus Veranus, auf dem die Basilika gebaut wurde (LP I, 181f.), und der allgemein mit dem Kaiser Lucius Verus (161-169) in Verbindung gebracht wird (Krautheimer, in: Corpus II, 27; Brandenburg 1992, 47). Für Lucius Verus ist allerdings nur eine Villa an der via Clodia bezeugt (Hist. Aug., Ver. 8, 8). Ebenso möglich ist die Herleitung des fundus von einer anderen Person gleichen Namens, etwa den Konsul P. Martius Verus, der nach Ausweis einer Bleifistula (CIL XV, 7504, Fundort unbekannt) möglicherweise in Rom über eine städtische domus oder eine Villa im Suburbium der Stadt verfügt hat.

145 Anders als bei der Basilika von Tor de' Schiavi, wo der Bau direkt neben einem moumentalen Grabtempel, der dem Besitzer der Villa gehört haben muss, liegt, gibt es keine Anhaltspunkte dafür, dass die basilica apostolorum zur Maxentiusvilla gehörte, die sich auf der anderen Seite der via Appia erhebt; eine derartige Zuweisung ist Spekulation (vgl. auch Tolotti 1982, 169). 
bereits bestehenden Nekropolen erhoben und dabei flächendeckende Zerstörungen von früheren Grabbauten in Kauf nahmen. Besonders bekannt ist die Nekropole auf dem vatikanischen Hügel, von der Teile durch die Grabungen in den 1940er Jahren freigelegt wurden: Konstantin ließ hier eine noch bis zum Baubeginn der Basilika genutzte Nekropole für seinen Bau der Petrusmemoria und der daran anschließenden Basilika planieren. Für die basilica apostolorum wurden vergleichbare Aufschüttungen vorgenommen, und bei den Basiliken von SS. Pietro e Marcellino, S. Agnese und S. Lorenzo f.l.m. bezeugt die Vielzahl von nichtchristlichen Grabfragmenten, die bei Grabungen zutage gefördert wurden, dass auch dort die Situation eine ähnliche gewesen und eine große Zahl von Vorgängerbauten den kaiserlichen Anlagen zum Opfer gefallen sein muss.

In einzelnen Fällen wie bei SS. Pietro e Marcellino und vermutlich auch bei S. Agnese handelte es sich dabei zwar zum Teil um Gräberfelder von Militäreinheiten (equites singulares, Prätorianerkohorten), die nach deren Auflösung in die Hände des Kaisers fielen und ein kaiserliches Verfügungsrecht begründeten. ${ }^{146}$ Für andere Fälle gilt dies jedoch nicht: Die Vatikannekropole war mit Familiengrablegen belegt, die zumindest teilweise auf einen höherrangigen Status der Besitzer schließen lassen - in einem der in der Nekropole gefundenen Sarkophage war die Tochter eines consul designatus bestattet - und die auch bei Baubeginn der Basilka noch genutzt wurden. ${ }^{147}$ Auch das Laurentiusgrab in S. Lorenzo hatte zur possessio einer Cyriaca gehört, ${ }^{148}$ deren Dimensionen zwar unklar sind, jedoch ebenfalls deutlich machen, dass es sich dort nicht um einen kaiserlichen Besitz handelte.

146 Zum sepulcretum der equites singulares bei SS. Pietro e Marcellino vgl. Guyon 1987, 30-33; Guyon erhält dort seine früher geäußerte Vermutung, dass sich der Friedhof der Angehörigen dieser Militäreinheit, von denen zahlreiche Grabfragmente im Bereich der Basilika entdeckt wurden, unterhalb der südlich an die Basilika angeschlossenen Portikus, befand, nicht mehr aufrecht. Bei S. Agnese hat man einen ähnlichen Friedhof der Prätorianer vermutet (Styger 1933, 208-210; Fasola 1974, 203). In beiden Fällen waren jedoch nicht nur Grablegen der von Konstantin aufgelösten Einheiten betroffen: In den Fundamenten von SS. Pietro e Marcellino wurden zahlreiche Bruchstücke von Mausoleen verbaut, die nicht zum sepulcretum der equites singulares gehörten (vgl. Deichmann/Tschira 1957, 70); bei S. Agnese wurden zahlreiche Bruchstücke von Grabdenkmälern kaiserlicher Freigelassener gefunden. Styger wertet dies als Hinweis auf ein Kolumbarium für Angehörige der domus Caesaris, das in kaiserlichem Besitz gewesen sei, doch erscheint dies angesichts der hohen Zahl von Freigelasseneninschriften aus Rom (vgl. Solin 1971, 135-137) wenig aussagekräftig.

147 Grabtitulus für Ostoria Chelidon... Ostorii Euhodiani consulis designati filiae... Vibius Iolaus a memoria imp(eratoris) Augusti uxori (CIL VI, 41321; an der Außenwand des Mausoleums F, neben dem Eingang, aufgestellter Sarkophag vom Ende des 3. Jh.). Bei den in der Vatikannekropole Bestatteten handelte es sich meist um Freigelassene, z. T. aus der kaiserlichen Administration (Toynbee/Ward Perkins 1956, 105-109). Dass die Gräber noch im 2. Jahrzehnt des 4. Jh. in Gebrauch waren, beweist der Fund einer Münze, die 317/318 geprägt wurde, in einer Urne des Mausoleums T (vgl. Arbeiter 1988, 57).

148 Vgl. LP I, 182. 
Die Forschung hat sich im wesentlichen darauf beschränkt, diese Überbauung der Nekropolen durch Konstantin aus einer sakralrechtlichen Perspektive zu kommentieren. Der Kaiser habe in seiner Eigenschaft als pontifex maximus die Möglichkeit gehabt, den Schutz, den die Gräber als res religiosae genossen, aufzuheben und die Unbedenklichkeit gegen eine Überbauung der Gräber zu erklären. ${ }^{149}$ Für die zivilrechtlichen Fragen, die mit der konstantinischen Auflassung der paganen Nekropolen berührt werden, ist dieser Hinweis auf die sakralrechtliche Kompetenz des Kaisers als pontifex maximus jedoch unerheblich. ${ }^{150}$ Die Grablegen mit ihren Bauten und Arealen blieben auch nach der Aufhebung ihrer religiosen Qualität das private Eigentum von Familien, in das der Kaiser durch seine Baumaßnahmen eingriff. Derartige Eingriffe in den Besitzstand dritter jedoch sind mit der Auffassung, der Kaiser habe die christlichen Sakralbauten auf seinem eigenen Grund und Boden errichtet, und diese seien deswegen privater Natur gewesen, nicht in Einklang zu bringen. Wie wenig die Überbauung von Nekropolen im großen Stil, wie sie von Konstantin betrieben wurde, eine kaiserliche „Privatangelegenheit“ war, sondern von den Zeitgenossen kritisch beurteilt wurde, zeigt das negative Echo, das Konstantins Maßnahmen in der Literatur ${ }^{151}$ und in der Gesetzgebung $^{152}$ hinterlassen haben.

149 Toynbee/Ward Perkins 1956, 12f.; Arbeiter 1988, 54. Zu den pontifikalen Kompetenzen des Kaisers im Grabrecht vgl. allgemein Stepper 2003, 173-176. Krautheimer, in: Corpus V, 189 ist der Ansicht, man habe aus Scheu vor der violatio sepulcri bei der Zerstörung der Gräber unter der Vatikanbasilika die größtmögliche Zurückhaltung walten lassen; der Tatbestand der violatio war jedoch bei jeglichem Eingriff in die Architektur der Grabbauten gegeben und machte sich nicht am Umgang mit den sterblichen Überresten der Toten fest (vgl. Thomas 1999).

150 Gräber waren zwar als res religiosae eine Sache extra commercium und damit der freien privatrechtlichen Verfügung entzogen (zu den Beschränkungen im einzelnen vgl. Thomas 1999, 4f.). Sie konnten jedoch wie privater Besitz veräußert werden, solange ihre Funktion als Grab nicht aufgehoben wurde (vgl. de Visscher 1963, 65-73).

151 Die Vita des Elagabal in der Historia Augusta erwähnt unter anderem, der Kaiser habe auf dem Vatikan Gräber abreißen lassen, um genug Platz für ein Rennen von vier Elefantenquadrigen zu schaffen (Hist. Aug., Heliog. 23, 1). Es ist sehr wahrscheinlich, dass sich hinter dieser Notiz eine Anspielung auf die Zerstörung der Vatikannekropole durch Konstantin verbirgt: Nach Birley 1991, 44 musste der Bezug auf die Petrusbasilika jedem Leser der Elagabalvita klar gewesen sein; ebenso Cracco Ruggini 1991, 145f. (anders Mazzarino 1966, 237-239, der diese Nachricht für historisch hält und meint, dass sie auf eine gut informierte Quelle zurückgeht). Für diese Deutung spricht, dass auch weitere Passagen der Elagabalvita Anspielungen auf Konstantin zu enthalten scheinen (z. B. Hist. Aug., Heliog. 15, 6f. mit der Weigerung des Kaisers, auf das Kapitol zu steigen, s. dazu u., Anm. 233).

152 Ein Gesetz des Jahres 349, in dem Constantius II. rückwirkend bis zum Jahr 333 die Verletzung von Grabbauten unter scharfe Strafe stellte (CTh 9, 17, 2), ist von der Forschung immer wieder mit den römischen Basilikalbauten Konstantins, vor allem mit S. Pietro, in Verbindung gebracht worden. Das Gesetz hält ausdrücklich fest, dass der Abriss von Grabbauten, auch für öffentliche Gebäude, nicht erlaubt sein soll; Eingriffe dürfen - unter Beiziehung der pontifices - nur vorgenommen werden, um die Grabbauten zu reparieren (reparationis gratia). Es erscheint plausibel, dass die auffällige zeitliche Begrenzung (nach 333) mit Blick auf die konstantinischen Umgangsbasiliken über stadtrömischen Nekropolen festgelegt wurde, die zu diesem Zeitpunkt abge- 
Krautheimers Argumentation erscheint dementsprechend gemessen an ihren eigenen Voraussetzungen als nicht ausreichend fundiert und in sich nicht schlüssig. Dass die christlichen Basilikalbauten auf kaiserlichem Privatbesitz errichtet und aus privaten Mitteln des Kaisers finanziert wurden, lässt sich nicht zweifelsfrei erweisen. Wesentlich wichtiger als diese Feststellung ist jedoch, dass Krautheimers Versuch das Binom publicus - privatus im Sinne einer dichotomischen Abgrenzung und Gegenüberstellung aufzufassen, bereits in seinem methodischen Ansatz problematisch ist. Wie insbesondere jüngere Studien zum politischen System Roms in der römischen Republik verdeutlicht haben, bildeten publicus und privatus - anders als in der semantischen Ausprägung, die das Begriffspaar seit der Frühen Neuzeit erfahren hat ${ }^{153}$ - keinen Gegensatz, sondern standen vielmehr in einem komplementären Verhältnis zueinander: Das Agieren eines Angehörigen der Oberschicht als privatus oder als Magistrat beruhte zwar auf unterschiedlichen Voraussetzungen, begründete aber keinen strukturellen Unterschied im Sinne einer Ausdifferenzierung gänzlich unterschiedlicher Handlungsbereiche ${ }^{154}$ - mit der Folge, dass auch die Kommunikation und Interaktion im privaten Raum der domus eine öffentliche Relevanz hatte. Diese nicht nur für die Republik, sondern auch für das spätantike Rom gültige Beobachtung ${ }^{155}$ wirft zwangsläufig die Frage auf, ob sich das Handeln und Auftreten des Kaisers im - nach den Maßstäben der

schlossen war und daher nicht mehr verfolgt werden konnte; so überzeugend Krautheimer 1989, 20f., der vor allem - im Unterschied zu der früheren Forschung, die das Gesetz ausschließlich mit S. Pietro in Verbindung brachte - darauf aufmerksam macht, dass diese Maßnahme nicht nur die Vatikanbasilika, sondern auch weitere römische Coemeterialbasiliken betrifft, bei denen Konstantin in die bestehende Sepulkrallandschaft eingriff. Dass die jüngst entdeckte Basilika an der via Ardeatina erst nach 336 begonnen wurde, widerspricht dem nicht, da hier nach bisherigem Kenntnisstand keine Gräber, sondern allenfalls Wohnstrukturen überbaut wurden (vgl. Spera, in: Fiocchi Nicolai u. a. 1995-1996, 143f.).

153 Im Zuge der frühneuzeitlichen Staatsbildung und Souveränitätslehre verdichtete sich im Begriff der Öffentlichkeit der alleinige staatliche Anspruch auf Herrschaft und politische Autorität, neben dem Formen privater Herrschaftsausübung keinen Anspruch auf Legitimität erheben konnten. Mit der Aufklärung im 18. Jh. wurde „Öffentlichkeit“ zu einem Leitbegriff der bürgerlichen Gesellschaft, die den für die staatliche Autorität okkupierten Öffentlichkeitsbegriff umdeutete und das staatliche Handeln der rationalen Beurteilung durch das bürgerliche Publikum als dem Träger einer „öffentlichen“ Meinung unterstellte. Für beide Varianten ist charakteristisch, dass die Bedeutung privaten politischen und gesellschaftlichen Handelns gegenüber dem Geltungsbereich der Öffentlichkeit abgewertet wurde (zur Begriffsgeschichte von publicus/privatus bzw. „öffentlich/privat“ und den beiden „Bedeutungsschwellen“ des Begriffspaars in der Frühen Neuzeit vgl. Hölscher 1978, 413f., 422-427, 438-445).

154 So nahmen die patres vermittels ihrer hausväterlichen Gewalt auch im privatum staatlich-öffentliche Disziplinierungs- und Integrationsfunktionen, erhielten durch ihre soziale Autorität als Patrone die gesellschaftliche Ordnung aufrecht und fungierten damit als Agenten der res publica: Private und staatliche Autorität bildeten dementsprechend keine Gegensätze, sondern ergänzten einander (vgl. dazu Martin 1990 [a], bes. 227-232; dens. 2002. Zur Komplementarität von privatum und publicum vgl. ferner Rilinger 1997; zuletzt Winterling 2005, 229f.).

155 Vgl. dazu u., S. 386-388. 
antiken Terminologie - „privaten“ Raum seiner domus oder Villa einem als publicus bezeichneten Bereich entgegenstellen lässt, oder ob man diese antike „Privatsphäre“ nicht als eine Fortsetzung von Öffentlichkeit begreifen muss mit der Folge, dass öffentlicher und privater Raum zwar unterschiedliche Handlungsfelder bildeten, diese Trennung aber keine dichotomische Differenz im Sinne einer Gegenüberstellung von städtischem Zentrum und kaiserlichem Privatbesitz begründete. ${ }^{156}$

In dieselbe Richtung weisen die Beobachtungen, die Aloys Winterling zur Übertragung der Terminologie von privatus und publicus auf den römischen Kaiser und seinen Verwaltungsstab angestellt hat. Aus ihnen wird deutlich, dass die Einbeziehung des Kaisers in dieses Begriffspaar die Römer (und nicht weniger die staatsrechtliche Forschung des ausgehenden 19. Jh.) vor keine geringen konzeptionellen Probleme stellte:157 Obwohl der Kaiser und sein Hof sich aus der domus der römischen Republik entwickelt hatten und damit nach traditonellen Maßstäben nur als privatum konzeptualisiert werden konnten, prägten sie bereits sehr früh Verstetigungstendenzen aus, die auch aus der Sicht der Römer als „öffentlich-staatlich“ aufgefasst wurden, auch wenn man sie zunächst nicht mit einer Terminologie bezeichnete, die traditionell den Institutionen der res publica vorbehalten blieb. Erst im Verlauf der weiteren Entwicklung versuchte man, der faktisch öffentlich-staatlichen Funktion des Kaisers dadurch Rechnung zu tragen, dass man bestimmte kaiserliche Kompetenzen und Handlungsbereiche als privatum bezeichnete: Die res privata wurde als privater Vermögensbereich des Kaisers im 2. Jh. aus dem fiscus ausgelagert; ${ }^{158}$ in der Kommunikation mit den Senatoren wählte der Kaiser bewusst den Habitus eines privatus, um sich auf diese Weise als princeps civilis $\mathrm{zu}$ erweisen. ${ }^{159}$ Dies waren jedoch allenfalls punktuelle Versuche, eine republikanische Terminologie auf die Person des Kaisers zu übertragen; eine klare Trennung zwischen einem privaten und öffentlichen Handeln des Kaisers konnte sie schon deswegen nicht etablieren, weil sie nicht systematisch durchgeführt wurde und die kaiserlichen Handlungsspielräume

156 Auch Brandenburg 1992, 34f., der Krautheimers Thesen zurecht kritisch gegenübersteht, löst sich nicht von konsequent von dessen methodischen Voraussetzungen, da er seine Einwände u. a. an die Bemerkung knüpft, zahlreiche römische Kirchen seien auf locus publicus errichtet worden - was übrigens beim titulus Clementis und den meisten anderen „Pastoralkirchen“, auf die Brandenburg im selben Zusammenhang verweist, nicht zutrifft, da die tituli in der Regel in privaten domus errichtet wurden (vgl. u., S. 333f.).

157 Winterling 2001, 198-206; zur Forschungsgeschichte vgl. dens., 1999, 84-89. Ähnliche Vorbehalte bezüglich der Versuche, den Kaiserhof mit Hilfe staatsrechtlicher Kategorien als partiell „öffentlich“ und partiell ,privat“ zu kategorisieren, formuliert mit Blick auf den spätantiken Kaiserhof Schlinkert 1996, $478 \mathrm{f}$.

158 Nesselhauf 1964.

$159 \mathrm{Zu}$ diesen und ähnlichen Gesten, die mit dem Begriff der kaiserlichen civilitas verbunden waren und die Einordnung des Kaisers in die Senatsaristokratie demonstrieren sollten, vgl. grundlegend Wallace-Hadrill 1982; s. auch u., Anm. 197. 
diejenigen der republikanischen nobiles, bei denen die Unterscheidung zwischen publicum und privatum bereits keine Grenze zwischen öffentlichen und privatem Handeln bezeichnet hatte, noch weit überschritten.

Diese Bemerkungen zur politischen Kultur Roms und den begrenzten Möglichkeiten, gesellschaftlichen Rang und politische Bedeutung insbesondere des römischen Kaisers vermittels semantischer Dispositive wie öffentlich und privat in segmentierte Teilbereiche auszudifferenzieren, legt auch einen neuen Blick auf die konstantinische Bautätigkeit im spätantiken Rom nahe. Anstatt von vornherein von einer räumlichen Trennung zwischen Zentrum und Peripherie als klar voneinander geschiedenen kaiserlichen Handlungsbereichen auszugehen, erscheint es sinnvoller, sich umgekehrt zunächst die Felder kaiserlicher Kommunikation in Rom und die daran beteiligten Gruppen und Akteure zu vergegenwärtigen, um von dort ausgehend die Frage zu stellen, ob den unterschiedlichen Kommunikationsräumen auch grundlegend verschiedene Formen und Inhalte der Kommunikation entsprechen oder ob sie - ähnlich wie publicum und privatum - als unterschiedliche Facetten einer politischen Kultur aufzufassen sind. Anders formuliert: Vollzogen sich unter Konstantin kaiserbezogene städtische und christliche Identitätsstiftung als strikt voneinander getrennte Prozesse oder sind sie als Bestandteile einer umfassenden Identitätskonstruktion zu verstehen, in der Konstantin unterschiedliche Aspekte des Verhältnisses des Kaisers zu seiner Stadt Rom mit unterschiedlichen Gruppen kommunizierte?

\section{1. 3. Konstantin und das Zentrum Roms}

Ausgehend von dieser Frage wenden wir uns damit erneut der konstantinischen Bautätigkeit im Zentrum Roms zu. Wie bereits erwähnt, beschränkten sich Konstantins Initiativen in diesem räumlichen Bereich darauf, die Memoria an seinen Vorgänger Maxentius auszulöschen, indem er die monumentalen Großbauten, die Maxentius auf der Velia errichtet hatte, mit seinem Namen versah. Diese memoriale Verdrängung erfolgte jedoch auf eine spezifische Weise: Konstantin stellte sich in den Bauinschriften nicht als Dedikant der Bauten des Maxentius dar, die er vollendete oder neu weihte. Vielmehr lässt die literarische und epigraphische Überlieferung erkennen, dass es in allen Fällen der Senat war, der dem Sieger über Maxentius die Bauwerke entlang der Velia dedizierte. Für den Venus und Roma-Tempel ebenso wie für die angrenzende Basilika des Maxentius hat Aurelius Victor, der spätere praefectus urbi, der über persönliche Kenntnisse der römischen Monumente und ihrer Bauinschriften verfügte, diesen Umstand ausdrücklich festgehalten: 
„Alle Werke, die er (scil. Maxentius) großartig errichtet hatte, das fanum urbis (= der Venus und Roma-Tempel) und die Basilika weihten die Senatoren den Verdiensten des Flaviers (scil. Konstantins) (meritis Flavii sacravere) “. ${ }^{160}$

Obwohl die Wendung meritis Flavii sacravere nicht sehr prägnant ist, ${ }^{161}$ signalisiert sie doch unmissverständlich, dass der Venus und Roma-Tempel und die Maxentiusbasilika in irgendeiner Form Konstantin dediziert wurden ${ }^{162}$ und der Nachfolger des Maxentius somit nicht als formaler Dedikant bzw. Erneuerer der beiden Bauwerke in Erscheinung trat.

Beim sogenannten Romulustempel deutet die nur fragmentarisch, durch mehrere divergierende Abschriften des 16. Jh. überlieferte Inschrift ebenfalls auf eine Dedikation an Konstantin hin. Der Name des Kaisers erscheint nach der maßgeblichen Abschrift von Onofrio Panvinio im Dativ und kann am plausibelsten zu [Imp(eratori) Caes(ari) Fl(avio)] Constantin[o] maximo [triu]mp[hatori - - ] ergänzt werden. ${ }^{163}$ Der Dedikant blieb in der fragmentarischen Inschrift nicht erhalten, doch dürfte über seine Identität kein großer Zweifel bestehen. Da es sich um ein Gebäude und nicht um eine Statuenstiftung han-

160 Aur. Vict., Caes. 40, 26: cuncta opera, quae magnifice construxerat (scil. Maxentius), urbis fanum atque basilicam Flavii (scil. Konstantin) meritis patres sacravere.

161 Vgl. auch Kähler 1952, 3.

162 Das meritis Flavii sacravere erinnert in seinem Duktus an die Weihinschrift der Diocletiansthermen, die Maximian „dem Namen“ Diocletians weihte (CIL VI, 1130: Diocletiani Aug(usti) fratris sui nomini consecravit, zur Lesung vgl. Walser 1987, 76f.).

163 CIL VI, 1147; die Ergänzung [trium]ph [atori] ergibt sich aus einer weiteren Abschrift der Inschrift von Cittadini (vgl. CIL VI, S. 3071). Coarelli 1986, 11f. mit Anm. 49 und mit ihm Curran 2000, 83 folgen stattdessen einer Abschrift und Zeichnung von Pirro Ligorio (veröffentlicht bei de Rossi 1867 [a], fig. 1) und lesen: Imp(erator) Caes(ar) Constantinus Maximus Triumph(ator) Pius Felix Augustus [---]. Ligorios notorische „Kreativität“ bei der Ergänzung von Inschriften und Monumenten gibt freilich auch im vorliegenden Fall zu Misstrauen Anlass: Ligorio überliefert die Inschrift in zwei leicht voneinander abweichenden Versionen, und auch in seiner Zeichnung der Fassade verfuhr Ligorio, wie Frazer 1964, 107-110 herausgestellt hat, ähnlich rekonstruktiv wie bei der Wiedergabe von Inschriften. Das Argument, Konstantin hätte keine Weihung an seine Person zugelassen (Coarelli 1986, 399, Anm. 50) und daher sei die Wendung im Dativ abzulehnen, ist bereits deswegen hinfällig, weil sich die Funktion des sogenannten „Romulustempels“ nicht genauer bestimmen lässt (s. o., S. 94). In welcher Weise das unter Konstantin neu geweihte Gebäude auf den Sieger über Maxentius bezogen war, ob es ihm selbst oder ihm zu Ehren geweiht war, wie beispielsweise der Konstantinsbogen, kann nach dem gegenwärtigen Erkenntnisstand nicht entschieden werden. Coarelli 1986, 8-10 möchte den Rundbau mit dem in den konstantinischen Regionarien genannten Iuppiter Stator-Tempel identifizieren; die Abfolge der Gebäude in den Regionarien (Venus und Roma-Tempel, Iuppiter Stator-Tempel, via sacra, Maxentiusbasilika, Faustinatempel) spricht jedoch für eine Lokaliserung des Iuppitertempels nicht zwischen Maxentiusbasilika und Faustinatempel, sondern in der Nähe des Venus und Roma-Tempels, bevor daran anschließend die via sacra und die an ihr liegenden Bauten aufgeführt werden. Die traditionelle Lokalisierung des Iuppiter Stator-Tempels südlich des Venus und Roma-Tempels, in der Nähe des Titusbogens, erscheint demnach nach Ausweis der Regionarien die wahrscheinlichste Lösung. Dass der sogenannte Romulustempel in den Regionarien zwischen der Maxentiusbasilika und dem Faustinatempel nicht erwähnt wird, ist vermutlich dadurch zu erklären, dass er ein Vestibül zu einem Teil des Forum Pacis bildete und diesem Bauwerk zugerechnet wurde. 
delt, die häufig auf das Konto von individuellen Stifterpersönlichkeiten ging, deutet alles auf den s(enatus) p(opulus)q(ue) $\mathrm{R}$ (omanus) als Dedikanten des Bauwerks hin ${ }^{164}$ - eine Schlussfolgerung, die zusätzlich dadurch gestützt wird, dass der Senat nach den oben erwähnten Angaben von Aurelius Victor in gleicher Weise auch bei der Maxentiusbasilika und beim Venus und RomaTempel als Dedikant fungierte.

Diesen drei Monumenten des Maxentius, die Konstantin vom Senat auf seinen Namen umweihen ließ, fügte der Senat schließlich noch den Konstantinsbogen hinzu, dessen Lage mit Bedacht gewählt worden war, um die Reihe der drei umgeweihten maxentischen Großbauten entlang der via sacra nach Süden hin zu ergänzen: ${ }^{165}$ Der Bogen erhob sich in Sichtweite des Maxentiusforums - in der Senke zwischen Kolosseum und Palatin, die den Zugang zum Venus und Roma-Tempel und den Beginn der via sacra von Süden her bildete. Während für die drei maxentischen Bauten an der via sacra eine Dedikation durch den Senat nur indirekt zu erschließen ist, weist die auf der Attika des Bogens angebrachte Inschrift diesen eindeutig als eine Stiftung des s(enatus) p(opulus)q(ue) R(omanus) aus. ${ }^{166}$

Alle vier Monumente an der Velia zeigen demnach, dass Konstantin, ähnlich wie bereits die Tetrarchen mit dem Fünfsäulendenkmal auf dem Forum Romanum, den Forumsbereich konsequent zum Schauplatz eines Kommunikationsmodus machte, bei dem der Kaiser dem Senat und dem populus Romanus die formale Rolle eines Akteurs und Dedikanten zuwies. Nur beim Konstantinsbogen verfügen wir über eine vollständig erhaltene Dedikationsinschrift, die seine Errichtung anlässlich der Decennalien bezeugt, die Konstantin im Juli 315 abhielt. ${ }^{167}$ Bei den übrigen drei Bauwerken bleibt man

164 So auch de Rossi 1867 (a), 66.

165 Es ist umstritten, ob der Bogen an dieser Stelle eigens für Konstantin errichtet wurde oder ob man einen älteren kaiserlichen Ehren- oder Triumphbogen aus hadrianischer Zeit umarbeitete (vgl. dazu zuletzt die kontroversen Ansichten von Pensabene/Panella 1993-1994, bes 174f.; 216222 [konstantinischer Bau mit hadrianischen Spolien] und Melucco Vaccaro 2001 [Umarbeitung eines hadrianischen Vorgängerbogens]). Ensoli 2000, 86f. denkt daran, dass eine Umarbeitung eines älteren Bogens schon unter Maxentius vorgenommen wurde und dass Konstantin auch hier einen maxentischen Vorgängerbau umweihen ließ, wofür es allerdings keine überzeugenden Anhaltspunkte gibt.

166 CIL VI, 1139 (vgl. 31245): Imp(eratori) Caes(ari) Fl(avio) Constantino Maximo / p(io) f(elici) Augusto s(enatus) p(opulus)q(ue) $\mathrm{R}$ (omanus) / quod instinctu divinitatis mentis / magnitudine cum exercitu suo, tam de tyranno, quam de omni eius / factione uno tempore iustis / rem publicam ultus est armis / arcum triumphis insignem dicavit.

167 Die Inschriften votis $X$ und votis $X X$ auf der nördlichen Frontseite des Bogens sowie sic $X$ und sic $X X$ auf der südlichen Frontseite, jeweils oberhalb der Rundmedaillons angebracht (CIL VI, 1139), signalisieren die decennalischen vota soluta und die vicennalischen vota suscepta, verweisen also auf das Jahr 315. Konstantins dies natalis war der 25. Juli; im Chronographen von 354 ist für den 18. und für den 21. Juli ein adventus divi verzeichnet (vgl. Degrassi [1963], in: Inscr. Ital. XIII, 2, 251), der sich auf Konstantins Rombesuche in den Jahren 315 und 326 bezieht. Eine Ent- 
bezüglich der Datierung auf Vermutungen angewiesen, doch muss ihre Umwidmung an Konstantin ebenfalls bald im Anschluss an den über Maxentius errungenen Sieg im Oktober 312 erfolgt sein. Es ist möglich, dass Konstantin den Beginn des Jahres 313 nutzte, um die Weihung an ihn bzw. seinen $\mathrm{Na}$ men vorzunehmen. Das Jahr wurde zu Januarbeginn regelmäßig mit vota für das Wohl der res publica und des Kaisers eröffnet. ${ }^{168}$ Konstantin befand sich zu dieser Zeit noch in Rom und hätte diesen Anlass - ähnlich bei den Regierungsjubiläen - zu einer publikumswirksamen Neuweihung der Gebäude nutzen können. ${ }^{169}$ Ebenso plausibel ist allerdings die Vermutung, dass man unmittelbar nach Konstantins Sieg an der milvischen Brücke auf die Niederlage des unterlegenen Rivalen reagierte und die Basilika an Konstantin umweihte. ${ }^{170}$

Unabhängig von Fragen der genauen Datierung bleibt vor allem die Tatsache ungewöhnlich und erwägenswert, dass der senatus populusque Romanus nicht nur bei dem für Konstantin errichteten Ehrenbogen, sondern auch bei den anderen Monumenten, die zusammen mit dem Bogen einen zusammenhängenden Komplex bildeten und Konstantins Beitrag zur Umgestaltung des römischen Zentrums darstellten, als Dedikant genannt wurde: Während die Weihung des Bogens für Konstantin durch den Senat sich ganz im Rahmen der traditionellen Stiftung von kaiserlichen Triumph- und Ehrenbögen durch den Senat bewegte und bekanntlich auch nach Konstantin noch senatorische Bögen für die Kaiser in Rom errichtet wurden, ${ }^{171}$ erscheint der Umstand, dass der senatus populusque Romanus noch auf drei weiteren Großbauten als Dedikant in Erscheinung trat, als eine außergewöhnliche Hommage an den Senat, ${ }^{172}$ dessen legitimierende Rolle für die konstantinische Herrschaft auch dadurch unterstrichen wurde, dass die patres Konstantin nach seinem Sieg über Maxentius den Rang eines führenden Augustus verliehen. ${ }^{173}$

Dass Konstantin sich dieses Kommunikationsmodus, der ihn zum Adressaten und Empfänger von Gaben des römischen Senats machte, in so ausgeprägter Weise bediente, ist auffällig und nur durch die besonderen Umstände zu erklären, unter denen er die Kontrolle über das Kaisertum und die Herrschaft über Rom erlangt hatte. Konstantin war im Oktober 312 nicht nur

scheidung darüber, welches der beiden Daten welchem Jahr zuzuordnen ist, ist allerdings nicht möglich (vgl. dazu die ausführliche Diskussion bei Fraschetti 1999, 123f.).

168 S. u., Anm. 229.

169 Konstantin hielt sich nach seinem Einzug vom 29. Oktober 312 noch bis mindestens zum 6. Januar 313 in Rom auf (vgl. u., S. 140).

170 So Kähler 1952, 9; Curran 2000, 80.

171 Bogen für Arkadios und Honorius 398 (CIL VI, 1187); Bogen für Arkadios, Honorius und Theodosius II. 405 (CIL VI, 1196).

$172 \mathrm{Zu}$ den - vergleichsweise wenigen - inschriftlichen Belegen dafür, dass der SPQR als Dedikant von Bauwerken in Erscheinung trat, vgl. die Übersicht von de Ruggiero 1925, 73-77.

173 Lact., mort. pers. 44, 11. 
als Sieger aus einem Bürgerkrieg hervorgegangen, sondern hatte die entscheidende Schlacht gegen Maxentius direkt vor den Toren Roms geschlagen und war am Tag darauf als Eroberer in die Stadt eingezogen. Wenn die antike Überlieferung übereinstimmend berichtet, Konstantin habe unter dem einhelligen Jubel der Bevölkerung die Stadt betreten, dürfte dies bereits das Produkt einer konstantinfreundlichen Darstellung sein, die den Ereignissen nachträglich unterlegt wurde. ${ }^{174}$ Am 29. Oktober 312 stellte sich die Situation wohl kaum so eindeutig dar: Maxentius war unter maßgeblicher Mithilfe der Prätorianer und der zivilen Bevölkerung Roms an die Macht gelangt und hatte über mehrere Jahre hinweg ein dezidiert römisches Kaisertum propagiert. Konstantins Sieg über seinen Rivalen war damit in noch weit stärkerem Maße als dies bei Auseinandersetzungen mit anderen „Usurpatoren“ in Bürgerkriegen üblich war, auch ein Sieg über Rom und seine Senatoren gewesen.

Die für die Legitimation des römischen Kaisers auch in der Spätantike zentrale Forderung nach kaiserlicher Sieghaftigkeit stieß damit auf Inszenierungsprobleme, die sich auch in den Monumenten, die den Sieg Konstantins über Maxentius in Erinnerung hielten, niederschlug. Deutlich sichtbar wird dies vor allem im Konstantinsbogen, der - in Ermangelung einer ähnlich guten Dokumentation für die unter Konstantin umgewandelten Bauten des Maxentius auf der Velia - die zentrale Quelle bildet, aus der die Absichten erschlossen werden müssen, die Konstantin bei seiner kaiserlichen Selbstinszenierung verfolgte. Wie seit Hans Peter L'Orange immer wieder betont worden ist, war der Konstantinsbogen kein Triumphbogen im technischen Sinne: Die Abbildungen des Bogens zeigen den nach der Schlacht an der Milvischen Brücke nach Rom einziehenden Kaiser bei einem adventus, der nicht wie ein Triumphator auf einem currus triumphalis stehend, sondern auf einer cathedra sitzend dargestellt ist. Auch werden in der pompa keine Opfertiere und gefangenen Feinde mitgeführt. ${ }^{175}$ Die vage Formulierung der auf dem Bogen angebrachten Inschrift - triumphis insignis - enthält zwar allgemeine Anklänge an das Motiv der kaiserlichen Sieghaftigkeit, vermeidet dadurch jedoch gerade die Anspielung auf einen konkreten „Triumph“ Konstantins über römische Bürger. ${ }^{176}$ Trotz der divergierenden Sichtweise eines anonymen Panegyrikers,

174 Zos. 2, 17, 1; Lact., mort. pers. 44, 10; Eus., v. C. 1, 39, 2; vgl. auch Hunt 2003, 105. Für eine unkritische Übernahme des von den Quellen präsentierten Bildes vgl. Odahl 2004, 108.

175 L'Orange/Gerkan 1939, 77, Anm. 1; aufgenommen von Fraschetti 1999, 21, 49f.; zuletzt ausführlich Giuliani 2000, 274-277. Auch im Chronographen von 354 wird der 29. Oktober nicht als Triumph, sondern als advent(us) Divi bezeichnet (Inscr. Ital. XIII, 2, 257).

176 So schon Kähler 1952, 2f., der triumphis insignis mit „den immer Siegreichen, den allzeit Triumphierenden“ paraphrasiert; ähnlich auch Giuliani 2000, 281f. Dies entspricht dem Charakter des Bogens als allgemeines Siegesmonument, das anlässlich eines Kaiserjubiläums, der konstantinischen Decennalien, geweiht wurde: Die triumphi erinnern allgemein an die Siege Konstantins und an die Sieghaftigkeit als diejenige Herrscherqualität, die die Grundlage für die kaiserliche Herrschaft bildete. Demensprechend sind auf den Reliefs des Bogens nicht nur der Sieg 
der im Jahr 313 Konstantins Sieg über Maxentius als einen Triumph feierte, ${ }^{177}$ besteht demnach kein Anlass zu der Annahme, dass Konstantin die Ausschaltung seines Rivalen als einen formalen Triumph inszenierte. ${ }^{178}$ Die Dedikationsinschrift verdeutlicht vielmehr, dass Konstantin seinen Sieg nicht als einen Triumph, sondern als eine Befreiung der res publica vom „Tyrannen“ Maxentius verstanden wissen wollte: de tyranno iustis rem publicam ultus est armis. ${ }^{179}$

Dass römische Kaiser ihre Siege über Konkurrenten in Bürgerkriegen als eine Befreiung der res publica inszenierten, war nichts Neues, ${ }^{180}$ und angesichts der während der gesamten Kaiserzeit ungebrochen kritischen Haltung, die die Senatsaristokratie gegenüber dem Vergießen von Bürgerblut und dem Niederwerfen innerer Gegner an den Tag legte, ${ }^{181}$ erfreute sich dieser Topos auch in der Spätantike ungebrochener Beliebtheit. ${ }^{182}$ Der nach dem Sieg über

über Maxentius, sondern auch Konstantins Erfolge über die Germanen abgebildet (vgl. Girardet 1998, 32). Dies erlaubte es, auch den Sieg über Maxentius in einen übergeordneten Zusammenhang kaiserlicher Sieghaftigkeit einzubeziehen, ohne ihn selbst damit explizit als „Triumph“ zu bezeichnen. Was auf dem Konstantinsbogen anlässlich eines Regierungsjubiläums inszeniert wurde, hatte sich bereits seit Commodus und Septimius Severus (vgl. Storch 1972) zu einem allgemeinen Kennzeichen kaiserlicher Legitimation und Repräsentation entwickelt: Sieghaftigkeit beruhte nicht mehr auf identifizierbaren Erfolgen. Sie entwickelte sich in der Spätantike zu einer abstrakten und ubiquitären Eigenschaft des Kaisers; Darstellungen kaiserlicher adventus wurden entindividualisiert und ihrer konkreten historischen Bezüge entkleidet. Der Konstantinsbogen ordnet sich in diese Entwicklung ein: Während die Reliefs noch auf bestimmte Ereignisse Bezug nehmen und konkrete stadtrömische Schauplätze abbilden, löst die Wendung triumphis insignis die kaiserliche Sieghaftigkeit aus ihren konkreten Bezügen und lässt sie als eine allgemeingültige Qualität erscheinen (vgl. McCormack 1981, 60f.; zu den Implikationen dieser Entwicklung aus herrschaftssoziologischer Sicht vgl. Martin 1984, bes. 115-120).

177 Pan. lat. 12 (9) 18, 3 (ioci triumphales); auch Nazarius bezeichnet in seinem 321 auf Konstantin gehaltenen Panegyricus den Sieg über Maxentius als einen Triumph (pan. lat. 4 [10] 30, 5; 32, 1). Allerdings muss man in der Sprache der Panegyrik eine untechnische Verwendung in Rechnung stellen: Der Panegyriker des Jahres 313 bezeichnet auch die im Juli dieses Jahres in Trier veranstalteten Siegesfeiern über die Franken als einen triumphus (pan. lat. 12 [9] 23, 3).

178 So auch Fraschetti 1999, 47-50.

179 CIL VI, 1139 (s. o., Anm. 166). Die Inschrift präsentiert zahlreiche Versatzstücke augusteischer Prinzipatsideologie; zu den einzelnen Textelementen vgl. die ausgewogene Diskussion bei Grünewald 1990, 63-86. Eusebius v. Caesarea behauptet, die konstantinische Kolossalstatue in der Maxentiusbasilika habe eine Inschrift getragen, auf der sich Konstantin als Befreier Roms vom Tyrannen und Wiederhersteller der Freiheit des Senates und Volkes von Rom bezeichnet

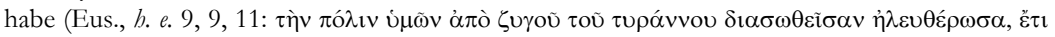

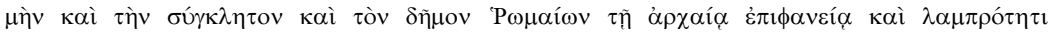

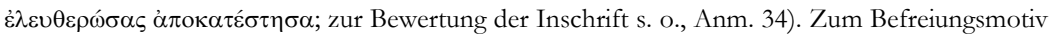
in Verbindung mit dem Sieg vom Oktober 312 vgl. für die Inschriften und Münzen Grünewald 1990, 63.

180 Vorbildhaft war die Stilisierung des Augustus als vindex libertatis (R. Gest. div. Aug. 1), die in der Folgezeit für die kaiserliche Selbstdarstellung prägend wurde (vgl. Béranger 1973, 244f., 260f.).

181 Vgl. dazu Vera 1980.

182 Dass Maxentius ungeachtet der Spielregeln politischer Semantik seinen Sieg über Domitius Alexander in der Form eines Triumphes inszeniert haben soll (Zos. 2, 14, 4), ist wenig glaubhaft: 
Maxentius auf dem Konstantinsbogen erstmals auftauchende Begriff tyrannus $^{183}$ für einen Usurpator signalisiert jedoch, dass das traditionelle Rächerund Befreiungsmotiv offensichtlich als zu schwach empfunden wurde, um dem Handeln Konstantins jeglichen Schatten des Illegitimen zu nehmen. Denn der neue Herrscher über Rom war nicht allein militärischer Sieger über einen Usurpator gewesen, sondern hatte an der milvischen Brücke einen Sieg über die Hauptstadt selbst errungen. Eusebius macht die Brisanz dieses Vorgangs deutlich, indem er den - unter taktischen Gesichtspunkten überraschenden - Auszug des Maxentius aus der Stadt mit der göttlichen Vorsehung erklärt, die durch die Schlacht vor den Toren der Stadt das Vergießen von römischem Bürgerblut habe verhindern wollen. ${ }^{184}$ Die Situation des Oktober 312 verlangte nach einer legitimatorischen Selbstinszenierung, die nicht den geringsten Zweifel daran aufkommen ließ, dass der militärische Erfolg über den Konkurrenten ein Akt der Befreiung gewesen war - und Konstantin fand sie in der terminologischen Zuspitzung, die Maxentius nicht zu einem schlechten Kaiser und dominus stilisierte, sondern ihn zum regelrechten $\mathrm{Ty}$ rannen erklärte. ${ }^{185}$

Den Senatoren fiel in der kaiserlichen Selbstinszenierung Konstantins als Befreier der Stadt aus tyrannischer Knechtschaft eine zentrale Rolle als symbolische Akteure zu. Nach den Gesetzen der Topik waren sie die typischen Opfer kaiserlicher Willkür und Unterdrückung, die die vom malus princeps unterdrückte und schließlich aus seinen Fesseln befreite res publica verkörperten. ${ }^{186}$ In beeindruckender Zahl und Übereinstimmung geben dementspre-

Es ist gut vorstellbar, dass diese Darstellung der Ereignisse auf das Konto einer verzerrenden maxentiusfeindlichen Propaganda geht, die sämtliche Quellen über den Gegenspieler Konstantins massiv überlagert hat. Zu den traditionellen Vorbehalten, Siege in Bürgerkriegen mit Triumphen oder Ovationen zu feiern, vgl. Val. Max. 2, 8, 7; Amm. 16, 10, 1-3; Pacatus, pan. lat. 2 [12], 46; Claud., de cons. Hon. VI, 392-406.

183 Zur Neuartigkeit der Begriffsprägung tyrannus für einen Usurpator nach dem Sieg Konstantins über Maxentius vgl. Grünewald 1990, 66-71, Barnes 1996, 60-62.

184 Eus., h. e. 9, 9, 4. Zu den realhistorischen Vorgängen vgl. Kuhoff 1991.

185 Anderer Auffassung ist Barnes 1996, der die Lexik tyrannus für Maxentius als Anlehnung Konstantins an die Bezeichnung für die Christenverfolger interpretiert, die in der christlichen


allerdings nicht überzeugend, weil auch die christlichen Quellen (Laktanz, Euseb) den tyrannus Maxentius im Vergleich mit den übrigen Tetrarchen weniger als einen Christenverfolger denn als einen Tyrannen im traditionellen Sinne, d. h. als Verfolger der Senatoren und Unterdrücker senatorischer libertas, präsentieren (s. u., Anm. 275).

186 Zum traditionellen Verständnis von libertas als spezifisch aristokratischer Freiheit vgl. Bleicken ${ }^{7} 1995,215-218$. Es ist in diesem Zusammenhang allerdings auch zu berücksichtigen, dass der $l i-$ bertas-Begriff in der Prinzipatsideologie eine beträchtliche Assoziationsbreite aufweist, die ihn auch außerhalb interner Konflikte zu einer Leitidee der idealen Kaiserherrschaft macht: So wird auch die Niederwerfung von Barbaren und die damit verbundene securitas römischer Bürger traditionell als Sicherung bzw. Wiedergewinnung römischer libertas aufgefasst (vgl. allgemein Wickert 1954, 1096f.). Eine charakteristische Verbindung beider Motive findet sich z. B. in pan. lat. 8 (5) 19, 1f., wo Constantius Chlorus nach der Niederwerfung des Allectus als vindex et libera- 
chend sowohl christliche als auch nichtchristliche Quellen zu erkennen, dass es die Senatoren und ihre Frauen waren, die unter den Nachstellungen des Maxentius in besonderer Weise zu leiden hatten, ${ }^{187}$ und in der Darstellung des konstantinischen Adventus von 312, die der Panegyriker Nazarius im Jahr 321 verfasste, schreiten anstelle von gefesselten Heerführern die befreiten Senatoren vor dem Wagen des Kaisers einher. ${ }^{188}$ Augenfälliger konnte die Umdeutung des Sieges über Maxentius aus einem Triumph in einen die Befreiung Roms symbolisierenden adventus kaum inszeniert werden. ${ }^{189}$ Auch spätere kaiserliche Einzüge in Rom haben dieses zeremonielle Element beibehalten und machen damit - ähnlich wie in der Tyrannentopik selbst, die seit Konstantin fester Bestandteil der politischen Rhetorik wurde, um einen Usurpator zu bezeichnen ${ }^{190}$ - den Modellcharakter der von Konstantin für ein spezifisches Problem gefundenen Lösung deutlich. ${ }^{191}$ Die im Jahr 312 (bzw. 315, bei der Einweihung des Konstantinsbogens) erfolgreich erprobte Etablierung des Tyrannentopos in der politischen Rhetorik und in der

tor begrüßt wird, der die Britanni „endlich wieder frei und endlich wieder zu Römern“ (tandem liberi tandemque Romani) gemacht habe.

187 Pan. lat. 12 (9) 4, 4; Eus., h. e. 8, 14, 4 u. 16f.; ähnlich ders., v. C. 1, 33f.; 35, 2; Eutr. 10, 4, 3; Prud., c. Symm. 1, 467-471. Aur. Vict., Caes. 40, 24 dehnt das Schreckensregiment des Maxentius über die Senatoren hinaus auch auf die ganze Bevölkerung aus. Diese Definition von libertas als eine spezifische libertas senatus, dessen Würde und Integrität vom Kaiser zu respektieren sind, entspricht der senatorische Prinzipatsideologie seit der frühen Kaiserzeit (vgl. Neri 1997, 71f.). Der Topos des „Senatorenmörders“ begegnet auch bei Themistios, Oratio 3, 6 mit Blick auf die Herrschaft des „Tyrannen“ Magnentius in Rom (351-353); die Parallele zu Maxentius wird explizit ebd., 3, 8 gezogen.

188 Pan. lat. 4 (10) 31, 1: non agebantur quidem ante currum vincti duces sed incedebat tandem soluta nobilitas.

189 Der Umstand, dass Konstantin in unterschiedlichen Bereichen der öffentlichen Kommunikation - den Inschriften und den Reliefs des Konstantinsbogens, ebenso wie der Panegyrik - seinen Sieg über Maxentius so nachdrücklich als einen Akt der Befreiung darstellte, relativiert den von Mayer 2002, 189 herausgestellten Tabubruch, auf einem Ehrenbogen einen kaiserlichen Sieg in einem Bürgerkrieg darzustellen, doch sehr: Im Konstantinsbogen kommt kein neuer, ,absolutistischer Herrschaftsanspruch“ und ,geringe(r) Respekt für die Traditionen der römischen Republik" (ebd., 194) zum Tragen, sondern umgekehrt der Versuch, ein in dieser Form noch nicht dagewesenes Ereignis in einer Sprache zu kommunizieren, die den traditionellen senatorischen Verhaltenserwartungen an einen ,guten Kaiser“ entsprach.

190 Neri 1997, bes. 73-86: tyrannus entwickelte sich im Verlauf der Folge zum allgemeinen terminus technicus für einen Usurpator - zunehmend unabhängig von dessen Verhalten gegenüber der senatorischen Oberschicht, der für die Aktivierung des Begriffs durch Konstantin noch die entscheidende Rolle gespielt hatte.

191 Diese Praxis, sich als liberator zu inszenieren, konnte zu Spannungen mit anderen Verhaltensnormen im Umgang mit Senatoren, in denen die civilitas principis demonstriert wurde, führen. Theodosius I. suchte 389 darin einen Ausgleich, dass er vom Wagen abstieg und einen Teil des Weges zusammen mit den Senatoren zu Fuß zurücklegte (Pacatus, pan. lat. 2 [12] 47, 3). Honorius untersagte 403 den Senatoren, vor seinem Wagen einherschreiten, um als civis und nicht als dominus zu erscheinen (Claud., de cons. Hon. VI, 550f., 559). Hierbei ist allerdings ist zu berücksichtigen, dass 403 eben kein Sieg über einen Usurpator gefeiert wurde, wie Claudian auch nachdrücklich hervorhebt (ebd., 392-399), sondern Stilichos Erfolge über Alarich. 
zeremoniellen Interaktion des Kaisers mit der römischen Oberschicht führte im Verbund mit der Tatsache, dass die kaiserliche Sieghaftigkeit in Ermangelung von Erfolgen über äußere Feinde im 4. Jh. sich zunehmend in der Niederwerfung von „Tyrannen“ manifestierte, ${ }^{192}$ dazu, dass eine ursprünglich situationsgebundene Semantik zur allgemeinen Bezeichnung für den Rivalen um die kaiserliche Macht wurde. Gerade, weil diese Bezeichnung aus späterer Perspektive so selbstverständlich erscheint, droht jedoch leicht aus dem Blick zu geraten, dass Konstantin mit dem Begriff des tyrannus eine originelle und neuartige Formel fand, mit der er auf die spezifischen Voraussetzungen seiner Übernahme der Herrschaft in Rom zu reagieren suchte und mit der er gewährleistete, dass - um mit dem späteren Panegyriker Pacatus zu sprechen, der sich nach der Niederwerfung des Maximus an Theodosius I. wandte - „sich niemand, während du siegst, als Besiegter vorkommt". 193

Unter diesen Voraussetzungen setzte die Weihung des konstantinischen Bogens andere Akzente als die übrigen Triumphbögen der Stadt, von denen sich der Konstantinsbogen äußerlich kaum unterschied: Der Bogen beim Colosseum war nicht nur ein staatliches Ehrenmonument, das die Sieghaftigkeit des herrschenden Kaisers vor Augen führte, sondern auch und in erster Linie eine Gegengabe des Senats, der dem Kaiser damit die Befreiung vom Joch des tyrannus Maxentius dankte. Auch die Umweihungen der maxentischen Bauwerke an Konstantin durch den Senat folgten dieser Semantik einer senatorischen Gegengabe, die sich nicht nur im Konstantinsbogen widerspiegelte, sondern auch in den Monumenten, auf die der Bogen durch seine Lage am Eingang der via sacra ausdrücklich bezogen war. Konstantin verdrängte hier nicht nur die Erinnerung an Maxentius - er nutzte diese Verdrängung gleichzeitig im Sinne seiner proagandistischen Befreiungsrhetorik. Dass der Senat auch hier als Dedikant auftrat, demonstrierte nachdrücklich die nunmehr „freie“ Verfügung der Senatoren über eben die Monumente, die ihnen ihr „Unterdrücker“ gesetzt hatte.

Die Selbstinszenierung Konstantins im Zentrum der Stadt stand damit zum einen in einer langen Tradition kaiserlicher Kommunikation mit der senatorischen Elite, ist damit allein in ihren semantischen Bezügen jedoch noch nicht hinreichend erklärt. Anders als in den tetrarchischen Residenzstädten, in denen kaiserliche Ehrenmonumente von Mitkaisern und Angehörigen des kaiserlichen comitatus errichtet wurden, wahrte in Rom der Senat seine traditionelle Bedeutung als Dedikant von „Staatsdenkmälern“, die auf den Kaiser

\footnotetext{
192 Zur Konjunktur kaiserlicher Siege über „Tyrannen“ im 4. und frühen 5. Jh. vgl. McCormick 1986, 80-83.

193 Pacatus, pan. lat. 2 (12) 45, 7: fecisti, ut nemo sibi victus te victore videatur.
} 
bezogen waren. ${ }^{194}$ Dass der Kaiser sich nicht selbst als Bauherr in Szene setzte - obwohl er und nicht der Senat die Bauten maßgeblich finanziert haben dürfte ${ }^{195}$ - ist als ein deutlich sichtbares Zugeständnis an die Senatsaristokratie und symbolischer Ausdruck der kaiserlichen Einbindung in die res publica zu verstehen: Der Kaiser verzichtete darauf, selbst Zeichen seiner Autorität zu setzen, sondern beschränkte sich - formal - darauf, sie aus der Hand des senatus populusque Romanus zu empfangen. Die damit signalisierte Haltung gegenüber dem Senat kam auch in der Bildersprache der Monumente selbst zum Ausdruck. Das tetrarchische Fünfsäulendenkmal auf dem Forum Romanum legte in dieser Hinsicht ein konservatives und an der Tradition orientiertes Herrschaftsverständnis der Tetrarchen an den Tag: Bei aller Betonung der tetrarchischen Herrscherideologie inszenierten die Kaiser sich dort zugleich in durchaus konventioneller Weise in ihrer Rolle als Magistrate und Agenten der res publica. ${ }^{196}$ Dieses am kaiserzeitlichen Ideal des princeps civilis orientierte Kaiserbild spiegelte sich auch im Bildprogramm und den Inschriften des Konstantinsbogens wider: Neben der Sieghaftigkeit, die das bestimmende Thema des Monuments bildete, wurde der Kaiser auch in Kommunikations- und Interaktionssituationen dargestellt, die seine Bezogenheit auf die Bürgerschaft herausstellten. ${ }^{197}$

Dass nach der Machtübernahme Konstantins nicht nur der Konstantinsbogen, sondern auch die maxentischen Bauten auf der Velia vom senatus populusque Romanus dediziert wurden, ist demnach einerseits ein Zugeständnis

194 Vgl. dazu Mayer 2002, bes. 1-27, der in diesem Zusammenhang von unterschiedlichen „panegyrischen Milieus“ kaiserbezogener Kommunikation spricht. Dabei ist allerdings zu berücksichtigen, dass sich die konkreten Modalitäten, unter denen sich die Umgestaltung der Kaiserresidenzen in tetrarchischer und konstantinischer Zeit vollzog, nur sehr unzureichend dokumentieren lassen. Die Frage, wie die Kaiser sich und ihre Baustiftungen beispielsweise durch Inschriften in Szene setzten, bleibt offen; die diesbezüglichen Verhältnisse beginnen erst für Konstantinopel in der Zeit der theodosianischen Dynastie klarer hervorzutreten.

195 Das aerarium Saturni, die Kasse des Senats, aus der bereits während der Kaiserzeit zunehmend geringere Ausgaben getätigt wurden, hatte bis zum Ende des 4. Jh. jegliche Bedeutung verloren (Corbier 1974, 698f.). Weniger skeptisch bezüglich einer Beteiligung des aerarium Saturni an Neubauten und Restitutionsarbeiten ist Daguet-Gagey 1997, 198-201, doch ist auch in diesem Fall mit kaiserlichen Zuschüssen an das aerarium zu rechnen.

196 S. o., S. 89.

197 Vgl. dazu Mayer 2002, 195-202, dessen Schlussfolgerungen allerdings kritisch zu bewerten sind (s. o., Anm. 189). Das kaiserzeitliche civilitas-Ideal tritt vor allen in den Reliefs aus trajanischer bis spätantoninischer Zeit, die als Bauspolien für den Konstantinsbogen verwendet wurden, zutage. Die semantische Bedeutung dieser Spolien als Erinnerungsträger wird allerdings in der jüngeren Forschung zurecht skeptisch beurteilt: Es ist unwahrscheinlich, dass die spoliierten Reliefs des Konstantinsbogens jenseits ihres darstellerischen Gehalts das traditionelle Herrscherideal auch dadurch kommunizierten, dass sie Erinnerungsbezüge an das 2. Jh. als die Zeit der ,guten Kaiser“ weckten (ebd., 196-200; Liverani 2004, 383-411). - Zur Bedeutung der civilitas für die Interaktion des römischen Kaisers mit der hauptstädtischen Bevölkerung und zur christlichen Transformation, die dieses Ideal in der neuen Hauptstadt Konstantinopel um die Wende vom 4. zum 5. Jh. erfuhr, vgl. Diefenbach 2002, bes. 31-39. 
des Kaisers an einen konservativen Herrschaftsdiskurs, der die Kommunikation des Kaisers mit den Eliten im monumentalen Zentrum der Stadt prägte. Darüber hinaus ist jedoch auch die besondere Situation zu berücksichtigen, in die Konstantin als Sieger über die Stadt im Oktober des Jahres 312 geraten war. Nicht weniger als die innovative Begriffsprägung tyrannus resultierte auch der Umgang mit dem Bauprogramm des „Tyrannen“ Maxentius auf der Velia aus dem Bemühen, den Sieg über den Usurpator und seine Stadt als Befreiung Roms und des Senats zu inszenieren: Die Bauinschriften machten implizit deutlich, dass Konstantin die Bauten des „Unterdrückers“ zurück in die Hände des senatus populusque Romanus gelegt hatte.

Folgt man dieser Interpretation, dann wird unmittelbar einsichtig, warum Konstantin die Maxentiusbasilika nicht zu dem monumentalen Kirchenbau machte, den er dann am Lateran für den Bischof und die christliche Gemeinde errichten ließ. Der Grund dafür liegt nicht darin, dass Konstantin im Jahr 312 dem christlichen Kult noch distanziert gegenüber gestanden hätte, und er ist auch nicht darin zu suchen, dass der Kaiser aus Respekt vor der paganen Oberschicht und dem öffentlichen Raum der Stadt auf einen derartigen Schritt verzichtet hätte. Noch unter Konstantin rückten die Bischöfe Roms mit dem Bau erster „Basiliken“ dicht an das monumentale Zentrum heran. ${ }^{198}$ Auch wenn die Dimensionen dieser Bauwerke nicht bekannt sind und sie wohl nicht mit den konstantinischen Basilikalbauten zu vergleichen waren, ${ }^{199}$ machen sie zumindest deutlich, dass die religiösen Vorbehalte einer paganen Oberschicht in der ersten Hälfte des 4. Jh. zu keiner effektiven Ausgrenzung christlicher Kultbauten aus dem Zentrum der Stadt führten. Konstantin benötigte vielmehr die maxentischen Bauten auf der Velia, um seine Selbstdarstellung als Befreier der res publica wirkungsvoll zu demonstrieren.

In dieser Option kaiserlicher Repräsentation und Kommunikation, die Konstantin angesichts der Situation von 312 für den Bereich der via sacra wählte, fiel der christlichen Gemeinde Roms zwar keine symbolisch wirksame Rolle als Akteur und Kommunikationspartner zu. Daraus zu schließen, Konstantin habe im Zentrum der Stadt seine Affinität zum christlichen Kult nicht offen zeigen können, wäre jedoch falsch. Von einer bei Eusebius beschriebenen, jedoch aufgrund der christlich transformierenden Wahrnehmung dieses Autors nur schwer zu deutenden ${ }^{200}$ Kolossalstatue des Kaisers in der Maxen-

198 Bischof Marcus (336) errichtete eine Basilika in urbe Roma iuxta Pallacinis (LP I, 202), die sich unmittelbar nördlich des Kapitols, am Beginn der via Lata, befand. Auf der gegenüberliegenden Seite der via Lata, nördlich des Trajansforums, ließ sein Nachfolger Iulius (337-352) eine weitere basilica erbauen (vgl. den Catalogus Liberianus des Chronographen von 354; MGH AA IX, 76: multas fabricas fecit: ... basilicam Iuliam quae est regione VII iuxra forum divi Traiani. Zur vermutlichen Lokalisierung der basilica Iulii vgl. Geertman 1986-1987, 68f.).

199 Zur Bedeutungsbreite des Begriffs basilica vgl. Verrando 1985, bes. 1048.

200 Zu der von Konstantin umgearbeiteten Kolossalstatue in der Maxentiusbasilika vgl. o., S. 92. 
tiusbasilika abgesehen, wird dies vor allem an einem Ereignis deutlich, dessen Wirkung - was nicht immer ausreichend beachtet wird - für uns vor allem in seinen retrospektiven Deutungen fassbar wird und das wegen der in den Quellen explizit thematisierten Verbindung von Topographie und städtischer Identität in Zusammenhang der hier verfolgten Fragestellung eine ausführliche Diskussion verlangt: der Verzicht Konstantins darauf, auf das römische Kapitol hinaufzusteigen.

\section{1. 4. Konstantin und das Kapitol}

Die Quellen für Konstantins vieldiskutierten ${ }^{201}$ Verzicht auf den Aufstieg zum Kapitol sind nicht zahlreich. Die einzige zusammenhängende Darstellung des Ereignisses und seiner Folgen verdanken wir Zosimos, der sie in seiner zu Beginn des 6. Jh. verfassten Nea Historia niederschrieb. ${ }^{202}$ Nach seinem Sieg über Licinius habe, so Zosimos, Konstantin seine natürliche Boshaftigkeit und Willkür nicht länger verborgen. In Rom angelangt, ermordet er zunächst Crispus und Fausta und erbittet sich daraufhin, von Gewissensbissen gepeinigt, Hilfe von den paganen Priestern, die ihn durch Opfer von seiner Schuld entsühnen sollen. Auf ihre abschlägige Antwort hin wendet Konstantin sich einem „Ägypter aus Spanien“ zu, der bei den Hofdamen Einfluss gewonnen hat und dem Kaiser verkündet, dass die Hinwendung zum Christentum ihn von aller Schuld reinigen könne. Konstantin kehrt sich daraufhin von den traditionellen Riten $\mathrm{ab}$, insbesondere verbietet er die Divination

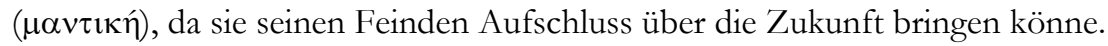

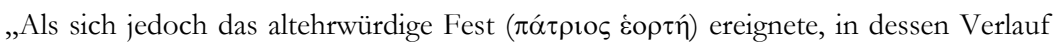
das Heer zum Kapitol hinaufsteigen und die traditionellen Riten erfüllen musste, da bekam Konstantin Angst vor den Soldaten und beteiligte sich an der Feierlichkeit. Als ihm aber der Ägypter eine Erscheinung sandte, die den Aufstieg zum Kapitol brüsk schmähte, entfernte er sich von der heiligen Handlung und erregte so den Hass des Senates wie des Volkes gegen sich“. 203

201 An wichtigsten Arbeiten sind zu nennen Straub 1955 (grundlegend); Paschoud 1971, der danach die Frage in Auseinandersetzung mit den Kritikern seiner Thesen mehrfach wieder aufgegriffen hat (ders. 1993, 1997, zuletzt im Kommentar zur zweiten Auflage seiner Budé-Edition von Zosimos' Nea Historia [Paris 2000, S. 234-240]); Wiemer 1994, bes. 480-493; Fowden 1994, 163-168; Girardet 1998, 30-36; Fraschetti 1999, bes. 9-31, 76-108; Curran 2000, $71-75$ (doxographisch).

202 Zos. 2, 29; zur Abfassungszeit vgl. Paschoud (2000), in: Zosimos, Bd. 1, vii-xx.

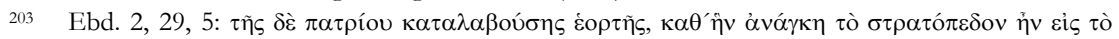

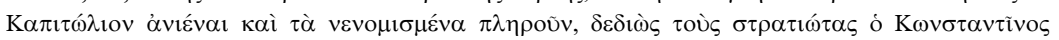

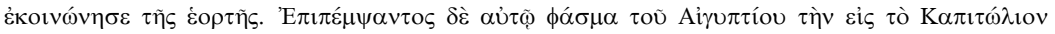

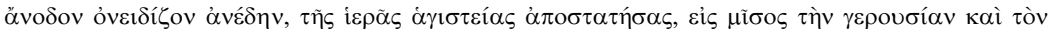
$\delta \tilde{\eta} \mu \mathrm{ov} \alpha \dot{\alpha} \varepsilon \dot{\sigma \tau \eta \sigma \varepsilon v . ~}$ 
Diese Ereignisse bilden den Anlass für die Gründung einer neuen Hauptstadt: Konstantin verlässt Rom und findet nach längerem Suchen in Konstantinopel eine Stadt, die ein „Gegengewicht“ zu Rom bilden soll und durch ein entsprechendes Bauprogramm dazu bestimmt wird, an die Stelle des alten caput imperii zu treten. ${ }^{204}$

Um die symbolische Bedeutung zu erfassen, die der kaiserliche Verzicht darauf, das Kapitol zu besteigen und dort ein Opfer zu vollziehen, hatte, empfiehlt es sich, von vornherein zwei Fragen klar voneinander trennen: zum einen, wann Konstantin auf den rituellen Aufstieg zum Kapitol verzichtete und zum anderen, welche Deutung sein Handeln durch welche Gruppen zu welcher Zeit erfuhr.

Zunächst zur Rekonstruktion der Handlungsebene: Obwohl Zosimos bzw. sein Gewährsmann Eunap, dessen Historien Zosimos hier ausschrieb, ${ }^{205}$ die oben wiedergegebene Episode unmittelbar an die Niederlage und Beseitigung des Licinius von 324/325 anschließt, können sich die Ereignisse unmöglich in der von Zosimos dargestellten Weise während Konstantins letztem Rombesuch im Juli 326 abgespielt haben. ${ }^{206}$ So wurde Crispus zwar im Jahr 326, jedoch nicht in Rom, sondern in Pola ermordet; 207 mit dem Verbot der unter dem Begriff der $\mu \alpha \nu \tau \iota \kappa ́$ bezeichneten Haruspizin sind zwei Gesetze gemeint, die Konstantin bereits in den Jahren 319 gegen den privaten Gebrauch der Haruspizin erlassen hatte; ${ }^{208}$ die im Anschluss an das Kapitel ausgeführte Entscheidung zur Gründung Konstantinopels schließlich fiel be-

\footnotetext{
204 Ebd. 2, 30f.

205 Zur Quellenfrage vgl. u., Anm. 247.

$206 \mathrm{Zu}$ den chronologischen Ungereimtheiten des Berichts vgl. vor allem Paschoud 1971, 342-344; dens. 1993, $742 \mathrm{f}$.

207 Marasco 1993, 300.

208 CTh 9, 16, 5, 1 u. 2. Wiemer 1994, 484f. bezweifelt, dass diese Gesetze, die sich an einen römischen Adressatenkreis richteten, Zosimos bzw. der Tradition, auf die er rekurrierte, bekannt gewesen seien, und führt Eus., v. C. 2, 45, 1 als Gewährsmann dafür an, dass man im griechischen Osten ein gesetzliches Verbot der „Mantik“ und der „geheimen Künste“ erst mit der Zeit nach Konstantins Sieg über Licinius assoziierte. Doch zeigt der Kontext der Passage in Zos. 2, 29, 5,

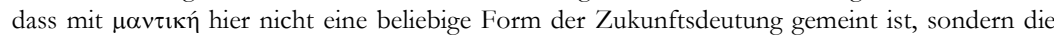
divinatio, die von Auguren und Haruspices ausgeübt wird (zur Terminologie vgl. auch Cass. Dio 52, 36, 3). Bei Zosimos wird vermutlich spezifisch auf die römische Haruspizin angespielt, da die Episode auf dem Kapitol angesiedelt ist (zur Verbindung von Haruspizin und Kapitol vgl. auch Zos. 5, 41, 1-3). Dies passt gut zu den beiden oben erwähnten Gesetzen, die an den römischen Stadtpräfekten bzw. den populus (wohl zu ergänzen: Romanus, trotz der Einwände von Noethlichs 1971, 241, Anm. 129, da auch ein weiteres, die vorigen Maßnahmen zur Haruspizin präzisierendes Gesetz CTh 16, 10, 1 an den römischen Stadtpräfekten gerichtet ist) adressiert waren, während die Bemerkung bei Eusebius v. Caesarea in dieser Hinsicht alles andere als eindeutig ist: Ein Gesetz, auf das sich Eusebius bezieht, ist nicht erhalten und in seiner Historizität stark umstritten (vgl. Bradbury 1994). Libanios, or. 30, 6 sagt explizit, dass Konstantin nach seinem Sieg über Licinius zwar die Tempelschätze zum Bau Konstantinopels verwendet, den Kult selbst jedoch in keiner Weise verändert habe.
} 
reits im November 324, unmittelbar nach dem bei Byzanz errungenen Sieg über Licinius. Bemerkenswert ist ferner auch der Hinweis auf den „Ägypter“ spanischer Provenienz, der sich dem kaiserlichen Hof annäherte und in dem die meisten Forscher wohl zurecht den Bischof Ossius von Corduba erkennen. ${ }^{209}$ Dem Bericht des Zosimos lässt sich entnehmen, dass anlässlich der geschilderten Ereignisse die erste Begegnung Konstantins mit dem „Ägypter“ Ossius erfolgte. Nun gibt es überzeugende Hinweise darauf, dass Ossius bereits im Winter 312/313 Konstantin so nahe stand, dass er ihn im Donatistenstreit als Vertrauensmann bei der Verteilung von Geldern an die Katholiken in Nordafrika einsetzte. ${ }^{210}$ Sollte der bei Zosimos fassbaren Überlieferung ein historischer Kern zugrundeliegen, dann kann die erste Kontaktaufnahme und Beeinflussung des Kaisers durch den spanischen Bischof nur im Zusammenhang mit Konstantins erstem Romaufenthalt stehen, der sich nach dem Sieg über Maxentius im Oktober 312 bis zum 6. Januar des folgenden Jahres erstreckte. ${ }^{211}$

Es darf nach dem Gesagten zunächst als eine begründete Hypothese festgehalten werden, dass Zosimos/Eunap mehrere, zeitlich zum Teil weit auseinanderliegende Ereignisse miteinander verband, offensichtlich in dem Bestreben, unterschiedliche Sachverhalte oder Traditionen, die mit der Bekehrung Konstantins in Verbindung gebracht wurden, zu einer paganen Version der conversio Constantini zu synthetisieren. Während die Verbindung mit der Ermordung von Crispus und Fausta eine Datierung der Ereignisse in das Jahr 326 und eine Verbindung mit Konstantins dritten und letzten Rombesuch anlässlich seiner Vicennalien nahelegt, sprechen die Anspielungen auf Ossius von Corduba eher für die Zeit unmittelbar nach dem Sieg über Maxentius. Für eine Entscheidung zwischen beiden Alternativen liefert der Text selbst zunächst keine weitere Handhabe; man ist daher auf flankierende Hinweise aus der sonstigen Überlieferung angewiesen.

Obwohl Hans-Ulrich Wiemer zuletzt erneut gewichtige Gründe dafür angeführt hat, die bei Zosimos/Eunap überlieferten Ereignisse in das Jahr 326

209 Vgl. das übereinstimmende Urteil von Straub 1955, 303; Paschoud 1971, 342f.; Aiello 1992, 29; Fraschetti 1999, 90. Zurückhaltend Lippold 1981; Wiemer 1994, 485.

210 Eus., h. e. 10, 6, 2; zur Datierung des Schreibens vgl. Barnes 1982, 240. Lippold 1981, bes. 5-7 bezweifelt, dass der in diesem Brief genannte Hosios mit Ossius von Corduba identisch ist, doch da eine Funktion des spanischen Bischofs als Berater des Kaisers in der frühen Phase des Donatistenstreites auch anderweitig bezeugt ist, erscheint diese Skepsis übertrieben.

211 Vgl. Barnes 1982, 95 u. 71. Für Konstantin lassen sich überhaupt nur drei Aufenthalte in Rom sicher nachweisen: nach dem Sieg über Maxentius suchte Konstantin die Stadt nur noch anlässlich der Regierungsjubiläen zu seinem dies imperii am 25. Juli auf (die Decennalien im Jahr 315; die Vicennalien im Jahr 326). Zu den präzisen Daten der Rombesuche vgl. Barnes 1982, 72 u. 77 sowie die ausführliche Diskussion von Fraschetti 1999, 97f. u. 123f.: Der Philokaluskalender verzeichnet kaiserliche adventus am 18. und am 21. Juli, die sich jedoch keinem der beiden Jahre eindeutig zuordnen lassen; im Sommer 315 blieb der Kaiser bis zum 27. September, im Jahr 326 verließ Konstantin die Stadt vor dem 26. September. 
zu legen, da es anlässlich der Vicennalien zu schweren Differenzen zwischen Konstantin und den Römern gekommen sein muss, ${ }^{212}$ kann es als sehr wahrscheinlich gelten, dass der von Zosimos angeführte Anlass für die Auseinandersetzungen, nämlich Konstantins Weigerung, auf das Kapitol hinaufzusteigen, schon lange vor dem Jahr 326 gegeben war. ${ }^{213}$ Einen wichtigen Hinweis darauf liefert der anonyme, vermutlich im Jahr 313 auf Konstantin gehaltene Panegyricus, in dem der Panegyriker die Ereignisse des Oktobers 312 Revue passieren ließ. Trotz einer ausführlichen Schilderung von Konstantins Einzug nach der Schlacht an der Milvischen Brücke ist in dem Panegyricus von einem Gang Konstantins auf das Kapitol nicht die Rede. ${ }^{214}$ Da der Opfergang zum Kapitol nicht nur ein traditioneller Bestandteil kaiserlicher Einzüge in Rom war, sondern insbesondere auch in den spätantiken Panegyrici als Topos kaiserlicher Rombesuche erscheint, hat man dieser „Darstellungslücke“ in der Forschung zurecht eine hohe Bedeutung zugemessen. ${ }^{215}$ Entsprechendes gilt auch für den Konstantinsbogen, der anlässlich der Decennalien von 315 geweiht wurde. In der Reihe von Reliefs, die in chronologischer Reihenfolge unterschiedliche Stationen von Konstantins Sieg über Maxentius kommemorieren, taucht ein kapitolinisches Opfer des Kaisers nicht auf. ${ }^{216}$ Ähnlich wie bei dem Panegyricus kommt auch hier dem argumentum e silentio insofern Bedeutung zu, als die Erbauer des Konstantinsbogens für die Reliefs in der Attika auf ein Monument aus der Zeit Mark Aurels zurückgriffen, das u. a. eine Darstellung enthielt, die den Kaiser beim Opfer für den kapitolinischen Iuppiter zeigte, bei der Auswahl der Bauspolien für den Konstantinsbogen je-

\footnotetext{
212 Wiemer 1994, bes. 469-479.

213 Vgl. zum folgenden Straub 1955, der erstmals auf diese Zusammenhänge aufmerksam gemacht hat. Straubs Position wurde zuletzt übernommen von Girardet 1998, 30-36; Brandt 2006, 47.

214 Pan. lat. 12 (9) 19, 3. Zur Datierung des Panegyricus vgl. Nixon/Rodgers 1994, 289f.

215 Vgl. die umfassende Zusammenstellung der Belege bei Straub 1955, 299-301, der auch deutlich macht, dass die Frage, ob es sich beim Einzug vom 29. 10. 312 formal um einen Triumph oder um einen adventus handelte, für den kapitolinischen Opfergang unerheblich ist: Der Gang auf das Kapitol gehörte in beiden Fällen zum protokollarischen Einzug des Kaisers. Die Einwände von Nixon/Rodgers 1994, 323f., Anm. 119, dass ein Panegyricus keine mimetische Reproduktion historischer Ereignisse darstelle und es daher nicht sinnvoll erscheine, ein nicht berichtetes Ereignis für unhistorisch zu erklären, verfangen nicht, da Straub auf der Ebene von Gattungskonventionen argumentiert. Zurecht fasst daher auch Fraschetti 1999, 19-31 („dossier su un silenzio") die Nichterwähnung von Opferhandlungen durch den Panegyriker von 313, der sich ein ähnliches Vorgehen des Nazarius in seinem 321 verfassten Panegyricus auf die Dezennalien Konstantins zur Seite stellen lässt, als ein absichtsvolles Verschweigen auf.

216 Dargestellt ist der ingressus Augusti auf der via Flaminia zwischen der porta Flaminia und dem Elephantenbogen Domitians im Bereich des nördlichen Marsfeldes (L’Orange/v. Gerkan 1939, 72-80): Im Zug erscheinen keine Opfertiere; auch die Abbildung eines abschließenden Opfer für den kapitolinischen Iuppiter fehlt. Die anschließenden Reliefs setzen erst wieder mit der Ansprache des Augustus an den populus Romanus, die der Kaiser von den augusteischen Rostren des Forum Romanum aus hält, ein (L'Orange/v. Gerkan 1939, 80-89).
} 
doch bezeichnenderweise nicht berücksichtigt wurde: ${ }^{217}$ Während der Kaiser auf den hadrianischen und aurelischen Reliefs, die für den Konstantinsbogen verwendet wurden, durchaus als Opfernder abgebildet war, wurde mit Blick auf das kapitolinische Opfer des Kaisers offenbar ganz bewusst darauf verzichtet, dieses Element in das Bildprogramm des Konstantinsbogens aufzunehmen, obwohl die Darstellung des Opfers für Iuppiter Capitolinus ein gängiges Motiv in der Darstellung historischer Kaiserreliefs war. ${ }^{218}$

Johannes Straub hat daraus den Schluss gezogen, dass Konstantin bereits bei seinem Einzug am 29. Oktober 312 auf das kapitolinische Opfer verzichtet habe. Vorsichtiger bewertet Augusto Fraschetti den Quellenbefund, indem er präzisiert, dass Konstantin bereits im Jahr 313 nicht mehr daran interessiert gewesen sei, von seinem Panegyriker mit einem Gang auf das Kapitol konfrontiert zu werden. ${ }^{219}$ Ein Verzicht auf das Opfer für Iuppiter Capitolinus im Oktober 312 ist für Fraschetti nach dieser Deutung nicht zwingend: Konstantin könnte während seines ersten Aufenthaltes in Rom diese symbolträchtige Handlung noch durchgeführt und erst nachträglich, aufgrund einer zwischenzeitlich erfolgten Annäherung an das Christentum, diesen Akt als problematisch empfunden und ihn dann bei nächster Gelegenheit, anlässlich der Decennalien im Sommer 315, ausgelassen haben. ${ }^{220}$ Diese Interpretation bietet zwar eine differenziertere Interpretation der Quellenlage, erscheint jedoch ein wenig gezwungen, da sie voraussetzt, dass der Panegyriker des Jahres 313 gleichsam prospektiv die kaiserliche Haltung gegenüber dem kapitolinischen Opfer richtig einschätzte, obwohl Konstantin selbst durch sein Handeln dazu noch gar keine Veranlassung gegeben hatte, da er ja nach dem Sieg über Maxentius noch das übliche Opfer vollzogen haben soll. Man wird daher davon ausgehen müssen, dass Konstantin bereits während seines ersten Romaufenthalts auf ein Opfer für Iuppiter Capitolinus verzichtet hatte, und dass dem Panegyriker dieser Umstand bekannt war. Damit ist jedoch noch nicht geklärt, unter welchen genauen Umständen Konstantins Opferverzicht im Jahr 312/313 erfolgte.

Die Darstellung des Zosimos hat ein Detail bewahrt, das in dieser Hinsicht näheren Aufschluss verspricht. Es war bereits davon die Rede, dass Zosimos/Eunap für seine Darstellung der conversio Constantini auf engstem Raum Ereignisse unterschiedlicher zeitlicher Provenienz zu einer geschlossenen Darstellung zusammenzog. Auch die Vorgänge, die das Kapitel II 29 be-

\footnotetext{
217 Dies hat erstmals Ruysschaert 1962-1963, 97f. als eine signifikante Auslassung gedeutet; zustimmend Mayer 2002, 201; ähnlich Girardet 1998, 32, Anm. 86.

218 Vgl. zuletzt - mit ausführlicher Literaturdiskussion - Fraschetti 1999, $26 \mathrm{f}$.

219 Fraschetti 1999, 19-31; ähnlich auch schon Paschoud 1971, $351 \mathrm{f}$.

220 Fraschetti 1999, 31; Fraschetti verbindet allerdings den von Zosimos berichteten Konflikt, der um das Auslassen des kapitolinischen Opfers entstand, erst mit dem Rombesuch Konstantins im Jahr 326 (ebd., 87-96).
} 
schließen, deuten auf derartige chronologische Verkürzungen hin: Dass Konstantin im Rahmen einer einzigen Zeremonie zunächst an dem ,,altehrwürdigen Fest“ mit dem Gang auf das Kapitol teilnahm, um sich dann aufgrund einer religiösen Vision des „Ägypters“ während der Handlung zu entfernen und damit die übrigen Beteiligten zu brüskieren, ist in der Realität schlicht nicht vorstellbar. ${ }^{221}$ Man könnte allenfalls an eine Sequenz unterschiedlicher Handlungen und Orte denken, etwa in dem Sinne, dass Konstantin nur den Beginn der Feier mitmachte, sich dann aber nicht dem Gang auf das Kapitol und dem damit verbundenen Opfer anschloss, ${ }^{222}$ beziehungsweise dass das Fest sich über mehrere Tage erstreckte, und der Kaiser an einem der folgenden Tage nicht auf das Kapitol hinaufzog. ${ }^{223}$ Der Bericht des Zosimos legt jedoch nahe, an zwei getrennte Feste zu denken, die sich in ihrem Charakter grundsätzlich voneinander unterschieden. Darauf deutet vor allem der Wechsel der am Geschehen beteiligten Gruppen hin: Der Kaiser nimmt zwar aus Furcht vor dem Heer an der Zeremonie teil, erregt dann jedoch, als er sich der heiligen Handlung enthält, nicht etwa den Hass der Soldaten, sondern den

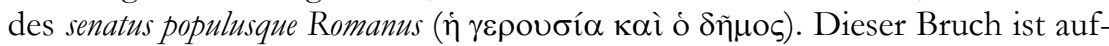
fällig, und er kann wohl nur auf eine Kombination zweier Ereignisse zurückgeführt werden, die sich nicht nur zeitlich, sondern auch in ihren Bezugsgruppen voneinander unterschieden, und die Zosimos/Eunap zu einer Handlungssequenz zusammengezogen und durch die Vision des Ägypters miteinander verbunden hat. ${ }^{224}$

Ausgehend von dieser Beobachtung hat François Paschoud hinter der Darstellung des Zosimos zwischen zwei unterschiedlichen Festen unterschieden und sie mit dem adventus Konstantins vom Oktober 312 (bei dem Kon-

221 Paschoud 1993, 745 macht auch sprachliche Gründe gegen eine derartige Möglichkeit geltend, die allerdings nicht überzeugen, vgl. die berechtigte Kritik von Wiemer 1994, 481f., Anm. 54; G. Weber 2000, 351, Anm. 225.

222 Als theoretische Möglichkeit erwogen von Paschoud 1971, 349.

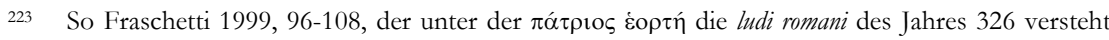
und zwischen deren Eröffnung am 12. September und dem am Tag darauf stattfindenden epulum Iovis, das mit dem dies natalis des kapitolinischen Tempels verbunden war, unterscheidet. Offen bleibt allerdings, warum man die ludi romani als ein Fest bezeichnen sollte, ,in dessen Verlauf“, wie Zosimos schreibt, „das Heer zum Kapitol hinaufsteigen musste“: Obwohl die Wehrhaftigkeit der römischen Jugend demonstriert wurde, nahm das Heer an dieser pompa circensis nicht teil (zur Darstellung der pompa bei Dionysios v. Halikarnass vgl. Bernstein 1998, 254-268). Fraschettis Aufnahme des Mommsenschen Diktums von der pompa circensis als „Triumphalprocession ohne Triumph“ (Fraschetti 1999, 103 u. Mommsen 1879, 45) ist demnach gegenstandslos: Es bezeichnet nichts anderes als Mommsens Theorie, wonach die pompa circensis - wegen ihres Ausgangs vom Kapitol - ursprünglich ein zweiter Teil des römischen Triumphzuges gewesen sei, von dem sie sich dann später gelöst habe: Die „Triumphalprocession ohne Triumph" ist ein historischer Erklärungsversuch, keine Aussage über einen militärischen Charakter der pompa circensis.

224 Der Unterschied zwischen den Akteuren, der auf eine militärische und auf eine zivile Feier verweist, wird auch von Paschoud 1993, 745f. hervorgehoben. 
stantin das Kapitol hinaufgestiegen sei) und den Decennalien des Jahres 315 (an denen Konstantin das kapitolinische Opfer ausgelassen habe) gleichgesetzt. $^{225}$ Dies berührt sich eng mit der oben skizzierten Auffassung von Fraschetti226 - und begegnet ähnlichen Problemen: Sowohl der Panegyriker von 313 als auch die Auftraggeber des Konstantinsbogens hätten nach dieser Deutung im vorhinein auf ein potentielles kaiserliches Handeln schließen müssen, einen Opferverzicht, den der Kaiser dann erst bei den Decennalien in die Tat umsetzte. Aus diesen Gründen erscheint eine andere Interpretation naheliegender, die am ehesten geeignet ist, die unterschiedlichen Indizien zu einem kohärenten Bild zu verbinden. Zur Erinnerung: In der Darstellung des Zosimos wird der Unterschied zwischen einer altehrwürdigen Feier, bei der das Heer auf das Kapitol gehen musste, und einer (zivilen) Zeremonie, bei der Konstantin durch sein Fernbleiben vom Kapitol den Senat und das Volk Roms brüskierte, greifbar. Unter den regulären Festen des römischen Kalenders lässt sich für die Zeiten, zu denen sich Konstantin in Rom befand, keines anführen, das einen spezifisch militärischen Charakter gehabt hätte. ${ }^{227}$ Man geht daher kaum fehl in der Annahme, dass mit dem ersten Fest, auf das Zosimos anspielt, ein Triumph oder ein kaiserlicher adventus, in dessen Inszenierung bereits seit dem 3. Jh. die Grenzen zu einem formalen Triumph zu verwischen begannen, gemeint ist: Nur bei dieser Gelegenheit trat der von Zosimos betonte militärische Charakter der Akteure klar zutage, und gleichzeitig verfügte der römische Triumph über eine hinreichende Tradition, um als „altehrwürdiges Fest“" bezeichnet zu werden. ${ }^{228}$

Umgekehrt lassen die Reaktionen des senatus populusque Romanus auf den kaiserlichen Opferverzicht an ein Fest denken, das in besonderer Weise auf die Stadt und die res publica bezogen war. Unter den Festen des römischen Kalenders, die diese Voraussetzung erfüllen, ragen an Bedeutung die Feiern

225 Paschoud 1971, 350. Zuletzt hat Paschoud diese Auffassung allerdings modifiziert und die Decennalien von 315 und die Vicennalien des Jahres 326 als Daten für die beiden Feste in Erwägung gezogen (vgl. dens. 1997, 28).

226 Die beiden Positionen unterscheiden sich einzig darin, dass nach Paschoud der bei Zosimos berichtete Eklat anlässlich der Decennalien stattfand, während Fraschetti diese Auseinandersetzung in das Jahr 326 legt.

227 Die ältere Forschung (vgl. die Nachweise bei Fraschetti 1999, 94) dachte an die transvectio equitum, die auch noch im 4. Jh. am 15. Juli stattfand (vgl. den Chronographen von 354 [Inscr. Ital. XIII, 2, 251]: equit(um) Ro(manorum) prob(atio). Konstantin aber befand sich bei keinem seiner drei Rombesuche an einem 15. Juli in der Stadt.

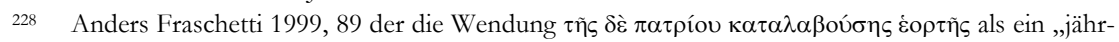
lich wiederkehrendes vaterländisches Fest“ des regulären stadtrömischen Kalenders versteht; aus rein formalen sprachlichen Gründen ist diese Auffassung möglich (wenn auch keinesfalls zwingend; vgl. Paschoud 1993, 738f.); inhaltlich kann sie nicht überzeugen. Wiemer 1994, 486 bezieht

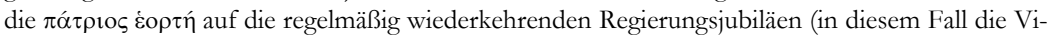
cennalien des Jahres 326); doch scheint das Adjektiv $\pi \alpha ́ \tau \rho ı \varsigma \varsigma$ auf einen Traditionszusammenhang zu verweisen, der über die Regierungszeit eines Kaisers hinausreicht. 
zur Eröffnung des römischen Jahres hervor. Bekanntlich war es die Aufgabe der Konsuln, die vota pro salute rei publicae im kapitolinischen Iuppitertempel durch Opfer zu vollziehen, ${ }^{229}$ ein Ritual, das auch in spätantiken Quellen hinreichend belegt ist. 230 Im Januar 313 fiel diese - aus seiner Sicht möglicherweise bereits fragwürdig gewordene - „Ehre“ dem Kaiser Konstantin selbst zu, der für das Jahr 313 zusammen mit Licinius den Konsulat bekleidete und sich noch mindestens bis zum 6. Januar in Rom aufhielt. ${ }^{231}$ Den von Zosimos berichteten Opferverzicht mit diesem Anlass in Verbindung zu bringen, erfährt Unterstützung durch eine Nachricht der Elagabalvita der Historia Augusta, nach der Elagabal sich am 1. Januar 222 weigerte, auf das Kapitol zu gehen, um dort die vota auszusprechen und die Feierlichkeiten - gemeint sind die Opfer - durchzuführen, und sich dabei stattdessen durch den praetor urbanus vertreten ließ, ,als wenn gar keine Konsuln anwesend gewesen wären", wie der Verfasser der Vita maliziös bemerkt. $^{232}$ Ebenso wie bei zahlreichen weiteren Stellen der Elagabalvita hat man auch hinter dieser Passage eine polemische Bezugnahme auf Konstantin vermutet, mit der der Verfasser auf das unterbliebene Opfer des Kaisers für den kapitolinischen Iuppiter angespielt habe. ${ }^{233}$ Möglicherweise spiegelt sich in der Elagabalvita jedoch nicht nur die grundsätzliche Kritik an Konstantins Verhalten, sondern mit den Januarkalenden auch der konkrete Anlass wider, bei dem Konstantin erstmals den Gang auf das Kapitol unterließ.

Folgt man dieser Interpretation, dann stand Konstantins adventus am 29. Oktober 312 ganz in der Tradition der kaiserlichen Einzüge in Rom, einbegriffen auch den Zug auf das Kapitol und das dort stattfindende Opfer. Erst in der darauffolgenden Zeit setzte sich beim Kaiser die Auffassung durch, dass dieses Opfer für den kapitolinischen Iuppiter mit den christlichen Vorbehalten nicht in Einklang zu bringen war. Dass daran christliche Berater wie Ossius von Corduba einen maßgeblichen Anteil hatten, wie es der Bericht des Zosimos nahelegt, liegt durchaus im Bereich des Möglichen. Ihren sichtbaren Ausdruck fand diese Auffassung erstmals anlässlich der Jahreseröffnung von

229 Zur Entwicklung der republikanischen vota pro salute rei publicae in der Kaiserzeit vgl. Scheid 1990, 298-309, der von einer Zweiteilung (mit Opfern verbundene solutio der alten vota am 1. Januar; Ankündigung (nuncupatio) der neuen vota am 3. Januar) ausgeht.

230 Vgl. z. B. Hist. Aug., Pert. 9, 4; Tert., coron. 12.

231 S. o., Anm. 211.

232 Hist. Aug., Heliog. 15, 7: in Capitolium ad vota concipienda et perficienda sollemnia ire noluit, omniaque per praetorem urbanum facta sunt, quasi consules illic non essent.

233 Vgl. Cracco Ruggini 1991, bes. 136-140; Lizzi Testa 2004 (a), 409. Zu weiteren Anspielungen der Elagabalvita auf Konstantin vgl. Turcan 1988; Fowden 1991, bes. 119-122 und o., Anm. 151. Fraschetti 1999, 36 ist hingegen der Auffassung, dass der Elagabalepisode ein historischer Kern zugrundeliegt. Sie befindet sich zwar in der Tat in einem Abschnitt der Vita, den Turcan als „le seul noyeau historiographique de la Vita Heliogabali" bezeichnet (Turcan [1993], in: Histoire Auguste III, 1, 64f.); dennoch wird sie von ihm als sekundärer Einschub bewertet (ebd., 71). 
313, bei der Konstantin auf die persönliche Erfüllung der konsularischen vota verzichtete und damit beim Senat und Volk Anstoß erregte. Der Panegyriker von 313 und ebenso die mit der Konzeption des Konstantinsbogens befassten Personen waren von dieser Entwicklung unterrichtet und sparten den Gang auf das Kapitol bzw. eine mit dem kapitolinischen Iuppiter verbundene Opferszene deshalb rückwirkend auch aus ihrer Darstellung des adventus von 312 aus.

Diese Rekonstruktion der Ereignisse bietet nicht nur die größtmögliche Übereinstimmung mit den verfügbaren Quellennachrichten, sondern erscheint auch mit Blick auf den historischen Kontext unmittelbar plausibel. Konstantins Einzug in die Stadt schloss sich unmittelbar an seinen militärischen Erfolg über Maxentius an. In dieser Situation erwarteten die Soldaten, die Konstantin angeführt hatte, von ihrem Feldherrn die Feier ihres gerade eben erst errungenen Sieges, die im Gang auf das Kapitol ihren Höhepunkt und symbolischen Abschluss fand. Auf seiten der römischen Bevölkerung und des Senats dürfte vor allem Unsicherheit über das Verhalten des Kaisers gegenüber der Stadt, die seinen Rivalen Maxentius über mehrere Jahre unterstützt hatte, vorgeherrscht haben. In dieser prekären und ungeklärten Lage empfahlen sich keine Experimente: Gefragt war ein stabiler und bekannter Kommunikationsrahmen, der den Römern die Möglichkeit gab, durch ihre Teilnahme am Opfer den Dank für die Götter und damit ihre Loyalität gegenüber dem siegreichen Kaiser und neuen Herren Roms unter Beweis zu stellen. Indem Konstantin im Jahr 312 an seinen Einzug den traditionellen Gang auf das Kapitol anschloss, tat er nur das, was alle relevanten Gruppen in diesem Moment von ihm erwarteten. ${ }^{234}$ Erst später - und möglicherweise erst ausgelöst durch Reaktionen von Christen auf sein Handeln vom Oktober

234 Dass Konstantin aus rein pragmatischen Gründen wegen der kurzen Vorbereitungszeit am Tag nach der Schlacht an der milvischen Brücke auf das kapitolinische Opfer verzichten musste und es erst im Jahr 315 im Rahmen eines regulären Triumphes nachholte (so Chastagnol 1987, 504; auch Kuhoff 1991, 165 macht den ,improvisatorischen Charakter“ von Konstantins Einzug als Grund für den Wegfall des Opfers geltend), ist nicht überzeugend: Abgesehen davon, dass Konstantin auch im Jahr 315 keinen regulären Triumph feierte, müssen im Oktober 312 umfassende Vorbereitungen für Opferfeiern bereits von Maxentius getroffen worden sein, da er am 28. 10. 312 den sechsten Jahrestag seines Herrschaftsantritts feierte (pan. lat. 12 [9] 16, 2) und die bereits begonnenen Feierlichkeiten unterbrach, um gegen Konstantin in die Schlacht zu ziehen (Lakt., de mort. 44, 7). Auch das Argument von Bleicken 1992, 34f., der Ingressus Konstantins am 29. Oktober 312 sei kein Triumph, sondern ein adventus gewesen, und Konstantin habe aus diesem Grund auf das kapitolinische Opfer verzichten müssen (ebenso Brandt 2006, 46f.), verfängt nicht. Straub 1955, 299-301 und Fraschetti 1999 (a), 237f. liefern genügend Belege dafür, dass auch nach Bürgerkriegen und bei kaiserlichen Einzügen, die im technischen Sinne keine Triumphe waren, der Gang auf das Kapitol den üblichen Abschluss eines kaiserlichen adventus bildete. Der Einzug von 312 war in der Tat im formalen Sinne kein Triumph, dies äußerte sich jedoch nicht in einem ausbleibenden Opfer, sondern vor allem darin, dass - abgesehen vom Kopf des Maxentius, der dem Zug vorangetragen wurde (vgl. pan. lat. 12 [9] 18, 3) - keine römischen Bürger als Besiegte im Zug des Kaisers mitgeführt wurden. 
312 - konnte Konstantin die Möglichkeit in Betracht ziehen, auf die zeremonielle Bedeutung des Kapitols für die Kommunikation im städtischen Kontext zu verzichten.

Mit den Motiven, die zu Konstantins Verzicht auf das kapitolinische Opfer führten, ist die Rekonstruktion der Handlungsebene bereits verlassen und die komplexere Frage nach der Semantik, die mit diesem Akt verbunden war, berührt. Wie wurde Konstantins Schritt wahrgenommen und bewertet? Welche Gruppenzugehörigkeiten und Identitätskonstruktionen wurden durch ihn berührt? Und zu welchem Zeitpunkt machten diese sich in Form von Reaktionen auf das kaiserliche Verhalten und Deutungen von Konstantins Handeln bemerkbar?

In der Forschung besteht eine nahezu einhellige Tendenz, das historische Handeln Konstantins und die Reaktionen, die es auslöste, entlang der Linien zu interpretieren, die Zosimos - beziehungsweise die Tradition, der er folgt vorgibt: Der Kaiser habe mit diesem Verhalten eine signalhafte Abwendung von den paganen Kulten vollzogen, die auf seiten der überwiegend nichtchristlichen Bevölkerung Roms Unverständnis und Ablehnung ausgelöst und zur Abwendung des Kaisers vom alten caput imperii maßgeblich beigetragen habe. Eine derartige Sichtweise setzt freilich voraus, dass der Kaiser erstmals während seines letzten Rombesuchs im Jahr 326 das kapitolinische Opfer unterließ. ${ }^{235}$ Geht man indessen davon aus, dass dieser Schritt bereits Anfang 313 erfolgte, relativiert dies die Semantik des unterlassenen Kapitolgangs erheblich: Die heftige Reaktion der stadtrömischen Bevölkerung auf das kaiserliche Verhalten kann in diesem Fall nicht in der Weise, wie Zosimos/Eunap es darstellt, im Jahr 313 erfolgt sein, da in der weiteren historischen Entwicklung nach 313 nichts auf eine gestörte Kommunikation zwischen dem Kaiser und dem Zentrum des Reichs hindeutet. ${ }^{236}$

235 Alföldi 1948, 62, 101-103; Chastagnol 1987, 504; Wiemer 1994, bes. 489f.

236 Dieser Umstand ist von der Forschung nicht oder nur unzureichend berücksichtigt worden. Straub 1955 betont zwar, dass es sich beim Opferverzicht Konstantins, den er auf den 29. Oktober 312 legt, um ein „epochales Ereignis“ gehandelt habe, diskutiert jedoch nicht, warum dessen Folgen erst wesentlich später fassbar wurden. Paschoud unternimmt einen wenig überzeugenden Spagat zwischen Konstantins Romaufenthalten in den Jahren 312 und 326, indem er die von Zosimos berichteten Reaktionen des senatus populusque Romanus auf den - kurz nach 312 gefassten und 315 in die Tat umgesetzten - Entschluss Konstantins für historisch hält, es jedoch erst nach einer noch weiteren Verschärfung 326 zu einem endgültigen Bruch kommen lässt (Paschoud 1971, 352; ähnlich Szidat 1985, 516). Fraschetti verknüpft mit der Entscheidung Konstantins eine wechselseitige Distanzierung zwischen dem Kaiser und der stadtrömischen Bevölkerung, die beiden Seiten bereits früh bewusst gewesen sei. Den vergleichsweise späten Ausbruch des latenten Konflikts im Jahr 326 erklärt er damit, dass unmittelbar zuvor Konstantins Verhältnis zu den Senatoren besonderen Spannungen ausgesetzt gewesen sei (die Kritik an der christenfeindlichen Haltung bestimmter Senatoren in der oratio ad sanctorum coetum; die Ernennung des Christen Acilius Severus zum Stadtpräfekten; die Feier der Vicennalien 325 in Nikomedien statt in Rom) und dass die Auslassung des kapitolinischen Opfers im Jahr 326 den Römern endgültig gezeigt habe, dass der Kaiser nicht mehr in das städtische Leben integrierbar gewesen sei (Fraschetti 
Offenkundig beschränkte sich die deutende Tätigkeit des Zosimos demnach nicht allein darauf, zeitlich weit auseinanderliegende Ereignisse zusammenzuziehen und ein Ereignis des Jahres 313 in einen zeitlichen Zusammenhang mit der conversio Constantini und der Gründung einer neuen Hauptstadt zu setzen. $^{237}$ Zosimos nahm in diesem Zusammenhang auch eine semantische Umdeutung des Ereignisses von 313 vor: Was sich in der historischen Situation von 313 nach allem, was über das weitere Verhältnis Konstantins zu Rom bekannt ist, nicht als konfliktträchtig erwies, ${ }^{238}$ wurde erst im nachhinein $\mathrm{zu}$ einem symbolischen Bruch des Kaisers mit den paganen Kulten und mit der alten Hauptstadt Rom umgedeutet.

Bevor die Genese dieser nachträglichen Umdeutung näher bestimmt werden soll, erscheint es sinnvoll, zunächst die historische Situation von 312/313 in den Blick zu nehmen und sich zu verdeutlichen, wie das Handeln Konstantins aus unterschiedlichen Perspektiven wahrgenommen wurde. Es kann kein Zweifel bestehen, dass die Entscheidung des Kaisers, den Gang auf das Kapitol zu unterlassen, aus der Sicht aller beteiligten Akteure eine Signalwirkung hatte. Aus christlicher Perspektive war das Kapitol ein Ort, der Abgrenzungen, Differenz- und Identitätsstiftung gegenüber der paganen Umwelt geradezu idealtypisch verkörperte. Insbesondere die stark legendarischen

1999, 76-87). Ähnlich meint auch Wiemer 1994, 490, dass erst in Verbindung mit anderen Faktoren das unterbliebene Opfer an Brisanz gewonnen habe. Die vorgebrachten Argumente sind jedoch im einzelnen skeptisch zu beurteilen: Vermutlich bezieht sich Konstantin in or. s.c. 22 nicht auf ein aktuelles „Fehlverhalten“ der Senatoren in dem gerade erst beendeten Konflikt mit Licinius, sondern auf die wesentlich länger zurückliegende Unterstützung, die Maxentius durch senatorische Kreise zuteil geworden war (so zuletzt mit überzeugenden Gründen Barnes 2001, 30f.). Ferner war mit hoher Wahrscheinlichkeit bereits einige Jahre vor Acilius Severus mit Ovinius Gallicanus (prafectus urbi 316/317; consul ordinarius 317) ein Christ mit der Übernahme der römischen Stadtpräfektur betraut worden (vgl. Champlin 1982). Dass schließlich Konstantin Rom nicht zur Eröffnung, sondern erst zum Abschluss seiner Vicennalien aufsuchte, ist nicht zwingend als ein Akt der Abwertung und Distanzierung zu interpretieren: Das Konzil von Nicaea erstreckte sich mindestens bis Mitte Juli 325 und hinderte den Kaiser schon aus rein pragmatisch-organisatorischen Gründen daran, zur Eröffnung der Vicennalien nach Rom zu kommen. Wenn Konstantin zum Ende seines zwanzigsten Regierungsjahres den obligatorischen Rombesuch pflichtschuldig nachholte, stellt sich die Frage, was höher zu bewerten ist: der „Affront“, dass der Kaiser sich aufgrund von Regierungsgeschäften im Juli 325 im Osten aufhielt, oder aber das betonte Signal der Verbundenheit mit dem caput imperii, das Konstantin zu Ende der Vicennalien setzte. Auch kann die Tatsache, dass der Kaiser aufgrund seiner Distanzierung von Opfern nicht in das städtische Festleben integrierbar war, den Römern schon lange vor 326 nicht verborgen geblieben sein (Fraschetti selbst rechnet damit, dass der Kaiser seit 315 keine Opfer in Rom mehr durchführte - und der Kaiser hielt sich im Sommer diesen Jahres volle zwei Monate in Rom auf).

237 So Straub 1955, 303.

238 Darauf weist vor allem die kaiserliche Bautätigkeit hin, die unter Konstantin keine Abwendung von der Stadt am Tiber erkennen lässt. Die angeblichen Reaktionen der Römer, die ihren „Befreier" nach dem Sieg über Maxentius mit Jubel begrüßt haben sollen, kann man freilich nicht als Argument heranziehen (so Wiemer 1994, 487); sie dürften auf das Konto einer konstantinfreundlichen Geschichtsdeutung gehen. 
Märtyrerakten der Spätantike sind voll von - zu einem nicht unerheblichen Teil bezeichnenderweise fiktiven - Kapitolen oder sacerdotes Capitolii, die den Märtyrern das Opfer abverlangen. ${ }^{239}$ Aber auch schon im 3. Jh. war der Ausdruck capitolium ascendere eine stehende Wendung der christlichen Quellen, um das pagane Götteropfer zu bezeichnen. ${ }^{240}$ Insbesondere auch für Rom selbst ist dies durch entsprechende Aussagen stadtrömischer Christen belegt. ${ }^{241} \mathrm{Im}$ Kapitol und im capitolium ascendere existierte damit bereits vor Konstantin eine - wie die weite Verbreitung der Wendung in der christlichen Literatur zeigt nachhaltige Chiffre für die Abgrenzung einer christlichen Identität von der paganen Umwelt. Unabhängig von der Frage, ob und wann es bei Konstantin zu einer inneren Hinwendung zum Christentum gekommen ist, muss diese Symbolik dem Kaiser unmittelbar eingängig gewesen sein, da sie kein tieferes Verständnis von Glaubensinhalten voraussetzte. Das Capitolium ascendere war ein klarer, jedem Christen sofort verständlicher Prüfstein dafür, ob er ein Anhänger seines Gottes war oder nicht. ${ }^{242}$

In gleicher Weise war das Kapitol auch ein fundamentales Symbol städtischer Identität: Seit den Tagen der Republik hatte das Kapitol die pietas der Römer verkörpert, die in römischem Selbstverständnis das fatum der urbs und den Weg zum römischen Imperium entscheidend bestimmt hatte. Auch in der Kaiserzeit blieb das Kapitol der Bezugspunkt einer religiös begründeten, wenn auch weniger expansiv ausgerichteten Reichskonzeption: Es war der Ort, an dem alle Kulte des Imperiums Aufnahme fanden und der damit Roms Stellung als Zentrum des Reichs unterstrich. ${ }^{243}$ Diese zentrale Bedeutung des Kapitols als Symbol römischer Identität impliziert jedoch nicht notwendig, dass sich für die Römer mit dem Kapitol in vergleichbarer Weise Identitätsdiskurse und -konstruktionen verbanden, wie es aus christlicher Perspektive der Fall war. Der wesentliche Unterschied liegt darin, dass das Kapitol - bezogen auf die stadtrömische Identität - in der Zeit vor Konstantin niemals den symbolischen Kristallisationspunkt einer Entscheidung zwischen zwei Alternativen gebildet hatte: Während sich in der christlichen Literatur des 3. Jh. der Gang auf das Kapitol geradezu zu einem Lackmustest zwischen zwei Optionen entwickelt hatte - Glaubensabfall oder Bewahrung der christlichen

239 Zu den Kapitolen in spätantiken Märtyrerakten das Dossier von Belegen bei Hermann 1954, 853f.; für das Kapitol und sacerdotes Capitolii in den gesta martyrum Romanorum vgl. Dufourcq 1900, Bd. 1, 135f.; Fraschetti 1999, 112-122, dens. 1999 (a), 239, 248.

240 Cypr., laps. 8; 24; Synode von Elvira, canon 59. Zum Kapitol als Inbegriff der paganen Kulte vgl. Tert., nat. 1, 10; apol. 13, 5; 17, 6; spect. 8, 10; insbesondere der römischen Kulte: Tert., spect. 11.

241 Cypr., epist. 8, 2 (Brief des römischen Klerus an Cyprian); epist. 21, 3 (Schreiben von römischen Confessoren an karthagische Bekenner).

242 Der zentrale Stellenwert des Symbols Kapitol für christliche Identitätsfragen zeigt sich auch darin, dass wiederaufgenommene lapsi polemisch als capitolini bezeichnet wurden (vgl. die Nachweise bei Hermann 1954, 858).

243 Zum kaiserzeitlichen Kapitol als Zentrum der Religionen des römischen Reichs vgl. u., S. 319. 
Identität -, hatte sich für die Römer bis zu Konstantin niemals die vergleichbare Frage gestellt, ob ein römischer Kaiser durch das kapitolinische Opfer seine Zugehörigkeit zu Rom unter Beweis stellen wollte oder nicht. ${ }^{244}$ Die symbolische (Be-)Deutung, die Zosimos Konstantins Handeln unterlegt, beruht jedoch auf eben einer solchen Entscheidung zwischen Alternativen: Mit seinem Verzicht darauf, das Opfer für den kapitolinischen Iuppiter vorzunehmen, signalisierte der Kaiser seine Abwendung von Rom und die Verlagerung der Hauptstadt des Imperiums in die Nea Roma am Bosporus. Dies wiederum setzt ein Wissen um die erst nach Konstantins Tod vollzogene Entwicklung Konstantinopels zu einer neuen Hauptstadt voraus, ${ }^{245}$ einen historischen Deutungshorizont, über den in konstantinischer Zeit keiner der Beteiligten - weder die Römer noch der Kaiser selbst - verfügte. ${ }^{246}$ Zosimos’ Darstellung der symbolischen Bedeutung von Konstantins Handeln - darin eingeschlossen auch die Reaktion, die die Römer auf Konstantins Verhalten an den Tag legten - trägt demnach unverkennbar die Züge einer retrospektiven Auslegung und Sinngebung der Ereignisse in sich: Sie ist Ausdruck einer historiographischen Konstruktion, die von der Perspektive der historischen Akteure klar unterschieden werden muss, und die erst nachträglich das Handeln des Kaisers zu einer identitätsrelevanten Aussage machte.

Dies führt auf die Frage nach den historiographischen Traditionen, denen Zosimos in seiner Darstellung der Ereignisse folgte, und damit auf das komplexe Gebiet der Quellenforschung zum 4. Jh. Es gilt als sicher, dass Zosimos für den Zeitraum, in den die Ereignisse des Kapitels II 29 seiner Nea Historia fallen, sich am Geschichtswerk des Eunap von Sardes orientierte, den er im wesentlichen unverändert übernommen haben dürfte. ${ }^{247}$ Weniger eindeutig

244 Anders Fraschetti 1999, 31-42, der die Ansicht äußert, dass bereits Elagabal das kapitolinische Opfer unterlassen und damit einen historischen Präzedenzfall für die Wahrnehmung von Konstantins Verhalten als eines signifikanten Akts der Abkehr von Rom und seinen religiösen Traditionen geschaffen habe. Nach Ausweis der zeitgenössischen Quellen erregte Elagabal jedoch vor allem durch seine Kleidung den Unwillen der Senatsaristokratie: Er weigerte sich sowohl beim ingressus in Rom als auch bei der Eröffnung des Jahres und der nuncupatio votorum in Nikomedien, die toga triumphalis zu tragen und bevorzugte stattdessen die auffällige syrische Priesterkleidung seines Schutzgottes aus Emesa, den er in Rom heimisch zu machen versuchte (Herodian. 5, 5, 37; Cass. Dio 79 [80], 8, 3 u. 11, 2). Die Weigerung, das Kapitol hinaufzusteigen und dort das Opfer zu vollziehen, wird nur von der Elagabalvita der Historia Augusta als Ausdruck der unrömischen Haltung Elagabals thematisiert - und eben diese Episode ist mit hoher Wahrscheinlichkeit auf das Vorbild Konstantins zurückzuführen (vgl. o., Anm. 233).

245 Vgl. dazu o., Anm. 2.

246 Für das Jahr 313, als Konstantin den Gang auf das Kapitol zum erstenmal unterließ, ist dies selbstverständlich. Doch auch im Jahr 326 war Konstantinopel noch weit davon entfernt, eine bedeutende Kaiserresidenz zu sein: Die Stadtgründung erfolgte zwar bereits 324, nach dem Sieg über Licinius, doch erst 328 wurden signifikante Erweiterungs- und Ausbaumaßnahmen in Konstantinopel vorgenommen (vgl. Alföldi 1947).

247 Von Belang ist in diesem Zusammenhang vor allem das Zeugnis des Photios, wonach Zosimos

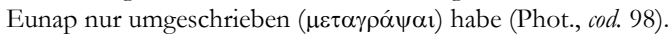


ist, woher Eunap seinerseits seine Informationen bezog. Ein Teil der Forschung vermutet, dass Eunap für seine Darstellung der mit der Bekehrung Konstantins verbundenen Ereignisse auf eine spezifisch östliche Version der conversio Constantini zurückgegriffen habe, die sich bis in die Mitte des 4. Jh. hinein, nämlich bis auf Kaiser Julian (361-363) zurückverfolgen lasse. ${ }^{248}$ Bei Julian selbst begegnet zwar nur die Vorstellung, dass Konstantin sich durch die christliche Buße von der Befleckung von Schuld habe reinigen wollen, und dass dies der Anlass für seine Bekehrung zum Christentum gewesen sei; ${ }^{249}$ das zweite zentrale Element in der Darstellung des Zosimos/Eunap, nämlich die Abkehr von Rom und die Gründung einer neuen Hauptstadt am Bosporus, wird von Julian nicht thematisiert. Nur wenige Jahre später, gegen 386, ließ jedoch Libanios in seiner Rede für die Tempel erkennen, dass sowohl die Gründung Konstantinopels nach dem Sieg über Licinius als auch die Verwandtenmorde des Jahres 326 als Schlüsselereignisse der konstantinischen Hinwendung zum Christentum angesehen wurden, auch wenn diese beiden Motivkreise von Libanios nur indirekt miteinander verbunden wurden. ${ }^{250}$ Es spricht daher nichts gegen die Annahme, dass die zentralen Versatzstücke der bei Eunap/Zosimos greifbaren Version (Alleinherrschaft nach dem Sieg über Licinius und moralische Depravierung des Kaisers; Ermordung von Crispus und Fausta; Bekehrung zum Christentum; Gründung einer neuen Hauptstadt) im Osten des Römischen Reichs schon bald nach Konstantins Tod geläufige Topoi einer konstantinkritischen Version seiner Bekehrung waren. ${ }^{251}$

Fraglich erscheint hingegen, ob dies auch für die Umstände, unter denen sich Konstantins Abkehr von Rom vollzog, zutrifft. Libanios verband seine

248 So Wiemer 1994, bes. 482, der als zentrales Argument anführt, dass die Vorstellung von einer konstantinischen Bekehrung zum Zeitpunkt nach dem Sieg Konstantins über Licinius, wie sie bei Zosimos fassbar wird, nur in östlichen Quellen begegne. Diese Vorstellung wird im Westen in der Tat erstmals in den actus Silvestri fassbar, in denen die Taufe und conversio Konstantins in die Zeit nach der Erringung der Alleinherrschaft - also in die Zeit nach dem Sieg über Licinius fallen; die Episode wird eingeleitet: Constantinus vero imperator pater augustus (var.: augustorum) monarchiam tenens... (ältere Textfassung A (1) der actus Silvestri, zit. nach Pohlkamp 1992, 156, Anm. 197).

249 Julian, Caes. 336 a und b.

250 Libanios, oratio 30, 6 erwähnt die Tempelplünderungen für die neue Hauptstadt; ebd., c. 37 präsentiert Libanios die Ermordung von Crispus und Fausta ebenso wie die dynastischen Morde nach 337 als eine Strafe der Götter für Konstantins Sakrileg. Verwandtenmord und Bekehrung zum Christentum erscheinen hier zwar in einem anderen Begründungszusammenhang als bei Eunap/Zosimos; entscheidender als die unterschiedliche kausale Verknüpfung ist jedoch die Tatsache, dass die Ereignisse von der paganen Polemik in einen Zusammenhang mit der conversio Constantini gesetzt wurden.

251 Auch Julian, oratio 7, 228 b polemisiert gegen die Plünderung der Tempel durch Konstantin, setzt diese allerdings nur zu den dynastischen Wirren nach 337 in Beziehung. Dies berührt sich jedoch so eng mit Libanios (vgl. die vorige Anm.), dass die Vermutung naheliegt, auch Julian habe die motivische Verbindung Tempelplünderungen für Konstantinopel - Ermordung von Crispus und Fausta gekannt. 
Kritik an der Gründung Konstantinopels nicht mit Konstantins Abwendung vom alten caput imperii mit seinen paganen Traditionen, sondern mit der Plünderung und Enteignung der Tempel, die zur Ausstattung und Finanzierung der neuen Kapitale dienten. ${ }^{252}$ Für einen Autor, der im östlichen Teil des Imperiums schrieb, und dem die Auswirkungen der Gründung Konstantinopels auf die regionale Sakraltopographie unmittelbar vor Augen standen, ist diese Perspektive naheliegend. Um so bemerkenswerter ist es, dass Zosimos dem Verbot der Haruspizin, dem unterlassenen Kapitolsopfer und dem Zerwürfnis mit dem senatus populusque Romanus - also Vorgängen, die die Auswirkungen der konstantinischen conversio im Westen betrafen - in seiner Darstellung so breiten Raum einräumte. Diese Besonderheit wird nicht zuletzt durch einen Vergleich mit Sozomenos deutlich, der sich in seiner Kirchengeschichte mit einer paganen Version der konstantinischen Bekehrung auseinandersetzte, die starke Ähnlichkeiten mit der von Zosimos berichteten Version aufweist und die nach Meinung der meisten Forscher unmittelbar auf Eunap Bezug nimmt: Konstantin habe - so die paganen Vorwürfe - nach der Ermordung des Crispus zunächst beim Philosophen Sopatros Hilfe erbeten, der jedoch seinen Bitten nach Sühnung eine abschlägige Antwort erteilt habe; daraufhin habe sich der Kaiser den christlichen Bischöfen zugewandt, die dem Kaiser eine Reinigung von der Schuld durch Buße und Taufe versprochen hätten. ${ }^{253}$ Trotz der unverkennbaren Anklänge der aus Sozomenos erschließbaren Darstellung an Zosimos/Eunap werden jedoch auch charakteristische Unterschiede sichtbar: Sozomenos, der sich auf nicht näher bezeichnete „Hellenen“ als Gewährsmänner beruft, gibt keinen Hinweis auf die Lokalisierung der Ereignisse, und anstelle der mit dem römischen Kapitol in besonderer Weise verbundenen haruspices ist es der Philosoph Sopatros, der Konstantins Ansinnen auf Sühnung seiner Schuld ablehnt. Obwohl offenbar auch in der Tradition, mit der Sozomenos sich auseinandersetzte, die Begegnung zwischen Konstantin und Sopatros in Rom stattgefunden hat, ${ }^{254}$ deutet die Einführung des Sopatros als Akteur darauf hin, dass die Geschichte in einem griechischen Milieu charakteristische Ausprägungen erfuhr, in denen spezifische Bezüge auf Rom, wie der unterbliebene Aufstieg auf das Kapitol, ausgeblendet und die Rahmenhandlung an die östlichen Verhältnisse angepasst wurde. Die bei Zosimos/Eunap fassbare Konzentration auf das Kapitol als symbolischen

252 Zum realhistorischen Hintergrund dieser Vorwürfe vgl. Wiemer 1994, 483, Anm. 58.

253 Soz., h. e. 1, 5. Dass Sozomenos hier von Eunap abhängt, vermuten Fowden 1994, 157; Wiemer 1994, 482, Anm. 56; Paschoud 1997, 17-22. Es ist zwar wahrscheinlich, dass Sozomenos in seiner Kirchengeschichte Eunap benutzt hat; ob dies aber auch in der fraglichen Stelle der Fall war, ist schwer zu entscheiden: Sozomenos selbst spricht vage von „den Hellenen“, gegen deren Sicht der konstantinischen conversio er Stellung bezieht, und spielt damit wohl eher auf eine allgemeine pagane Tradition als auf eine konkrete literarische Vorlage an.

254 Überzeugend Paschoud 1997, 19 f. 
Handlungsschauplatz muss demnach einer spezifisch westlichen, vermutlich stadtrömischen Tradition entspringen, die Eunap in seinem Geschichtswerk verarbeitete, während „die Hellenen“, von denen Sozomenos spricht, die Geschichte in einer Weise abwandelten, die ihrem Erfahrungshintergrund eher entsprach, und mit Sopatros anstelle der haruspices eine Figur ins Spiel brachten, die im Osten des Imperiums zwar mit der Gründung der neuen Hauptstadt, nicht mit der Abwendung vom alten caput imperii assoziiert war. ${ }^{255}$

Diese stadtrömische Tradition, die in Eunaps Darstellung von Konstantins unterbliebenem Opfer für den kapitolinischen Iuppiter Eingang gefunden hat, ist mit einer lateinischsprachigen Quelle des ausgehenden 4. Jh. zu identifizieren, die nach Ansicht zahlreicher Forscher nicht nur im Geschichtswerk des Eunap weitere Spuren hinterlassen hat, ${ }^{256}$ sondern auch von der Epitome de Caesaribus und von Ammianus Marcellinus benutzt wurde, und die häufig mit den Annalen des Nicomachus Flavianus, die dieser vermutlich im Jahr 389 Kaiser Theodosius I. widmete, ${ }^{257}$ in Verbindung gebracht wird. ${ }^{258}$ Mit Blick auf die wenigen Nachrichten zum Geschichtswerk des Nicomachus, die sich auf die knappen Andeutungen der bekannten, durch Nicomachus' Sohn verfassten Rehabilitationsinschrift aus Rom beschränken und allenfalls ein spekulatives Bild vom Charakter und Inhalt des Werkes erlauben, ${ }^{259}$ erscheint es freilich geratener, von einer nicht näher bestimmbaren Quelle auszugehen, die in der zweiten Hälfte des 4. Jh. verfasst wurde und in der eine spezifisch stadtrömische Perspektive deutlich akzentuiert gewesen zu sein scheint. ${ }^{260}$

255 Zur Beteiligung des Sopatros an den Gründungsriten Konstantinopels vgl. Johannes Lydos, de mensibus 4, 2. Baldini 1984, 166, ders. 1995 erklärt die Unterschiede zwischen den Darstellungen bei Zosimos und bei Sozomenos damit, dass Sozomenos sich auf die erste Redaktion von Eunaps Historia beziehe, während Zosimos die zweite Redaktion benutzt habe. Für die hier interessierende Frage ist die Differenzierung von nachrangiger Bedeutung, da auch nach dieser Hypothese der Kapitolgang auf eine westliche Tradition zurückgeführt wird (Eunap soll erst in seiner zweiten Redaktion eine Einarbeitung von Quellennachrichten westlicher Provenienz vorgenommen haben; vgl. zusammenfassend Baldini 1984, 155f.).

256 Deutlich wird dies in der von Zos. 4, 36, 5 berichteten Niederlegung des pontifex maximus-Titels durch Gratian, die auf ein lateinisches Wortspiel mit der Etymologie von pontifex zugeschnitten ist (vgl. den Kommentar des Herausgebers Paschoud, in: Zosime, Bd. 4, 421).

257 CIL VI, 1783: annalium quos consecrari sibi a quaestore et praefecto suo voluit. Zur mutmaßlichen Dedikation im Rahmen von Theodosius' Romaufenthalt im Jahr 389 vgl. Bleckmann 1995, 96.

258 Vermutungsweise geäußert z. B. von Schlumberger 1974, 237-243; Baldini 1984, 120; Bleckmann 1995, 94; Paschoud 1997, 11; zuletzt als gesichert vorausgesetzt von Festy (1999), in: Epitome de Caesaribus, XV-XX; Paschoud (2000), in: Zosimos, Bd. 1, XXXVIIIf., 234, 245; vgl. auch u., Anm. 260. Zur Rückführung der Kapitolsepisode auf diese Quelle des 4. Jh. vgl. zuletzt Baldini 1995, 273f.; Paschoud 1997, 24 f.

259 Zur Inschrift s. o., Anm. 257. Für den Abschluss der nikomachischen Annalen mit Gratians Tod hat zuletzt Festy 1997, 472-475 plädiert, doch bestehen berechtigte Einwände gegen diesen und ähnliche Rekonstruktionsversuche (vgl. zuletzt Barnes 2004, 122-124 und Burgess 2005, 168f.).

260 Für den hier interessierenden Argumentationszusammenhang ist eine Identifizierung dieser Quelle mit einem bestimmten Autor bzw. Werk nicht entscheidend; vorausgesetzt wird jedoch die Existenz einer solchen Quelle, deren Spuren sich bei Eunap und in anderen historiographi- 
In welchem Zusammenhang die Kapitolsepisode in dieser von Eunap benutzten Quelle stand, lässt sich aufgrund der Überlieferung bei Zosimos nicht sicher bestimmen. Jedoch verfügt man mit der sogenannten „Leoquelle“ über eine von Eunap/Zosimos unabhängige Tradition, die ebenfalls diese lateinischsprachige Quelle verarbeitet hat. Bei der im 19. Jh. erschlossenen „Leoquelle“ handelt es sich um ein Geschichtswerk des 6. Jh., dessen Spuren sich bei Zonaras und in der mittelbyzantinischen Chronistik erhalten haben, und von dem nach den grundlegenden Studien von Bruno Bleckmann als gesichert gelten kann, dass es von Petros Patrikios verfasst wurde. ${ }^{261}$ Ebenfalls dem Petros Patrikios zugeschrieben werden die Fragmente des sogenannten Anonymus post Dionem, ${ }^{262}$ unter denen sich auch ein Ausspruch Konstantins befindet, dass er Serdika als ein zweites Rom betrachte. ${ }^{263}$ Unter der Voraussetzung, dass Petros Patrikios diese Angabe seiner lateinischsprachigen Quelle entnahm, ${ }^{264}$ kommt der Aussage Konstantins für die Rekonstruktion dieser Quelle eine zentrale Bedeutung zu: Da Konstantin sich ausschließlich

schen Werken des späten 4. Jh. erhalten haben. Vgl. in diesem Sinne neben der o., Anm. 258 genannten Literatur Schlumberger 1974, bes. 172-182; 205-207; 223f.; 235f.; Baldini 1984, 119178; Bleckmann 1995; Birley 2003, 130-132. Auf eine spezifisch stadtrömische Perspektive dieser Quelle deutet neben der Episode von Konstantins unterlassenem Gang auf das Kapitol auch die Ablehnung des pontifex maximus-Titels hin, die Gratian gegenüber einer römischen Senatsdelegation zum Ausdruck brachte (s. o., Anm. 256); vgl. auch Bleckmann 1995, 84. Skepsis gegenüber einer solchen lateinischsprachigen Quelle ist hingegen vor allem in der angloamerikanischen Forschung verbreitet; vgl. u. a. Blockley 1981, 23f.; Cameron 1999, 115; Barnes 2004, 124.

261 Zur Identifizierung mit Petros Patrikios vgl. Bleckmann 1992, bes. 32f., 43-53, 411f.; dens. 1995, 83f.; zustimmend Barnes 2004, 122. Zu den byzantinischen Geschichtswerken, die auf die Leoquelle bzw. -tradition zurückgegriffen haben, vgl. Bleckmann 1992, 43f. Aufgrund der Verwandtschaft zahlreicher Stellen bei Zonaras mit Ammianus Marcellinus, die zum einen der Leoquelle entstammen und zum anderen nicht auf eine direkte Abhängigkeit von Ammian zurückgeführt werden können, vertritt Bleckmann die Auffassung, dass die Leoquelle (=Petros Patrikios) und Ammian für das 4. Jh. eine gemeinsame Quelle benutzt haben, deren Spuren sich auch in der Epitome de Caesaribus wiederfinden, und bei der es sich um eben die lateinischsprachige Quelle handelt, in der auch von Konstantins unterlassenem Kapitolopfer berichtet wurde. Auf der Grundlage dieser Abhängigkeitsbeziehungen können Werke der byzantinischen Zeit wie die Weltchronik des Zonaras oder die Logothetenchronik als eigenständiger Traditionszweig herangezogen werden, um den Inhalt und die Struktur der lateinischen Quelle näher zu bestimmen.

262 Die Fragmente des Anonymus post Dionem werden bereits seit dem späten 19. Jh. mit dem Geschichtswerk des Petros Patrikios in Verbindung gebracht (zu dieser - auch noch in der gegenwärtigen Forschung überwiegend akzeptierten - Zuweisung vgl. Bleckmann 1992, 51-53).

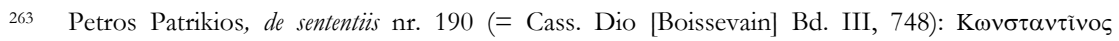

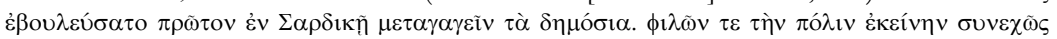

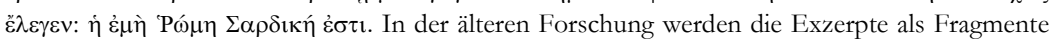
eines Anonymus post Dionem geführt (de sententiis $190=$ Anonymus post Dionem, fr. 15, 1, ed. FHG [Müller], IV, 199).

264 Diese Annahme liegt wegen der eindeutig stadtrömischen Perspektive, die in der Ausssage zutagetritt, nahe. 
in den Jahren zwischen 316 und 322 bevorzugt in Serdika aufhielt, ${ }^{265}$ kann sich seine Bemerkung sinnvollerweise nur auf diesen Zeitraum beziehen. ${ }^{266}$ Konstantin wurden also schon vor 326 Pläne in den Mund gelegt, Rom den Rücken zu kehren und eine neue Hauptstadt zu errichten, was wiederum die Schlussfolgerung nahelegt, dass auch die Störungen im Verhältnis zur römischen Bevölkerung - die nach Eunap/Zosimos erst anlässlich der Vicennalien im Jahr 326 erfolgten - in der Darstellung der lateinischsprachigen Quelle bereits früher angesiedelt gewesen waren. ${ }^{267}$ Vermutlich hat ihr Verfasser ein Zerwürfnis Konstantins mit der stadtrömischen Bevölkerung mit dem zu Jahresbeginn 313 erstmals unterbliebenen Opfer für den kapitolinischen Iuppiter verbunden - eine Angabe, die dann von Eunap dekontextualisiert und mit den Verwandtenmorden des Jahres 326 in Verbindung gebracht wurde.

Als eine für den hier interessierenden Kontext zentrale Frage bleibt abschließend zu klären, ab wann sich diese Deutung, die den Verzicht Konstantins auf das kapitolinische Opfer mit einer ostentativen Abkehr des Kaisers von Rom gleichsetzte, im stadtrömischen Kontext verbreitete. Die von Eunap und Petros Patrikios benutzte lateinischsprachige Quelle wurde gegen Ende des 4. Jh. verfasst. Etwa eine Generation früher steht uns mit Aurelius Victor ein Autor zur Verfügung, der die stadtrömischen Verhältnisse aus eigener Anschauung kannte und neben der Enmannschen Kaisergeschichte weitere Quellen, darunter vermutlich auch stadtrömische Traditionen, in seinen liber de Caesaribus einfließen ließ.268 Bemerkenswert ist, dass Aurelius Victor zwar die feindselige Haltung der stadtrömischen Bevölkerung gegenüber Konstantinopel als einer Rivalin Roms thematisiert, diese jedoch nicht in einen Zusammenhang mit einer religiös bedingten Abkehr des Kaisers von Rom oder der Gründung Konstantinopels bringt, sondern mit der Entscheidung des Kaisers, sich im neuen und nicht im „,erneuerten“ Rom bestatten zu

265 Barnes 1982, 69 u. 73-75.

266 So auch Barnes 1982, 69, Anm. 99, Bleckmann 1991, $353 \mathrm{f}$.

267 Anders zuletzt Bleckmann 1995 (a), bes. 60-62, der eine Angabe der Logothetenchronik, nach der Konstantin aus Furcht vor dem Senat wegen seines christlichen Glaubens die Stadt Rom verlassen habe und daraufhin in einen Krieg gegen die Skythen gezogen sei, mit militärischen Aktionen Konstantins gegen die Donaubarbaren aus dem Jahr 328 in Verbindung bringt. Da die Logothetenchronik - vermittelt über die Leoquelle/Petros Patrikios - Material aus der lateinischsprachigen Quelle des 4. Jh. verarbeitet hat (s. o., Anm. 261), zieht Bleckmann den Schluss, dass in dieser Quelle des 4. Jh. der unterbliebene Gang Konstantins auf das Kapitol in einer engen zeitlichen Korrelation mit den Militäraktionen von 328 gestanden habe und mit den Vicennalien von 326 verbunden gewesen sei (zustimmend Paschoud 1997, 22-25). Eine Auseinandersetzung mit dieser Hypothese würde den Rahmen einer Anmerkung sprengen: Die Frage soll demnächst in einem eigenen Beitrag behandelt werden.

268 Der liber de Caesaribus wurde um 360 verfasst; eine ausgeprägt stadtrömisch-senatorische Perspektive tritt z. B. ebd., 39, 45 hervor. Zur Auffassung, dass Aurelius Victor im Vergleich mit Eutrop ein breiteres, über die Enmannsche Kaisergeschichte hinausreichendes Spektrum von Quellen berücksichtigt habe, vgl. Bleckmann 1997, bes. 14f., $20 \mathrm{f}$. 
lassen. ${ }^{269}$ Eine ähnliche Sicht der Dinge findet sich auch schon beim Zeitgenossen Konstantins, Eusebius v. Caesarea, der in der Vita Constantini die vergeblichen Bemühungen der Römer, die sterblichen Überreste Konstantins zur Bestattung und zur Konsekration nach Rom zu holen, und die Verstimmungen beschreibt, die eine Ablehnung dieses Ansinnens auslöste. ${ }^{270}$ Etwa zeitgleich mit Aurelius Victor rief ferner auch Themistios in einer Rede, die er als Gesandter Konstantinopels in Rom anlässlich des Besuchs von Constantius II. im Sommer 357 hielt, und in der er die Verdienste Konstantinopels gegenüber Rom herausstellte, dem römischen Auditorium in Erinnerung, dass sich das Grabmal von Constantius' Vater in Konstantinopel und eben nicht in Rom - befand. ${ }^{271}$

Aurelius Victor machte Konstantins Distanzierung von Rom und die komplementäre Aufwertung Konstantinopels demnach nicht an dem kaiserlichen Verzicht auf das kapitolinische Opfer und der dadurch ausgelösten Suche nach einer neuen Hauptstadt fest. ${ }^{272}$ Eine derartige Perspektive wird erstmals gegen Ende des 4. Jh. mit der lateinischsprachigen Quelle, auf der Zosimos'/Eunaps Darstellung basiert, fassbar: Erst jetzt wurde der unterlassene Gang auf das Kapitol zu einem Symbol dafür, dass Konstantins Christentum und die durch das Kapitol symbolisierte städtische Identität unvereinbare Gegensätze bildeten, die zu einer Trennung von christlichem Kaiser und paganer Stadt führten. Diese retrospektive Deutung hatte mit den Wahrnehmungen und dem Verhalten der Akteure in konstantinischer Zeit jedoch wenig zu tun: Bereits im Jahr 313 verzichtete der Kaiser darauf, das kapitolinische Opfer vorzunehmen, ohne dass dies zu erkennbaren Spannungen mit der städtischen Bevölkerung und der senatorischen Oberschicht geführt hätte. Noch bei Aurelius Victor kurz nach der Mitte des 4. Jh. finden sich keine Anzeichen für einen derartigen Identitätsdiskurs, der möglicherweise erst mit der theodosianischen Zeit, in der sich Polarisierungen zwischen

269 Aur. Vict., Caes. 41, 17: funus relatum in urbem sui nominis. quod sane populus Romanus aegerrime tulit, quippe cuius armis legibus clementi imperio quasi novatam urbem Romam arbitraretur. Die Bezeichnung „Neues Rom“ für Konstantinopel erscheint erstmals unter Theodosius I., in den Konzilsakten von 381 (Dagron 1974, 54); auch Aurelius Victor spricht nur von der „Stadt mit Konstantins Namen“ scheint jedoch die Charakterisierung Konstantinopels als nova Roma im Unterschied zur novata Roma bereits implizit vorauszusetzen.

270 Eus., v. C. 4, 69, 2.

271 Themistios, Oratio 3, 6. Zur Frage, ob die Rede wirklich in Rom gehalten wurde oder der Schauplatz fingiert ist, vgl. die Einleitung von Leppin, 1998, 68f.

272 Die Vermutung von Neri 1992, 18-23, Aurelius Victor habe eine der Darstellung bei Eunap/Zosimos entsprechende Version der konstantinischen conversio - bestehend aus den Verwandtenmorden, der anschließenden Bekehrung des Kaisers und der dadurch ausgelösten Weigerung, das kapitolinische Opfer zu vollziehen - zwar gekannt, jedoch bewusst ignoriert, ist wenig überzeugend. 
„pagan“ und „christlich“ auf zahlreichen Feldern des kulturellen Lebens bemerkbar zu machen begannen, ${ }^{273}$ Gestalt gewann.

Dieser Befund ist für das Verhältnis von Kaiser, Christentum und städtischer Identität in mehrfacher Hinsicht bemerkenswert. Zum einen bleibt festzuhalten, dass Konstantin mit dem unterbliebenen Opfer auf dem Kapitol seine Verehrung für den christlichen Gott öffentlich an einem Ort zum Ausdruck brachte, ${ }^{274}$ der für die kollektive Identität der urbs Roma von zentraler Bedeutung war. Es gibt daher keinen Anlass zu der Vermutung, Konstantin habe im Zentrum Roms wegen eines paganen und traditionsorientierten Senats auf öffentliche Äußerungen seiner Nähe zum christlichen Kult verzichtet und versucht, durch die Randlage seiner christlichen Sakralstiftungen an der Peripherie und im Suburbium der Stadt eine Einbeziehung des Christentums in die urbs Roma zu verhindern. Wenn Konstantin keine Anstalten unternahm, im Zentrumsbereich des forum Romanum christliche Kultbauten zu errichten, dann hatte dies andere Gründe: Die Befreiung der res publica vom Tyrannen, die Konstantin im Zentrum Roms in monumentaler und zeremonieller Weise durch die Umweihungen der maxentischen Bauten an der Velia und durch die Stilisierung seiner Eroberung Roms nicht als Triumph, sondern als adventus in Szene setzte, war ein Kommunikationszusammenhang, in dem diejenigen Gruppen von symbolischer Bedeutung waren, die die res publica repräsentierten: der populus Romanus und vor allem die senatorische Oberschicht. Dass die christliche Gemeinde in diesem Kontext keine Berücksichtigung fand, war keine Frage der Ausgrenzung, sondern der kommunikativen Optionen: Ihr fiel für die symbolische Inszenierung des Befreiungssieges über Maxentius keine Rolle als Akteur zu. ${ }^{275}$

$273 \quad$ S. dazu u., S. 311 f., 316.

274 Dass das unterlassene Opfer für den kapitolinischen Iuppiter auch von der heidnischen Bevölkerung als eine deutliche Hinwendung Konstantins zum Christentum verstanden worden sein muss, wird von Girardet 1998, 26-30 zurecht betont.

275 Bezeichnend ist, dass auch in der Darstellung christlicher Autoren wie Laktanz und Eusebius v. Caesarea Konstantins Sieg über Maxentius nicht als eine Befreiung der Christen von einem Verfolger, sondern als eine Befreiung der Stadt und der senatorischen Oberschichten von einem Gewaltherrscher erscheint, dessen Züge nach dem traditionellen Bild der Tyrannenimago gezeichnet sind. Für Laktanz war Maximinus Daia nach dem Tod von Galerius, Maximian und Diocletian der letzte der verbliebenen adversarii $D e i$ - zu einer Zeit, als Maxentius noch lebte (vgl. Lact., mort. pers. 43, 1). Eusebius bezeichnet Maxentius zwar als einen gottlosen Tyrannen, stellt ihn auf eine Stufe mit Maximinus Daia und vergleicht ihn mit dem ägyptischen Pharao. Auch Eusebius konzentriert jedoch seine Beschuldigungen gegen Maxentius auf die Tatbestände der Magie und der Tötung von Senatoren: Der Umstand, dass Maxentius auch einer christlichen Angehörigen des Senatorenstandes Gewalt antun wollte, wird nicht zu einem allgemeinen Vorwurf der Christenverfolgung ausgeweitet, sondern ist eine Variation der traditionellen Topik des Gewaltherrschers, der die senatorische Oberschicht und die Bevölkerung Roms unterdrückt (vgl. Eus., v. C. 1, 33-36; h. e. 8, 14, 5f.; 9, 9, 2-4 u. 9-11). 
Zum anderen machen die Äußerungen von Aurelius Victor und Eusebius v. Caesarea übereinstimmend deutlich, dass die städtische Identität Roms in elementarer Weise mit der Frage verbunden war, wo der verstorbene Kaiser seine letzte Ruhestätte fand. Wenn Aurelius Victor nicht die Gründung Konstantinopels selbst, sondern erst seine Funktion als kaiserliche Grablege als das kennzeichnet, ,worüber das römische Volk ungehalten war" (quod populus Romanus aegerrime tulit), ist dies ein bemerkenswert klarer Hinweis darauf, in welchem Maße Roms Selbstverständnis als Hauptstadt des Imperiums vom Kaiserkult und der Kaiserkommemoration geprägt war: Die Bestattung des Kaisers im Apostoleion von Konstantinopel ${ }^{276}$ stellte die Identität der Römer auf eine härtere Probe als es der Verzicht Konstantins auf das kapitolinische Opfer getan hatte. Mit der Bestattung und kultischen Verehrung des Kaisers war jedoch ein Sektor kaiserbezogener städtischer Identitätsstiftung berührt, der - anders als bei der Befreiung der Stadt - der christlichen Gemeinde eine tragende Rolle als Kommunikationspartner zuwies. Hatten die Christen als symbolische Bezugsgruppe für die kaiserliche Inszenierung als Befreier der urbs keine Rolle gespielt, ohne deswegen aus dem städtischen Raum ausgegrenzt zu werden, kehrten sich diese Voraussetzungen nun um: In den Coemeterien Roms und den dort errichteten christlichen Kultbauten entstanden Zentren für eine neue Form des Kaiserkults, in dem der senatus populusque Romanus die Rolle als Adressat der kaiserlichen Kommunikation der christlichen Gemeinde überließ.

\section{2. Kaiserkult und Kommemorationstopographie}

Die nach ihrer charakteristischen Bauform benannten „Umgangsbasiliken“277, die Konstantin in großer Zahl im Suburbium Roms errichten ließ, und die rein quantitativ den größten Anteil am Bauprogramm des Kaisers in Rom ausmachten, waren große überdachte Friedhöfe, für die in der modernen Forschung die Bezeichnung coemeteria subteglata geprägt wurde, ${ }^{278}$ und die über

\footnotetext{
276 S. dazu u., S. 211 f.

277 Unter den übergreifenden Darstellungen zu den konstantinischen Umgangsbasiliken verdienen besondere Erwähnung Pietri 1976, Bd. 1, 29-69; Brandenburg 1979, 61-154; ders. 1992; Tolotti 1982; Schumacher 1987; Torelli 1992; Fiocchi Nicolai 1997; La Rocca 2000; Lehmann 2003. Brandenburg 2004, 55-91 und Holloway 2004, 86-115 bieten aktuelle Überblicke über die wichtigsten Ergebnisse. Vgl. außerdem die Diskussion der vor wenigen Jahren entdeckten Basilika an der via Ardeatina und ihre Einordnung in das Ensemble der bisher bekannten Umgangsbasiliken durch Fiocchi Nicolai et al. 1995-1996, 69-139 (ebd., 69f., Anm. 3 enthält eine umfassende Bibliographie zu den römischen Coemeterialbasiliken).

278 Die Wendung geht zurück auf Krautheimer 1960, 28. Der Terminus coemeterium begegnet erstmals im Eintrag des Catalogus Liberianus zum Bischof Fabian (236-250): multas fabricas per cimiteria fieri iussit (MGH AA IX, 75); ob mit coemeteria hier einzelne Gräber gemeint sind (so Rebillard
} 
mehrere Lagen hinweg tausende von Gräbern in sich aufnahmen. ${ }^{279}$ Konstantin griff damit eine Bestattungspraxis auf, für die sich bereits Vorbilder während des 3. Jh. in der christlichen Gemeinde Roms finden lassen, ${ }^{280}$ und die von den römischen Bischöfen, die das architektonische Vorbild der konstantinischen Coemeterialbasilika aufgriffen, in eigener Initiative weitergeführt wurde. ${ }^{281}$ Die Nutzung der konstantinischen Basiliken als Grablegen hat in der Forschung zu anhaltenden Kontroversen darum geführt, ob es sich bei ihnen um reine Friedhöfe oder um Kirchen im Sinne liturgischer Versammlungsräume gehandelt habe. Diese - in der zugespitzten Form einer alternativlosen Zuordnung falsch gestellte - Problematik soll an späterer Stelle aufgenommen und diskutiert werden. ${ }^{282}$ Zunächst erscheint es jedoch methodisch sinnvoller, die Frage nach den in den Basiliken vollzogenen kultischen Praktiken (über die im übrigen nur wenig Konkretes bekannt ist) zurückzustellen, und stattdessen von ihrer gesicherten Eigenschaft als Bestattungsplätze auszugehen: Die archäologische Disposition dieser Anlagen liefert Aufschlüsse, die es erlauben, ihre Funktion jenseits einer allgemeinen Zweckbestimmung als kollektiv genutzte Grablegen schärfer zu fassen.

1993) oder Areale kollektiver Grablegen, ist umstritten. Für die konstantinischen Bauten ist der Ausdruck nicht gesichert (vgl. u., Anm. 330); da jedoch Krautheimers Bezeichnung die Funktion der Bauten zutreffend erfasst, wird sie auch im folgenden verwendet.

279 Erstmals deutlich herausgestellt von Krautheimer 1960. Sichtbar ist diese Funktion vor allem in der gut erhaltenen Basilika von S. Sebastiano. Dort liegen an den Außenwänden bis zu drei Lagen von Arkosolgräbern oberhalb und bis zu fünf Lagen unterhalb des Bodenniveaus übereinander; auch die Bodengräber in der Basilika reichen in drei bis vier Lagen in den Boden hinab (vgl. Tolotti 1982, 159f.). In SS. Pietro e Marcellino lassen die Sondierungsgrabungen auf eine dichte Belegung der Basilika und der südlich anschließenden Porticus mit Gräbern schließen (vgl. Guyon 1987, 268-272). Für die basilica bei Tor de' Schiavi vgl. Luschi/Ceccherelli $1987-$ 1988, 425-427; für die basilica maior von S. Lorenzo f.l.m. vgl. Krautheimer, in: Corpus II, 119; für S. Agnese s. Deichmann 1946, 224f.; Barbini/Severini 2002, 761-768. Bei allen Bauten lässt sich demnach eine intensive Nutzung als Bestattungsort sicher nachweisen. Die Funktion der Umgangsbasiliken als monumentale Grablegen wird auch von der neu entdeckten Basilika des Marcus an der via Ardeatina bestätigt (vgl. Fiocchi Nicolai 2002, bes. 1175-1185).

280 Eine mit den konstantinischen Basiliken vergleichbar intensive Belegung mit Gräbern findet sich z. B. in der area I des Kallixtcoemeteriums an der via Appia, wo entlang der die area umgebenden Mauer Gräber in bis zu zehn Schichten übereinander lagen (vgl. Fasola 1986, 179-182). Die area I des Kallixtcoemeteriums zählt zu denjenigen Grabarealen des römischen Suburbiums, bei denen bereits für das frühe 3. Jh. gesichert ist, dass sie Eigentum der römischen Kirche waren und als Gemeindegrablege dienten.

281 Dies belegt die Basilika an der via Ardeatina, die zwar von Konstanin mit einem Landgut dotiert, jedoch auf Initiative des Bischofs Marcus (336) hin errichtet wurde (vgl. LP I, 202: bic (scil. Marcus) fecit duas basilicas, unam via Ardeatina, ubi requiescit... ex buius suggestione obtulit Constantinus Augustus basilicae quem cymiterium constituit via Ardeatina: fundum rosarium cum omnem agrum campestrorum, praest. sol. XL).

282 Vgl. dazu u., S. 167 f. 
III. 2. 1. Totenkult und Märtyrerkult: zur Funktion der römischen Coemeterialbasiliken

Die Bestattungen im Bereich der coemeteria subteglata beschränkten sich nicht auf uniforme Boden- und Arkosolgräber, die seriell in den Boden und entlang der inneren Seite der Außenwände dieser Basiliken angelegt wurden. Bestimmte Tote nahmen im Verhältnis zu den übrigen Bestatteten eine prominentere Lage ein. Dies gilt in erster Linie ${ }^{283}$ für die Mausoleen, die an die Grabbasiliken angebaut wurden. Vor allem in S. Sebastiano ist eine große Zahl dieser Mausoleen an der Südseite des Gebäudes erhalten geblieben. Sie stellen spätere Erweiterungen und Anbauten an die Basilika dar, die als zentraler Baukörper die später errichteten Mausoleen auf sich hin orientierte und damit - im Unterschied zu paganen Nekropolen - den Grabarealen, auf denen sich diese und andere Coemeterialbasiliken erhoben, eine klare räumliche Ausrichtung gab. ${ }^{284}$

Im Unterschied zu diesen erst sekundär vorgenommenen Anbauten sind jedoch vermutlich sämtliche konstantinischen Coemeterialbasiliken bereits bei ihrer Errichtung mit einem an die Basilika angebauten Mausoleum verbunden worden, das dem Erbauer der Basilika eine besonders privilegierte Grabstätte verlieh. In SS. Pietro e Marcellino wurde ein großer Rundbau, in dem 329 die Mutter Konstantins, Helena, bestattet wurde, an die Frontseite der Basilika angeschlossen. Obwohl das Mausoleum unmittelbar nach der Basilika errichtet worden sein muss, ist in der Forschung umstritten, inwieweit die beiden Bauten von vornherein als eine einheitliche Anlage konzipiert waren. Die Ausgräber der Basilika, Deichmann und Tschira, haben die Reste einer einige Meter vor dem östlichen Abschluss der Basilika quer durch das Mittelschiff und die beiden Seitenschiffe verlaufenden Mauer als Hinweis auf eine ursprüngliche Frontmauer der Basilika interpretiert, vor der sich ein Narthex in der Höhe der umlaufenden Seitenschiffe erstreckt habe. Dieser basilikale Narthex sei auch nach Errichtung des Mausoleums beibehalten worden und habe als ein sichtbarer architektonischer Abschluss die Eigenständigkeit der Basilika gegenüber dem Mausoleum betont, das seinerseits ebenfalls mit einem narthexartigen Vorbau versehen war, dessen Höhe jedoch die des basilikalen Narthex erheblich überstieg. Basilika und Mausoleum erscheinen nach dieser Rekonstruktion als zwei separate Baukörper, die erst später zu einem einheitlichen Baukörper verschmolzen, als man den basilikalen Narthex aufgab und die Schiffe der Basilika bis zum Narthex des Mausoleums hin verlängerte. ${ }^{285}$

283 Auch innerhalb der Basiliken gab es herausgehobene Bestattungsplätze, vgl. u., Anm. 306.

$284 \mathrm{Zu}$ diesem Unterschied zwischen paganen und christlichen Nekropolen vgl. Brandenburg 1994.

285 Zur Abfolge dieser hypothetischen Bauphasen vgl. Deichmann/Tschira 1957, 62-64 mit Abb. 23 (ohne Datierungsvorschlag). 
Eine solche Verbindung von Basilika und Mausoleum zu einem einheitlichen Baukörper muss allerdings bereits sehr früh, unmittelbar nach der Errichtung des Mausoleums erfolgt sein, da die bis an den Narthex des Mausoleums herangezogenen Pfeiler der basilikalen Schiffe die Lage der umliegenden Bodengräber beeinflusst haben. ${ }^{286} \mathrm{Da}$ zudem die bei der Ausgrabung aufgefundenen Mauerreste, die als ursprüngliche Frontmauer der Basilika aufgefasst wurden, so gering sind, dass sie keine überzeugende Grundlage für die Existenz eines basilikalen Narthex abgeben, und da es ferner schwer vorstellbar erscheint, dass die Basilika zunächst einen Narthex erhalten haben soll, der dann unmittelbar darauf aufgegeben wurde, um den Basilikalbau mit dem Mausoleum zu verbinden, hat Jean Guyon überzeugend dafür plädiert, dass ein derartiger Narthex der Basilika von SS. Pietro e Marcellino nie existiert hat. ${ }^{287}$ Daraus aber folgt, dass die Basilika und das Mausoleum nicht nur zu einem frühen Zeitpunkt zu einem einheitlichen Bau verbunden wurden, sondern auch, dass ein derartiger Baukomplex auch schon von vornherein als solcher geplant gewesen ist: Es gibt keinen Hinweis darauf, dass Basilika und Mausoleum als eigenständige Baukörper konzipiert worden sind. ${ }^{288}$

Ähnlich wie SS. Pietro e Marcellino wurde auch in S. Agnese ein Mausoleum zeitgleich mit der Basilika errichtet. Unter S. Costanza, dem noch heute sichtbaren Rundmausoleum an der Südseite der Basilika, in dem die Tochter Konstantins, Constantina (gest. 354), und ihre Schwester Helena (gest. 360) beigesetzt waren, sind vor einigen Jahren Spuren eines Vorgängerbaus aufgefunden worden, der vermutlich die Form einer Trikonche hatte. ${ }^{289}$ Trotz anderslautender Interpretationsversuche, die in diesem Trikonchenbau kein Mausoleum, sondern ein Baptisterium vermuten, das nach Ausweis des Liber Pontificalis unter Konstantin bei S. Agnese errichtet worden sein soll, ${ }^{290}$ wird

286 Guyon 1987, 215; Rasch 1998, 45 geht davon aus, dass diese Verlängerung der basilikalen Schiffe bis zum Narthex des Mausoleums noch während der abschließenden Arbeiten an der Rotunde erfolgte (etwa zwischen 322 und 324/325).

287 Guyon 1987, 214-217; bereits Tolotti 1982, 190f. hatte sich gegen die Existenz eines Narthex an SS. Pietro e Marcellino ausgesprochen. Rasch 1998, 31-35 hält hingegen weiterhin an der Existenz eines eigenständigen basilikalen Narthex fest, der dann nach nur wenigen Jahren entfernt worden sein soll.

288 Hervorgehoben von Guyon 1987, 238.

289 Zum Vorgängerbau von S. Costanza vgl. Stanley 1994, 259f., der aus den spärlichen Resten von Mauerfragmenten eine Trikonche mit einer Breite von 10,20m rekonstruiert (vgl. ebd., Abb. 15 und 17).

290 LP I, 180. Mackie 1997 identifiziert die Trikonche mit diesem Baptisterium, in dem Constantina 354 bestattet worden sei; die Errichtung des späteren Rundbaus weist sie Julian zu, der dort dann 360 seine Gattin Helena bestatten ließ. Wie oben bereits ausgeführt wurde (s. o., Anm. 105), ist jedoch die Notiz zur Stiftung der Basilika stark durch spätere hagiographische Texte beeinflusst worden. Dies dürfte sich auch auf die Gründung eines Baptisteriums und auf die dortige Taufe der Constantina beziehen. In zwei römischen Märtyrerpassionen (der passio Gallicani und der passio Agnetis) ist davon die Rede, dass Constantina durch die Hilfe der Heiligen Agnes von der Lepra geheilt worden sei. Die actus Silvestri, die in Rom eine weite Verbreitung fanden (vgl. decret. 
man auch in diesem Vorgängerbau ein Mausoleum erkennen: Die - für das Mausoleum bei S. Agnese freilich stark hypothetische - Trikonchenform ist für römische Mausoleen des 4. Jh. durchaus charakteristisch, ${ }^{291}$ während tribzw. tetrakonchenförmige Baptisterien im Westen erstmals um 400 nachweisbar und aus Rom sonst nicht bekannt sind. ${ }^{292}$ Nicht nur in seinen bescheideneren Dimensionen, sondern auch in der Lage unterscheidet sich dieser Vorgängerbau von S. Costanza vom Helenamausoleum: Während dieses vor die Frontseite der Basilika von SS. Pietro e Marcellino gesetzt wurde, nahm das Mausoleum bei Agnese einen weniger auffälligen Ort an der Südseite der Basilika ein.

Auch bei der basilica apostolorum an der via Appia wurde zeitgleich mit der Basilika an der Südseite ein rechteckiger Anbau mit einer Apsis errichtet, für den sich ebenfalls eine Deutung als Mausoleum als die naheliegendste Erklärung anbietet. ${ }^{293}$ Das Mausoleum wurde zu einem nicht genauer bestimmbaren Zeitpunkt nach seiner Errichtung aufgelassen und am Ende des 4. Jh. durch zwei kleinere Mausoleen überbaut. ${ }^{294}$ Dieser Umstand hat verstärkt Anlass zu Spekulationen über den Besitzer des Mausoleums, seine Beziehung zur Erbauung der Basilika und die Gründe für die Auflassung des Baus gegeben. Man hat verschiedentlich daran gedacht, dass das Mausoleum

Gelas. 4, 4, 222-224), verbinden die Heilung Konstantins von der Lepra mit seiner Taufe durch Bischof Silvester. Die Vermutung liegt nahe, dass der Verfasser des Liber Pontificalis (oder die verlorene hagiographische Quelle, die er benutzte) nach dem Vorbild der Silvesterakten Constantinas Heilung von der Lepra mit einer Taufe durch Silvester und der Errichtung eines Baptisteriums bei S. Agnese kombinierte. Experten auf dem Feld der römischen Hagiographie wie Duchesne (1886), in: LP I, 197 und Franchi de' Cavalieri 1899, 60 haben zwar angenommen, dass die passio Agnetis ihre Nachricht aus dem Liber Pontificalis beziehe, doch ähnlich wie bei der vermeintlichen Taufe der Konstantinschwester Constantina dürften die Abhängigkeitsverhältnisse zwischen dem Liber Pontificalis und der Hagiographie umgekehrt sein: Der Verfasser des Liber Pontificalis verarbeitete in der Stiftungsnotiz legendarische Traditonen (so auch - allerdings ohne weitere Begründung - Pietri 1976, Bd. 1, 47; Orgels/Grégoire 1954, 590 mit Anm. 1).

291 An derselben Stelle wie die Trikonche von S. Agnese wurde ein trikonchenförmiges Mausoleum an die basilica maior von S. Lorenzo f.l.m. angebaut, allerdings erst nach 384 (vgl. u., Anm. 298). Zwei vergleichbare Trikonchen befinden sich auf dem oberirdischen Gelände der area I des Kallixtcoemeteriums (vgl. Fasola 1983). Das heißt nicht, dass die Trikonche ein prinzipiell auf Mausoleen beschränkter Bautyp gewesen wäre (vgl. Ward-Perkins 1969, 14f.), aber im funerären Kontext erscheint diese Deutung naheliegend.

292 Vgl. Ristow 1998, 60. Parallelen für ein Baptisterium als Annexbau zu einer Umgangs- oder Märtyrerbasilika fehlen. Die Hypothese von Schumacher 1986, wonach die südliche Rotunde im Anschluss an das Querschiff von S. Pietro das vatikanische Baptisterium gewesen sei, hat sich nicht durchgesetzt (das vatikanische Baptisterium war vermutlich kein Annexbau, sondern ist am nördlichen Ende des Querschiffs zu lokalisieren, wo es auch in der gesamten Tradition der mittelalterlichen Quellen erscheint, vgl. de Blaauw 1994, Bd. 2, 487-491).

293 Im Plan von Tolotti 1953 das Mausoleum nr. 43.

294 Die Mausoleen nr. 44 und 45 im Plan von Tolotti 1953. Zur Datierung der Nachfolgerbauten in das ausgehende 4./beginnende 5. Jh. vgl. Spera 1999, 230; Torelli 1992, 205 datiert die Auflassung des Mausoleums nr. 43 in das 3. Viertel des 4. Jh.; ähnlich Krautheimer, in: Corpus IV, 132 (kurz nach der Mitte des 4. Jh.). 
ursprünglich als Grablege für Konstantins Gattin Fausta vorgesehen gewesen sei, die 326 in kaiserliche Ungnade fiel und nach ihrer Hinrichtung den Anspruch auf eine Beisetzung in dem ihr zugedachten Mausoleum verloren habe. ${ }^{295}$ Eine zwingende Erklärung für die Auflassung des Mausoleums nr. 43 ist dies allerdings nicht, da nicht einzusehen ist, warum eine damnatio memoriae zur Aufhebung der Funktion des Grabbaus führen musste: Das Mausoleum hätte ohne weiteres von einem anderen Mitglied der kaiserlichen Familie belegt werden können; außerdem wurde das Mausoleum, der Datierung der Nachfolgebauten nach zu urteilen, wohl erst geraume Zeit nach 326 aufgelassen. Was immer die Ursache für die Aufgabe des Mausoleums war, sie dürfte in der Relation zur basilica apostolorum selbst gelegen haben, die als Ort für ein kaiserliches Begräbnis offenbar nicht mehr passend erschien. ${ }^{296}$ Die genaueren Umstände und Gründe für diese Umbewertung entziehen sich unserer Kenntnis. Es besteht jedoch kein Anlass, von der Vermutung abzurücken, dass es sich auch bei dem Mausoleum an der basilica apostolorum um eine geplante Grablege für ein Mitglied des Kaiserhauses handelte, die allerdings später nicht als solche genutzt wurde. ${ }^{297}$

Bei der basilica maior von S. Lorenzo f.l.m. erlauben die punktuellen Grabungsbefunde keinen sicheren Aufschluss darüber, ob es auch hier ein ähnliches Mausoleum gegeben hat, doch hat man an der Südseite der Basilika einen Maueransatz gefunden, der zeitgleich mit der Basilika errichtet wurde und auf die Existenz eines Mausoleums hindeutet. ${ }^{298}$ Als Hinweis auf ein Stiftermausoleum wie bei den oben vorgestellten Basiliken reicht dieser Befund jedoch nicht aus.

Kein direkter baulicher Zusammenhang, aber eine klar erkennbare Beziehung besteht zwischen der Coemeterialbasilika bei Tor de' Schiavi und dem großen Grabtempel, in dessen unmittelbarer Nachbarschaft die Basilika er-

295 Schumacher 1987, 150, Anm. 117; Brandenburg 1992, 44. Ähnliche Erwägungen ließen sich auch für die Schwester Konstantins und Gattin des Licinius, Constantia, anstellen, deren Name (vermutlich nach dem Krieg gegen Licinius 324) aus Inschriften getilgt wurde (vgl. CIL VI, 1153).

296 Tolotti 1982, 192 vermutet, dass das Mausoleum an der basilica apostolorum als Bestattungsplatz für Helena dienen sollte, sie dann jedoch 329 in dem ursprünglich für Konstantin vorgesehenen Mausoleum bei SS. Pietro e Marcellino beigesetzt worden sei, weil zu diesem Zeitpunkt bereits klar war, dass Konstantin sich nicht dort, sondern in Konstantinopel bestatten lassen würde. Dies erscheint plausibel; allerdings bleibt auch in dieser Hypothese die fehlende Verwendung des Mausoleums durch ein anderes Mitglied der kaiserlichen Familie ein offener Punkt.

297 Anders Torelli 1992, 205f. der die Auflassung eines kaiserlichen Mausoleums für unwahrscheinlich hält und stattdessen an eine „famiglia di rango“ denkt.

298 Vgl. Krautheimer, in: Corpus II, 100f. u. die Rekonstruktionszeichnung ebd., 119, fig. 121. An derselben Stelle, an der sich bei der Basilika von S. Agnese das ursprünglich trikonchenartige Mausoleum der Constantina befand, wurde auch an der basilica maior eine Trikonche errichtet, in der ein Bischof Leo beigesetzt wurde (vgl. ebd., 95). Dessen Grabelogium ist wohl erst in die Zeit nach 384 zu datieren (vgl. Ferrua [1942], in: Epigrammata damasiana, 241f.). 
richtet wurde. Dieses aufwendige Mausoleum war - ähnlich wie das bautypologisch mit ihm verwandte Maxentiusmausoleum an der via Appia, das kurz nach dem Mausoleum bei Tor de' Schiavi errichtet wurde ${ }^{299}$ - mit hoher Wahrscheinlichkeit für einen Angehörigen des Kaiserhauses bestimmt. ${ }^{300} \mathrm{Da}$ mit hat wohl auch an der via Praenestina, ebenso wie beim Helenamausoleum und den Mausoleen bei S. Agnese und der basilica apostolorum, eine Verbindung zwischen der Errichtung einer Coemeterialbasilika und dem Totenkult für ein Mitglied der kaiserlichen Familie bestanden.

Im Unterschied zu den Mausoleen bei SS. Pietro e Marcellino, S. Agnese und der basilica apostolorum, die gleichzeitig mit der jeweiligen Basilika errichtet und mit den Basiliken zu einer baulichen Einheit verbunden wurden, bilden an der via Praenestina die Coemeterialbasilika und das Mausoleum getrennte Baukörper. Obwohl dieses Ensemble für die römischen Coemeterialbasiliken untypisch ist, eröffnet es dennoch interessante Aspekte auf die Relation der in den übrigen Coemeterialbasiliken zu einer Einheit verbundenen Baukörper von Basilika und Mausoleum zueinander. In dem Komplex an der via Praenestina war das Mausoleum derjenige Bau, der die Ausrichtung der Basilika festlegte: Die Basilika war eindeutig auf das Mausoleum bezogen, in dessen Temenos sie eindrang, ${ }^{301}$ nicht umgekehrt. Offenbar hatte hier bereits vor der Errichtung der Basilika ein freistehender Grabtempel existiert, der von seiner Anlage her unmöglich nachträglich in einen Annexbau für eine Basilika umgewandelt werden konnte. Wollte man, wie an der via Praenestina, erst im Nachhinein eine Beziehung zwischen einem Mausoleum und einer Coemeterialbasilika herstellen, dann bot sich keine andere Lösung an, als die Basilika dicht an das Mausoleum heranzurücken und auf diese Weise beide Gebäude aufeinander zu beziehen, ohne sie in eine direkte räumliche Verbindung miteinander zu bringen. ${ }^{302}$ Diese Disposition gibt Anlass zu der Hypothese, dass

299 Zum Verhältnis der beiden Bauten zueinander vgl. ausführlich Rasch 1993, bes. 92f., der das Maxentiusmausoleum aus bautypologischen Gründen in die Zeit kurz nach dem Bau des Mausoleums bei Tor de' Schiavi datiert; für den letzteren Bau unterscheidet Rasch zwei Bauphasen, die er mit ca. 305/306 und ca. 307/309 veranschlagt (ebd. 78f.).

300 Vgl. o., Anm. 82.

301 An der Stelle des geringsten Abstandes zwischen den beiden Bauten rückt die Basilika bis auf weniger als 5 Meter an das Mausoleum heran. Eine derartige Nähe zu einem anderen Bauwerk war in der Konzeption des Grabtempels bei Tor de' Schiavi ursprünglich sicher nicht vorgesehen, wie ein Vergleich mit dem Mausoleum der Maxentiusvilla zeigt, wo der Raum um den Grabtempel durch eine Temenosmauer abgegrenzt wurde, die die Anlage weiträumig umlief. Das Mausoleum bei Tor de' Schiavi war zwischen 307 und 309 in ähnlicher Weise als freistehender Grabtempel geplant worden; dass man eine spätere Störung dieses Temenos-Bezirks durch die Coemeterialbasilika in Kauf nahm, kann man nur damit erklären, dass der Erbauer des Mausoleums beziehungsweise einer seiner Nachfolger den Bau der Basilika in der Nähe des Mausoleums bewusst intendierte.

302 Rasch 1993, 80 bestreitet eine Beziehung zwischen der Basilika und dem Mausoleum von Tor de' Schiavi. Doch obwohl zwischen der Apsis der Basilika und dem Mausoleum keine ursprüng- 
auch bei den übrigen Coemeterialbasiliken, die von vornherein als Einheiten aus Basilikalbau und Mausoleum konzipiert waren, die Mausoleen nicht als Annexbauten der Basiliken fungierten, sondern umgekehrt diejenigen Baukörper waren, die für die Errichtung der Basilikalbauten Anlass gaben. ${ }^{303}$

Bisher hat sich demnach bei allen kaiserlichen Coemeterialbasiliken - mit der Ausnahme von S. Lorenzo f.l.m., wobei die unsicheren Grabungsbefunde hier kein sicheres Urteil erlauben - eine Verbindung zwischen der Basilika und einem hervorgehobenen Mausoleum nachweisen lassen, das wohl in allen Fällen für ein Mitglied der kaiserlichen Familie bestimmt war. Es bleibt abzuwarten, in welcher Weise die neuentdeckte Basilika an der via Ardeatina, deren Ausgrabungen noch nicht abgeschlossen sind, ${ }^{304}$ dieses Bild bestätigt oder modifiziert. Es ist bekannt, dass der römische Bischof Marcus (336) sich in diesem Coemeterium, das zwar aus kaiserlichen Mitteln, aber auf seine Initiative hin erbaut wurde, beisetzen ließ. ${ }^{305}$ Zwar steht kaum zu erwarten, dass ein Bischof, der nur wenige Monate sein Amt ausübte, in einem ähnlich auffällig plazierten Mausoleum untergebracht war wie die aus der kaiserlichen Familie stammenden Erbauer der übrigen Coemeterialbasiliken. ${ }^{306}$ Dennoch wird erst der weitere Verlauf der Grabung zeigen, ob die Errichtung von Gründermausoleen ein Privileg der kaiserlichen Familie war und in welcher Weise die römischen Bischöfe in ihren eigenen Bauprojekten und Grablegen auf die kaiserlichen Monumentalbauten und Mausoleen reagierten. 307

Ein abschließender Blick auf S. Pietro verdeutlicht die besondere Erscheinung der konstantinischen Umgangsbasiliken im Unterschied zur vatikanischen Petrusbasilika, die der Monumentalisierung eines Märtyrerschreins diente. Anders als bei den Umgangsbasiliken wurde an S. Pietro zunächst kein kaiserliches Mausoleum angebaut. Erst mit der (im Jahr 757 der Heiligen Petronilla geweihten) Rotunde am südlichen Ende des Querschiffs erhielt auch S. Pietro ein kaiserliches Mausoleum. Die früheste dort nachweisbare Bestattung ist die der Kaiserin Maria, der 407/408 verstorbenen Gattin des

liche Verbindung nachweisbar ist (vgl. Luschi/Ceccherelli 1987-88, 421: eine Tür, die sich von der Apsis in Richtung Mausoleum öffnete, wurde erst in späterer Zeit angelegt), muss man davon ausgehen, dass die Basilika in eine Relation zum Mausoleum gesetzt werden sollte.

303 Vgl. dazu mehr u., S. 165-171.

304 In Fiocchi Nicolai 1995-1996 ist nur der nordwestliche Sektor (innere Apsis; großer Teil des Umgangs im Apsisbereich, angrenzende Portikus und ein Mausoleum), der bei Grabungen von 1993-1996 freigelegt wurde, publiziert. Auf das Vorhandensein weiterer Mausoleen an der westlichen Längsseite der Basilika machen die Ausgräber bereits aufmerksam; darunter befindet sich ein auffällig großes Mausoleum, dessen Lage dem Mausoleum nr. 43 an der basilica apostolorum entspricht (ebd., 106; Fiocchi Nicolai 2002, 1179).

305 LP I, 202.

306 Bisher wurde ein besonders herausgehobenes Grab am Scheitelpunkt der inneren Apsis gefunden, das die Ausgräber als mögliches Grab des Gründers der Basilika ansprechen (vgl. Fiocchi Nicolai 1995-1996, 125).

307 Picard 1969, 736-740; zurückhaltender urteilt zurecht Borgolte 21995, 39. 
Kaisers Honorius (395-423); später wurden auch mehrere andere Mitglieder der honorisch-valentinianischen Dynastie dort beigesetzt. ${ }^{308}$ Dass die Petronillarotunde erst unter Honorius errichtet und von ihm als Mausoleum eingerichtet wurde, wird auch durch die Typologie des 1514/1519 abgerissenen Baus bestätigt, soweit sie sich aus frühneuzeitlichen Grundrisszeichnungen und Vergleichen mit der benachbarten und besser dokumentierten Rotunde von S. Andrea rekonstruieren lässt: Die beiden Rundbauten wurden gleichzeitig, und zwar erst um 400, an der Südseite von S. Pietro als Mausoleen erbaut. ${ }^{309}$

Dieser späte Anbau eines kaiserlichen Mausoleums lässt die besondere Funktion der konstantinischen Coemeterialbasiliken, bei denen die Mausoleen für Mitglieder der kaiserlichen Familie bereits beim Bau der Basiliken errichtet worden waren, nochmals deutlich hervortreten. Obwohl Konstantin mit der Petrusbasilika das größte und aufwendigste seiner Bauprojekte in Rom ins Werk setzte, haben weder er noch die Angehörigen seiner Familie diesen Bau als geeigneten Ort betrachtet, um sich dort bestatten zu lassen. Erst eine neue Dynastie suchte mit ihrem Mausoleum die Nähe zum bedeutendsten Heiligen der Stadt. Möglicherweise orientierte sich diese Initiative am Vorbild Konstantinopels, wo Kaiser Arkadios (395-408) an der Apostelkirche ein neues Mausoleum errichtete und dadurch auch seinen Bruder Honorius veranlasst haben könnte, im Westen des Reiches eine entsprechende dynastische Grablege in unmittelbarer Nachbarschaft eines Apostelgrabs anzulegen. ${ }^{310}$

308 Vgl. die Übersicht bei Johnson 1991, 334-339. Abgesehen von Maria ist kein weiteres namentlich identifizierbares Kaisergrab in der zu Beginn des 16. Jh. abgerissenen Rotunde entdeckt worden. Alle darauf bezüglichen Nachrichten beruhen auf z. T. späten literarischen Überlieferungen; dennoch erscheint unbestreitbar, dass der Bau als Mausoleum auch für andere Angehörige der honorisch-valentinianischen Dynastie fungierte.

309 Zu den Details vgl. Biering/v. Hesberg 1987, bes. 167-172; Rasch 1990, bes. 17f. (nach 360/370; vermutlich zu Beginn des 5. Jh.). Tolotti 1988, 308f. möchte die Rotunden von S. Petronilla und S. Andrea in die erste Hälfte des 4. Jh. datieren und vermutet in S. Petronilla das Mausoleum der Konstantinschwester Anastasia, doch spricht - wie Tolotti selbst bemerkt - die Typologie der beiden Rundbauten mit ihren quadratischen Nischen für eine spätere Datierung. Die Hypothese, dass in S. Petronilla Angehörige der konstantinischen Familie bestattet wurden, war bereits von Schumacher 1986 aufgeworfen worden, doch ist seine Rekonstruktion der Baugeschichte von S. Petronilla und S. Andrea nicht haltbar (vgl. dazu Biering/v. Hesberg 1987, 172) und auch die Inschriften aus der Vatikanbasilika, die Schumacher als Beleg für ein Mausoleum der konstantinischen Dynastie anführt, sind nicht aussagekräftig, da sie zum einen nicht mit der Petronillarotunde in Verbindung gebracht werden können und zum anderen die Beziehungen der dort genannten Personen zur konstantinischen Dynastie in hohem Maße spekulativ sind (vgl. auch u., S. 376, Anm. 180).

310 Darauf weist Johnson 1991, 339 hin. Damit erledigt sich auch die von Biering/von Hesberg 1987 aufgestellte Hypothese, wonach bereits Kaiser Theodosius I. (379-395) die beiden Rotunden als dynastische Grablege für seine Nachfolger (S. Petronilla) und als Kenotaph für sich selbst (S. Andrea) errichtet habe. 
Dies ist ein deutlicher Hinweis darauf, dass eine Deutung der Basiliken als monumentale Märtyrergedenkstätten, in denen sich die Angehörigen der kaiserlichen Familie einen privilegierten Platz ad sanctos hätten sichern wollen, zu kurz greift. Zu diesem Schluss gelangt man nicht nur deswegen, weil die konstantinische Familie ausgerechnet die Nähe zum angesehensten und mächtigsten Heiligen der Stadt offensichtlich nicht gesucht hat. Auch die unterschiedliche Architektur der Umgangsbasiliken und der vatikanischen Basilika weist in diese Richtung. Denn die Coemeterialbasiliken heben sich nicht nur in bautypologischer Hinsicht, durch ihre Form als Umgangsbasilken, von der vatikanischen Petrusbasilika ab, die als eine Verbindung von einem Querschiff mit Apsis und einer an diesen Baukörper angesetzten fünfschiffigen Basilika konzipiert wurde. Auch der Märtyrerkult erhielt in S. Pietro ein ganz anderes Gewicht: Dort ließ Konstantin unter höchstem architektonischen Aufwand den gesamten Bau auf die Ädikula, die vorkonstantinische Kultstätte des Apostels Petrus, die sich in einem Hof der vatikanischen Nekropole befand, ${ }^{311}$ ausrichten: Von einem Baldachin überwölbt und unmittelbar vor der Apsis plaziert, bildete die Petrusmemoria den architektonischen Mittelpunkt der Basilika. ${ }^{312}$

Gemessen an den aufwendigen Baumaßnahmen, die mit der Ausrichtung der vatikanischen Basilika auf die als Grabstätte des Petrus angesehene Ädikula verbunden waren, erscheinen Konstantins Bemühungen, die Grabstätten von Märtyrern in die Architektur der Coemeterialbasiliken einzubeziehen, um so verhaltener. Im Unterschied zur Vatikanbasilika, aber auch zu den frühesten, bereits unter Damasus (366-384) eingerichteten ${ }^{313}$ ad corpus-Basiliken verzichtete man darauf, die Basiliken so anzulegen, dass sie die Gräber von Heiligen einschlossen. Abgesehen von der basilica apostolorum, die direkt über der Triklia ad catacumbas errichtet wurde, ist nicht einmal ein direkter Zusammenhang zwischen den Coemeterialbasiliken und den Märtyrergräbern in den benachbarten Katakomben gegeben. Bei SS. Pietro e Marcellino, S. Agnese und S. Lorenzo f.l.m. lagen die Gräber der Märtyrer nicht unter der jeweiligen Basilika, sondern in unterirdischen Grabanlagen, die sich neben der Basilika erstreckten.

Auf diese Tatsache ist bereits vor längerer Zeit aufmerksam gemacht worden. ${ }^{314}$ Weniger Aufmerksamkeit hat man dem Umstand geschenkt, dass die Basiliken auch sonst keine besondere Ausrichtung auf die in ihrer Nähe bestatteten Märtyrer erkennen lassen. Bei der basilica apostolorum wurde die mit

311 S. o., S. 38.

312 Zur Einbeziehung der Petrusädikula in den konstantinischen Basilikalbau und zum hohen statischen Aufwand, den die Ausrichtung der Basilika auf die Ädikula erforderte, vgl. Arbeiter 1988, 51-55.

313 Vgl. o., Anm. 79.

314 Vgl. Deichmann 1946. 
der Apostelmemoria verbundene Triklia durch den Bau der Basilika unzugänglich: ${ }^{315}$ Einzig für das ebenfalls durch die Basilika überbaute Hypogäum mit dem Sebastiansgrab wurde durch die Anlage eines Zugangs von der Basilika aus gewährleistet, dass man es weiterhin erreichen konnte. In S. Agnese führte vom Atrium der Basilika aus ein monumentaler Zugang direkt zu dem in nördlicher Richtung gelegenen Agnesgrab, der in seiner erhaltenen Form jedoch vermutlich erst unter Bischof Liberius (354-366) angelegt wurde. Dass bereits in konstantinischer Zeit ein monumentaler Abstieg in die Katakombe der Heiligen bestand, ist nicht wahrscheinlich. ${ }^{316}$ Auch bei S. Lorenzo f.l.m. ist zwar in der Silvesterbiographie von gradus ascensionis und descensionis zum Laurentiusgrab die Rede, die Konstantin angelegt haben soll, aber es ist unklar, ob sie von der basilica maior ihren Ausgang nahmen. ${ }^{317}$ Noch auffälliger ist die Situation an der via Labicana und an der via Praenestina. In SS. Pietro e Marcellino existierte zu keiner Zeit ein unmittebarer Zugang, der von der Basilika zu den Gräbern der Heiligen Petrus und Marcellinus führte. ${ }^{318}$ Dies ist um so bemerkenswerter, als von der Basilika aus durchaus Treppen und Abgänge angelegt wurden, die eine Entwicklung neuer unterirdischer Gangsysteme mit Bestattungsplätzen unterhalb der Basilika zur Folge hatten. ${ }^{319}$ Obwohl die Basilika also Zugänge zu den unterirdischen Katakombenanlagen eröffnete, bildeten die Märtyrergräber kein besonderes Ziel und wohl auch nicht das Motiv für die Anlage dieser Abgänge. Noch deutlicher wird eine bestimmende Rolle der Märtyrergräber für die Anlage der Coemeterialbasiliken durch die Basilika bei Tor de' Schiavi an der via Praenestina in Frage gestellt: Hier hat eine Verbindung der Basilika mit einem unterirdischen Märtyrergrab nach dem gegenwärtigen Erkenntnisstand nie existiert, und es bestanden auch keine Verbindungen zu einer unterirdischen Grabanlage. ${ }^{320}$

\footnotetext{
315 Spera 1999, 220.

316 Fasola 1974, 204 macht unter den Stufen Spuren einer früheren Treppenanlage aus, datiert diese aber nicht in die konstantinische Zeit.

317 LP I, 181: fecit (scil. Konstantin) basilicam beato Laurentio martyri via Tiburtina in agrum Veranum supra arenario cryptae et usque ad corpus sancti Laurenti martyris fecit grados ascensionis et descenionis. Archäologische Hinweise auf eine Verbindung zwischen der basilica maior und dem Märtyrergrab wurden nicht entdeckt.

318 Ein Vorläufer der monumentalen scala S, der einen direkten Zugang zum Grab der Heiligen Petrus und Marcellinus ermöglichte, wurde erst nach 360, vermutlich unter Damasus, angelegt. Diese Treppe nahm ihren Ausgang nicht von der konstantinischen Coemeterialbasilika, sondern von einem Gebiet nördlich der Basilika (vgl. Guyon 1987, 389-397).

319 Die Regionen $\mathrm{C}$ und $\mathrm{M}$ waren durch Zugänge von der Basilika aus zu erreichen; die Region S durch einen Einstieg von der Portikus aus, die zusammen mit der Basilika errichtet wurde. Alle diese Regionen wurden nach dem Bau der konstantinischen Basilika angelegt (vgl. Guyon 1987, 288-300). Diese neuen, von der Basilika aus angelegten Regionen, wurden erst später mit der Region X verbunden, die das Grab der Heiligen Petrus und Marcellinus enthielt; zu den Verbindungen vgl. Guyon 1987, 289 (Region M) und 374f. (Region C). 
Zieht man eine Bilanz zur Verbindung zwischen den konstantinischen Umgangsbasiliken und den Märtyrergräbern in den ihnen benachbarten Katakomben, dann kann man kaum der Meinung derjenigen Forscher beipflichten, die die Basiliken als monumentale Zugänge $\mathrm{zu}$ den unterirdischen Heiligengräbern betrachten, auf deren Kult sie in besonderer Weise ausgerichtet gewesen seien. ${ }^{321}$ Die Basiliken erhoben sich zwar in der Regel in der Nachbarschaft unterirdischer Grabanlagen, in denen sich Märtyrergräber befanden. Doch sind direkte Verbindungen zwischen der Basilika und den Märtyrergräbern entweder gar nicht nachweisbar oder erst in späterer Zeit angelegt worden, als die Heiligengräber durch Monumentalisierungen wie die des römischen Bischofs Damasus (366-384) zunehmend an Bedeutung gewannen. ${ }^{322}$ Die Treppen zu den Katakomben, die zum Teil aus den Basiliken heraus angelegt wurden, unterscheiden sich in nichts von den Zugängen, die im Bereich jeder Katakombe in größerer Zahl an unterschiedlichen Stellen bestanden, um den Einstieg zu den einzelnen Regionen der Katakombe zu ermöglichen. ${ }^{323}$ Die konstantinischen Basiliken führten mit der Anlage derartiger Zugänge bereits bestehende Strukturprinzipien von Nekropolen weiter, ohne in irgendeiner Weise eine besondere Bezugnahme auf die unterirdisch bestatteten Märtyrer zu signalisieren: Sie sind, wie eingangs bereits erwähnt, ihrer äußeren Gestalt nach zunächst nichts anderes als monumentale Grablegen.

Dies heißt selbstverständlich nicht, dass die Coemeterialbasiliken keinerlei Bezug zum Märtyrerkult gehabt hätten: Das ist schon deswegen nicht anzunehmen, weil sich der Märtyrerkult als eine besondere Form aus dem Totenkult heraus entwickelt hat. Eine einseitige Interpretation der Basiliken als Märtyrerkultstätten weist den konstantinischen Anlagen jedoch von vornherein eine Funktion zu, die durch ihre architektonische Disposition nicht gedeckt wird. Aus diesem Grund erscheint es sinnvoller, bei den konstantinischen Coemeterialbasiliken die allgemeine Funktion als Stätten der Totenkommemoration in den Vordergrund zu stellen, von der das Märtyrergedenken ein zentraler, aber eben nur ein Teil ist. Damit wird ein neuer Blick auf die Anlagen und insbesondere auf die Mitglieder der kaiserlichen Familie möglich, die in ihren Mausoleen einen deutlich sichtbaren Anspruch auf kultische Kommemoration in den an die Mausoleen angeschlossenen Basiliken

321 So beispielsweise Tolotti 1982, 154, der die Relation der Basiliken zu den Gräbern als die eines „luogo esterno, quasi svincolato, come un atrio superiore, rispetto al sotteraneo“ auffasst.

322 S. dazu u., S. 303-305, 323.

323 Die Katakombenforschung der letzten Jahrzehnte hat insbesondere auf die kleinteiligen Ursprünge der unterirdischen Katakombenanlagen aufmerksam gemacht: Eine große Zahl einzelner, zum Teil nur wenige Gänge umfassender Hypogäen, die mit separaten Zugängen ausgestattet waren und erst später untereinander verbunden und zu großflächigen Gangsystemen ausgebaut wurden (vgl. zu dieser Entwicklung Spera 1999). 
formulierten. Im folgenden soll, ausgehend von der Anlage von SS. Pietro e Marcellino, der für die historische Entwicklung der römischen Coemeterialbasiliken eine Schlüsselfunktion zukommt, der Versuch unternommen werden, die kommemorative Funktion dieser Baukomplexe genauer zu bestimmen.

\section{2. 2. Märtyrerkult oder Kaiserkult?}

Wie bereits erwähnt, werden die kaiserlichen Mausoleen an den Coemeterialbasiliken allgemein als eine depositio ad sanctos aufgefasst, bei der die Basiliken den räumlichen und kultischen Orientierungspunkt der Heiligenverehrung gebildet hätten, auf den die Mausoleen als Annexbauten bezogen gewesen seien. Zuletzt hat Jürgen Rasch mit Blick auf SS. Pietro e Marcellino und das Helenamausoleum erneut nachdrücklich diese Relation der beiden Gebäude zueinander hervorgehoben: Im Ensemble von Basilika und Mausoleum sieht Rasch die Zuordnung eines Mausoleums an eine Kirche und damit eine „Unterordnung des Kaisers unter den Gott der Christen“"324 gegeben.

Diese Einschätzung beruht im wesentlichen auf der Stellung, die die Helenarotunde im architekturgeschichtlichen Kontext der Entwicklung spätantiker Kaisermausoleen einnimmt. Noch zu Beginn des 4. Jh. verkörpern das Maxentiusmausoleum und das Mausoleum bei Tor de' Schiavi freistehende Podiumrundbauten mit einem Pronaos und einem temenosartigen Bezirk, der die Eigenständigkeit dieser Baukörper betont. Im Helenamausoleum, das an eine Basilika angebaut wird, geht diese Eigenständigkeit sichtbar verloren: Das Mausoleum verliert seinen Temenos ebenso wie den Vorbau und das Podium, zu dem der Vorbau hinaufführte. Die Basilika bestimmt die Struktur des Mausoleums, dessen Bodenniveau an das der Basilika angeglichen wird, und das für seine architektonische Gestaltung als Obergadenrundbau charakteristische Elemente römischer Annexbauten aufgreift und weiterentwickelt. $^{325}$

Weiter unten wird deutlich werden, dass das, was sich aus einer rein architekturgeschichtlichen Perspektive als eine „Herabwürdigung“ vom Grabtempel zu einem Annexbau darstellt, anders zu bewerten ist, sobald man die kultischen Aspekte in diese entwicklungsgeschichtliche Abfolge vom freistehenden Podiumrundtempel zu einem an die Basilika angebauten Mausoleum miteinbezieht. ${ }^{326}$ Doch selbst, wenn man nur den architekturgeschichtli-

\footnotetext{
324 Rasch 1998, 48-50. Ähnlich bezeichnen Deichmann/Tschira 1957, 64 den Komplex aus Basilika und Mausoleum an der via Labicana als eine aus zwei Polen bestehende Struktur, heben jedoch die Abhängigkeit des Mausoleums von der Basilika hervor (ebd., 86-89).

325 Unmittelbare architektonische Vorbilder von Annexbauten lassen sich für das Helenamausoleum allerdings nicht geltend machen, vgl. Rasch 1998, $102 \mathrm{f}$.

326 Vgl. u., S. $210 f$.
} 
chen Kontext für eine Interpretation des Komplexes an der via Labicana zugrundelegt, sagt allein die Tatsache, dass hier ein kaiserliches Mausoleum an die Basilika angebaut wurde noch nichts über die Hierarchieverhältnisse der beiden Bauten zueinander aus. Bei der Basilika von Tor de' Schiavi, wo das Alter des Baus leider nicht genauer bestimmt werden kann, war es nachweislich das Mausoleum, das als Orientierungspunkt für die spätere Errichtung einer Coemeterialbasilika diente. Der Komplex aus Mausoleum und Basilika an der via Praenestina zeigt demnach eine Annäherung nicht des Mausoleums an die Basilika, sondern umgekehrt der Basilika an das Mausoleum, wie man sie ohne weiteres auch für SS. Pietro e Marcellino in Erwägung ziehen kann. ${ }^{327}$ Dass man jeweils zu unterschiedlichen architektonischen Lösungen kam, war allein dadurch bedingt, dass man an der via Praenestina einen bereits fertiggestellten Rundtempel vorfand, während bei SS. Pietro e Marcellino beide Bauten gleichzeitig errichtet wurden und damit andere Möglichkeiten bestanden, eine Bezugnahme der Basilika auf das Mausoleum baulich umzusetzen.

Folgt man dieser Hypothese, dann bildete auch an der via Labicana nicht die Basilika, sondern das Mausoleum den entscheidenden Bezugspunkt der gesamten Anlage, der auch die Errichtung der Basilika bestimmte. Zwar wurde die Basilika kurz vor dem Mausoleum errichtet, aber nach der oben vorgestellten Rekonstruktion war von vornherein ein Ensemble aus beiden Bauten ohne einen vorläufigen Abschluss des Basilikalbaus geplant gewesen. Zugegebenermaßen bleibt eine Entscheidung bezüglich der Relation der beiden Bauten zueinander jedoch schwierig, solange sie sich allein auf die architektonische Struktur der Anlage von SS. Pietro e Marcellino stützt. Man wird daher, um in dieser Frage weiter zu kommen, auch die kultische Disposition der Anlagen mit berücksichtigen müssen.

Auch in dieser Hinsicht ist in weiten Teilen der Forschung die Ansicht vorherrschend, dass die kaiserlichen Mausoleen auf die kultischen Vollzüge ausgerichtet gewesen seien, die sich in den Coemeterialbasiliken vollzogen. Die Basiliken gelten meist als Schauplätze einer liturgischen Märtyrerverehrung, für die diese neuen monumentalen Kulträume eigens errichtet wurden, und in den auch die Kaiser miteinbezogen werden sollten. ${ }^{328}$ Der räumlichen

327 Brandenburg 1979, 76; 1992, 45 verfolgt ähnliche Überlegungen, da er die Basilika von Tor de' Schiavi für die früheste unter den römischen Coemeterialbasiliken hält. Man muss jedoch SS. Pietro e Marcellino und den Komplex an der via Praenestina nicht in eine bestimmte zeitliche Relation zueinander setzen, um die These von einer Annäherung der Basilika an das Mausoleum auch für SS. Pietro e Marcellino anzunehmen; es genügt, davon auszugehen, dass hinter den beiden Anlagen ähnliche Vorstellungen standen, die sich jedoch bei SS. Pietro e Marcellino in anderer Weise verwirklichen ließen, weil hier die Basilika zusammen mit dem Mausoleum errichtet wurde.

328 Vgl. Schumacher 1987, 173, der die Basiliken als Mittel betrachtet, um den Märtyrerkult in die kirchliche Liturgie einzubinden. Von einer Teilhabe des Kaisers an der Kommemoration der 
depositio ad sanctos habe also auch in kultischer Hinsicht eine Ausrichtung der Kaiser auf den zu Ehren der Heiligen veranstalteten Kult entsprochen.

Insgesamt sind wir freilich über die kultischen Praktiken, die sich in den römischen Coemeterialbasiliken abspielten, so unzureichend unterrichtet, dass man diese Sicht der Dinge nicht zur Voraussetzung einer Deutung dieser Baukomplexe machen kann. Exemplarisch für den Interpretationsspielraum, der hinsichtlich der kultischen Nutzung der Coemeterialbasiliken besteht, ist eine bekannte Kontroverse zwischen Richard Krautheimer und Friedrich W. Deichmann. Krautheimer vertrat die Ansicht, dass die Coemeterialbasiliken nichts anderes als gewöhnliche Friedhöfe gewesen seien, die mit der Verehrung der Märtyrer, die sich an deren Gräbern in den Katakomben vollzogen habe, nichts zu tun gehabt hätten. Die Basiliken seien als reine Bestattungsund Totenkultanlagen von der kirchlichen Liturgie im wesentlichen unberührt gewesen, und der dort gefeierte Kult habe sich auf die Abhaltung nichtliturgischer Totenmähler beschränkt. ${ }^{329}$ Dem hielt Deichmann entgegen, dass man in den Coemeterialbasiliken sehr wohl die Eucharistie gefeiert habe, und dass die Märtyrer nicht nur in den unterirdischen Katakomben verehrt worden, sondern durch die Feier der eucharistischen Liturgie auch in den Coemeterialbasiliken, die sich über den Katakomben erhoben, präsent gewesen seien. ${ }^{330}$

Märtyrer und damit einer liturgischen Einbindung des Kaiserkommemoration in den Märtyrerkult geht aus Brandenburg 1992, 49-54; ders. 1995, 73 f.

329 Krautheimer 1960. Krautheimers Position hat sich in der Forschung weitgehend durchgesetzt, vgl. die o., Anm. 279 genannte Literatur.

330 Deichmann 1970. Zuletzt hat sich - in Anlehnung an Deichmann - erneut Lehmann 2003, bes. 68-73, dafür ausgesprochen, die Umgangsbasiliken des römischen Suburbiums als reguläre Kirchengebäude aufzufassen, die auch zum Zweck der Bestattung genutzt wurden. Er beruft sich darauf, dass die von Bischof Iulius (337-352) errichteten Bauten im Catalogus Liberianus des Chronographen von 354 unterschiedslos - also unabhängig von ihrer Lokalisierung innerhalb oder außerhalb der Stadtmauern - als basilicae bezeichnet werden, und dass erst im Liber Pontificalis zu Beginn des 6. Jh. die suburbanen dieser iulianischen Basiliken als cymeteria erscheinen. Lehmanns Schlussfolgerung, dass die suburbanen Basiliken ursprünglich Gemeindekirchen gewesen seien, die im Laufe des 5. Jh. ihren Status verloren hätten und dann zu reinen Grablegen abgesunken seien, stellt die historische Entwicklung jedoch auf den Kopf: Erst seit der Wende vom 4. zum 5. Jh. entwickelten sich die Heiligengräber und die Gebäude, in denen sie lagen, zu Zonen der Sepulkralarchitektur, aus denen nicht-liturgische Kultpraktiken abgedrängt wurden (vgl. die folgende Anm.), was wiederum die Voraussetzung dafür war, dass die bis dahin ausgeprägte Trennung zwischen regulären kirchlichen Versammlungsräumen für die Gemeinde und Bestattungsplätzen, die nur sporadisch für liturgische Versammlungen genutzt wurden, verschwand. In Rom selbst wird diese Entwicklung im Brief des römischen Bischofs Innozenz I. (401-417) an Decentius von Gubbio aus dem Jahr 416 fassbar: Innozenz unterscheidet zwischen den innerhalb der Stadt gelegenen tituli und den extra muros liegenden coemeteria als zwei unterschiedlichen liturgischen Zonen, die beide mit einem eigenen Klerus ausgestattet sind und einer regulären Gemeindeliturgie dienen (den Anlass des Schreibens bildete die Frage, ob der Bischof von Rom Partikel der in der Bischofsliturgie geweihten Eucharistie, das fermentum, nur an die Titelkirchen oder auch an die Coemeterien schickte, um es den Gaben der dort begangenen Eucharistiefeier beizumengen; dazu und zur Entwicklung der römischen Coemeterialbasiliken zur pfarrkirchen- 
Problematisch an dieser Forschungskontroverse ist vor allem der von beiden Seiten erhobene Anspruch auf Ausschließlichkeit. Er setzt eine eindeutige Funktionszuweisung der Basilikalräume voraus, der in konstantinischer Zeit noch gar nicht bestand und die erst gegen Ende des 4. Jh. auf zunehmenden Druck des Klerus hin angestrebt wurde. ${ }^{331}$ Bis zu dieser Zeit besteht aller Grund zu der Annahme, dass sowohl liturgische als auch nichtliturgische Versammlungen in den Coemeterialbasiliken stattfanden. Damit aber besteht auch keine Notwendigkeit, die Basiliken entweder als (nichtliturgische) Totenkult- oder als (der kirchlichen Liturgie vorbehaltene) Märtyrerkultstätten zu begreifen. Man muss vielmehr davon ausgehen, dass unterschiedliche Formen des Totengedenkens am selben Ort praktiziert wurden und die Coemeterialbasiliken keine eindeutig definierten Kulträume waren. ${ }^{332}$ Es empfiehlt sich daher, nicht von vornherein bestimmte - liturgische oder nichtliturgische - Kultpraktiken zum Ausgangspunkt einer Deutung der konstantinischen Coemeterialkomplexe zu machen. Sinnvoller erscheint es, allgemeiner von Totenkultpraktiken auszugehen, die in der Basilika und dem angrenzenden Mausoleum stattfanden, um von dort ausgehend den Versuch zu unternehmen, die Relation zwischen den Kultanlagen von Basilika und Mausoleum genauer zu bestimmen.

ähnlichen Gebilden für das Umland Roms seit dem 6. Jh. vgl. zuletzt Fiocchi Nicolai 1999). Der Ausdruck coemeterium im Liber Pontificalis bedeutet demnach nicht, wie Lehmann meint, „Grablege“ im Unterschied zu „Kirche“, sondern ist - analog zum titulus innerhalb des Stadtgebiets - eine administrative Bezeichnung für eine pfarrkirchenartige Verwaltungseinheit außerhalb der Stadtmauern (vgl. den Kommentar von Geertman 2003 [a], 309, Anm. 62f. zu der von Bischof Marcus 336 an der via Ardeatina errichteten Basilika, quem cymiterium constituit [LP I, 202]). Hinsichtlich der im Catalogus Liberianus begegnenden Bezeichnung basilicae für die von Bischof Iulius im Suburbium errichteten Gebäude ist zu bemerken, dass der Ausdruck basilica zwar auf eine Funktionsbezeichnung der Gebäude, nicht etwa auf einen bestimmten Architekturtyp abzielt (zur Bedeutung basilica $=$ aedes sacra vgl. Ferrua 1931-1933). Eine liturgische Nutzung der Coemeterialbasiliken bedeutet jedoch nicht, dass es sich bei ihnen um reguläre Gemeindekirchen gehandelt hat: Die Coemeterien wurden nur gelegentlich zu Gottesdiensten genutzt.

331 Die in den Basiliken veranstalteten Refrigerien wurden moralisch als „Saufgelage“ disqualifiziert und als häretische Praxis (Aug., epist. 29, 11; dens., mor. eccl. 1, 75; dens., serm. [cod. Guelf.] 28, 5; Zeno 1, 25, 11) oder als Relikte paganer Religiosität (Aug., conf. 6, 2; ders. serm. [Morin] 13, 4; ders., in psalm. 59, 15) verurteilt. Diese Versuche, die Schauplätze des Toten- und Heiligenkults einer amtskirchlichen Kontrolle zu unterwerfen, haben eine umfangreiche Behandlung in der Literatur erfahren; zu den wichtigsten Darstellungen zählen Quasten 1940; van der Meer 21951, 514-542; Saxer 1980, 133-149; Kotila 1992, 61-110. Für die Verhältnisse in Rom sind Äußerungen von Augustinus und Paulinus v. Nola von Interesse, aus denen hervorgeht, dass noch an der Wende vom 4. zum 5. Jh. solche Feiern in der vatikanischen Petrusbasilika abgehalten wurden (Paul. Nol., epist. 13, 11-14; Aug., epist. 29, 10).

332 Dass die Coemeterien bis zum ausgehenden 4. Jh. keine regulären Gemeindekirchen bildeten, sondern nur an bestimmten Toten- und Märtyrergedenktagen als liturgische Versammlungsräume dienten, hat bereits Wieland 1912, bes. 74-82, 91-96, 137-144 nachdrücklich hervorgehoben; zustimmend zuletzt Brandenburg 1995. 
Unter dieser Prämisse lohnt sich ein Blick auf die liturgische Ausstattung des Helenamausoleums und der Basilika von SS. Pietro e Marcellino, über die wir durch die Angaben der Silvestervita des Liber Pontificalis vergleichsweise gut unterrichtet sind. Wie für die anderen konstantinischen Sakralbauten, deren Gründung in der Silvestervita erwähnt wird, überliefert der Liber Pontificalis auch für die Basilika der Heiligen Petrus und Marcellinus und für das Mausoleum der Helena eine lange Liste von Gegenständen - Altäre, Patenen, Kelche, Leuchter - die für die beiden Bauten gestiftet wurden. 333

Basilika und Mausoleum weisen in der Stiftungsnotiz des Liber Pontificalis ein nahezu identisches Ausstattungsprogramm auf. Auf die einleitende Bemerkung, dass Konstantin die Basilika und das Mausoleum errichtet habe, folgt nach der Ankündigung posuit dona voti sui zunächst eine Reihe von Gegenständen, die sich auf das kaiserliche Mausoleum beziehen. Daran anschließend wird - eingeleitet durch die eingeschobene Bemerkung item in basilica sanctorum Petri et Marcellini donum dedit - das aufgeführt, was der Kaiser an kultischen instrumenta dem Basilikalbau zugedacht hatte. ${ }^{334}$ Beide Listen sind zwar in ihren Details unterschiedlich, entsprechen einander jedoch in der Art der aufgeführten Gegenstände: Es gibt kein spezifisches Gerät, das auf einen besonderen Kult in der Basilika, der sich von dem des Mausoleums unterschieden hätte, schließen lässt. Die Übereinstimmung zeigt vielmehr, dass dem gesamten Komplex, sowohl der Basilika als auch dem Mausoleum, eine gleichwertige Eigenschaft als Kultort zugewiesen wurde.

In welchem Verhältnis die beiden Bauwerke zueinander standen, verdeutlicht nicht nur die Reihenfolge der Auflistung im Liber Pontificalis, bei der die Ausstattungsstücke des Mausoleums an erster Stelle genannt werden, sondern auch der unterschiedliche Wert der Materialien: Die für das Mausoleum gestifteten Gegenstände übertreffen deutlich an Materialwert und an Gewicht die Stücke, die Konstantin für die Basilika stiftete. ${ }^{335}$ Für die Relation der bei-

333 LP I, 182f. Seit Duchesne (1886), in: LP I, CXLIII-CLIV geht die Forschung davon aus, dass diese im Liber Pontificalis überlieferten Listen auf historische Stiftungen zurückgehen, da die Listen Angaben enthalten, die zu Beginn des 6. Jh., als der Liber Pontificalis redigiert wurde, nicht mehr bekannt gewesen sein dürften (vgl. zuletzt Geertman 2003, 271 und - speziell mit Blick auf die Stiftungslisten der Silvestervita - Vera 2003).

334 Diese Liste für die Basilika enthält einen Altar und verschiedene Gefäßtypen, jedoch keine Gegenstände zur Beleuchtung der Basilika. Guyon 1987, 241 vermutet, der Verfasser des Liber Pontificalis habe die Ausstattung mit Lichtern bei der Basilika vergessen. Dass die Listen im Liber Pontificalis prinzipiell nicht vollständig sind, betont auch Geertman 1988, 139f. Beide Gebäude enthalten jeweils: einen Altar; eine bzw. zwei (Basilika) Patenen; mehrere amae und calices; die Basilika zusätzlich noch mehrere scyphi, deren Größe zwischen denen der amae und calices liegt. Die größere Anzahl von Gefäßen erklärt sich durch den im Vergleich zum Mausoleum größeren Teilnehmerkreis, der sich in der Basilika versammelte.

335 Zur Verteilung der liturgischen Gefäße zwischen Basilika und Mausoleum vgl. die Übersicht bei Guyon 1987, 240-242. Für die Ausstattung mit Leuchtern fehlt der Vergleichswert der Basilika (vgl. die vorige Anm.); ein Vergleich mit den übrigen konstantinischen Basiliken zeigt jedoch 
den Bauten zueinander setzte diese unterschiedliche Dotierung ein unmissverständliches Signal: Sowohl die Basilika als auch das Mausoleum verfügten über ein Ausstattungsprogramm mit liturgischen instrumenta, das sie zu selbständigen Kultorten machte, doch den Schwerpunkt innerhalb des Gesamtkomplexes bildete nicht die Basilika, sondern das Mausoleum.

Unter den Gegenständen, die für das Mausoleum gestiftet wurden, befand sich auch ein silberner Altar, der vor dem Porphyrsarkophag der Helena aufgestellt war. ${ }^{336}$ Überlegungen zur konkreten kultischen Funktion dieses altare sollen für einen Moment zurückgestellt werden: ${ }^{337}$ Entscheidend für die Relation von Basilika und Mausoleum zueinander ist zunächst die Tatsache, dass das Mausoleum, ebenso wie die Basilika, über einen eigenen Altar verfügte. Seine Lokalisierung vor der kaiserlichen Grablege signalisiert einen Kult, der direkt auf den Kaiser ${ }^{338}$ bezogen war. Der Kaiser hatte nicht etwa nur an einem Gedenken der Heiligen und der übrigen Toten teil, das in der angrenzenden Basilika stattfand, sondern zentrierte das kultische Gedenken unmittelbar auf seine Person. Die Kaiserkommemoration war demnach keine Teilhabe am Heiligenkult; sie vollzog sich vielmehr als ein selbständiger Kult, dessen kultische Parameter (Altar, Patene, Kelche) denen entsprachen, die auch in der angrenzenden Coemeterialbasilika vorhanden waren.

Inwieweit der Kaiser bei der Ausstattung seiner Grablege und des angrenzenden Basilikalbaus Maßgaben folgte, die sich an den kultischen Erfordernissen einer eucharistischen Heiligenliturgie orientierten, lässt sich nicht sicher bestimmen. Klar scheint jedoch, dass die Ausstattungselemente des Mausoleums stark von einer zeremoniellen, auf den Kaiser ausgerichteten Symbolik beeinflusst waren. Dies zeigen insbesondere die Lichter und Leuchter, mit denen das Mausoleum - wie auch die übrigen konstantinischen Sakralbauten Roms - in großer Zahl ausgestattet wurden, und deren Unterhalt durch die Stiftung von Öl bzw. von eigenen Landgütern in servitio luminum sichergestellt war. ${ }^{339}$ Obwohl Lichter und Feuer im Totenkult eine zentrale Rolle spielten, ${ }^{340}$ folgte die Ausstattung des Mausoleums und der römischen

auch hier, dass die Ausstattung des Mausoleums besonders kostbar war (vgl. Geertman 1988, 148f.).

336 Altarem ex argento purissimo, pens. lib. CC, ante sepulchrum beatae Helenae Augustae, qui sepulchrum est ex metallo puphyriticus exculptus sigillis.

337 Vgl. dazu u., S. 208-210.

338 Obwohl im Rundmausoleum bei der Basilika an der via Labicana die Mutter Konstantins, Helena, beigesetzt wurde, war das Mausoleum ursprünglich für die Bestattung Konstantins vorgesehen gewesen (vgl. u., S. 178f.).

339 LP I, 183: annis singulis oleum nardinum pisticum lib. DCCCC (SS. Pietro e Marcellino und Helenamausoleum), Öl in Verbindung mit Landgütern: LP I, 177f. (S. Pietro); 179 (S. Paolo f.l.m.); in servitio luminum: LP I, 173 (Lateranbasilika).

340 Vgl. Salomonson 1956, 20-27 (Lichter auf Grabreliefs); Scheid 1984, 121-126 (Rolle von Fackeln und Lichtern bei Leichenprozessionen). Zu Lichtern im christlichen Totenkult vgl. Rush 1941, 225-228. 
Coemeterialbasiliken keiner sepulkralen Symbolik: ${ }^{341}$ Auch die konstantinischen Sakralbauten nichtfuneralen Charakters, die Lateranbasilika und die Kirche im palatium Sessorium, waren ebenso reich mit Lichtern ausgestattet wie die Kultgebäude im Suburbium der Stadt. Mit den vier großen candelabra, die Konstantin im Mausoleum der Helena aufstellen ließ, nahm der Kaiser ein Element der kaiserlichen Repräsentation auf und übertrug es in den sepulkralen Kontext der kaiserlichen Bestattung. ${ }^{342}$

Diese Beobachtungen verkehren die These, der Kaiser habe an der via Labicana durch die Nähe zur Coemeterialbasilika am Kult für die Märtyrer partizipiert, tendenziell in ihr Gegenteil. Das Mausoleum war eine eigene Kultstätte, die in Relation zur angrenzenden Basilika den kultischen Schwerpunkt bildete, unmittelbar auf den Kaiser bezogen war und Elemente ihrer Ausstattung direkt aus der kaiserlichen Repräsentation übernahm. Die Ausstattung der Basilika folgte diesem Muster, und auch der dort vollzogene Totenkult, der vermutlich vorzugsweise für die Märtyrer gefeiert wurde, dürfte sich in seinen äußeren Formen an dem Modell orientiert haben, das die Kommemoration des toten Kaisers abgab. Vorbehaltlich der hier zunächst unberücksichtigt gebliebenen Kultpraktiken, die in der Basilika und dem Mausoleum vollzogen wurden, lässt sich damit allein aufgrund der räumlichen Disposition und der Ausstattung der Komplexe mit kultischen instrumenta die folgende Hypothese festhalten: Die römischen Coemeterialbasiliken verdankten ihr Entstehen in erster Linie nicht dem Märtyrerkult, sondern waren auf den Kaiser bezogene Kultstätten, die es ihm ermöglichten, den Herrscherkult an die Grablege des Kaisers und damit in ein Terrain zu verlagern, das im herkömmlichen römischen Kaiserkult keine Rolle spielte. ${ }^{343}$

Diese mit Blick auf den Coemeterialkomplex von SS. Pietro e Marcellino und Helenamausoeleum entwickelte Hypothese lässt sich durch weitere Beobachtungen zum Ensemble an der via Labicana stützen. Neben der Architektur der Anlage und ihrer Ausstattung mit kultischen Gerätschaften liefert auch die Lokalisierung Anhaltspunke dafür, dass nicht ein mit der via Labicana verbundener Märtyrerkult das bestimmende Motiv für die Errichtung der dortigen Basilika und des Mausoleums war. Darauf, dass das Grab der Heili-

341 Anders als die Verwendung von Lichtern und Kerzen bei der Dedikation von Kirchen: Dieser Usus geht auf Totenkultpraktiken zurück, da seit dem 6. Jh. jeder Altar mit Reliquien ausgestattet wurde und bei der Übertragung der Reliquien wie bei einer Leichenprozession Lichter mitgeführt wurden (vgl. dazu des Graviers 1962, bes. 122-125).

342 Gegen Johnson 1986, 179, der die Ausstattung des Helenamausoleums mit Lichtern aus dem Totenkult heraus erklärt. Zu Kandelabern in der kaiserlichen Repräsentation vgl. Alföldi 1970, 111-113 (Abbildungen auf dem Trajansbogen in Benevent und auf dem Severusbogen in Rom), weitere Belege bei Dendy 1956, 74-76. Eine Übertragung auf den funeralen Bereich ist für die Bestattung Konstantins explizit belegt: Der Kaiser wurde im Palast zwischen goldenen Kandelabern aufgebahrt (Eus., v. C. 4, 66).

343 Dazu und zu den Motiven der Verlagerung s. u., S. 181-190 u. 196-199. 
gen Petrus und Marcellinus, nach denen die Basilika zu einem genau bestimmbaren Zeitpunkt benannt wurde, in keiner räumlichen Verbindung zur Basilika stand und von der Basilika aus ursprünglich nicht zu erreichen war, wurde bereits hingewiesen. ${ }^{344}$ Die naheliegende Vermutung, dass nicht diese beiden Heiligen der Grund für die Anlage der Basilika waren, findet auch von anderer Seite Bestätigung. In der depositio martyrum des Chronographen von 354, die in der vorliegenden Form wohl bereits 336 erstellt wurde, ${ }^{345}$ ist kein Tag für den Kult der Heiligen Petrus und Marcellinus verzeichnet. Man hat diesen auffälligen Umstand, dass nur wenige Jahre nach dem Bau der Basilika keine kalendarischen Nachrichten zu den beiden Heiligen überliefert sind, deren Verehrung dieser Bau vermeintlich gelten sollte, damit zu erklären versucht, dass die depositio martyrum ein nur unvollständiges Verzeichnis der römischen Märtyrergedenktage enthalte. ${ }^{346}$ In der Tat ist die Zahl der in der depositio martyrum verzeichneten Heiligentage im Vergleich mit dem römischen Heiligenkalender des beginnenden 5. Jh. auffällig klein. ${ }^{347}$ Diese allgemeine Zunahme der römischen Märtyrergedenktage während des 4. Jh. hat jedoch andere Ursachen: Im Zuge des während des 4. Jh. stärker zunehmenden Heiligenkults gewannen auch immer mehr Märtyrergräber überlokale Bedeutung und vervielfältigten sich zudem die Orte, an denen in Rom man Märtyrergräber vermutete. ${ }^{348}$ Die Unvollständigkeit der depositio martyrum signalisert nichts anderes, als dass der Kult von Petrus und Marcellinus in den 30er Jahren des 4. Jh. zu unbedeutend war, um in das Verzeichnis aufgenommen zu werden übrigens im Unterschied zum Heiligen Gorgonius, der ebenfalls in der Katakombe von SS. Pietro e Marcellino bestattet lag und in der depostio matyrum aufgeführt ist. ${ }^{349}$

344 Vgl. o., Anm. 318.

345 Sicher ist, dass die als Pendant zur depositio martyrum erstellte depositio episcoporum des Chronographen von 354 in einer ersten Fassung im Jahr 336 redigiert wurde (vgl. zuletzt Salzman 1990, 280); für die depositio martyrum kann man dasselbe annehmen.

346 Deichmann/Tschira 1957, 76, Anm. 92. Mohlberg 1952, bes. 58-61 interpretiert die depositio martyrum wenig überzeugend als einen novatianischen Heiligenkalender (vgl. dazu u., S. 257f.).

347 Aufschlüsse über den römischen Heiligenkalender des frühen 5. Jh. erlaubt das Martyrologium Hieronymianum, in dessen ursprüngliche Redaktion, die um die Mitte des 5. Jh. in Italien erfolgte, ein stadtrömischer Heiligenkalender eingegangen ist, der unmittelbar nach 422 verfasst wurde (vgl. u., S. 456). Grundlegend für die Rekonstruktion dieses Kalenders von 422 ist Kirsch 1924; zur Beziehung zwischen der depositio martyrum und dem Kalender des frühen 5. Jh. vgl. ebd., 15f.

348 Zum Ausbau der römischen Heiligentopographie insbesondere unter Bischof Damasus (366384) s. u., S. 289f., 303-305, 323.

349 MGH AA IX, 72: V idus Sept. Gorgoni in Lavicana. Das Grab des Gorgonius muss sich nach Ausweis der frühmittelalterlichen Pilgerführer in der Katakombe bei der Basilika von SS. Pietro e Marcellino befunden haben, lässt sich allerdings nicht lokalisieren (vgl. Guyon 1987, 409f.). 
Bestätigt wird diese Skepsis gegenüber einem bedeutenden Kult für Petrus und Marcellinus an der via Labicana, der für den Bau der konstantinischen Basilika verantwortlich gewesen sei, durch die unterschiedlichen Bauphasen des Heiligengrabes, die Jean Guyon eingehend untersucht hat. Eine erste Erweiterung der Grabkammer von Petrus und Marcellinus und eine Verbindung mit denjenigen Regionen der Katakombe, die unter der Basilika lagen und durch deren Anlage entstanden waren, erfolgte erst, nachdem sich diese Regionen bereits über einige Jahre hinweg entwickelt und ausgedehnt hatten. ${ }^{350}$ Guyon zieht daraus die naheliegende Schlussfolgerung, dass nicht der Kult der beiden Heiligen zum Bau der Basilika geführt, sondern umgekehrt die Basilika den Kult von Petrus und Marcellinus populär gemacht habe. ${ }^{351}$ Dass die Silvestervita des Liber Pontificalis in der Einleitung zu den Listen mit den Stiftungsgütern für die Basilika und das Mausoleum die Basilika als eine konstantinische Gründung für den Presbyter Marcellinus und den Exorzisten Petrus ausweist, fällt demgegenüber nicht weiter ins Gewicht. Dort, wo er über die reine Aufführung der in den Stiftungslisten enthaltenen Güter hinausgeht, zeigt sich der Verfasser der Silvestervita auch sonst stark von der späteren hagiographischen Überlieferung beeinflusst, ${ }^{352}$ und seine Angaben verdienen in diesem Punkt entsprechend wenig Vertrauen.

Was für den Komplex an der via Labicana gilt, ist nicht ohne weiteres auf die anderen römischen Coemeterialbasiliken übertragbar. Aus S. Agnese ist eine Widmungsinschrift überliefert, aus der klar hervorgeht, dass Constantina die Basilika der Märtyrerin Agnes zueignete: Der Bau ist ein templum victricis virginis Agnes, ein dignum munus, das der Jungfrau Agnes zum Geschenk gemacht wurde. ${ }^{353}$ Anders als das Helenamausoleum in SS. Pietro e Marcellino, das an der Front der Basilika einen Gegenpol zum Basilikalbau bildete, ist das Mausoleum der Constantina an einer weniger prominenten Stelle, nämlich an der Seite der Basilika untergebracht. Auch war das Mausoleum zunächst deutlich weniger repräsentativ als das Mausoleum der Helena an der via Labicana: Dem späteren Rundbau von S. Costanza ging ein wesentlich bescheideneres

\footnotetext{
350 Guyon 1987, 365-367.

351 Ebd., 262, 367. Auch Pietri 1976, Bd. 1, 30 vertritt die Ansicht, dass der Kult von Petrus und Marcellinus für die Errichtung der Basilika keine Rolle gespielt habe. Eine ähnliche Überlegung wurde bereits von Schäfer 1932, 97-100 vorgetragen, der allerdings nicht den konstantinischen Bau, sondern den Bischof Damasus für die Prominenz des Kultes der beiden Heiligen verantwortlich machte.

352 LP I, 182: eisdem temporibus fecit Augustus Constantinus basilicam beatis martyribus Marcellino presbitero et Petro exorcistae in territurio inter duos lauros. Für Einflüsse der römischen Märtyrerlegenden auf die Stiftungsnotiz der Agnesbasilika vgl. o., Anm. 105 und 290.

353 De Rossi, Inscr. II, 44f. (= Damas., epigr. 71): Constantina deum venerans Christoq(ue) dicata /...sacravit templum victricis virginis Agnes /... dignum igitur munus, martyr, devotaque Christo , / ex opibus nostris per saecula longa tenebis, / o felix virgo memorandi nominis Agnes.
} 
Mausoleum voraus. ${ }^{354}$ Zudem taucht unter den Stiftungen des Liber Pontificalis für S. Agnese nur die Basilika auf; ein Mausoleum wird nicht erwähnt. ${ }^{355}$

Die Basilika von S. Agnese ist möglicherweise noch unter Konstantin begonnen worden, doch die Dedikationsinschrift wurde erst später, zwischen 337 und 351, angebracht. Damit liegt zwischen dem Komplex von SS. Pietro e Marcellino und der Agnesbasilika eine Spanne von 20 bis 30 Jahren, nicht eingerechnet die Tatsache, dass es nicht mehr Konstantin selbst, sondern seine Tochter war, die hier die Weihung vornahm. Auch in Konstantinopel, wo sich Konstantin im Apostoleion eine Grablege schuf, die die Konzeption des Komplexes an der via Labicana konsequent weiterentwickelte, ${ }^{356}$ geriet das Konzept, das der Kaiser verfolgt hatte, bereits unter seinem Sohn und Nachfolger Constantius II. (337-361) in die Kritik, die 359 zu einem Umbau der Anlage führte. ${ }^{357}$ Wenn etwa zur selben Zeit, möglicherweise nur wenige Jahre zuvor, auch in Rom die Coemeterialbasiliken ihren Status als Kaiserkultstätten verloren, dann sicher auch deswegen, weil eine Generation nach Konstantin das Verhältnis von Kaiser und Kirche kritischer beurteilt wurde. Die Spielräume, über die Konstantin für seine Interpretation des Christentums verfügte, engten sich ein, und die originellen Lösungen, die Konstantin in Rom und später auch in Konstantinopel für den Kaiserkult entwickelte, haben in beiden Fällen ihren Schöpfer nicht lange überlebt.

Damit nochmals zurück zur Coemeterialbasilika an der via Labicana. Wenn es nicht der Heiligenkult war, was bewegte Konstantin dann dazu, die Basilika ausgerechnet dort zu errichten? Konstantin schenkte dem Bau an der via Labicana, verglichen mit den übrigen Coemeterialbasiliken im Suburbium der Stadt, eine außergewöhnlich hohe Aufmerksamkeit. Die Summe der für den dortigen Komplex gestifteten Güter betrug 3754 solidi - ein Betrag, der weit über den S. Agnese (695 solidi) und S. Lorenzo f.l.m. (869 solidi) zugedachten Liegenschaften lag und sogar noch die Aufwendungen für die Petrusbasilika (3708 solidi) übertraf. Unter den von Konstantin im römischen Suburbium gestifteten Basilikalbauten nahm SS. Pietro e Marcellino damit die führende Position ein. ${ }^{358}$

Die Stiftungsliste des Liber Pontificalis liefert jedoch noch weitere Hinweise auf den Rang, den Konstantin der Basilika an der via Labicana zudachte. Unter

\footnotetext{
354 S. o., Anm. 289

355 LP I, 180.

356 Zum Apostoleion vgl. u., S. $211 \mathrm{f}$.

357 Vgl. Mango 1990, 59.

358 Für S. Paolo f.l.m. verzeichnet der Liber Pontificalis Güter in der Höhe von 4070 solidi, doch diese Liste ist in der überlieferten Form nicht konstantinisch, sondern vermutlich erst später, nach dem Neubau der Basilika Ende des 4. Jh. entstanden. Die ursprüngliche Stiftung beschränkte sich wohl auf eine insula Gordianon mit dem Ertrag von 800 solidi beim kilikischen Tarsos, das als Geburtsort des Paulus in besonderer Weise mit der Erinnerung an ihn verbunden war (vgl. Krautheimer 1980-1982, 210f.; zustimmend Marazzi 1998, 44, Anm. 45).
} 
den Ländereien, die Konstantin der Basilika übertrug, befindet sich an erster Stelle der Stiftungsliste ein fundus Laurentum, der sich, von der porta Sessoriana ausgehend entlang der via Labicana, im Norden und Süden von der via Latina und der via Praenestina begrenzt, bis hin zu einem mons Gabus erstreckte. ${ }^{359}$ Die genaue Ausdehnung dieses Landguts nach Osten ist wegen der Ungereimtheiten bezüglich des mons Gabus umstritten. ${ }^{360}$ Fest steht jedoch, dass dieser fundus von der porta Sessoriana, von der aus die via Labicana ihren Ausgang nahm, bis mindestens zur Basilika SS. Pietro e Marcellino, die gut drei Kilometer von den Stadtmauern entfernt an der via Labicana lag, reichte.

Diese topographische Schwerpunktsetzung an der via Labicana korreliert auffällig mit der übrigen Baupolitik des Kaisers im südöstlichen Bereich der Stadt. Um die porta Sessoriana herum hatte Konstantin nach 312 einen umfassenden Residenzkomplex geschaffen: In severischer Zeit waren im Südosten Roms mehrere kaiserliche Villen entstanden, die Konstantin zu einem einheitlichen Grundbesitz zusammenfasste, der von da an den Namen Sessorium erhielt. ${ }^{361}$ Das Ergebnis war ein zusammenhängendes kaiserliches Terrain, das sich beiderseits der aurelianischen Mauer vom amphitheatrum castrense bis hinauf zur porta Tiburtina erstreckte und in der Forschung vollkommen zutreffend als ein neues „,centro di potere“ bezeichnet worden ist. ${ }^{362}$

Es ist nicht bekannt, in welchem Maße diese Reorganisation des Territoriums im Südosten Roms auch das an den Palast anschließende Suburbium einbezog. Die severischen horti spei veteris, die im konstantinischen Sessoriumspalast aufgingen, umfassten auch Gebiete außerhalb der aurelianischen Mauer, die sich entlang der via Labicana erstreckten und erst durch den Mau-

359 LP I, 183: fundum Laurentum iuxta formam cum balneum et omnem agrum a porta Sessoriana usque ad via Penestrina a via itineris Latinae usque ad montem Gabum.

360 Guyon 1987, 244f. denkt an ein großes Mausoleum, das sich etwa 1, 5 Kilometer südlich von SS. Pietro e Marcellino erhob und im Mittelalter unter dem Namen monte del Grano bekannt war (so auch de Francesco 1990, 51f.). Sprachlich näher liegt jedoch die Identifizierung mit dem auch als monte Cavo bezeichneten Albanerberg, der allerdings in erheblicher Entfernung von Rom liegt; unmöglich ist diese Identifizierung dennoch nicht, da der fundus Laurentum kein geschlossenes Territorium war (vgl. u., Anm. 364) und der Albanerberg nach dieser Deutung nur die östliche Begrenzung eines kaiserlichen Streubesitzes bildete.

361 Vgl. dazu grundlegend Colini 1955. Den Kern der konstantinischen Anlage bildeten die borti spei veteris, die von Sepimius Severus begonnen und bis zu Elagabal, der dort ein Heiligtum für den Sonnengott aus Emesa errichten ließ, als Residenz genutzt worden waren. Unklar ist, wie weit sich das Sessorium darüber hinaus, vor allem in nördlicher Richtung erstreckte; Guidobaldi 1999 verweist auf kaiserliche Repräsentationsbauten aus konstantinischer Zeit in diesem Bereich und schließt daraus überzeugend, dass die kaiserliche Residenz sich bis zur porta Tiburtina ausdehnte und neben der Anlage ad spem veterem weitere horti einbezog, die Kaisern des 3. Jh. als Aufenthaltsorte gedient hatte (die horti Lamiani des Alexander Severus; die horti des Gallienus). Die Bezeichnung Sessorium ist erstmals im 6. Jh. nachweisbar und geht vermutlich auf die konstantinische Zeit und die flächendeckende räumliche Neuorganisation im Südosten der Stadt zurück.

362 Colli 1996, 809. 
erbau von der Stadt abgetrennt wurden. ${ }^{363}$ Es besteht Grund zu der Annahme, dass der fundus Laurentum, von dem im Liber Pontificalis die Rede ist, den Versuch darstellt, auch die zwischen der via Latina und der via Praenestina gelegenen Besitzungen des südöstlichen Suburbiums zu einem flächendeckenden fundus zusammenzufassen. Wie Filippo Coarelli überzeugend dargelegt hat, kann man nicht davon ausgehen, dass dieser neugebildete fundus ein durchgehendes Territorium bildete, das, von der aurelianischen Mauer ausgehend, den gesamten Bereich zwischen der via Latina und der via Praenestina umfasste. ${ }^{364}$ Vielmehr ist klar, dass diese beiden Straßen nur die äußeren Begrenzungen eines Gebiets bezeichneten, und dass die via Labicana, die ungefähr auf der Mitte zwischen der via Praenestina und der via Latina verlief, das Zentrum dieses fundus bildete, da in der Stiftungsnotiz des Liber Pontificalis als westliche Begrenzung des fundus Laurentum mit der porta Sessoriana eben der Punkt angegeben ist, an dem die via Labicana in die Stadt mündete. Damit kann es als sehr wahrscheinlich gelten, dass Konstantin nicht nur den Sessoriumspalast, dessen Gebiet über die aurelianische Mauer hinaus auf den Beginn der via Labicana übergriff, sondern auch den weiteren Verlauf der via Labicana bis mindestens zur Höhe des Coemeterialkomplexes von SS. Pietro e Marcellino zu einem einheitlichen Grundbesitz zusammenfasste. ${ }^{365}$

Die mit der Bildung des Sessorium verbundene Verlagerung der kaiserlichen Präsenz in den Südosten Roms führte nicht nur zur Gründung des coemeterialen Baukomplexes an der via Labicana, sondern beeinflusste auch die christliche Sakraltopographie innerhalb der Stadt. Im Sessoriumspalast selbst erhob sich die Kirche von S. Croce, und die erste Bischofskirche der Stadt Rom ließ Konstantin nur wenige hundert Meter westlich vom neuentstandenen konstantinischen Machtzentrum entfernt anlegen. Es ist daher naheliegend, die Basilika am dritten Meilenstein der via Labicana als Teil eines weitgespannten Projektes zu verstehen, das auf den Südosten der Stadt und des Suburbiums zentriert war. Mit S. Croce und der Lateranbasilika hatte

363 Vgl. Paterna 1996, 818.

364 Coarelli 1986, 35-40. Der fundus Laurentum setzte sich, wie ein Flickenteppich, aus unterschiedlichen kaiserlichen Ländereien zusammen, die sich in dem genannten Bereich entlang der via Labicana, die zwischen der via Latina und der via Praenestina verlief, befanden.

365 Ähnlich Drijvers 1992, 30-34 der ebenfalls davon ausgeht, dass der fundus Laurentum und das Sessorium eine Einheit bildeten; allerdings sieht er in der riesigen Fläche keinen Residenzkomplex Konstantins, sondern der Kaisermutter Helena. Die erhebliche Größe des im fundus Laurentum zusammengefassten Gebietes wird aus seiner Rendite von 1120 solidi ersichtlich, die den Betrag anderer im Suburbium gelegener Landstiftungen, die in den konstantinischen Stiftungslisten des Liber Pontificalis auftauchen, deutlich übersteigt (vgl. Marazzi 1998, 45). Es besteht im übrigen kein Grund zu der Annahme, dass der fundus erst nach Helenas Tod im Jahr 328/329 als eine „Seelstiftung“ der Kaiserin an die Basilika SS. Pietro e Marcellino übertragen wurde (so Piganiol 1932, 113; Deichmann/Tschira 1957, 75): Das Gebiet im südöstlichen Suburbium Roms dürfte schon frühzeitig, parallel zum Ausbau des Sessoriums, arrondiert und zur Lokalisierung und Finanzierung der kaiserlichen Coemeterialbasilika bestimmt worden sein. 
Konstantin die beiden einzigen christlichen Sakralbauten, die er innerhalb der Stadtmauern errichten ließ, als Teil seines Palasts bzw. in dessen unmittelbarer Nachbarschaft errichten lassen. Dieses Ensemble aus Bischofs- und Palastkirche vervollständigte Konstantin durch die Errichtung eines monumentalen Kaiserkultkomplexes, der ebenfalls an den topographischen Schwerpunkt angeschlossen wurde, der im Südosten Roms durch die Gründung des Sessorium und des fundus Laurentum entstanden war. Alle drei Projekte wurden vermutlich bereits bald nach 312 ins Leben gerufen, ${ }^{366}$ was ebenfalls zeigt, dass Bischofs-, Palast- und Coemeterialbasilika an der via Labicana Teil einer einheitlichen und umfassenden Planung waren. Die Vermutung liegt nahe, dass auch die anonyme Basilika an der via Praenestina im Zusammenhang mit dieser Installation einer christlichen Kulttopographie im südöstlichen Rom und seinem Suburbium steht. Die Basilika von Tor de' Schiavi zeigt eine Reihe von Eigenschaften, die sie der an der via Labicana annähern: Ähnlich wie bei SS. Pietro e Marcellino findet sich auch hier eine Ausrichtung der Basilika auf das Mausoleum, Verbindungen zu einem martyrialen Kultkomplex lassen sich nicht nachweisen, und die Lokalisierung an der via Praenestina lässt es möglich erscheinen, dass auch die Basilika bei Tor de' Schiavi Teil des fundus Laurentum war, der sich im Norden bis zur via Praenestina erstreckte. Damit könnte die Errichtung der Basilika von Tor de' Schiavi ebenfalls im Zusammenhang mit der Reorganisation des südöstlichen Suburbiums und der dortigen Installation einer christlichen Kulttopographie stehen - was freilich angesichts der vielen offenen Fragen, die sich mit diesem Bau verbinden, vorläufig eine Vermutung bleiben muss.

Dieser Hypothese, die der Coemeterialbasilika an der via Labicana eine besondere Bedeutung innerhalb des konstantinischen Bauprogramms zuweist, steht die von einem Teil der Forschung vertretenen Meinung entgegen, wonach die basilica apostolorum an der via Appia noch vor SS. Pietro e Marcellino errichtet worden sei. ${ }^{367}$ Diese Auffassung stützt sich jedoch entweder auf bautypologische Kriterien, die nach neuerem Erkenntnisstand eher auf eine spätere Entstehung der basilica apostolorum hinweisen, ${ }^{368}$ oder auf

366 S. o., S. 103-106.

367 Tolotti 1982, bes. 171, 175-178, 184; Brandenburg 1992, bes. 49f. Anders hingegen Rasch 1998, 46 u. 48, der für SS. Pietro e Marcellino einen etwas früheren Baubeginn ansetzt als für die basilica apostolorum.

368 Der Rundbau des Helenamausoleums wird mitunter als unmittelbare Vorstufe zum Mausoleum von S. Costanza bei S. Agnese interpretiert, wo der Bautyp des Rundmausoleums gegenüber dem Helenamausoleum weiter entwickelt und an einer anderen Stelle, der südlichen Seitenflanke der Basilika, plaziert worden sei (so Brandenburg 1992, 50, der daraus eine Reihenfolge basilica apostolorum - SS. Pietro e Marcellino - S. Agnese ableitet). Da S. Costanza jedoch nach neueren Erkenntnissen ursprünglich gar kein Rundmausoleum war, zeigt nicht SS. Pietro e Marcellino, sondern die basilica apostolorum eine engere Verwandtschaft mit dem Bau an der via Nomentana: Sowohl bei der basilica apostolorum als auch bei S. Agnese waren die Mausoleen keine Rundbauten, und in beiden Fällen waren sie an der Südseite der Basilika angebracht. Auch Tolotti 1982 sieht, 
kulttopographische Erwägungen, deren Folgerichtigkeit in Frage gestellt werden kann. ${ }^{369}$ Die oben entwickelte Überlegung, wonach die Bauten an der via Labicana und an der via Praenestina die frühesten Ausformungen des Typus der römischen Coemeterialbasilika darstellen, kann die größere Plausibilität für sich beanspruchen, nicht zuletzt, weil sie neben der Bautypologie auch andere Kriterien berücksichtigt. ${ }^{370}$ Die raison d'être der römischen Coemeterialbasiliken, als deren frühestes Beispiel die Basilika von SS. Pietro e Marcellino gelten kann, war danach nicht der Märtyrerkult, sondern der Kult für den verstorbenen Kaiser bzw. ein Mitglied des Kaiserhauses. Diese Situation änderte sich in nachkonstantinischer Zeit, als die Gebäude stärker auf den Märtyrerkult ausgerichtet waren: S. Agnese ist dafür ein sicherer Beleg, vermutlich aber auch schon die basilica apostolorum, da in beiden Gebäuden die kaiserlichen Mausoleen seitlich an die Basiliken angebaut wurden und nicht mehr ihrerseits die Ausrichtung der Basilika bestimmten, wie dies bei SS. Pietro e Marcellino und der Basilika bei Tor de' Schiavi der Fall war.

Dass Konstantin mit dem aufwendig dotierten Komplex an der via Labicana ursprünglich eine Grablege geplant hatte, in der er selbst seine Ruhestätte finden sollte, dürfte außer Zweifel stehen. Euseb spricht mit Blick auf das Mausoleum bei SS. Pietro e Marcellino nicht von einem Mausoleum der Helena, sondern unbestimmt von „den kaiserlichen Grabstätten“, in die die tote Kaisermutter 328 oder 329 überführt worden sei. ${ }^{371}$ Das Sujet des mit Schlachtenszenen geschmückten Porphyrsarkophags, in dem Helena bestattet wurde, ist auf ein männliches Mitglied des Kaiserhauses zugeschnitten. Am ehesten ist hier an Konstantin selbst zu denken, der ursprünglich mit seiner

ähnlich wie Brandenburg, in der basilica apostolorum den Prototyp der römischen Coemeterialbasiliken, aus dem sich SS. Pietro e Marcellino und die Basilika an der via Praenestina entwickelt hätten. Allerdings wirkt sein Versuch, die Anlage von Basilika und flankierendem Stiftermausoleum als eine Aufnahme der Struktur der Triklia unterhalb der basilica apostolorum zu interpretieren und damit den modellbildenden Charakter der Anlage an der via Appia zu erweisen, eher abwegig (vgl. Tolotti 1982, 172f. u. 184; 191f.).

369 Brandenburg 1992, 49f. geht davon aus, dass das an das südliche Seitenschiff der basilica apostolorum angesetzte Mausoleum nr. 43 in einer axialen Beziehung zu einem im Mittelschiff der Basilika aufgestellten Altar gestanden habe; das Helenamausoleum habe diesen axialen Bezug fortgeführt, jedoch den Platz an der südlichen Flanke verlassen und sich stattdessen in Längsausrichtung der Basilika befunden; in S. Costanza schließlich sei das Mausoleum wieder an die Südflanke der Basilika zurückgewandert, allerdings hier ohne einen axialen Bezug auf den Altar. Angesichts der Tatsache, dass das Helenamausoleum über einen eigenen Altar verfügte, muss man jedoch offenlassen, ob eine axiale Ausrichtung auf den Altar der Basilika im Komplex an der via Labicana überhaupt eine bestimmende Rolle gespielt hat.

370 Bedenken gegen die Möglichkeit, allein aufgrund ihrer bautypologischen Entwicklung die Coemeterialbasiliken von Tor de' Schiavi, SS. Pietro e Marcellino und die basilica apostolorum in eine zeitliche Reihenfolge zu bringen, erhebt Guyon 1987, 251-253, da über den Aufbau und den Kontext der Gebäude zu wenig bekannt sei.




Bestattung in Rom gerechnet hatte, jedoch schon vor Helenas Tod Ende der zwanziger Jahre mit Blick auf die neuentstandene Metropole am Bosporus andere Pläne verfolgte und daher den Sarkophag seiner Mutter überließ. ${ }^{372}$ Basilika und Mausoleum an der via Labicana sind daher vermutlich ebenso wie der Sessoriumspalast selbst Teil eines Residenzkomplexes, der ursprünglich nicht - bzw. nicht ausschließlich - für Helena, sondern für den Kaiser selbst bestimmt war. ${ }^{373}$ Konstantin verfolgte offenbar bereits bald nach 312 den Plan, die kultische Kommemoration des toten Kaisers an Räume zu binden, die von Christen für den Totenkult genutzt wurden.

Damit aber wurden die Christen von Konstantin in einen zentralen Bereich städtischer Identitätsstiftung und öffentlicher Kommunikation, nämlich den Kaiserkult, einbezogen. Dessen identitätsstiftendes Moment auf unterschiedlichen Ebenen, nicht nur für das Reich, die Provinzen und lokale Gemeinden, sondern vor allem auch für die Stadt Rom selbst ist offenkundig. Beim Tod des Kaisers, für den Konstantin durch seine Dispositionen an der via Labicana Vorsorge traf, wurde seine Bindung an Rom und an den Senat, der das caput imperii repräsentierte, besonders deutlich sichtbar: Die auf den Tod folgende Divinisierung des Kaisers, die mit seiner Erhebung zum divus einen Kaiserkult offiziell begründete, war Sache des römischen Senats, der traditionellen Führungselite der Stadt Rom. Der Kaiserkult war - ebenso wie seine Selbstdarstellung als Befreier von Unterdrückung und Willkürherrschaft, die Konstantin im Zentrum der Stadt inszenierte ${ }^{374}$ - eines der zentralen Kommunikationsfelder, durch das der Kaiser eine auf ihn bezogene Form städtischer Identitätsstiftung vermittelte. ${ }^{375}$

Die Coemeterialbasilika an der via Labicana war demnach alles andere als eine kaiserliche „Privatangelegenheit“. Sie war nicht nur allgemein zugänglich, nicht nur öffentlich in dem Sinne, dass sie in der Nähe des Kaisergrabs einen großen Versammlungsraum schuf, in dem große Menschenmengen zusammenkommen und ein - im rein numerischen Sinne - öffentliches Gedenken

372 Deichmann/Tschira 1957, 64, 74; Pietri 1976, Bd. 1, 32; Guyon 1987, 257. Anders Johnson 1986, 78-80, der von der Zweitverwendung eines maxentischen Sarkophags ausgeht.

373 So auch Colli 1996, 808f. Drijvers 1992, 30-34, 45-48 betrachtet das Sessorium als Residenz und Besitz der Helena, ebenso wie den in südöstlicher Richtung angrenzenden fundus Laurentum, der in der Stiftungsnotiz des Liber Pontificalis in einem Zusatz als eine possessio Helenae bezeichnet wird. Dabei dürfte es sich jedoch um einen späteren Einschub handeln, da die Auflistung der fundi im Liber Pontificalis sonst nicht attributiv mit derartigen Zusätzen wie possessio $N N$ verbunden werden (vgl. dazu Coarelli 1986, 39, der den Zusatz allerdings für original hält und als Präzisierung dahingehend versteht, dass nicht das gesamte Gebiet zwischen via Latina und via Praenestina, sondern nur der Besitz der Helena an die Basilika gehen sollte - wenig überzeugend, da ja mit fundus Laurentum bereits eine präzise topographische Angabe gegeben war und mit dem Zusatz posessio Helenae kein zusätzlicher Präzisionsgewinn verbunden gewesen sein dürfte).

374 S. o., S. 122-133.

375 Zur identitätsrelevanten Bedeutung des Kaiserkults für das politische Reichszentrum Rom und die Kommunikation des Kaisers mit den senatorischen Eliten vgl. auch Gradel 2002, 341-349. 
an den Kaiser begehen konnten. ${ }^{376}$ Konstantin bekundete vielmehr mit der Errichtung dieser Kaiserkultstätte die Absicht, einen bestimmten Aspekt kaiserlich vermittelter städtischer Identitätsstiftung aus der traditionellen Kommunikation mit dem senatus populusque Romanus auszugliedern und stattdessen die christliche Gemeinde Roms zur Trägerin dieses Bereichs der öffentlichen Kommunikation zu machen. Wie die Konsekration selbst, die vom Senat vorgenommen wurde, waren auch die Kaiserkultstätten häufig auf den Beschluss des senatus populusque Romanus hin errichtet worden ${ }^{377}$ - anstelle eines derartigen, vom Senat beschlossenen und errichteten Kaiserkulttempels war es eine Coemeterialanlage auf einem christlichen Friedhof, die Konstantin als künftigen Kultort für den verstorbenen Kaiser ausersehen hatte.

Hugo Brandenburg hat in einem zentralen Beitrag zu den konstantinischen Kirchenbauten Roms die Neuartigkeit des konstantinischen Konzepts der Coemeterialbasilika hervorgehoben: Die kaiserlichen Mausoleen, die während des 3. Jh. im römischen Suburbium errichtet wurden, hätten keine den Coemeterialbasiliken vergleichbaren Kultstätten in ihrer Nähe gehabt, und generell ließen sich keine unmittelbaren architektonischen Vorbilder für die konstantinische Verbindung von kaiserlicher Grablege und basilikaler Kultstätte benennen. ${ }^{378}$ Diese Beobachtung ist zutreffend, aber sie kann unter Einbeziehung einer religions- und kulturgeschichtlichen Perspektive in einen weiteren Kontext gestellt und hinsichtlich möglicher Vorläufer und Anstöße für die konstantinischen Anlagen präziser gefasst werden. Die folgenden Teilkapitel sind diesen beiden Aspekten gewidmet. Zunächst soll die traditionelle Trennung von Kaisergrablege und -kultstätte vor dem Hintergrund der römischen Divinisierungspraxis erläutert werden. In diesem Punkt begannen sich seit dem ausgehenden 3. Jh. deutliche Veränderungen abzuzeichnen, die jedoch innerhalb des traditionell bestehenden Systems kultischer Ehrungen für den Kaiser zu nur schwer überbrückbaren Spannungen führten. Diese wurden erst durch Konstantin ausgeglichen, der mit dem christlichen Märtyrer-

376 Abwegig erscheint die Vorstellung von Mackie 1997, 393f., die kaiserlichen Mausoleen hätten private, von den basilikalen Hauptgebäuden abgesetzte Räume für die ,personal needs of the imperial family“ gebildet. Die ganze Struktur der Anlagen legt das Gegenteil nahe, nämlich in der Nähe des Kaisergrabs Öffentlichkeit schaffen zu wollen. An der via Labicana wurde die enge Verbindung zwischen Basilika und Mausoleum außerdem dadurch unterstrichen, dass sie einen einheitlichen Baukomplex bildeten. Auch das große Fassungsvermögen der für das Helenamausoleum gestifteten amae, die mehrere hundert Liter umfassten, überstiegen den Bedarf einer im Mausoleum versammelten Gemeinschaft von Feiernden bei weitem; möglicherweise wurde in diesen Gefäßen Wein gesammelt, der dann für Mahlteilnehmer auch in der Basilika ausgeschenkt wurde (vgl. Tolotti 1986 [a], 496, der dabei an einen eucharistischen Gottesdienst denkt).

377 Vgl. die Dedikationen für Vespasiantempel und für den Antoninus Pius und Faustina-Tempel: CIL VI, 938: divo Vespasiano s(enatus) p(opulus)q(ue) R(omanus) imp(eratores) Caes(ares) Severus et Antoninus pii felic(es) Aug(usti) restituer(unt); CIL VI, 1005: divo Antonino et divae Faustinae ex s(enatus) d(ecreto).

378 Vgl. Brandenburg 1992, $52 \mathrm{f}$. 
und Totenkult auf ein neuartiges Modell zur Verbindung von diviner Göttlichkeit und Grabkult zurückgriff und dadurch die schon seit längerer Zeit bestehenden Tendenzen einer konsequenten Lösung zuführte.

\section{2. 3. Rituelle Strukturbedingungen des römischen Kaiserkults}

Für den römischen Kaiserkult konstitutiv war die Existenz eines Tempels oder einer aedicula für den divinisierten Kaiser, die von seiner Grablege getrennt war. Erst als Toter erlangte der Kaiser offiziell einen göttlichen Status als divus - und dies warf zugleich Probleme für die kultische Verehrung des gleichzeitig toten und divinisierten Kaisers auf. Denn sein religiöser Status als divus, in den der Kaiser nach seinem Tod überführt wurde, erforderte für den Kaiserkult Schauplätze und kultische Handlungen, die den divinisierten Kaiser von seiner Stellung als Toter klar abhoben.

Das Grab, in dem die sterblichen Überreste des Kaisers ruhten, verwies auf eine unbestimmte Schatten- und Unterwelt, als welche in zahlreichen römischen Grabinschriften der Aufenthaltsort erscheint, in den die Seelen der Toten gelangten. ${ }^{379}$ Auch die am Grab vollzogenen Totenkultriten zeigten durch die spezifische Art der Opfergaben und ihrer Darbringung, dass sie eine rituelle Überführung der Toten in eine von der oberirdischen Welt der Lebenden getrennte Unterwelt bewirken sollten. ${ }^{380}$ Während der alljährlich im Februar zur Feier des Totenkults stattfindenden parentalia blieben die Tempel geschlossen: Zwischen den Toten und den di superi sollten keine Berührungspunkte bestehen. ${ }^{381}$ An diesem Status der Toten scheinen auch die positiveren Jenseitsvorstellungen der Kaiserzeit ${ }^{382}$ nichts Grundlegendes geändert zu haben. Auch unter der Vorgabe, dass die Seelen der Toten zunehmend in einem nicht mehr unterhalb der Erde gelegenen Bereich des Kosmos vermutet wurden, gelangten sie dennoch nicht in die Regionen der Götter - Götter- und Totenwelt blieben voneinander getrennte Bereiche.

\footnotetext{
379 Vgl. o., S. 57.

380 Das Blut der anlässlich der Bestattung geopferten porca praesentanea lässt sich ebenso wie das der bei den Leichenspielen getöteten Gladiatoren als eine spezifische Gabe für die Toten auffassen (vgl. Maurin 1984, 203f.). Das Motiv des Ausgießens von Opfergaben, die in den Boden versenkt wurden, wiederholte sich bei den Kommemorationsfeiern für die Toten: Wein wurde bei Libationen in den Boden gegossen; die Opfergaben für den Toten wurden ebenfalls auf dem Boden plaziert, er erhielt keinen Platz am Tisch der lebenden Mahlteilnehmer zugewiesen (vgl. Scheid 1984, 133f., der auch das Ausstreuen von Veilchen und Rosen über dem Grab als einen Gestus des Ausgießens auffasst; dens. 2000, 135f.). Bestimmte der bei den Totenmählern (Bestattung und Kommemoration) den Toten zugedachten Speisen (Milch, Honig, dunkle Opfertiere, schwarze Bohnen, vgl. dazu Lindsay 1998, 75f.; dens. 2000, 167) unterschieden sich von den Opfergaben für die di superi und entsprachen denen für chthonische Gottheiten.

381 Scheid 1993, 197.

382 Vgl. o., S. 59.
} 
Mit der Divinisierung hingegen wurde der tote Kaiser in ein Register von Göttlichkeit gehoben, das andere Formen der kultischen Verehrung verlangte als der Totenkult. Der senatorische Beschluss, einem divus himmlische Ehren (honores caelestes) zu erweisen, ${ }^{383}$ stellte den toten Kaiser ausdrücklich in eine Reihe mit den di superi, deren Sphäre von derjenigen der Toten, wie oben gesehen, streng geschieden war. Obwohl der Begriff divus eine spezifische Form von Göttlichkeit signalisierte, die den zum Gott erhobenen Menschen von den dei perpetui unterschied, ${ }^{384}$ stiftete dies keine erkennbare Differenz zwischen divi und dei: Der Tod - das zentrale Merkmal, das die menschliche Herkunft des divus dokumentierte - bewirkte nicht, dass man den divus mit der Welt der Toten in Verbindung brachte. Vielmehr nahm der divus in der Kommunikation mit der menschlichen Welt eine Stellung ein, die derjenigen der oberirdischen Götter entsprach. Die vom Senat verfügte relatio inter divos war dementsprechend auch gleichbedeutend mit einer Versetzung unter die Götter (dę). ${ }^{385}$ An dieser Einbeziehung des Kaisers in ein System kultischer Ehrungen, wie sie für Götter dargebracht wurden, hat sich bis in die Spätantike hinein nichts geändert: Eutrop schreibt von allen divinisierten Kaisern bis hin zu Iovian (364), man habe sie unter die divi aufgenommen beziehungsweise ihnen göttliche Ehren verliehen. ${ }^{386}$

Die dadurch bedingten Unterschiede des Kaiserkults zum Totenkult werden vor allem deutlich, wenn man sich kontrastierend die postumen Feiern für mehrere männliche Angehörige des iulisch-claudischen Kaiserhauses vergegenwärtigt, die am Jahrestag ihres Todes durch besondere Kultfeiern geehrt, jedoch nicht divinisiert wurden. An diesen Feiertagen blieben - wie auch

383 Vgl. die Fasti Amiternini zum 17. September: eo die divo Augusto honores caelestes a senatu decreti (Inscr. Ital. XIII, 2, 193), ebenso Fasti Antiates (ebd., 209); Fasti viae dei Serpenti (ebd., 215); ferner Tac., ann. 12, 69, 1: caelestesque honores Claudio decernuntur, ähnlich Hist. Aug., Hadr. 6, 1: Traiano divinos bonores datis ad senatum et quidem accuratissimis litteris postulavit (scil. Hadrian). Weitere Beispiele bei Clauss 1999, 24f.

384 Vgl. die in diesem Zusammenhang häufig zitierte Bemerkung des Serv., Aen. 5, 45: ,divum et ,deorum indifferenter plerumque ponit poeta, quamquam sit discretio, ut deos perpetuos dicamus, divos ex bominibus factos, quasi qui diem obierint: unde divos etiam imperatores vocamus.

385 Vgl. das SC de Gnaeo Patre Pisone (Eck 1996), Z. 69f.: antequam in deorum numerum referre $\{n\}$ tur (über Augustus); Sueton, Caesar 88, 1 (in deorum numerum relatus est); Sueton, Augustus 97, 1-3 (ut inter deos referretur); Eutr. 8, 10, 4 (über Lucius Verus): inter deos relatus est als Variante zum bei Eutrop üblichen inter divos relatus est.

386 Eutr. 8, 7, 3 (über Hadrian): senatus ei tribuere noluit divinos honores; die übliche Formulierung lautet inter divos relatus est. Leichtere Modifikationen der Formulierung sollte man nicht überbewerten; so ist die Wendung meruit inter divos referri keine Abschwächung mit Blick auf die christlichen Kaiser des 4. Jh., schon deswegen nicht, weil sie bei Eutrop auch im Zusammenhang mit Decius und Aurelian auftaucht und weil umgekehrt auch für den christlichen Kaiser Iovian die gängige Formulierung (inter divos relatus est, Eutrop 10, 18, 2) gebraucht wird (vgl. auch Cracco Ruggini 1977, 433; anderer Auffassung ist Schumacher 1995, 110f.). 
an den parentalia im Februar - die Tempel geschlossen, ${ }^{387}$ die Riten fanden am Grab des Verstorbenen statt, ${ }^{388}$ und die Art der dargebrachten Opfer entsprachen denen, die man für Gottheiten der Unterwelt opferte (Holocaustum, Milch, Honig). ${ }^{389}$ Es waren besonders aufwendige und im Namen der Gemeinde (publice) dargebrachte Totenopfer (parentationes), die sich an die Manen der Verstorbenen richteten, ${ }^{390}$ und die nicht an den Geburts-, sondern an den Todestagen der Geehrten stattfanden. ${ }^{391}$

Im Unterschied zu diesen parentationes wurde der tote Kaiser in seiner Eigenschaft als divus nicht mit Gräbern und mit Bestattungsriten in Verbindung gebracht. Den räumlichen Fokus der Verehrung des divus bildete nicht das Grab, sondern der - räumlich vom Grab getrennte - Tempel des Kaisers; und zu den unterschiedlichen Ereignissen, die im kalendarischen Ablauf des Jahres besonderen Anlass zur kultischen Verehrung gaben, zählten vor allem der Geburtstag und der dies imperii, nie jedoch der Todestag des divinisierten Kaisers. In der pompa funebris eines verstorbenen Kaisers, die traditionell diejenigen Vorfahren des Verstorbenen vorführte, die durch ihre politischen Leistungen hervorgetreten waren, fehlten die Bilder seiner divinisierten Vorgänger. Dies wird übereinstimmend und plausibel als eine bewusste Abgren-

387 Für Germanicus ist sicher belegt, dass anlässlich der jährlichen parentatio die Tempel geschlossen blieben (tabula Hebana, Z. 57-59 [in: Crawford 1996, Bd. 1, 521]: utiq(ue) a(nte) d(iem) [(sextum) id(us) Oct(obres) quo die Germanicus Caes(ar) defun]/ctus est templa deor(um) inmortalium quae in urbe Roma $\{m\}$ prop $\{r\}$ iusve urbem [Romam passus (mille) sunt erunt quot annis]/ clausa sint idque ut fiat ii qui eas aedes tuendas redemptas habent b [abebunt curent. Für Drusus berichtet Tac., ann. 4, 9, 2, dass dieselben Ehrungen wie für Germanicus, mit einigen Zusätzen versehen, beschlossen worden seien (eadem quae in Germanicum decernuntur, plerisque additis). Im Pisaner Ehrenbeschluss bezüglich der Totenfeiern für Lucius Caesar ist ein entsprechender Passus nicht überliefert, allerdings wird abschließend festgehalten, dass man sich zusätzlich zu dem Dekretierten an dem orientieren wolle, was der römische Senat an diesem Tag ,zu vermeiden und zu unterlassen“ beschlossen habe (CIL XI, 1, 1420, Z. 31-33: nam quod ad cetera/ sollemnia, quae eodem illo die vitari caverique placuissent placerent/que, id sequendum quod de iis senatus p(opuli) R(omani) censuisset). Möglicherweise implizierte diese Formel, dass auch am Todestag Lucius Caesars die Tempel geschlossen bleiben sollten.

388 Am Todestag des Germanicus war das Augustusmausoleum der Schauplatz von parentationes, die von den sodales Augustales vorgenommen wurden (tabula Siarensis fr. (b), col I, Z. 4f. (in: Crawford 1996, Bd. 1, 516): eodem ritu sacrifici quo [publice inferiae mittuntur] manibus C(ai) et L(uci) Caesarum und tabula Hebana, Z. 59-61 (ebd., 521): utiq(ue) eodem die magistri]/ sodalium Augustalium qui quoq(ue) anno erunt inferias ante tumulu[m divi Augusti manibus Germanici Cae]/saris mittendas curent); zur Bestattung des Germanicus im Augustusmausoleum s. v. Hesberg/Panciera 1994, 118-129.

389 Vgl. dazu - mit Blick auf die pisanischen Opfer für L. Caesar und das bei Vergil beschriebene Totenopfer für Anchises (Verg., Aen. 5, 42-103) - Scheid 1993, 197-199, dens. 2000, 134-136.

390 Für die Pisaner Ehrendekrete für L. und C. Caesar vgl. CIL XI, 1, 1420, Z. 16-21: utique/ apud eam aram quodannis... p] ublice manibus eius per magis/tratus eosve, qui ibi iure dicendo pr[ae]runt... /...inferiae mi/ttantur, bosque et ovis atri infulis caerulis infulati diis manibus ein $/ \mathrm{s}] /$ mactentur und CIL XI, 1, 1421, Z. 31-33: ut[ique] eo die quodannis publice manibus eius per magistratus eosve,/ qu[i Pi]sis iure dicundo praerunt eodem loco eodemque modo quo/ L. C[aes]ari parentari institutum est, parentetur.

391 Zur kalendarischen Kommemoration der Todestage des Lucius und Caius Caesar, des Germanicus und des Drusus in den Fasten vgl. Vidman 1971. 
zung des vergöttlichten Kaisers von der Sphäre des Todes erklärt: ${ }^{392}$ Die Bilder der divi hatten den Status von Kultbildern und unterlagen damit einer ähnlichen Grenzziehung wie die Tempel der di superi, die während der parentalia und bei öffentlichen Leichenbegängnissen ebenfalls geschlossen waren. Auch die Grabtituli der toten Kaiser sind kürzlich in einem ähnlichen Licht interpretiert worden. Während unter normalen Umständen ein vergöttlichter Kaiser alle Namensbestandteile der Titulatur ablegte, die er zu Lebzeiten geführt hatte, und von da an nur noch als divus bezeichnet wurde, ${ }^{393}$ gaben die Grabinschriften der Kaiser - obwohl zum Teil sicher erst nach deren Divinisierung angefertigt - nicht die divus-Titulatur, sondern das Namensformular wieder, das der Kaiser zum Zeitpunkt seines Ablebens geführt hatte. ${ }^{394} \mathrm{Ob}-$ wohl die Gründe dafür wohl primär politischer, nicht religiöser ${ }^{395}$ Natur

392 Scheid 1993, 197; Fraschetti 2000, 151; Gradel 2002, 332. Diese Sicht der Dinge ist schon antik (vgl. Cass. Dio 47, 19, 2).

393 Vgl. das Material bei Chastagnol 1984, der auch vereinzelte Ausnahmen und Mischformen zwischen der Titulatur des lebenden Kaisers und der des divus diskutiert. Ein genereller Sonderfall ist Trajan, da er seinen parthischen Triumph postum abhielt und ihm der Titel Parthicus erst verliehen wurde, nachdem er bereits zum divus ernannt worden war (zu Parthicus als regulärem Bestandteil der divus-Titulatur Trajans und zu den außergewöhnlichen Umständen seiner Beisetzung vgl. unten).

394 Vgl. die Grabtituli im Augustus- und Hadriansmausoleum: CIL VI, 40375 (Vespasian; zur Ergänzung der fragmentarischen Inschrift vgl. Panciera, in: v. Hesberg/Panciera 1994, 142-144; die Skepsis von Arce 1988, 78 bezüglich einer Bestattung Vespasians im Augustusmausoleum erscheint unbegründet); CIL VI, 40376 (Nerva); CIL VI, 984 (Hadrian); 986 (Antoninus Pius); 991 (Lucius Verus); 992 (Commodus). Zur Anfertigung der Grabinschriften erst nach der Divinisierung der Herrscher vgl. Chastagnol 1984, 285-287.

395 Die Eigenheiten der kaiserlichen Grabtitulatur sind sicher nicht allein aus einer religiösen Unvereinbarkeit von Divinität und funeralem Konetxt zu erklären, da für die divinisierten Kaiserinnen - im Unterschied zu den toten Kaisern - die Titulatur als diva auf Grabinschriften durchaus kein Problem war; vgl. aus dem Hadriansmausoleum CIL VI, 984 (Sabina als diva, zusammen mit Hadrian, der in der typischen Titulatur des Kaisers in Grabinschriften, ohne den divus-Titel, erscheint); ferner CIL VI, 987 (Faustina maior als diva). Ohne dieser Frage im Detail weiter nachgehen zu können, scheint für die fehlende Darstellung kaiserlicher Divinität im funeralen Kontext auch der Umstand eine Rolle gespielt zu haben, dass die Bestattung und insbesondere die pompa funebris ein traditionelles Feld aristokratischen Wettbewerbs bildete, in dem konkurrenzierbare Leistungen vorgeführt wurden: Sie war ein ein politisches - kein religiöses - Ritual, das aristokratische Konkurrenz zugleich regelte, indem sie sie an ein bestimmtes, auf die res publica bezogenes System von Leistungen band, und innerhalb dieses Rahmens Konkurrrenz weckte, indem sie allen Mitgliedern der Aristokratie die Möglichkeit in Aussicht stellte, das Gehörte und Gesehene durch eigene Leistungen zu übertreffen (vgl. Flaig 1995). Die honores caelestes, die dem Kaiser durch die Divinisierung verliehen wurden, fielen nicht darunter: Die Erringung von Göttlichkeit durch den Prinzeps war in ein System von Leistungen und Auszeichnungen, das aus dem Bestreben heraus entstanden war, Statusrelationierungen innerhalb der aristokratischen Oberschicht zu ermöglichen, nicht integrierbar; das Verbot, die Bilder von divi in einer pompa funebris mitzuführen - obwohl als ein Ehrenrecht für den verstorbenen Kaiser beschlossen - verhinderte, dass göttliche Ehren in Relation zu einem Statussystem gesetzt wurden, das durch sie gesprengt worden wäre. Für die Kaiserinnen, die nicht in ein System aristokratischer Konkurrenz eingebunden waren, stellte sich dieses Problem nicht: Sie konnten daher auch ihren divinen 
waren, machen auch die Titulatur und der Ausschluss der Imagines von divi aus der pompa funebris deutlich, dass der divine Status eines Kaisers im funeralen Kontext seines Grabes nicht kommuniziert wurde.

Dabei ist zu berücksichtigen, dass der Status als divus die kaiserliche Grabstätte und damit auch den Status des Kaisers als Toter nicht ausblendete. Mit seiner Erhebung zum divus wurde nicht gleichzeitig - im Sinne einer ontologischen Ausssage - dekretiert, dass der Kaiser Gott „,war“.396 Die vom Senat getroffene Entscheidung über die Zuweisung von honores caelestes legte einzig bestimmte rituelle und situative Kontexte fest, in denen der Kaiser als Gott verehrt wurde, ohne damit andere Kommunikationsbereiche, in denen eine Divinität des Kaisers nicht gegeben war, aufzuheben. Wenn Caracalla im Jahr 212 nach Getas Ermordung diesem die göttlichen Ehren aberkannte und ihm stattdessen nur noch ein jährliches Totenopfer darbringen ließ, ${ }^{397}$ wurde die Rückstufung des divus zu einem normalen Toten zwar dadurch signalisiert, dass Geta von da an nur noch als Toter verehrt wurde. Dies impliziert jedoch nicht zwangsläufig, dass nicht auch für divi an deren Gräbern parentationes stattfanden. ${ }^{398}$ Ammianus Marcellinus - ein allerdings später und wegen der spätantiken Annäherung von Toten- und divus-Kult nicht unproblematischer Autor - bezeugt, dass Kaiser Julian am Grab Gordians III. ein Opfer vollzog, das Ammian ausdrücklich als eine parentatio bezeichnet. ${ }^{399}$ Die Divinisierung

Status in den Grabinschriften signalisieren, während sich die Kaiser darauf beschränkten, in ihrem titulus alle anderen honores bis auf die honores caelestes aufzuführen, die zum System aristokratischer Ehrzuweisungen in keiner Relation standen. In diesem Zusammenhang ist zu berücksichtigen, dass das Mitführen von imagines in der pompa funebris auch nach der Begründung des Prinzipats von führenden Familien praktiziert wurde, wodurch die kaiserliche pompa formal in einen traditionellen Zusammenhang aristokratischer Selbstdarstellung und Konkurrenz eingebunden blieb. Erst in severischer Zeit kam offenbar das Mitführen von imagines bei aristokratischen pompae funebres außer Gebrauch und wurde zu einem ausschließlichen Privileg der kaiserlichen Familie (vgl. Flower 1996, 263; anders Blösel 2000, 89f.).

396 Die von Clauss 1999, bes. 17-38 aufgeworfene Frage, ob der Kaiser Gott „war“ oder nicht, läuft, so gestellt, ins Leere, da sie von unterschiedlichen rituellen, situativ bestimmten Kontexten abstrahiert und sie durch eine ontologische Aussage ersetzt. Zwar betont Clauss ebd., 23, mit Sätzen wie „der Kaiser ist Gottheit“ keine Aussage über das Sein des Kaisers treffen zu wollen, sondern sich einer Sprachregelung zu bedienen, um ,umständliche“ Formulierungen (der Kaiser wurde als Gottheit angesehen, akzeptiert, verehrt etc.) zu vereinfachen. Dabei geht es jedoch um mehr als nur um reine „Sprachregelungen“: Für die Frage nach dem religiösen Status des römischen Kaisers sind die rituellen - aber auch politischen und literarischen - Kontexte, in dem ihm Göttlichkeit zugewiesen wurde, von essentieller Bedeutung.

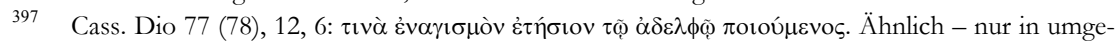
kehrter Richtung - ist die Nachricht der Historia Augusta zu verstehen, dass Antoninus Pius für Hadrian anlässlich seiner Konsekration bei Puteoli ,anstelle eines Grabmals“ (pro sepulchro) einen Tempel errichtet habe (Hist. Aug., Hadr. 27, 3: templum denique ei pro sepulchro aput Puteolos constituit et quinquennale certamen et flamines et sodales et multa alia, quae ad honorem quasi numinis pertinerent).

398 Anders Scheid 1993, 199, dens. 2000, 136.

399 Amm. 23, 5, 8: ubi cum pro ingentia pietate consecrato principi parentasset... Unklar ist, ob es sich bei dem von Amm. 23, 5, 7 erwähnten tumulus um die Grablege oder ein Kenotaph Gordians III. handelt 
des toten Herrschers schloss alternative religiöse Kommunikationsbeziehungen zu ihm also nicht kategorisch aus. Vielmehr gilt für den römischen Kaiserkult wie für die griechische und römische Religion insgesamt, dass die rituellen Handlungen selbst eine kognitive Funktion erfüllten, da die Position der Adressaten religiöser Kommunikation nicht durch ein schriftlich fixiertes Dogma oder durch ein allgemein verbreitetes und anerkanntes theologisches System festgelegt war. ${ }^{400}$ Auf den Kaiserkult übertragen heißt dies, dass man konsequent von situativen Kontexten ausgehen muss, um die jeweilige Relation zu bestimmen, die einzelne oder Gruppen von Verehrern zum Kaiser als einem Toten oder als divus - einnahmen. ${ }^{401}$

Unter dieser einschränkenden Maßgabe, dass die kaiserlichen Grablegen nicht aus der rituellen Kommunikation mit dem toten Kaiser ausgeblendet waren, bleibt dennoch die weiter oben bereits getroffene Feststellung gültig, dass die Grablege keinen Schauplatz darstellte, an dem der Kaiser in seinem Status als divus verehrt wurde. Dies lässt sich anhand des Kultes für Augustus und andere Angehörige des julisch-claudischen Kaiserhauses verdeutlichen, über deren stadtrömische Schauplätze wir durch die Akten der Arvalbrüder, die an den offiziellen Kaiserkultfeiern teilnahmen, vergleichsweise gut unterrichtet sind. ${ }^{402}$ Aus ihnen ist klar ersichtlich, dass die kultische Verehrung der divi und divae in keiner Verbindung mit seinem Grab stand. Die meisten Opfer fanden auf dem Kapitol oder vor den Kaisertempeln, wie dem templum novum des Augustus, statt; seltener sind auch andere Schauplätze wie die Statue des Augustus vor dem Marcellustheater bezeugt. ${ }^{403}$ Die Nachrichten der Arval-

(zu den widersprüchlichen Quellentraditionen vgl. Johnson 1986, 245-247). Für die Bezeichnung der Kulthandlung als parentatio ist jedoch allein entscheidend, dass Ammian davon ausgeht, dass Gordian an der Stelle, an der Julian das Opfer vollzog, begraben lag (vgl. die Rede Julians in: Amm. 23, 5, 17).

400 Vgl. für Rom Rüpke 2001, 86-118.

401 Mit Blick auf den Kaiserkult im Osten hervorgehoben von Price 1980, 43; für den Kult der divi im Westen vgl. die entsprechenden Bemerkungen von Fraschetti 2000, 157 („privilegiando dunque i rituali e non le credenze").

402 Die Arvalbrüderakten erlauben fraglos wichtige, aber dennoch nur begrenzte Einblicke in die statdtrömische Opferpraxis des Kaiserkults, da die Arvalbrüderschaft zwar an Feiern des Kaiserkults beteiligt war, das Zentrum ihrer kultischen Aktivitäten jedoch, im Unterschied zu den eigens für den Kaiserkult gegründeten sodalitates, die Verehrung der Dea Dia bildete. Dementsprechend waren die Arvalbrüder einzig an denjenigen Festen, die im Zusammenhang mit dem divus Augustus standen, regelmäßig beteiligt, und auch dies gilt nur für die Zeit der iulisch-claudischen Dynastie. Bei den übrigen Kaisern beschränkten sich die Feiern auf Anlässe, die den jeweils regierenden Kaiser, seine Familie und seine Maßnahmen bezüglich der Vorgänger (Divinisierung) betrafen (vgl. dazu Scheid 1990, 417-422).

403 Kapitol: Commentarii fratrum arvalium, 29, nr. 12a, 13; 37, nr. 13fgh, 2; templum novum: ebd., 29, nr. 12c, 11f.; 31, nr. 12c, 99; 36, nr. 12abcd, 10; Augustusstatue vor dem Marcellustheater: ebd., 30 (nr. 12 c, 26). Zu den stadtrömischen Schauplätzen und Anlässen für mit dem Kaiserkult verbundene Feiern vgl. allgemein Fishwick 1987-2004, Bd. 2, 1, 483-489; 505-509. 
brüderakten über den Kaiserkult bestätigen, dass die kaiserlichen Gräber im Kult für die Divinisierten keine Rolle spielten. ${ }^{404}$

Diese räumliche Absetzung des Kaiserkults äußerte sich auch darin, dass die Tempel für die divi niemals mit ihren Grablegen zusammenfielen. Im 2. Jh. wurden zwar zunehmend die ustrinae in eine räumliche Verbindung mit dem Tempel für einen divus gebracht - vermutlich der Ausdruck eines veränderten Konsekrationszeremoniells, bei dem die Apotheose des Kaisers durch einen bei der Verbrennung aufsteigenden Adler inszeniert wurde. ${ }^{405}$ Doch während die Verbrennungsstätte den Aufstieg des zum Gott erhobenen Kaisers zum Himmel versinnbildlichte, blieb die Grablege des toten Kaisers, wo sich seine sterblichen Überreste befanden, ein Ort, der nicht mit dem Status des toten Kaiser als divus assoziierbar war. Die kaiserlichen Gräber blieben auch weiterhin von den Tempeln der divi getrennte Bereiche. ${ }^{406}$ Die beiden einzigen Ausnahmen von dieser Regel407 - Domitians templum gentis Flaviae und die Trajanssäule - sind Sonderfälle, die eine kurze Erläuterung verlangen.

Das Prinzip einer Trennung von Bestattungsort und Kaiserkultstätte scheint erstmals bei der Errichtung des domitianischen templum gentis Flaviae durchbrochen worden zu sein: Domitian ließ bei der Errichtung des Tempels für Angehörige seiner Gens nicht nur sein Geburtshaus in einen Tempel umwandeln, sondern auch die Überreste von divinisierten Mitgliedern seiner Familie dort beisetzen. ${ }^{408}$ Welche Bedeutung aber kam dieser Symbiose von Mausoleum und Kaiserkultstätte für die Relation von Toten- und Kaiserkult zu? Strebte Domitian mit seinem Bau, der sich zugleich über das Prinzip der extramuralen Bestattung der Toten hinwegsetzte, eine Verschmelzung dieser beiden rituellen Bereiche - von Toten- und divus-Kult - an oder liegen dieser eigentümlichen Disposition des Bauwerks andere Motive zugrunde?

404 Wenn Sen., dial. 9, 14, 9 von den täglichen Opfern für „den Kaiser, unseren Gott,“ an seinem Grabmal (tumulus) spricht, besteht kein Anlass, darin Opfer für den Kaiser als divus oder überhaupt ein reguläres Opfer zu vermuten. Der Kontext der Passage ist die Hinrichtung des Canus Iulius unter Caligula, die als ein Opfer für Caligula dargestellt wird - das cotidianum sacrum ist hier wohl eher als eine Anspielung auf die ständigen Bluttaten des Kaisers zu verstehen (gegen J.-C. Richard 1966, 132, der in der Passage ein Indiz für die Angleichung von Kaiserkultstätte und Grablege sieht).

405 Vgl. Price 1987, 68, 94-97.

406 Für eine Übersicht über die räumlichen Verteilung der Tempel und aedicula, der ustrinae und der Grabstätten der divinisierten Kaiser in Rom vgl. Gradel 2002, 344.

407 Vgl. die Übersicht von Waurick 1973.

408 Vgl. Suet., Dom. 1, 1 (Umwandlung von Domitians Geburtshaus in ein templum gentis Flaviae). Von den divi der flavischen Gens war dort nachweislich nur die 89 gestorbene Tochter des Titus, Iulia, bestattet (vgl. Suet., Dom. 17, 3). Stat., silv. 5, 1, 240f. enthält eine Anspielung auf die Umsetzung der sterblichen Überrreste weiterer Mitglieder der flavischen Gens in das domitianische templum; gemeint sind wohl Vespasian (vgl. auch Mart., epigr. 9, 34, 7f.), der zunächst im Augustusmausoleum beigesetzt worden war, und Titus, der vermutlich ebenfalls zunächst im Augustusmausoleum seine letzte Ruhestätte gefunden hatte (vgl. Arce 1988, 80-82). 
Für diese Frage ist zu berücksichtigen, dass es in Rom neben dem templum gentis Flaviae eigene Tempel für die beiden divi Vespasian und Titus gab, und dass Domitian nicht nur an der Errichtung des Tempels für die flavische Gens, sondern auch an der Fertigstellung dieser Kultstätten seines Vaters und seines Bruders maßgeblichen Anteil hatte. Der Vespasiantempel zwischen dem Concordiatempel und der porticus deorum consentium, der schon unter Titus begonnen worden war, wurde von Domitian vollendet und war vermutlich nicht nur Vespasian, sondern auch dem vergöttlichten Bruder Domitians geweiht. ${ }^{409}$ In ähnlicher Weise vereinte auch die von Domitian errichtete porticus divorum auf dem Marsfeld die Verehrung der beiden Vorgänger Domitians. ${ }^{410}$ Die Nutzung des templum gentis Flaviae als Grablege erweist sich damit nicht als ein programmatischer Versuch, den Bestattungsort und die kultische Verehrung von divi der flavischen Dynastie zusammenzubringen. Domitian orientierte sich in dieser Hinsicht an den traditionellen Maßgaben des Kaiserkults: Die divi erhielten Tempel, die mit ihren Grablegen in keiner Verbindung standen. Eine grundlegend neue Ausrichtung des Kaiserkultes, seine Verlagerung in den Bereich der sterblichen Überreste des Kaisers, war von Domitian durch die Anlage des templum gentis Flaviae nicht intendiert. ${ }^{411}$ In diesem Bau stand vielmehr der lebende Herrscher im Zentrum des Interesses: Wenn Domitian sein Geburtshaus zu einem regelrechten templum umgestaltete, dann diente dieser Tempel nicht primär dem Kult für die dort bestatteten Angehörigen der gens Flavia, ${ }^{412}$ sondern der sakralen Überhöhung seiner eigenen Person, des lebenden Princeps. ${ }^{413}$

Im Gegensatz dazu war die Beisetzung Trajans im Sockel der Trajanssäule ein eindeutiger Versuch, die Grablege und die Kultstätte für den divus in

409 Die Dedikationsinschrift (CIL VI, 938) erwähnt zwar nur den divus Vespasianus, doch im Curiosum urbis Romae des 4. Jh. erscheint der Tempel als templum Vespasiani et Titi (Codice topografico, Bd. 1, 115).

410 Zu beiden Seiten des Bogens, der den Zugang an der nördlichen Schmalseite der porticus eröffnete, befand sich je eine aedes divi Vespasiani und divi Titi.

411 Vgl. auch J.-C. Richard 1966, 134, der daran die - allerdings nicht weiter konkretisierte - Bemerkung knüpft, im templum gentis Flaviae habe kein Kult für einzelne der dort bestatteten Personen stattgefunden, vielmehr habe es einem überindividuellen dynastischen Kult gedient. Ähnliches scheint auch Gradel 2002, 323, Anm. 93 zu meinen, wenn er von einem Kult für die „Personifikation der Gens" spricht, die jedoch in Rom nicht existiert zu haben scheint.

412 Es ist nicht bekannt, dass das templum gentis Flaviae zum Schauplatz von Kulthandlungen für die dort bestatteten divi wurde.

413 Mario Torelli hat Domitians Bauprogramm als konkurrierende Bezugnahme auf die topographische Inszenierung des Augustuskults in Rom gedeutet: Die Dopplung von porticus divorum und templum gentis Flaviae entspräche nach dieser Auffassung den beiden Tempeln des vergöttlichten Augustus auf dem Palatin und am Forum, wobei der Tempel für die Angehörigen der flavischen Gens in Analogie zum sacrarium auf dem Palatin, dem Geburtshaus des Augustus, errichtet worden sein soll (Torelli 1987, 563-572). Implizit erhob Domitian damit den Anspruch in seinem Geburtshaus ebenfalls als Gott verehrt zu werden (ebd., 570; ähnlich auch Waurick 1973, 117). 
einen unmittelbaren räumlichen Zusammenhang zu bringen. ${ }^{414}$ Dass Trajan von vornherein eine Bestattung im Sockel der 113 geweihten Säule und die Anlage eines Tempels auf seinem Forum plante, kann als sicher gelten. ${ }^{415}$ Die Umstände, unter denen die Beisetzung erfolgte, zeigen jedoch auch, dass eine derartige Bestattung eines divus rituell nicht ohne weiteres zu „bewältigen“ war: Hadrian nutzte den Umstand, dass Trajan auf der Rückkehr von seinem Partherfeldzug verstorben war und ließ den verstorbenen - und divinisierten - Kaiser, vertreten durch ein Bildnis, als postumen Triumphator in Rom einziehen. ${ }^{416}$ Als Begründung soll Hadrian vorgebracht haben, dass Trajan auch nach seinem Tod die dignitas triumphi behalten solle. Dieser triumphale Einzug bot jedoch nicht nur die Begründung dafür, eine Bestattung innerhalb des Pomeriums vorzunehmen, ${ }^{417}$ sondern auch eine rituelle Handhabe, um den divus als Toten innerhalb der Stadt zu installieren: Aufgrund der Verwandtschaft von pompa triumphalis und pompa funebris erschien der Einzug Trajans im Jahr 117 als ein Prozessionsritual zwischen Triumph und Leichenbegängnis, das ihn zu seinem Bestattungsplatz im Zentrum der Stadt führte. ${ }^{418}$ Die Bedeutung dieser durch den Triumphzug bewerkstelligten rituellen Installierung blieb auch in der Titulatur des vergöttlichten Trajan erkennbar, der mit Parthicus als einziger römischer Kaiser einen Siegernamen als regulären Bestandteil seiner divus-Titulatur führte. ${ }^{419}$

Diese Beisetzung des Kaisers in der Stadt und die angestrebte Verbindung von Toten- und divus-Kult war jedoch nicht nur in ihrer Planung, sondern auch in ihrer rituellen Umsetzbarkeit außergewöhnlich voraussetzungsreich. Dies macht die Bestattung Trajans zu einem Sonderfall, der keine Nachfolger fand: Trajans Nachfolger Hadrian schuf sich eine Grabstätte außerhalb der Stadt; und Antoninus Pius brachte zwar ebenso wie Mark Aurel der Trajanssäule vergleichbare Säulenmonumente in eine räumliche Verbin-

414 Die Säule erhob sich, flankiert von den beiden Bibliotheken, gegenüber vom Zugang zum Tempel des vergöttlichten Trajan.

415 Überzeugend Zanker 1970, 530-542. Der Tempel wurde vermutlich erst nach 121 geweiht, dürfte jedoch von vornherein in die Konzeption der Forumsanlage miteinbezogen gewesen sein (vgl. ebd., 537f.); er muss gegenüber der Säule gelegen haben, die sich zwischen den beiden Räumen der bibliotheca Ulpia erhob.

416 Hist. Aug., Hadr. 6, 3: cum triumphum ei (scil. Hadrian) senatus, qui Traiano debitus erat, detulisset, recusavit ipse atque imaginem Traiani curru triumphali vexit, ut optimus imperator ne post mortem quidem triumphi amitteret dignitatem; zum Vorgang vgl. J.-C. Richard 1966 (a), 351f.

417 Zur Bestattung von Triumphatoren im Pomerium vgl. Zanker 1970, der daneben den griechischen Heroenkult als ein weiteres bestimmendes Vorbild für die trajanische Platzanlage ausmacht.

418 Zur Verwandtschaft von pompa funebris und pompa triumphalis vgl. Wesch-Klein 1993, 107f. Cass. Dio 56, 34, 1 behauptet, auch bei der Bestattung des Augustus sei ein Wachsbild des Verstorbenen im Triumphalornat mitgeführt worden.

419 Vgl. dazu Kierdorf 1986 (a). 
dung mit dem divus-Tempel und der Verbrennungsstätte, doch beide Kaiser ließen sich außerhalb der Stadt bestatten.

Die Trennung von den göttlichen Ehren, die man dem Kaiser als divus erwies, und seiner Grabstätte, an der allenfalls parentationes praktiziert werden konnten, die jedoch als rituelles Element für die Verehrung des divinisierten Kaisers nicht von Bedeutung waren, lässt sich demnach als eine Strukturbedingung des römischen Kaiserkults bezeichnen. Konstantin hob diese Trennung auf, indem er seine Grablege in den Rang einer zentralen Kultstätte erhob. War dies eine völlig neue Entwicklung, ursächlich bedingt durch Konstantins Nähe zum Christentum, in dem der Umgang der Lebenden mit den Toten weniger stark von Abgrenzungen geprägt war als im paganen Totenkult? Oder griff der Kaiser hier bereits bestehende Tendenzen in der Entwicklung des Kaiserkults auf, denen er durch die Einbindung des Kaiserkults in die christlichen Kommemorationspraktiken zum Durchbruch verhalf?

\section{2. 4. Wandlungen der Kaiserkulttopographie vor Konstantin}

Konstantins Wahl der südöstlichen Außenbezirke Roms und des daran anschließenden Suburbiums für seine stadtrömische Residenz bedeutete keine abrupte Neuorientierung. Wie bereits erwähnt, waren dort schon in severischer Zeit ausgedehnte Kaiservillen entstanden, auf die Konstantin bei der Errichtung des Sessoriums zurückgriff. Auch Konstantins Vorgänger Maxentius hatte eine ausgedehnte Residenz im römischen Suburbium, an der via Appia, errichtet. Sowohl Maxentius als auch Konstantin betrachteten nicht oder nicht in erster Linie den Palatin als ihren Aufenthaltsort in Rom, sondern schufen sich außerhalb bzw. am Rande der Stadt ausgedehnte Wohn- und Residenzkomplexe, die die alte Funktion des kaiserlichen Palastes im Zentrum Roms übernahmen. Die Maxentiusvilla an der via Appia bietet jedoch nicht allein aufgrund ihrer dezentralen Lokalisierung instruktive Parallelen zum konstantinischen Bauprogramm. Vielmehr finden sich in ihrer Anlage deutliche Hinweise darauf, dass die konstantinische Verbindung von Toten- und Kaiserkult dort bereits vorbereitet war, und dass Konstantin mit seinem Baukomplex aus Coemeterialbasilika und Mausoleum Tendenzen aufgriff, die sich schon in tetrarchischer Zeit abzeichneten und in enger Verbindung mit einem gewandelten Herrschaftsverständnis standen.

Die Maxentiusvilla an der via Appia umfasste drei Bereiche: die Villa, einen Circus und ein großes Mausoleum, das in der Form eines Podiumrundbaus angelegt war. ${ }^{420}$ Von der Villa ist nur so wenig erhalten, dass die Relation der Gebäudekomplexe zueinander über die allgemeine Lokalisierung

$\overline{420}$ Zum Aufbau der gesamten Anlage vgl. Frazer 1966; Rasch 1993, 3 f. 
hinaus nicht genauer geklärt werden kann. ${ }^{421}$ Sicher ist jedoch, dass dem Mausoleum innerhalb dieser Villenanlage eine zentrale Bedeutung zukam. Seine Front war auf die via Appia hin orientiert, und die Möglichkeit, ein derartiges Monument direkt an dieser Gräberstraße plazieren zu können, hat wohl auch die Wahl dieses Ortes für den maxentischen Wohn- und Residenzkomplex maßgeblich beeinflusst. Obwohl es nicht ungewöhnlich war, dass Mausoleen in der Verbindung mit Villen errichtet wurden, ${ }^{422}$ ist hier der Zusammenhang demnach ein umgekehrter: Bei der Maxentiusvilla handelte es sich nicht, wie sonst üblich, um eine Villa mit einem Mausoleum, sondern eher umgekehrt um ein Mausoleum mit einer angebauten Villa. ${ }^{423}$

Diese zentrale Rolle des monumentalen Grabbaus für die Lokalisierung der Villa, die sich auch in dem ausgesprochen aufwendigen Architekturtyp des Mausoleums niederschlug, rückte den Toten in das Zentrum des gesamten Wohn- und Residenzkomplexes. Dabei bildete der in dem Mausoleum bestattete Tote den räumlichen Bezugspunkt von Architekturformen und rituellen Schauplätzen, die seinen divinen Status kommunizierten. Der neben dem Mausoleum gelegene Circus der Maxentiusvilla ist von Mario Torelli überzeugend als eine architektonische Bauform interpretiert worden, die kosmische aeternitas und den Anspruch auf ein ewiges Leben symbolisch zum Ausdruck brachte. ${ }^{424}$ Daneben war der maxentische Circus sicherlich allein aufgrund seiner Größe kein reines Schaumonument, sondern - ebenso wie etwa der Circo Variano in der severischen Villa der horti spei veteris - dazu bestimmt, größere Menschenmengen zusammenzubringen. ${ }^{425}$ Angesichts der Relevanz von Circusspielen für die religiösen Feste des römischen Kalenders im 4. Jh., darunter ganz besonders für diejenigen Feiertage, die auf den Kaiser bezogen waren, ${ }^{426}$ scheint eine kultische, spezifischer: eine kaiserkultische Funktion des Circus an der via Appia nicht von der Hand zu weisen. ${ }^{427}$

Auch die Architektur des Grabbaus selbst legt nahe, dass in ihm die traditionelle Trennung von Grablege und Kaiserkultstätte aufgehoben wurde. Das Maxentiusmausoleum stellt - ebenso wie der mit ihm eng verwandte Grabbau

\footnotetext{
421 Zu den Überrresten der Villa vgl. Pisani Sartorio/Calza 1976, 121-129.

422 Vgl. Waurick 1973, 124-133; Bodel 1997.

423 So auch Frazer 1966, 386, $391 \mathrm{f}$.

424 Torelli 1992; ders. 2002, bes. 1101-1107. Torellis zentrale These, dass die Grundrissform des Circus auch den konstantinischen Coemeterialbasiliken zugrundeliege und dem antiken Betrachter dieser Gebäude eine aeternitas-Symbolik vermittelt habe, hat Lehmann 2003, 65-68 mit guten Gründen zurückgewiesen; diese Einwände sind für den hier interessierenden Zusammenhang jedoch nicht von Bedeutung.

425 Elagabal ist in dem Circus der Villa in den horti spei veteris selbst als Rennfahrer aufgetreten (Herodian. 5, 6, 6f.; Cass. Dio 79 [80], 9; vgl. dazu Paterna 1996, 839 u. 845f.).

$426 \mathrm{Zu}$ der starken Zunahme von kaiserbezogenen Festtagen, die der Chronograph von 354 im Vergleich mit früheren Kalendern erkennen lässt, vgl. Salzman 1990, 131-146.

427 Dies ist auch die Einschätzung von Ioppolo 1999, 195.
} 
bei Tor de' Schiavi - eine besondere Form des Grabtempels dar, einen sogenannten Podiumrundbau, der in seinen ersten Vorläufern zu Beginn des 3. Jh. fassbar wird. ${ }^{428}$ Dieser Bautyp verband eine ringförmig angelegte Grabkammer mit einem darüberliegenden Stockwerk, das von einer hohen Kuppel überwölbt wurde, und dem eine giebelgekrönte Vorhalle vorgelagert war, zu der eine Treppe emporführte. ${ }^{429}$ Ein wesentlicher Unterschied zwischen diesen Podiumrundbauten und früheren Mausoleen besteht darin, dass mit der kuppelüberwölbten Halle ein ausgedehnter Versammlungsraum in unmittelbarer Nähe zu den im unteren Geschoss bestatteten Toten geschaffen wurde. So hat das Obergeschoss des Mausoleums bei Tor de' Schiavi die stattlichen Maße von ca. 13,70m Durchmesser und 13,76m Höhe. ${ }^{430}$ Ältere Kaisergräber wie das Augustus- und Hadriansmausoleum, aber auch noch der zuweilen als Grabmal des Alexander Severus (222-235) gedeutete tumulus nördlich der via Tusculana, der sogenannte monte del Grano, ${ }^{431}$ sind hingegen eindeutig nicht auf eine Begehbarkeit durch größere Gruppen hin konzipiert worden. Die Grabkammern, in denen die Urnen oder Sarkophage der Kaiser und ihrer Familienangehörigen aufgestellt wurden, waren kleine, enge Räume, die ohne eine ausreichende Beleuchtung und Belüftung angelegt wurden. Im Inneren waren diese tumuli von ringförmigen Zugängen durchzogen, die um die Grabkammer herumführten und durch diese circumitio eine spezifische Form der Annäherung an den Toten bewirkten, die man allgemein als Ausdruck römischer Totenkultriten interpretiert. ${ }^{432}$ Als Versammlungsräume in der Nähe der Toten waren die tumuli jedoch, trotz ihrer monumentalen Größe nicht konzipiert.

Das Maxentiusmausoleum und das Mausoleum bei Tor de' Schiavi behielten in ihren unteren Stockwerken, die als Grablegen fungierten, die herkömmlichen Strukturmerkmale bei, wie sie auch in der Anlage der Tumulusgräber begegnen. Im Unterschied zum kuppelüberwölbten oberen Stockwerk war die in das Podium eingelassene Grabkammer als Ringkanal, der um einen Mittelpfeiler herumführte, angelegt. Sie bot vergleichsweise geringen Raum und war auch nicht für Besucher vorgesehen, da die Eingangstreppe des Mausoleums in das obere Stockwerk führte. Um so eindrücklicher treten die Kuppelräume oberhalb der Grabkammern als ein neues Architek-

$428 \quad$ Als eines der frühesten Beispiele für die im folgenden beschriebenen stilistischen Eigenschaften lässt sich der sogenannte Portumnustempel in Porto (vgl. Crema 1959, 563; v. Hesberg 1992, 189; Rasch 1984, 79, dens. 1998, 104) aus severischer Zeit anführen.

429 Vgl. die ausführlichen Analysen von Rasch 1984; dems. 1993.

430 Vgl. Rasch 1993, 44f.

431 Für eine Identifizierung mit dem Grab des Alexander Severus plädiert Coarelli 1986, 55-58; skeptisch Johnson 1986, 242.

432 Zur Interpretation von ringförmigen Gängen in römischen Grabbauten als symbolischer Ausdruck eines rituellen Umschreitens des Toten vgl. Windfeld-Hansen 1965, bes. 58-63; Davies 2000, 124-126. 
turelement hervor, das eine Begehbarkeit durch größere Gruppen in unmittelbarer Nähe der sterblichen Überreste des Kaisers erlaubte.

Über die Riten, die in den überkuppelten Sälen gefeiert wurden, ist nichts bekannt. Eine Nutzung der Nischen innerhalb der Kuppelräume für Statuen, Throne oder Speisetische bleibt spekulativ. ${ }^{33}$ Dennoch liefert die architektonische Disposition dieser tetrarchischen Mausoleen überzeugende Hinweise darauf, dass die Vorzeichen, unter denen der Kaiser kultisch verehrt wurde, sich änderten und der Kult für den toten Kaiser und für den divus, die traditionell klar voneinander getrennte rituelle Systeme gewesen waren, einander angenähert wurden. So lässt sich als das vermutlich direkte architektonische Vorbild für die kuppelüberwölbten Bauten des Maxentiusmausoleums und des Mausoleums bei Tor de' Schiavi das römische Pantheon bestimmen. ${ }^{434}$ Auch wenn dessen Funktion keine geringeren Rätsel aufgibt als die kuppelüberwölbten Räume in den tetrarchischen Grabtempeln, ist sich die Forschung darin einig, dass der Bau eine Beziehung zum Kaiserkult gehabt haben muss. ${ }^{435}$ Die beiden tetrarchischen Mausoleen in der Maxentiusvilla und an der via Praenestina stellen den erkennbaren Versuch dar, eine Verbindung zwischen unterschiedlichen Architekturtypen und den mit ihnen verbundenen Konnotationen - Totenkult und divus-Kult - herzustellen: Sie setzten sich aus einer Kaisergrablege im Untergeschoss und einer Kaiserkultstätte im Obergeschoss des Grabtempels zusammen. ${ }^{436}$

433 Unter dem Vorbehalt einer möglichen Vermutung geäußert von Tolotti 1986 (a), 492; ähnlich v. Hesberg 1992, 191; Rasch 1993, 90 vermutet, dass in den Wandnischen im Obergeschoss des Mausoleums bei Tor de' Schiavi Statuen aufgestellt gewesen seien. Schumacher 1987, 173 spricht vage und ohne nähere Erläuterung von „Apotheosenkult“. Eine ausführliche Bilanz unserer faktischen Unkenntnis in diesem Punkt zieht Johnson 1986, 218-225.

434 Zum Pantheon als Vorbild für das Maxentiusmausoleums vgl. Frazer 1966, 387; Rasch 1984, 79; zum Mausoleum bei Tor de' Schiavi vgl. dens. 1993, 84. Während diese beiden Grabtempel sich am Pantheon orientierten, ist bei anderen Mausoleen mit kuppelüberwölbten Zentralbauten (Portumnustempel, Mausoleum, Gallienusmausoleum) eine direkte Bezugnahme auf einen sakralen Bau nicht gegeben. Sie reihen sich in eine bautypologische Entwicklung ein, die nicht an bestimmte Funktionen gebunden ist, sondern sich in Tempel- und Grabbauten ebenso äußert wie in Vestibülen oder Garten- und Palastpavillons, und die allgemein als Repräsentationsarchitektur charakterisiert werden kann (vgl. dazu Brandenburg 1998, 16-40, der die architektonische Entwicklung des römischen Zentralbaus ausgehend vom 2. Jh. bis hin zu den gegliederten, mit einem Umgang versehenen Zentralbauten des 4. Jh. skizziert, wie sie erstmals in der christlichen Sakralarchitektur - Anastasisrotunde in Jerusalem, Bischofskirche von Antiochia, S. Costanza in Rom - erscheinen).

435 Vgl. Taliaferro Boatwright 1987, 46 u. 73.

436 Diese Deutung der Podiumrundbauten als eine Verbindung von tumulus-Grab und Tempel vertritt auch Tolotti 1986 (a), 485-492, allerdings in anderer Interpretation als sie hier im folgenden vertreten wird, da Tolotti von einer Verbindung von Grablege und Kaiserkultstätte ausgeht, ohne zu berücksichtigen, dass auch die Grablegen eigene (Toten-)Kultanlagen waren und dass die räumliche Annäherung von Grabstätte und Tempel eine Spannung zwischen zwei kultischen Systemen (der Kaiser als Toter und der Kaiser als divus) herbeiführte, die architektonisch nicht 
In der Verbindung dieser beiden Elemente blieb ihre unterschiedliche Provenienz allerdings weiterhin sichtbar: Das Maxentiusmausoleum und das Mausoleum bei Tor de' Schiavi brachten architektonisch Grablege und Tempel zwar in einen unmittelbaren räumlichen Zusammenhang, machten jedoch zugleich durch die Trennung von Grabbereich und kuppelgewölbtem Überbau auch die Vorbehalte deutlich, die beiden damit verbundenen rituellen Systeme, Toten- und divus-Kult, unmittelbar ineinander zu integrieren. Dasselbe gilt auch für das kaiserliche Mausoleum im Diocletianspalast von Split, wo das obere Kuppelgeschoss von der Grablege im Podium klar getrennt blieb. ${ }^{437}$ Hierin spiegelt sich eine gegenüber der traditionellen Trennung von kaiserlicher Grablege und Kaiserkultstätte veränderte Mentalität wider, die einerseits das Bemühen, Toten- und divus-Kult miteinander $\mathrm{zu}$ verbinden, gleichzeitig aber auch die Spannungen reflektiert, denen dieser Versuch aufgrund der traditionellen rituellen Trennung der beiden Bereiche begegnete. Die tetrarchischen Mausoleen von Split und aus Rom sind Ausdruck einer Annäherung des Kaiserkults an die Grablege, ohne beide Bereiche ineinander zu überführen. Diese weiterhin bestehende, unausgeglichene Spannnung zwischen zwei unterschiedlichen kultischen Kommunikationszusammenhängen vorausgesetzt, ist das Bestreben, die Grablege, die für die Verehrung des Kaisers als divus traditionell keine Rolle gespielt hatte, zum räumlichen Bezugspunkt des Kaiserkults zu machen, jedoch unübersehbar. In der Maxentiusvilla an der via Appia bildete die Grablege des Divinisierten zugleich den örtlichen Fokus für seine Verehrung als Gott. Dies verdeutlichen auch die vermauerten Durchgänge der Quadriportikus, die das Maxentiusmausoleum umgab: Sie bildeten einen abgegrenzten Bezirk, einen Temenos, der den sakralen Charakter des Bauwerks als Tempel nachhaltig herausstrich: ${ }^{438}$

Dass dem Maxentiusmausoleum eine derartige Funktion zukam, wird durch weitere Hinweise gestützt, die zugleich das Phänomen der Annäherung von Grablege und Kaiserkultstätte in einen weiteren herrschaftssoziologischen Kontext stellen. Im Bereich des neben dem Mausoleum liegenden Circus wurden Fragmente zweier identischer Inschriften gefunden, die eine Dedikation an Romulus, den im Jahr 309 noch in jugendlichem Alter verstor-

aufgelöst wurde. Rasch 1993, 84 führt den Unterbau der Podiumsrundbauten nicht auf einen tumulus, sondern auf einen Tholos zurück und sieht darin eine Bezugnahme auf den Heroenkult.

437 Zum Mausoleum in Split vgl. Johnson 1986, 47-55, der für eine - in der Forschung zuweilen bestrittene - Aufstellung des Sarkophags in der in das Podium eingelassenen Ringkrypta und nicht im darüberliegenden Kuppelraum plädiert.

438 Zur Funktion der vermauerten Quadriportikus als Temenosbegrenzung vgl. Frazer 1964, 29; Johnson 1986, 61f. (Schumacher 1987, 159 verfällt auf die wenig überzeugende Erklärung, die vermauerten Duchgänge hätten als Windschutz für diejenigen gedient, die sich im Hof zu Totenmählern niederließen). In ähnlicher Weise verfügte auch das Diocletianmausoleum in Split über einen Temenos (Johnson 1986, 48f. u. Abb. 28), ebenso wie das allerdings nur aus Beschreibungen erhaltene Mausoleum des Julian bei Tarsos (Gr. Naz., or. 5, 18). 
benen Sohn des Maxentius, darstellen: divo Romulo n(obilissimae) m(emoriae) v(iro) co(n)s(uli) or[d(inario) II] filio d(omini) n(ostri) Maxent[ii] invict(i) [ac perpet(ui)] Aug(usti) nepoti [di]vi [M]axim[i]ani sen(ioris) [e]t divi [Maximiani iuni]oris ac [---]. ${ }^{439}$ Vermutlich gehörten die Inschriften zu Statuenbasen für den vergöttlichten Sohn des Maxentius, die im Bereich des Circus aufgestellt waren und damit nicht in einer unmittelbaren Beziehung zum Mausoleum standen, in dem der tote Romulus bestattet lag. ${ }^{440}$ Interessant ist jedoch, dass das Inschriftenformular auf eine ähnliche Annäherung von totem und divinisiertem Kaiser hindeutet, wie sie auch in der architektonischen Disposition des Maxentiusmausoleums zum Ausdruck kam. Weiter oben war bereits von der Eigentümlichkeit die Rede gewesen, dass Grabinschriften verstorbener Kaiser den vollständigen cursus honorum ohne eine Hinzufügung des Attributs divus enthielten, während umgekehrt die divus-Titulatur auf Angaben zu den Auszeichnungen, die der Kaiser zu Lebzeiten errungen hatte, verzichtete: Aristokratische bonores und honores caelestes gehörten unterschiedlichen Symbolsystemen an. Die oben aufgeführte Inschrift für den divinisierten Romulus brach mit diesem Prinzip, indem sie neben der Attribution als divus gleichzeitig die beiden Konsulate aufführte, die Romulus bekleidet hatte. Damit wurde auch in der Titulatur des toten Kaisersohnes eine zunehmende Verwischung der ursprünglich klar ausgeprägten Grenzziehung zwischen totem und divinisiertem Kaiser artikuliert - kein Sonder- und Einzelfall, sondern durchaus Ausdruck einer zeittypischen Entwicklung, wie vergleichbare Beispiele aus dem späteren 4. Jh. zeigen. ${ }^{441}$

In dieselbe Richtung weisen eine Reihe von Münzprägungen aus der Regierungszeit des Maxentius, die der Kaiser für seinen Sohn Romulus und für weitere mit ihm verwandte divi schlagen ließ. Auf dem Revers dieser Kommemorationsprägungen war ein Rundbau dargestellt, der meist mit dem sogenannten „Romulustempel“ an der via sacra identifiziert wird, während manche Forscher - zumindest bei einem Teil der Prägungen - davon ausgehen, dass hier das Mausoleum an der via Appia dargestellt sei. Wie an anderer Stelle bereits ausgeführt, ${ }^{442}$ ist es wahrscheinlich, dass keines der beiden Monumente dargestellt war, sondern dass der Bau auf den Münzen - ähnlich wie der rogus auf früheren Konsekrationsprägungen - als ein abstraktes Symbol für den divinisierten Kaiser fungierte. Auffällig - und für den hier interessierenden Zusammenhang wichtiger als die Frage der Identifizierbarkeit der auf den Mün-

\footnotetext{
439 CIL VI, 1138 (= Dessau 673).

440 Die Fragmente wurden in der Nähe der porta pompae - also auf der dem Mausoleum abgewandten Seite des maxentischen Circus - gefunden. Zu Fundort und Deutung vgl. Frazer 1966, 383, $388 f$.

441 CIL VI, 36960 (= Dessau 8950) (Inschrift für Thermantia, die Gattin von Theodosius dem Älteren): coniugi divi [Theodosi inlust]ris comitis utrius[que militiae mag(istri)]. Zur Divinisierung des Vaters von Theodosius I. vgl. Symm., rel. 9, 4f.

442 S. o., S. 94.
} 
zen dargestellten Rotunde - ist jedoch die Tatsache, dass Maxentius einen Bau mit eindeutig funeralen Assoziationen auf seine divus-Prägungen setzen ließ. Die flankierenden Graberoten, die zweiflügelige Tür, der halboffene Türspalt, ${ }^{443}$ schließlich auch der Bau selbst, der wegen seiner Rotundenform an einen tumulus erinnerte, ${ }^{444}$ bilden ein Ensemble ikonographischer Elemente, das unmissverständlich deutlich macht, dass Maxentius hier einen Grabbau darstellen wollte. Die traditionelle Trennung zwischen Grab und divinem Status des Kaisers wurde damit auf der Ebene der symbolischen Kommunikation aufgehoben.

Inwieweit diese Entwicklung bereits im 3. Jh. vorbereitet wurde, lässt sich aufgrund unserer geringen Kenntnisse über Kaisermausoleen des 3. Jh. und der unsicheren Identifizierung der Grablegen nicht sicher sagen. Mit allem Vorbehalt scheint sich jedoch hier um die Mitte des 3. Jh. ein Wechsel abzuzeichnen: Während Alexander Severus (222-235) vermutlich in einem tumulus traditionellen Zuschnitts beigesetzt wurde, fand Gallienus (253-268) allem Anschein nach in einem Podiumrundbau seine letzte Ruhestätte. ${ }^{445}$ Die Zahl der oben angeführten Beispiele zeigt in jedem Fall, dass spätestens seit tetrarchischer Zeit die Trennung zwischen divus und bestattetem Kaiser obsolet zu werden begann. ${ }^{446}$ Was aber waren die Gründe für diese Entwicklung, die mit einem zentralen Paradigma der römischen Tradition des Kaiserkults brach?

Sabine MacCormack hat an die maxentischen Kommemorationsprägungen eine Reihe von Beobachtungen geknüpft, die für eine Antwort auf diese Frage richtungweisend sind, weil sie auf einen allgemeinen Wandel in der

443 Vgl. Luschi 1984 (Graberoten, Türspalt); Zanker 1970, 533 (zweiflügelige Türform).

444 Rasch 1984, 76f. bestimmt das auf den Münzen dargestellte Gebäude als einen Tholos.

445 Zum monte del Grano als möglichem Grabbau des Alexander Severus s. o., Anm. 431. Zum Gallienusmausoleum am neunten Meilenstein der via Appia vgl. Johnson 1986, 43-47 und 251, der eine Identifizierung mit der Grablege des Gallienus für wahrscheinlich hält. Über die Grablegen der Kaiser des 3. Jh. ist jedoch insgesamt zu wenig bekannt, als dass sich hier eine Entwicklung nachvollziehen ließe.

446 Außer den oben bereits diskutierten Beispielen (Maxentiusmausoleum, das Mausoleum bei Tor de' Schiavi, das vermutlich einem Angehörigen des kaiserlichen Hauses gehörte, und das Diocletianmausoleum in Split) lassen sich aus tetrarchischer Zeit keine weiteren Grabbauten desselben Typs einem Kaiser oder einem Mitglied des Kaiserhauses zuordnen. Der lange für ein Mausoleum des Galerius gehaltene Rundbau in Thessaloniki diente einem anderen Zweck, da Galerius nicht dort, sondern in Romuliana bestattet wurde. Dort wurden vor einigen Jahren zwei Mausoleen - vermutlich die Grablegen von Galerius und seiner Mutter Romula - in Verbindung mit zwei monumentalen Anlagen außerhalb der Stadt gefunden, die als riesige Verbrennungs- und Konsekrationsanlagen gedeutet worden sind (vgl. Srejović/Vasić 1994). - Coarelli 1986, 15 meint, dass auch für Constantius Chlorus bei Trier ein Rundtempel als Mausoleum errichtet worden sei, da eine üblicherweise in das Jahr 307/308 datierte Prägung aus Ticinum, die Maxentius für Constantius Chlorus schlagen ließ, diesen Bau zeige. Es erscheint jedoch naheliegender, dass diese Prägung später zu datieren und nur eine Variante der übrigen, in Rom und Ostia geschlagenen Prägungen des Maxentius ist, die einen Rundtempel zeigen (vgl. Frazer 1964, 44f, dens. 1966, 389, Anm. 40); damit erübrigt sich eine Bezugnahme der Ticinum-Prägung auf ein vermeintliches Rundmausoleum des Constantius Chlorus bei Trier. 
Konzeptualisierung der Göttlichkeit des römischen Kaisers schließen lassen. In den bereits erwähnten Prägungen des Maxentius für unterschiedliche divi trat der Grabbau an die Stelle einer Reihe von älteren Symbolen, die auf Konsekrationsprägungen des 3. Jh. erscheinen, und unter denen der rogus, auf dem der Kaiser bzw. später ein Wachsbild des Kaisers verbrannt wurden, eine besonders prominente Rolle einnahm. ${ }^{447}$ Ferner verzichtete Maxentius auf die Umschrift CONSECRATIO und wählte stattdessen AETERNA(E) MEMORIA(E) oder MEMORIA, um den göttlichen Status der kommemorierten Kaiser zu bezeichnen. ${ }^{448}$ Technisch gesprochen sind die maxentischen Münzen daher auch keine Konsekrations-, sondern Kommemorationsprägungen. ${ }^{449}$

MacCormack deutet diese Änderungen der Motive und der Umschriften auf den Münzen des Maxentius überzeugend als den Versuch, den göttlichen Status des Kaisers aus dem Bereich menschlicher Handlungsbeziehungen zu lösen und stattdessen Göttlichkeit als eine Eigenschaft des Kaisers zu deklarieren, die unabhängig von Zuschreibungen war und sich nicht in bestimmten Leistungen äußern musste, die dann - gleichsam als Gegenleistung - durch die Erhebung des Kaisers zum divus honoriert wurden. ${ }^{450}$ Die traditionelle Divinisierung des Kaisers hatte auf diesem Prinzip der Zuschreibung beruht: Die Erhebung in den Rang eines divus setzte einen Senatsbeschluss voraus, der dem Kaiser honores caelestes zuwies. Auch die Konsekration im eigentlichen Sinne, die den Kaiser durch einen Kultakt (Verbrennung, Gründung eines Tempels) als Gott installierte, beruhte auf menschlichem Handeln und machte den göttlichen Status des Kaisers damit von menschlicher Zuschreibung abhängig. ${ }^{451}$ Die traditionellen Konsekrationsmotive, wie der rogus, aber auch der Tempel und die Quadriga, verwiesen übereinstimmend auf die kultischen Akte, die den Kaiser in den Rang eines Gottes erhoben, oder themati-

447 Einen allgemeinen - nicht nur auf die maxentischen Prägungen beschränkten - Wechsel in den Symbolen der Konsekrationsprägungen des frühen 4. Jh. hebt auch Bruun 1954, 25 hervor; eine Übersicht über die unterschiedlichen Motive vermittelt Schulten 1979, 18-43. Zu der bereits seit dem 2. Jh. gestiegenen Bedeutung des rogus im Rahmen des Konsekrationszeremoniells, die sich auch in den Münzprägungen widerspiegelte, vgl. Price 1987, 93-96. Die letzte Konsekrationsprägung mit einem rogus wurde von Konstantin 310/313 in Trier für Constantius Chlorus geschlagen (RIC VI, 221, nr. 809; vgl. Schulten 1979, 146, nr. 396; ungenau ebd., 22). Diese konstantinische Prägung ist jedoch nur eine vereinzelte Wiederaufnahme des rogus-Motivs, die im 4. Jh. keine Nachahmung gefunden hat; MacCormack 1981, 111f. erklärt dies mit der Anlehnung an die Konsekrationsprägungen für Claudius Gothicus, in dessen dynastische Tradition sich Konstantin stellte.

448 Zu den maxentischen Prägungen vgl. Talamo 1981.

449 Betont auch von Frazer 1966, 389.

450 MacCormack 1981, 106-115; vgl. auch Holloway 2004, 14.

451 Zu dieser Differenzierung zwischen der Divinisierung, in der der Senat die Zuerkennung göttlicher Ehren für den verstorbenen Kaiser beschloss, und der Konsekration, die als ein aus diesem Beschluss resultierender Kultakt den Kaiser unter die Götter versetzte, vgl. Kierdorf 1986. 
sierten die für den Kaiser beschlossenen honores caelestes. ${ }^{452}$ Denselben Handlungszusammenhang unterstrichen auch die Münzlegenden: Die Umschrift CONSECRATIO, häufig mit der Beischrift SC oder SPQR verbunden, machte deutlich, dass die Göttlichkeit des Kaisers auf einen von Menschen vollzogenen Kultakt (consecratio) zurückging, der seinerseits die Autorisierung durch einen Senatsbeschluss zur Voraussetzung hatte. ${ }^{453}$

Maxentius hingegen verzichtete darauf, Göttlichkeit als das Ergebnis menschlicher Zuschreibung darzustellen: Er wählte daher weder die traditionellen Konsekrationsmotive noch die Beischrift CONSECRATIO für seine Prägungen, obwohl man sicher davon ausgehen kann, dass der römische Senat den von Maxentius geehrten divi die honores caelestes in üblicher Weise zuerkannt hat. Stattdessen verwiesen die maxentischen Prägungen mit der Darstellung eines Grabbaus auf einen Bereich, der traditionell nicht in den Rahmen der kultischen Ehrungen für einen divus einbezogen war. Der göttliche Status des Kaisers war, dies machte dieses Symbol deutlich, nicht an Beschlüsse und Ehrzuweisungen gebunden, sondern an die Person des Kaisers: Göttlichkeit war keine Auszeichnung, sondern eine Eigenschaft des Kaisers, der - wie im Leben ${ }^{454}$ so konsequenterweise auch im Tod - aus sich selbst heraus beanspruchte, divus zu sein.

Wie Jochen Martin gezeigt hat, ist diese Erscheinung das Ergebnis eines fundamentalen Wandels in der Konzeptualisierung der Göttlichkeit des Herrschers, der sich bereits im 3. Jh. abzeichnete: Durch ihre Berufung auf göttliche Beauftragung machten die Kaiser Göttlichkeit zur Begründung von Handeln, während bis dahin umgekehrt ihr Handeln und besondere Leistungen den Ausschlag dafür gegeben hatten, den Kaisern Göttlichkeit zuzuerkennen. ${ }^{455}$ Die Kommemorationsprägungen und die neuen Grabtempel der tetrarchischen Zeit machen deutlich, dass diese Veränderungen des Handlungs- und Kommunikationsrahmens auch Auswirkungen auf den Umgang mit dem toten Kaiser hatten. In dem Maße, in dem Göttlichkeit und diviner Status nicht mehr als das Ergebnis von Zuschreibung begriffen wurden, sondern dem Kaiser als eine persönliche Qualität eigneten, verlagerte

452 Für das Motiv des Tempels ist dies unmittelbar einsichtig; vgl. auch die Inschrift auf dem Antoninus- und Faustinatempel, dass er ex s(enatus) d(ecreto) errichtet worden sei (CIL VI, 1005). Auch die Quadriga nimmt Bezug auf die dem Kaiser verliehenen bonores divinae, nämlich auf die pompae, bei denen ein Götterbild des Kaisers auf einer Quadriga in den Circus gezogen wurde (vgl. dazu Cracco Ruggini 1977, 427-429).

453 Z. B. noch in den konstantinischen Konsekrationsprägungen für seinen Vater Constantius Chlorus, vgl. o., Anm. 447.

454 Seit dem 3. Jh. wurde die - zuvor nur dem toten Kaiser vorbehaltene - Bezeichnung als divus auf den lebenden Kaiser ausgedehnt, vgl. Koep 1957, 1254-1256 mit der wenig glücklichen Charakterisierung als „Ehrenprädikat“ - eine sakrale Überhöhung bereits des lebenden Kaisers trifft den Sachverhalt angemessener.

455 Vgl. Martin 1984, 115-120. 
sich auch die räumliche Ausrichtung des Kaiserkults: Die Grablege, die in die traditionelle Zuschreibung diviner Ehrungen nicht einbezogen gewesen war, versinnbildlichte konsequent, dass der Kaiser in seiner eigenen Person - und damit auch in seinen sterblichen Überresten - Anspruch auf göttliche Verehrung erheben konnte.

Die vorausgehenden Überlegungen haben gezeigt, dass einschneidende Veränderungen in der Entwicklung des Kaiserkults nicht erst mit Konstantin und nicht erst bedingt durch die Christianisierung einsetzten. Es ist unbestritten, dass Konstantin für die Transformation des Kaiserkults eine entscheidende Bedeutung zukommt, doch sollte dies nicht den Blick darauf verstellen, in welchem Maße er bereits bestehende Entwicklungen aufnahm. Eine Lösung der Göttlichkeit des Kaisers vom Vorgang der Konsekration ist nicht primär das Ergebnis einer Annäherung Konstantins an den christlichen Kult, die bestimmte Formen von Opfern nicht mehr zuließ ${ }^{456}$ Konsekrationsmünzen im engeren Sinne begegnen nicht erst für den divus Constantinus nicht mehr, ${ }^{457}$ sondern wurden bereits von Maxentius gar nicht und von Konstantin selbst nur in sehr geringem Maße geprägt. ${ }^{458}$ Konstantins Verzicht auf den kultischen Akt einer consecratio führte damit bereits bestehende Vorstellungen fort, wonach der Vorgang der Konsekration keine bestimmende Rolle für den göttlichen Status des Kaisers mehr spielte.

Diese Redimensionierung einer „konstantinischen Wende“ im Kaiserkult erlaubt es auch, Konstantins Monumentalisierung der kaiserlichen Grablegen durch die Errichtung von Coemeterialbasiliken in einem weiteren Kontext zu sehen. Sie ist nicht das einfache Ergebnis einer Christianisierung, in deren Gefolge der in den christlichen Gemeinden praktizierte Märtyrerkult die Aufmerksamkeit des Kaisers auf das Grab als einen neuen Ort kultischer Verehrungspraktiken lenkte. Vielmehr haben die obigen Beispiele gezeigt, dass sich bereits in tetrarchischer Zeit der Bestattungsort des Kaisers zu demjenigen Bereich entwickelte, der einen neuformulierten Anspruch der Herrscher auf Göttlichkeit am konsequentesten zum Ausdruck brachte. Dieser Wandel warf

456 So aber Schumacher 1995, bes. 114, dessen Überlegungen darauf zulaufen, dass divus ,,sowohl im christlichen als auch im heidnischen Sinne" interpretierbar gewesen sei, die Frage der Konsekration aber den entscheidenden Unterschied zwischen christlichen und paganen Vorstellungen gebildet habe. In ähnlicher Weise fasst auch Bonamente 1994, 160f. Konstantin als den entscheidenden Einschnitt auf, mit dessen Tod sich eine Umdeutung der kaiserlichen Divinisierung vollzogen habe.

$457 \mathrm{Zu}$ den Kommemorationsprägungen für den vergöttlichten Konstantin vgl. Bruun 1954, 25f.; Koep 1958, 96 f.

458 Konstantin nahm seit 306 die zur Zeit der 1. Tetrarchie ausgesetzten Konsekrationsprägungen sporadisch wieder auf, machte bevorzugt von den Umschriften MEMORIA oder REQUIES Gebrauch (vgl. Bruun 1954, 21-25; MacCormack 1981, 111f.). Die vergleichsweise wenigen CONSECRATIO-Prägungen kopierten ältere Konsekrationsprägungen (vgl. MacCormack, ebd., und Cracco Ruggini 1977, 428, Anm. 9). 
allerdings in ritueller wie konzeptioneller Hinsicht Probleme auf, die nicht ohne weiteres zu bewältigen waren. Wenn der Kaiser unabhängig von Divinisierungsbeschlüssen und Konsekration beanspruchte, als divus verehrt zu werden, und diesen Anspruch auf seine Grablege übertrug, dann bezog er damit einen Bereich in die kultische Verehrung des Kaisers ein, der aus rituellen Gründen traditionell vom divus-Kult getrennt gewesen war. Die Analyse der Podiumrundtempel in Rom hat gezeigt, dass sie zwar eine architektonische Kombination aus Grabbau und Tempel waren, dass aber zwischen den beiden Bereichen keine Verbindung bestand. Gegen eine Einbeziehung der Grablege in den divus-Kult stand eine Trennung zweier ritueller Register Totenkult und Kult für die di superi-die nicht ohne weiteres zu überbrücken war. Unter welchen Vorzeichen ließ sich diese Spannung auflösen? Verfügte die römische Religion über ein kulturelles Modell, ${ }^{459}$ eine Konzept von Göttlichkeit, unter deren Vorzeichen sich Toten und divus-Kult rituell integrieren ließen?

III. 2. 5. Die Verehrung des toten divus - auf der Suche nach einem kulturellen Modell

Seit André Grabar, der die kaiserlichen Grabbauten der Tetrarchenzeit als heroa bezeichnete, hat man immer wieder auf das Modell der Heroengrabes zurückgegriffen, um die göttliche Überhöhung des Kaisers an der Stätte, wo seine sterblichen Überreste bestattet waren, auf den Begriff zu bringen. 460 Wenn der Ausdruck Heroon mehr bezeichnen soll, als nur einfach eine monumentale Grablege, ${ }^{461}$ dann schließt sich die Frage an, ob mit der Figur des Heros und dem Heroenkult ein kulturelles Modell zur Verfügung stand, um

459 Zum Begriff vgl. Quinn/Holland 1987.

460 Grabar 1946, 31-33; 144; 217-222; 278 und öfter. Frazer 1964, 34-41; ders. 1966, bes. 387-389; MacCormack 1981, 112; Rasch 1984, 76; Wesch-Klein 1993, 114; La Rocca 2000, 214-220. Von einer Bezugnahme des Apostoleions in Konstantinopel auf Heroengräber geht Bauer 1996, 130 aus.

461 Bei Grabar 1946 ist der Begriff nicht präzise gefasst: Zum Teil erscheint ein Heroon einfach als ein „mausolée de grand style“ (ebd., 85), dann wieder spezifischer als Grablege oder Monument eines Heros, vor allem eines Ktistes, so z. B. die kaiserlichen Mausoleen von Diocletian und von Konstantin, die Grabar als Heroa von Gründerheroen interpretiert (ebd., 231-234; den Aspekt des Heroenkults, den Grabar als Vorläufer des Märtyrerkults begreift, hebt Grabar ebd., 31-33 hervor). Kader 1995 verwendet Heroa unspezifisch als Sammelbegriff für besonders aufwendige - teilweise nicht einmal innerhalb der Stadt gelegene - Grabbauten, ohne dass sich für die dort Bestatteten eine Verehrung $\omega \varsigma$ ท̆ $\rho \omega \iota$ nachweisen ließe (Beispiele aus der Kaiserzeit und dem

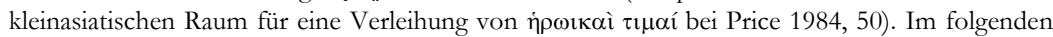
wird eine spezifische Verwendung des Begriffs zugrundegelegt, d. h. die Bezeichnung als Heroon macht nur dann Sinn, wenn man damit nicht nur einen Bautyp bezeichnet, sondern auch Aussagen über - am Heroenkult orientierte - kultische Praktiken treffen möchte, die im Zusammenhang mit diesen Grablegen stehen. 
die spannungsreiche Verbindung von Grablege und göttlicher Verehrung, wie sie oben beschrieben wurde, rituell zu bewältigen. Es ist im folgenden nicht möglich, die damit verbundenen religionsgeschichtlichen Probleme im Detail aufzurollen, ${ }^{462}$ dennoch erscheint es offensichtlich, dass die Heroenverehrung die bestehende Spannung zwischen Toten- und divus-Kult nicht löst, sondern nur reproduziert.

Die Figur des Heros lässt sich nicht auf einen einfachen Nenner bringen: Sie umfasst einen heterogenen Kreis unterschiedlicher Personengruppen ( $z$. B. Städtegründer, Athleten), deren verbindendes Element als Heroen weniger in einer bestimmten Eigenschaft als in der Tatsache gesucht werden muss, dass in allen Fällen ein Grab oder Kenotaph den Fokus der Heroenverehrung bildete. ${ }^{463}$ Diese Verbindung zum Grab- und Totenkult erklärt eine Reihe von Eigentümlichkeiten in den Kultpraktiken griechischer Heroenkulte, die sie vom olympischen Götterkult unterscheiden und in die Nähe des Kultes von chthonischen Gottheiten rücken. ${ }^{464} \mathrm{Im}$ Heroenkult tritt daher zwar ein göttlicher Status des Rezipienten der Kulthandlungen zutage, der ihn jedoch mehr oder weniger deutlich - von den himmlischen Gottheiten absetzt. ${ }^{465}$

462 So z. B. die Frage nach den Ursprüngen des Heroenkultes in Rom. Es kann wohl mittlerweile als Konsens in der religionsgeschichtlichen Forschung gelten, dass der Heroenkult rein eine griechische Erscheinung war und es in Rom keine Heroenkulte gegeben hat (vgl. dazu zuletzt Ekroth 2002, 106). Für den spätantiken Kaiserkult ist dieses Problem jedoch insofern sekundär als man mit späteren Übertragungen rechnen kann und muss - bereits die Bestattungen von nichtdivinisierten Angehörigen des iulisch-claudischen Kaiserhauses scheinen vom Heroenkult und damit verbundenen Vorstellungen beeinflusst zu sein (vgl. u., Anm. 468).

463 Vgl. dazu Ekroth 2002, 335-341, die sich gegen eine Kategorie des Heroen als vorgriechisches Substrat der griechischen Religion wendet. Dass es Sinn macht, von einer kult- anstatt von einer personenbezogenen Definition von Heros auszugehen, zeigt beispielsweise Herakles, der sowohl als Gott als auch als Heros verehrt werden konnte.

464 Die Trennung zwischen olympischen und chthonischen Gottheiten verbindet sich mit einer langen Forschungsgeschichte und -kontroverse, die hier nicht näher ausgeführt werden kann. Unlängst hat Scullion 1994 dafür plädiert, die Unterscheidung als eine antike Konzeptualisierung aufrechtzuerhalten. Angesichts der prinzipiell unterschiedlichen Kultpraktiken, die mit der Trennung olympisch-chthonisch bezeichnet werden, scheint es in der Tat sinnvoll, an der Unterscheidung weiterhin festzuhalten, solange man sie nicht schematisch bestimmten Gottheiten zuordnet und mit der Kombination chthonischer und olympischer Kultpraktiken und der Modifizierbarkeit ritueller Handlungen und Handlungssequenzen rechnet.

465 Sichtbar an bestimmten Opferpraktiken wie dem Vergießen des Blutes in der Erde, dem vollständigen Verbrennen des Opfers (ohne Beteiligung der Feiernden am Mahl), der Wahl bestimmter - meist dunkelfarbiger - Opfertiere, nächtlichen Opfern und in einer spezifischen

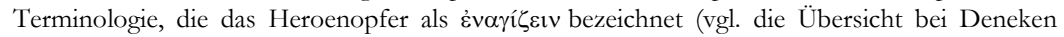
1886-1890, 2503-2510). Anders Ekroth 2002, die darauf aufmerksam macht, dass auch in Heroenkulten Mahlfeiern wie bei Götteropfern die Regel waren und im Kontext von Heroen-


olympischen Götter geläufig ist. Dies relativiert den besonderen Status der Heroen jedoch nur zum Teil: So können sich beispielsweise auch dort, wo im Zusammenhang mit Heroenkulten von Mahlfeiern die Rede ist, diese an Riten anschließen, die sich spezifisch an Heroen richten 
Damit wird zugleich die Rolle des Heros als kulturelles Modell für die Integration von kaiserlichem Toten- und divus-Kult und als Vorbild für die Grabtempel der tetrarchischen Zeit in Frage gestellt: Der Heroenkult fand zwar im funerären Kontext statt, aber er schuf deswegen keine rituelle Verbindung zwischen den unterschiedlichen Status des Kaisers als Toter und als divus. Vielmehr begegnet man im Verhältnis des Heroenkults zum (olympischen) Götterkult einer ähnlichen Trennung wie der zwischen parentatio und divus-Kult in der Verehrung des toten römischen Kaisers.

Ausgehend von dieser Beobachtung, dass Heroen- und Götterkult unterschiedliche Register von Göttlichkeit bezeichnen, hat man dementsprechend die Rolle des Heroenkults für die Entwicklung des Kaiserkults sehr zurückhaltend beurteilt. Insbesondere Simon Price hat sowohl für den östlichen Teil des Imperiums, wo sich der Kaiserkult in Anlehnung an den hellenistischen Herrscherkult entwickelte, als auch für seine westliche Variante, die auf den toten Herrscher bezogen war, die Unterschiede zwischen dem Heroen- und Götterkult hervorgehoben und deutlich gemacht, dass die Verehrung des römischen Kaisers sich an den kultischen Ehrungen für Götter, nicht für Heroen, orientierte. ${ }^{466}$ Dies wird bestätigt durch den Vergleich mit den außerordentlichen postumen Ehrungen für nichtdivinisierte Mitglieder des iulisch-claudischen Kaiserhauses (Agrippa maior; Lucius und Gaius Caesar; Germanicus; Drusus minor), deren Kult, wie weiter oben bereits ausgeführt, ${ }^{467}$ auf die Grablege, den Todestag und die parentationes ausgerichtet war. Hier begegnen unverkennbar Elemente, die nicht nur aus der Tradition römischer Totenkultriten zu erklären sind, sondern auf eine Übernahme aus dem griechischen Heroenkult verweisen und daher den Begriff der „Heroisierung“" als angebracht erscheinen lassen. ${ }^{468}$ Es ist demnach durchaus möglich, den Heroenkult als kulturelles Modell zu verstehen, das auch in Rom seine Wirkung entfaltete - doch er erwies sich bezeichnenderweise genau in den Fällen als vorbildhaft, in denen es zu keiner Divinisierung kam. Der römische Kaiserkult blieb vom Heroenkult erkennbar unberührt.

(vgl. z. B. Ekroth 2002, 135f.: zuerst ein Blutopfer für den Heros, daran anschließend eine Mahlfeier der Feiernden).

466 Price 1984, 32-36, 207-220 (Osten); ders. 1987, bes. 79 (Westen). Anderer Ansicht ist Fishwick 1987-2004, Bd. 1, 1, 3-5; eine vermittelnde Position bezieht Klauck 1995-1996, Bd. 2, 25 f.

467 S. o., S. $182 \mathrm{f}$.

468 Vgl. z. B. das Holocaustopfer für L. Caesar in Pisa. Auch in kleinasiatischen Münzprägungen erscheinen nichtdiviniserte Mitglieder des Kaiserhauses (L. Caesar; Nero Claudius Drusus) als „Heroen“ (vgl. Price 1984, 34 mit Anm. 41). Wenig aussagekräftig ist hingegen eine - ergänzte Inschrift aus Acerra (CIL X, 3757), in der von einem templum sacratum her[oibus] die Rede ist, und die sich auf L. und C. Caesar bezieht; vermutlich ist heros hier nur eine Übersetzung für lar. Die Bezeichnung „Heroisierung“ verwenden u. a. Fraschetti 1984, ders. 2000, bes. 151-154; v. Hesberg/Panciera 1994, 174f. 
Wir sind damit erneut bei den Strukturbedingungen des Kaiserkults angelangt, die mit dem Beginn der römischen Monarchie gelegt wurden. Gilt diese Gegenüberstellung jedoch in gleicher Weise auch noch für das 3. Jh., in dem sich die ersten Tendenzen abzeichnen, den Kaiserkult auch auf den Bereich des Grabes auszudehnen?

Beim severischen Historiker Cassius Dio erscheint die Bezeichnung vorzugsweise für die Kaisertempel, die nach der Konsekration errichtet wurden und in denen der Kult für den divus stattfand, zum Teil aber auch für die Grabbauten, in denen der Kaiser bestattet lag. Dies lässt sich jedoch nicht als eine Annäherung von divus- und Totenkult unter den Vorzeichen des Heroenkultes deuten, ${ }^{469}$ sondern ist Teil einer Cassius Dio eigentümlichen Sprachregelung, die darauf berechnet ist, den göttlichen Status des Kaisers herabzustufen. So greift Cassius Dio auch sonst konsequent auf die Terminologie des Heros zurück, um den divinisierten Kaiser zu bezeichnen: Die dem Kaiser vom Senat verliehenen honores caelestes erscheinen in seiner Dar-


die Aufnahme des toten Kaisers unter die divi, die relatio inter divos, wählt Dio nicht die übliche Übersetzung von divus mit $\theta \varepsilon$ sós, sondern bezeichnet den



Wenn Dio hier von den divi als Heroen spricht, dann nicht, um veränderte kultische Dispositionen zu bezeichnen, sondern weil die Heroen im Vergleich mit den Göttern eine geringere Stufe von Göttlichkeit einnehmen. Dieser Status verlieh dem Kaiser zwar Unsterblichkeit, beließ ihn jedoch auf einer Ebene unterhalb der Götter. Diese mit der Rede von den „,heroischen Ehren" implizierte Zwischenstellung kommt deutlich in einer sprachlichen Variation zum Ausdruck, in der Cassius Dio mit Blick auf Caligulas Schwester, Drusilla, nicht von heroischen Ehren, sondern von $\tau \imath \mu \alpha i ̀$

469 Gegen J.-C. Richard 1966, 131; dens. 1978, 1131; auch Wesch-Klein 1993, 114 hebt - unter Hinweis auf den Sprachgebrauch von Cassius Dio - den Charakter der kaiserlichen Grablegen als beroa hervor.

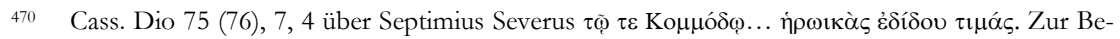
zeichnung ทं ebd. 70, 1, 2 (für Hadrian); 74, 17, 4 (für Pertinax).

471 Cass. Dio 56, 34, 2: Im Leichenzug des Augustus wurde ein Bildnis Caesars unter den imagines der verstorbenen Vorfahren nicht mitgeführt, weil „man ihn unter die Heroen aufgenommen

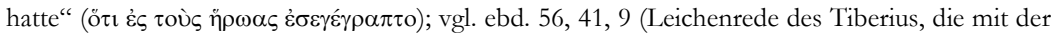
Bemerkung endet, das römische Volk habe Augustus zum Heros gemacht und für unsterblich

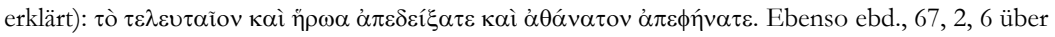


zung für divus, vgl. ebd., 51, 20, 6: Augustus genehmigt nach Actium mehreren östlichen Städten die Einrichtung eines Kultes für Roma und Caesar, den Augustus als „Heros Iulius“ verehren


1984 (a). 
$\delta \alpha \iota \mu o ́ v ı \iota^{472}$ redet: Mit dieser Formulierung nimmt Dio Bezug auf die Daimones als Zwischenwesen, die nach der gängigen Vorstellung der hohen Kaiserzeit in einem Raum zwischen der menschlichen und der göttlichen Sphäre angesiedelt waren. ${ }^{473}$ Die Rede von Heroen, heroischen Ehren und Heroentempeln hat bei Dio demnach keinerlei erkennbare funerale Implikation - sie enthält keine Anspielung auf den Heroenkult als Grabkult, sondern signalisiert einzig, dass Cassius Dio zwar bereit war, den divi und divae des Kaiserhauses eine Stellung unterhalb der göttlichen Sphäre zuzuweisen, sie jedoch nicht mit Göttern auf eine Stufe zu stellen.

Was bei Cassius Dio eher als eine idiosynkratische Sprachregelung erscheint, ${ }^{474}$ begegnet in ähnlicher Weise auch in modernen Interpretationen, die im Heros ein kulturelles Modell für das neues Selbstverständnis der Kaiser des 3. Jh. sehen. Deren Auffassung, als gottbeauftragte Herrscher zu handeln habe sie, so eine jüngst geäußerte Vermutung, in eine Zwischenstellung zwischen Göttern und Menschen gebracht, die sie nach eigenem Verständnis den Heroen angenähert und dabei in „Heroa“ wie dem Maxentiusmausoleum ihren adäquaten Ausdruck gefunden habe. ${ }^{475}$ Gegen diese Sicht der Dinge lassen sich jedoch ähnliche Argumente geltend machen, wie sie auch schon im Zusammenhang mit dem Wortgebrauch bei Cassius Dio angeführt wurden. Der Heros avancierte seit der Kaiserzeit verstärkt zu einem Synonym für einen Gott zweiten Ranges, eine Form von Göttlichkeit, die auch für Honoratioren und Euergeten auf lokaler Ebene verfügbar war. ${ }^{476}$ Dass die Kaiser des 3. Jh. ihren divinen Status in dieses Symbolsystem zurückstuften, mag zwar einem senatorischen Geschichtsschreiber wie Cassius Dio Gelegenheit zu einer indirekten Kritik am Kaiserkult gegeben haben, entsprach jedoch kaum dem Selbstverständnis dieser Herrscher, die sich zwar als gottbeauftragt verstanden, gleichzeitig jedoch die Distanz zwischen menschlicher und göttlicher Welt verstärkten und in ihrer Selbstdarstellung immer stärker aus menschlichen Handlungszusammenhängen entrückt wurden. Überzeugende Hinweise darauf, dass die Kaiser des 3. Jh. sich am Modell des Heros orien-

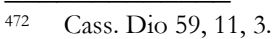

473 Zur Dämonologie als einer eigenen philosophischen Disziplin seit dem 2. Jh. n. Chr. und zu der den unterschiedlichen Dämonologien gemeinsamen Auffassung, die Daimones nähmen eine Mittlerstellung zwischen Göttern und Menschen ein, vgl. Andres 1918, 301-322; Dodds 1985 (1965), 44-66.

474 Zur Sonderstellung von Cassius Dio in seiner Bewertung des divinisierten Kaisers vgl. Clauss 1999, 356. Dios grundsätzliche Zurückhaltung gegenüber der kultischen Verehrung des Kaisers wird vor allem aus der Rede des Maecenas ersichtlich, dem Dio die Aussage in den Mund legt, Göttlichkeit beruhe nicht auf außerordentlichen Ehren, Statuen und Tempeln, sondern auf guten Taten des Herrschers und der daraus resultierenden, nicht an äußere Zeichen gebundenen Dankbarkeit (Cass. Dio 52, 35).

475 So zuletzt La Rocca 2000, 214-220; ähnlich Frazer 1964, 34-41.

476 Nock 1944, 162-166; Price 1984, 49 f. 
tiert haben, finden sich nicht: Die in dieser Zeit verstärkt auftretenden Bezugnahmen auf Hercules spiegeln wohl kaum eine Tendenz zur Heroisierung des Kaisers wider, da ihr Bezugspunkt nicht der griechische Heros Herakles war, sondern Hercules, der in Rom nicht als Heros, sondern als Gott verehrt wurde. ${ }^{477}$

Für unsere Ausgangsfrage, in welcher Weise die Kaisergrablegen rituell in den divus-Kult integriert werden konnten, ist weniger eine - unwahrscheinliche - direkte Angleichung des divus an den Status eines Heros von Interesse, als vielmehr die allgemeineren religionsgeschichtlichen Perspektiven, die sich mit der Entwicklung des Heroenkultes in der Kaiserzeit verbinden. Die in dieser Zeit in den griechischen Städten des Ostens populäre Praxis, Euergeten durch heroische Ehren einen göttlichen Status zuzuerkennen, war gleichzeitig mit einer Annäherung dieser Heroenkulte an die kultischen Praktiken des Götterkults verbunden: Der charakteristische Typ des Götteropfers ( $\theta v \sigma i ́ \alpha)$ wurde unterschiedslos auch auf die Verehrung dieser Heroen übertragen. ${ }^{478}$ Dies wirft konsequenterweise die Frage auf, ob das im vorigen zugrundegelegte Muster einer klaren Trennung zwischen Toten- und Götterkult in der Kaiserzeit überhaupt noch vorausgesetzt werden kann: Wurde eine derartige Trennung nicht in dem Maße obsolet, in dem es möglich war, herausgehobene Tote an ihren Gräbern in kultischen Formen zu verehren, die dem Götterkult entsprachen?

Eine Antwort auf diese Frage würde eine genauere Untersuchung der konkreten Erscheinungsformen dieser neuen Heroenkulte, vor allem auch ihrer lokal unterschiedlichen Ausprägungen, erfordern, die den Rahmen der hier verfolgten Überlegungen sprengen würde. Doch scheint so viel sicher, dass die Annäherung von Heroen- und Götterkult im Osten des Imperiums ohne Auswirkungen auf die Parameter des römischen Kaiserkultes blieb, der weiterhin klar zwischen divus- und Totenkult unterschied. In diesem Zusammenhang lohnt es, noch einmal auf Cassius Dio zurückzukommen. Im Jahr 212 verfügte Caracalla nach Getas Ermordung dessen damnatio memoriae, die neben einer Tilgung von Getas Namen aus Inschriften und der Beseitigung von Münzen auch vorsah, dass Caracalla für Geta ein jährliches Totenopfer

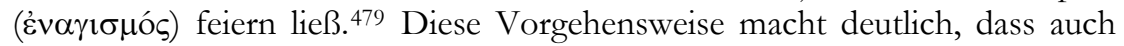

477 Nicht berücksichtigt von La Rocca 2000, 216f., ebensowenig wie die unspezifische Verwendungsweise des Begriffs Heroon durch Grabar, die keineswegs die Existenz eines Heroenkults voraussetzt.

478 Vgl. dazu Price 1984, 35f., der allerdings nicht konkreter auf die kultischen Dispositionen eingeht, sondern nur allgemein vom Typ des $\theta v \sigma i ́ \alpha$-Opfers spricht. Für Ekroth 2002, bes. 129-169 ist eine derartige Annäherung der Opferpraxis an den Götterkult bereits in archaischer in klassischer Zeit gegeben.

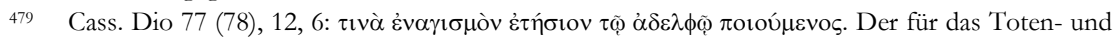

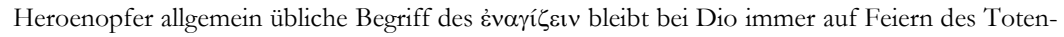
kults beschränkt und taucht niemals im Zusammenhang mit dem Kaiserkult auf; zum Wort- 
noch zu Beginn des 3. Jh. der Kaiser als „,normaler“ Toter den Fokus von spezifischen Riten bildete, die nicht in Verbindung mit dem divus-Kult standen: Nach seiner damnatio verblieb Geta nur noch die parentatio, die mit seinem einstigen Status als divus explizit nichts zu tun hatte. ${ }^{480}$

Es gibt demnach auch für die spätere Kaiserzeit keinen Grund zu der Annahme, der Kaiserkult sei von den Strukturbedingungen abgerückt, die sich mit dem Beginn der römischen Monarchie entwickelt hatten: Die Trennung zwischen den unterschiedlichen Status des verstorbenen Herrschers als Toter und als divus erwies sich noch zu Beginn des 3. Jh. als zentrales Merkmal des römischen Kaiserkults. Und obwohl die Grenzen zwischen Heroenund Götterkulten in den Städten des Ostens zunehmend zu verschwimmen begannen, ist es unwahrscheinlich, dass der Heroenkult ein geeignetes kulturelles Modell bildete, um die Grablege des Kaisers in den Bereich seiner Verehrung als Gott einzubeziehen. Es scheint vielmehr so, dass gerade kaiserzeitliche Autoren in archaisierender Weise versucht haben, die griechischen Heroenkulte in die Nähe von Totenkulten zu rücken und sie damit als etwas zu konzeptualisieren, was sich von den Götterkulten unterschied. ${ }^{481}$

Dies ist deswegen von besonderem Interesse, weil hierin kaiserzeitliche Klassifikations- und Ordnungssysteme von Göttlichkeit fassbar werden, ein Rahmen religiöser Konzeptualisierungen und Vorstellungen, der einer die Verbindung von divus und totem Kaiser, wie sie seit tetrarchischer Zeit begegnete, eher Grenzen setzte als Deutungsmöglichkeiten eröffnete. Mit allem Vorbehalt erscheint die Aussage gerechtfertigt, dass sich auf dieser Konzeptualisierungsebene von Göttlichkeit kein Modell bot, das in der Lage war, diese beiden unterschiedlichen Bereiche ineinander zu integrieren. Man mag gegen diese Sicht der Dinge einwenden, dass sie der Existenz von Ordnungen und Konzeptualisierungen zu großes Gewicht einräumt, und stattdessen aus ritualtheoretischer Perspektive hervorheben, dass durch die Kombinierbarkeit und Modifizierbarkeit von rituellen Handlungen flexible Lösungen denkbar waren, die eine Verehrung des Kaisers als Gott an seinem Grab ermöglichten. Wie eine derartige Vermittlung zwischen parentatio und divus-Kult ausgesehen haben könnte, ist nicht bekannt, und es ist wenig ertragreich, über die kultischen Vollzüge im Maxentiusmausoleum und dem angrenzenden Circus an der via Appia zu spekulieren. Was man jedoch sicher festhalten kann, ist, dass die räumliche Einbeziehung des Grabs in den Kaiserkult eine neue Situation schuf, für die keine etablierten Modelle zur Verfügung standen, und die daher Raum entweder für ganz neue Lösungen oder aber für den Rückgriff auf Al-

gebrauch bei Dio und anderen griechischen Autoren, die über römische Verhältnisse schreiben, vgl. Ekroth 2002, 106-110.

$480 \quad$ Zu dieser Deutung vgl. auch Price 1987, 91.

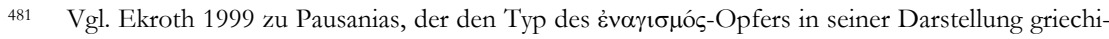
scher Heroenkulte stark betont. 
ternativen ließ, die sich außerhalb des Angebots der etablierten Kultpraktiken und der damit verbundenen religiösen Ordnungssysteme bewegten.

Unter diesen Voraussetzungen ist es naheliegend, dass der christliche Toten- und Heiligenkult ein Modell und einen rituellen Rahmen lieferte, der den an ihn gestellten Anforderungen entsprach und dazu führte, dass Konstantin den Kaiserkult als einen zentralen Sektor der öffentlichen Kommunikation in den Bereich christlicher Kultpraktiken verlagerte. In der Person des Märtyrers verbanden sich nahezu idealtypisch auf der einen Seite ein Totenkult, der an der Grablege des Märtyrers vollzogen wurde, und auf der anderen Seite die Vorstellung, dass der an seinem Grab Verehrte unmittelbar nach seinem Tod die Aufnahme bei Gott gefunden habe. ${ }^{482}$ Der Märtyrerkult war damit ein geeignetes Modell, um die seit der Tetrarchie auftretende Verbindung einer Verehrung des Kaisers als Toter und als divus rituell und konzeptionell zu bewältigen. Es kann kaum ein Zweifel daran bestehen, dass Konstantin mit seiner Anlage aus Coemeterialbasilika und kaiserlichem Mausoleum an der via Labicana diese Struktur der Märtyrerverehrung aufgriff und auf den toten Kaiser übertrug: Der in seinem Mausoleum mit einem eigenen altare ausgestattete Kaiser erstrebte keine depositio ad sanctos und auch kein liturgisches Gedenken, das ihn der Fürbitte eines Märtyrers anempfahl. Er wollte selbst verehrt werden wie ein Heiliger.

Hinsichtlich der rituellen Vollzüge verlangte dies weder aus christlicher noch aus paganer Perspektive fundamentale Akkomodationen. Daran, dass Konstantin im christlichen Kult die formale Stellung eines Heiligen beanspruchte, konnten auch diejenigen Christen keinen Anstoß nehmen, die - anders als etwa Eusebius v. Caesarea ${ }^{483}$ - nicht bereit waren, dem Kaiser eine derartige Position zuzugestehen und sie den Märtyrern und Confessoren vorbehielten, in denen sich das „fundamental Christliche“ zu Beginn des 4. verkörperte. ${ }^{484}$ Seiner äußeren Erscheinung nach war der Märtyrerkult nichts anderes als ein Kult für besonders herausgehobene Tote. ${ }^{485}$ Ihre besondere Qualität als bereits unmittelbar nach ihrem Tod zu Gott gelangende Interzessoren, die sie aufgrund ihres Martyriums erreicht hatten, äußerte sich bei den Märtyrern nicht durch eine besondere Hervorhebung in der liturgischen Kommemoration. Wie für andere Tote auch, betete man im Totenmemento

482 Dass die Märtyrer sofort nach ihrem Tod zu Gott gelangen, ist eine bereits sehr früh verbreitete Vorstellung, die von den unterschiedlichen eschatologischen Vorstellungen der frühen Kirche unbeeinflusst blieb: Auch die Vertreter eines unterirdischen Zwischenzustandes der Toten bis zum Jüngsten Gericht, wie z. B. Irenäus oder Tertullian, gingen davon aus, dass die Märtyrer, anders als die übrigen Toten, nicht in einem derartigen Wartezustand verharren mussten (vgl. Stuiber 1957, 76).

483 Dafür, dass Eusebius in den Abschlusskapiteln der Vita Constantini den toten Konstantin als redivivus und damit als Heiligen konzipierte, vgl. Arce 2000, 123.

484 Zu dieser Definition des Heiligen vgl. Kretschmar 1977, 91.

485 Vgl. o., S. 25, Anm. 74. 
für die Märtyrer, nicht zu ihnen. Eine derartige Differenzierung zwischen denjenigen Toten, die einer Fürbitte bedurften und denen, die als Interzessoren eine Fürbitte weiterleiteten, wird in den christlichen Liturgien erstmals gegen Ende des 4. Jh. greifbar. ${ }^{486}$ In dieses liturgische Totengedenken, das die Märtyrer und die normalen Toten unterschiedslos einschloss, war auch der Kaiser ohne weiteres integrierbar. Ohne ihm deswegen den Status eines Heiligen zuerkennen zu müssen, sicherte die Kommemoration als besonderer Toter dem Kaiser im Kult einen Platz zu, der ihm formal denselben Status einräumte wie den Märtyrern auch.

Umgekehrt bedeutete aus der Sicht des Kaisers das christliche Totengedenken, das für ihn durchgeführt wurde, keine Verlagerung des Kaiserkultes in ein völlig fremdes Feld kultischer Praktiken ohne Bezüge zu denjenigen Ritualen, die Konstantin auch aus dem Bereich des paganen Kultes vertraut waren. Das altare, das im Helenamausoleum vor dem kaiserlichen Sarkophag aufgestellt war, wird in der Forschung zwar meist als Hinweis auf eine eucharistische Liturgie gedeutet, die im Mausoleum stattgefunden habe. ${ }^{487}$ Dies ist auch in der Tat anzunehmen, da die vom Kaiser für das Mausoleum gestifteten instrumenta auch der für Kirchen üblichen Ausstattung mit liturgischen Gerätschaften (Patene - unterschiedliche Arten von Kelchen) entsprachen, ${ }^{488}$

486 Vgl. für die Jerusalemer Liturgie Kretschmar 1977, 104-107 mit weiteren Hinweisen auf die Entwicklung in den anderen östlichen Liturgien. In der römischen Liturgie waren das Memento für die Toten und die Lebenden und die Heiligenkommemoration im eucharistischen Hochgebet seit dem 5. Jh. voneinander getrennt: Die Heiligen erscheinen in den Abschnitten des Communicantes und des Nobis quoque als Gruppe, mit denen man Gemeinschaft haben möchte, während die Bitte um das göttliche Erbarmen sich auf die Toten (Memeno etiam, domine) und die zur Eucharistie versammelte Gemeinschaft (Memento, Domine) bezieht. Eine frühe Form des Communicantes wurde noch vor Leo I. (440-461), vermutlich in der ersten Hälfte des 5. Jh. in den Messkanon eingefügt (vgl. Capelle 1962, 269-272; Kennedy 21963, 37f.); andere Liturgiewissenschaftler führen das Communicantes auf Leo selbst zurück (di Napoli 1995, 417f. mit älterer Literatur). In Afrika ist eine ähnliche Trennung um 400 nachweisbar: Augustinus unterscheidet mehrfach die Märtyrer- von der Totenkommemoration, die sich auch darin äußere, dass die Märtyrer an einer anderen Stelle des eucharistischen Gebets kommemoriert würden als die Toten, vgl. z. B. serm. 159, 1: ideoque habet ecclesiastica disciplina, quod fideles noverunt, cum martyres eo loco recitantur ad altare Dei, ubi non pro ipsis oretur, pro caeteris autem commemoratis defunctis oratur. Iniuria est enim pro martyre orare cuius nos debemus orationibus commendari (vgl. die Zusammenstellung und Diskussion der übrigen Augustinusbelege bei Saxer 1980, 162-165). Augustinus’ Insistieren, dass beide Bereiche nicht miteinander verwechselt werden dürften, deutet darauf hin, dass sich eine derartige Trennung in der Liturgie noch nicht vor allzu langer Zeit vollzogen hatte.

487 So Pietri 1976, Bd. 1, 124; Johnson 1986, 178f.; Guyon 1987, 258. Tolotti 1986 (a) meint, die liturgischen Gerätschaften (altare und amae) des Helenamausoleums seien für die Aufnahme von Oblationen bestimmt gewesen, die dann bei Eucharistiefeiern in der Basilika geweiht worden seien.

488 Anders als die großen silbernen Schalen in der Basilika des Grabeskirchenkomplexes in Jerusalem, die auf Säulen standen und offensichtlich keine praktische kultische Funktion erfüllten (vgl. Eus., $v$. C. 3, 38), waren die amae im Helenamausoleuem zur Aufnahme von Trankspenden bestimmt, wie auch die übrigen von Konstantin für das Mausoleum gestifteten Trinkgefäße (drei calices) zeigen. Im Unterschied zu den amae handelt es sich bei den calices um kleinere Gefäße, die 
und da nach der oben formulierten Hypothese der Kaiser das Objekt eines auf ihn ausgerichteten und ihn im Status eines Heiligen kommemorierenden christlichen Kultes bilden sollte. Damit ist die Funktion dieses altare jedoch vermutlich nicht erschöpft, da Oblationspraktiken auch im Rahmen des nichtliturgischen christlichen Totenkults eine zentrale Rolle spielten. Während die für die Eucharistie charakteristische Darbringung (oblatio) von Opfergaben sich bereits seit dem 3. Jh. von einer Darbringung der Kultteilnehmer, die diese Gaben zur gemeinsamen Kultfeier mitbrachten, hin zu einer Darbringung durch den Priester zu verschieben begann, ${ }^{489}$ blieb der Bereich des christlichen Totenkultes noch lange Zeit geprägt von nichtliturgischen Oblationen von Gaben, die auf den Gräbern der Toten niedergelegt wurden. ${ }^{490}$ In den römischen Katakomben haben sich zahlreiche mensae erhalten, die zur Aufnahme derartiger Oblationen bestimmt waren, ${ }^{491}$ und auch der römische Bischof Damasus (366-384) schuf durch die architektonischen Umgestaltungen der Märtyrergräber, die er aus den Wänden und Gängen der Katakomben freilegte und in kastenartige Tische umwandelte, keine Altäre für die Feier eucharistischer Gottesdienste, sondern mensae, die derartige Oblationen für die Märtyrer aufnehmen sollten. ${ }^{492}$ Auch bei dem silbernen altare im Helenamausoleum signalisiert der Begriff keine liturgische Determinierung, in dem Sinne, dass es sich hier um einen Altar für die Darbringung der eucharistischen Opfergaben durch einen Priester gehandelt hätte: In der konstantinischen Lateranbasilika waren gleichfalls sieben (ebenfalls silberne) altaria aufgestellt, die dort nicht als eucharistische Opfertische, sondern als Oblationstische zur Sammlung der von den Feiernden mitgebrachten Gaben bei

zum Empfang des Weins bei der Kommunion dienten. Sie gehören zur regelmäßigen liturgischen Ausstattung der Titelkirchen wie der Basiliken und betragen zwischen 5 in den tituli und bis zu 50 in großen Basiliken, vgl. dazu Duchesne (1886), in: LP I, CXLIV.

489 Dazu grundlegend Berger 1965, 42-64; vgl. für Tertullian ferner Mattei 1985.

490 Augustinus' Mutter Monika trug Speisen zu den Gräbern der Heiligen (vgl. Aug., conf. 6, 2, 2: cum ad memorias sanctorum, sicut in Africa solebat, pultes et panem et merum adtulisset). Von einer Niederlegung der Gaben auf den Gräbern der Toten, die er unter bestimmten Voraussetzungen auch weiterhin tolerieren möchte, spricht Aug., epist. 22, 6: oblationes pro spiritibus dormientium, quas vere aliquid adiwvare credendum est, super ipsas memorias non sint sumptuosae atque omnibus petentius sine typho et cum alacritate praebeantur et non vendantur.

491 Vgl. die von Février 1978 zusammengestellten Beispiele.

492 So überzeugend Tolotti 1986, der in diesem Zusammenhang u. a. auf Parallelen in oberirdischen Mausoleen aufmerksam macht, in denen die - ebenfalls tisch- oder kastenartig erhöhten - Mensagräber quer zum Hauptraum lagen, d. h. mit der Schmalseite auf ihn ausgerichtet waren, und daher eine Nutzung als Altar unwahrscheinlich erscheinen lassen. Die Vorstellung, dass die in mensae umgewandelten Märtyrergräber Altäre für die Feier ,privater“ eucharistischer Gottesdienste im kleinen Kreis von Gläubigen bilden sollten (so z. B. Kirsch 1930, 112f.; jüngst erneut aufgenommen von Bauer 2002, 85), beruht auf einer erst später, gegen Ende des 4. Jh., entwickelten Verbindung von Altar und Märtyrerreliquien, die für Damasus' Zeit noch nicht allgemein vorausgesetzt werden kann (vgl. dazu Brandenburg 1995). 
Gottesdiensten dienten. ${ }^{493}$ In einer solchen Funktion als Oblationstisch könnte der Silberaltar im Helenamausoleum, ebenso wie die beiden riesigen amae, die Konstantin für das Mausoleum stiftete, auch zur Aufnahme von Oblationen bestimmt gewesen sein, die nicht im eucharistischen Kult verwendet wurden.

In der ausgeprägten Oblationspraxis des christlichen Totenkults waren starke äußere Kontinuitäten von paganen Totenkultpraktiken wirksam. ${ }^{494}$ Für die Frage, wie Konstantin den von ihm im Helenamausoleum initiierten Kult interpretiert hat, sind diese strukturellen Parallelen von unmittelbarem Interesse. Es ist naheliegend, dass die Oblationen, die im Rahmen eucharistischer Gottesdienste und nichtliturgischer Totenfeiern auf dem altare des Mausoleums abgelegt wurden, Konstantin maßgeblich dazu bewegten, das kulturelle Modell des Heiligen unter Beibehaltung von Oblationspraktiken, die ihm auch aus dem nichtchristlichen Totenkult bekannt und vertraut waren, aufzugreifen. Dass Konstantins Wahrnehmung des Christentums insgesamt stark von den kultischen Aspekten dieser Religion bestimmt war, ist aus seinen Äußerungen bekannt. ${ }^{495}$ Die Option, den Kult für den toten Kaiser und den Kult für den divus bruchlos ineinander integrieren zu können ohne dabei auf kulturelle Vermittlungsprobleme zu stoßen, musste den christlichen Toten- und Heiligenkult aus konstantinischer Perspektive zum geeigneten Modell für einen Kaiserkult machen, dessen Voraussetzungen sich im Laufe des 3. Jh. grundlegend gewandelt hatten.

Diese Interpretation gibt Anlass, die architektonische Disposition des Kultkomplexes an der via Labicana erneut zu überdenken. Die bauliche Verbindung von Mausoleum und Basilika verlieh dem Mausoleum, dessen unmittelbare Vorläufer als freistehende Podiumrundbauten konzipiert worden waren, auf den ersten Blick einen Appendixcharakter: In der zweipoligen Anlage verlor das Mausoleum seine Selbständigkeit und bildete nicht mehr den alleinigen architektonischen Fokus der Herrscherinszenierung. Mit der architektonischen Entwicklung vom Podiumrundbau zum Obergadenrundbau verband sich jedoch mehr als nur die Adaption eines bestehenden Bautyps an eine neue Funktion als Anbau. Auch die interne Disposition der Anlage veränderte sich: Im Unterschied zu den tetrarchischen Mausoleen, bei denen die Toten in der ringförmigen cella unterhalb der Kuppelräume bestattet lagen und die Annäherung von Toten- und divus-Kult zwar zu einer Iuxtaposition, aber nicht zu einer Verschmelzung beider Bereiche geführt hatte, fiel im kaiserlichen Mausoleum von SS. Pietro e Marcellino die räumliche Trennung zwischen den beiden Ebenen weg. Durch die Umwandlung vom freistehen-

493 LP I, 172. Zur Deutung dieser altaria als Oblationstische vgl. Klauser 1935.

494 Ambrosius verbot das Mitbringen von Speisen an die Gräber der Heiligen mit der Begründung, dass man hierin die parentalia der Heiden nachahme (Aug., conf. 6, 2).

495 Vgl. Konstantins Brief an Anulinus in Eus., h. e. 10, 7, $1 \mathrm{f}$. 
den Tempel zum Annexbau verschwanden Podium und cella: Der kaiserliche Sarkophag fand im Helenamausoleum im lichtdurchstrahlten Kuppelraum seinen Platz. In dieser architektonischen Disposition spiegelt sich zugleich die charakteristischste Veränderung wider, die der Kaiserkult unter Konstantin genommen hatte: eine unter den Vorzeichen eines christlichen Toten- und Heiligenkultes vorgenommene erfolgreiche Integration von Toten- und divusKult, die über eine Annäherung der beiden Bereiche, wie sie in tetrarchischer Sicht sichtbar wurde, noch hinausging.

In der Konstantinsstadt am Bosporus griff der Kaiser das an der via Labicana entwickelte Konzept unter veränderten Vorzeichen erneut auf. Mit dem Apostoleion, wo Konstantin sich inmitten von 12 Kenotaphen der Apostel bestatten ließ, schuf er - ähnlich wie im römischen Kultkomplex an der via Labicana - eine Kultstätte, in der die Grablege des toten Herrschers als der Fokus seiner kultischen Verehrung fungierte. Die ursprüngliche Gestalt und Funktion des Apostoleions sind umstritten, da der Bau unter Constantius II. verändert wurde und die konstantinische Anlage einzig aus einer Beschreibung in der eusebischen Vita Constantini bekannt ist. ${ }^{496}$ Eusebius erweckt beim Leser den Eindruck, der Kaiser habe eine Kirche für die Apostel errichtet und sich später dort bestatteten lassen. Zwischen den Zeilen wird jedoch deutlich, dass es sich beim Apostoleion um eine Grablege handelte, in der nach dem Willen des Kaisers ,auch Gottesdienste gehalten werden sollten“. ${ }^{497}$ Man hat zurecht darauf hingewiesen, dass diese Order des Kaisers bei einer Kirche überflüssig gewesen wäre:498 Das Apostoleion war von vornherein als eine kaiserliche Grablege konzipiert worden, die den toten Kaiser zum Zentrum des Herrscherkults machte. Die Forschung hat sich mit Blick auf die Selbstinszenierung des Kaisers vor allem auf seine Bestattung im Kreis der 12 Apostel konzentriert und unterschiedliche Erklärungen für die damit verbundene Symbolik angeboten. Doch jenseits der vieldiskutierten Frage, ob Konstantin als ein alter Christus, als 13. Apostel oder als 13. Gott gesehen wer-

496 Eus., v. C. 4, 58-60. Nach 359 wurde das konstantinische Apostoleion umgebaut; es entstand ein Komplex aus einer kreuzförmigen Kirche mit einem angebauten Mausoleum (zu den einschlägigen Quellennachrichten und der Bauchronologie des Apostoleions vgl. Krautheimer 1964, 226229; Mango 1990, 56f.). Aus der Beschreibung bei Eusebius lassen sich keine klaren Hinweise auf die konstantinische Gestalt des Baus ableiten; daher hat auch der Charakter der nach 359 erfolgten Umbauten unterschiedliche Interpretationen gefunden. Das Gros der Forschung plädiert dafür, dass Konstantin die kreuzförmige Kirche erbaut habe, an die später das Mausoleum angebaut worden sei (Krautheimer 1964; Leeb 1992, 99-103; Speck 1995, 144); Mango 1990 vermutet umgekehrt, dass Konstantin das Mausoleum habe errichten lassen und die Kirche ein späterer Zusatz sei. Unabhängig von der Frage, welches der beiden Architekturelemente das ursprünglich war, ist klar, dass Konstantin den Bau nicht als eine Kirche, sondern als ein Mausoleum konzipierte.

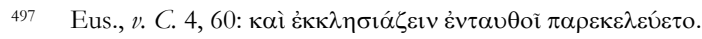

498 So bereits Heisenberg 1908, 100f.; ebenso Mango 1990, 57. 
den wollte, ${ }^{499}$ ist eine wesentliche Neuerung, die sich mit dem Apostoleion verband, dass nämlich der christliche Totenkult die sterblichen Überreste des Herrschers in das Zentrum der kultischen Verehrung rückte, unbeachtet geblieben. In dieser Hinsicht setzte die Anlage in Konstantinopel - so neuartig und spektakulär Konstantins wenig verhohlene Annäherung an Christus auch war - nur eine Entwicklung fort, die ihren Anfang bereits in den Coemeterialbasiliken des römischen Suburbiums genommen hatte und in räumlicher wie konzeptioneller Hinsicht als eine entscheidende Weiterentwicklung des spätantiken Kaiserkults einzustufen ist.

\section{3. Ergebnisse}

Unter Konstantin wurden durch die ersten repräsentativen christlichen Sakralbauten im Stadtbild Roms die Bezugsfelder von Raum, Erinnerung und städtischer Identität des caput imperii grundlegend neu definiert. Diese Neudefinition äußerte sich jedoch nicht in einer dichotomischen Trennung zwischen Zentrum und Peripherie, senatsbezogenen Kommunikationsräumen und neuer christlicher Sakraltopographie, städtischer Öffentlichkeit und privater Bautätigkeit des Kaisers. Konstantins Interaktion mit unterschiedlichen Gruppen der Stadt Rom produzierte keine Abgrenzungen, sondern im Gegenteil eine Transformation und Ausweitung von städtischer Identität. Die Grundlage für diese Transformation bildete die Person des Kaisers. Unabhängig von einer Trennung zwischen publicus und privatus, die schon vor der Kaiserzeit keine klare Abgrenzung zwischen Öffentlichkeit und Privatheit bezeichnet hatte und mit Blick auf den Kaiser zudem auch vor formale Kategorisierungsprobleme stellte, entschieden nicht die Räume über öffentliche und private Dimensionen kaiserlichen Handelns, sondern war es der Kaiser selbst, der in seinen Kommunikations- und Handlungsbezügen Öffentlichkeit in „seiner“ Stadt stiftete. Die christliche Gemeinde Roms wurde durch die Sakralbauten, die der Kaiser errichtete, Teil einer durch Konstantin vermittelten, nicht allein auf den Senat als die traditionelle Elite der Stadt beschränkten städtischen Identität.

Die Tatsache, dass Konstantin im monumentalen Zentrum der Stadt keine Kirchenbauten errichten ließ, sondern seinen Palast im Südosten der Stadt zu einem Herrschaftszentrum machte, an dem sich die Bischofskirche und der christliche Kaiserkultkomplex an der via Labicana orientierten, war kein Ausdruck einer gezielten räumlichen Trennung zwischen Gruppen, die -

499 Vgl. die Bilanz der unterschiedlichen Forschungspositionen bei Rebenich 2000, der sich selbst, ebenso wie das Gros der Forschung, für eine christusgleiche Selbstinszenierung des Kaisers entscheidet. 
wenn auch in unterschiedlichen Räumen - in derselben Weise auf den Kaiser bezogen waren, und die in der Kommunikation mit ihm Aspekte der kaiserlichen Herrschaft thematisierten, die für die urbs Roma in ihrem Verhältnis zum Kaiser von elementarer identitätsstiftender Bedeutung waren: Im Zentrum die Befreiung der Stadt von der Tyrannis des Maxentius, in der Peripherie den Kaiserkult, der unter den Vorzeichen eines christlichen Toten- und Heiligenkults an Veränderungen anschloss, die sich bereits während der Tetrarchie abgezeichnet hatten. Dass dies in unterschiedlichen städtischen Räumen geschah, entsprang nicht dem Bemühen, voneinander getrennte Öffentlichkeiten herzustellen: Es war eine Frage der Optionen, die sich dem Kaiser boten. Das Zentrum der Stadt, das durch Maxentius eine ausgeprägte Monumentalisierung erfahren hatte, war für Konstantin ein geeigneter Repräsentationsraum, um sich als vindex libertatis und als Sieger über den Tyrannen (nicht jedoch als Triumphator) zu stilisieren. Der Adressat dieser Botschaft waren die römische Bevölkerung und vor allem die senatorische Oberschicht, deren Verhältnis zum Kaiser traditionell den zentralen Beurteilungsmaßstab für die Qualität seiner Herrschaft bildete. Den Christen fiel hingegen in der Inszenierung von Unterdrückung und Befreiung der urbs Roma kein Part als Akteur zu, sie fanden dementsprechend auch keine Aufnahme in dem von der Maxentiuserinnerung geprägten Kommunikationsraum im Zentrum der Stadt.

Anders im römischen Suburbium. Ähnlich wie das Zentrum Roms bot auch die Coemeterialtopographie vor den Toren der Stadt dem Kaiser spezifische Möglichkeiten zur Kommunikation, bei der jedoch in diesem Fall die Christen die bestimmende Rolle spielten. Die für den römischen Kaiserkult charakteristische Trennung zwischen Grablege und Kaiserkultstätte, zwischen dem Kaiser als einem Toten und als divus war bereits vor Konstantin brüchig geworden: Das Bestreben, die Sakralität des Herrschers von der Divinisierung und der Zuschreibung von Göttlichkeit zu lösen, hatte schon in tetrarchischer Zeit erkennbar die Grablege in den Fokus der Herrscherverehrung gerückt. Indem Konstantin an der via Labicana eine Kultstätte für den toten Kaiser mit einem christlichen Coemeterium verband und damit dem Kaiserkult die Form eines Heiligenkults gab, fand er nicht nur eine Möglichkeit, die kultische Verehrung des Kaisers unter den Voraussetzungen der christlichen Religion weiterzuführen. Der christlichen Toten- und Heiligenkult bot zugleich ein kulturelles Modell, um den Status als Toter und den Anspruch auf Divinität - in der römischen Religion voneinander getrennte Register von Göttlichkeit miteinander zu verbinden. Mit dieser Verlagerung des Kaiserkults in den Bereich der christlichen Coemeterialtopographie wurde die christliche Gemeinde Roms zur kommunikativen Bezugsgruppe in einem Bereich, der für die Identität Roms traditionell von zentraler Bedeutung war.

Konstantin kommunizierte mit unterschiedlichen Gruppen in unterschiedlichen Räumen der Stadt, jedoch unter den Vorzeichen einer übergrei- 
fenden städtischen Identitätsstiftung. Die städtischen Kommunikationsräume bewirkten keine Abgrenzungen unterschiedlicher Identitäten. Die Deutungsgeschichte von Konstantins unterbliebenem Opfer auf dem Kapitol zeigt exemplarisch, dass der Kaiser auch im Zentrum der Stadt seine Zugehörigkeit zur christlichen Kultgemeinschaft an den Tag legen konnte, ohne dass dies von seinen Zeitgenossen als eine identitätsrelevante Aussage - im Sinne einer Absage an das caput imperii - aufgefasst wurde. Zu einer Identitätsfrage wurde diese Episode erst ex post facto umgestaltet, zu einer Zeit, in denen urbs und ecclesia als voneinander getrennte Identitätskonstruktionen deutliche Konturen gewannen und das unterlassene Opfer auf dem Kapitol zum Anlass für einen Bruch des Kaisers mit Rom umgedeutet wurde. Aurelius Victor, der den historischen Ereignissen näher stand, sah hingegen nicht hierin, sondern in der Bestattung des Kaisers in Konstantinopel den entscheidenden Schritt, der den symbolischen Bruch Konstantins mit der alten Hauptstadt bewirkte. Damit bestätigt er implizit, dass die unterschiedlichen Handlungs- und Kommunikationsräume Konstantins in Rom als Teile einer umfassende Identitätskonstruktion wahrgenommen wurden: Eine Bestattung des Kaisers in Rom hätte dem alten caput imperii städtische Identität vermittelt - auch wenn sie an der via Labicana unter christlichen Vorzeichen erfolgte wäre. 